\title{
Human capital and employee entrepreneurship
}

Citation for published version (APA):

van Wetten, S. J. L. (2020). Human capital and employee entrepreneurship: The role of skills, personality characteristics and the work context. [Doctoral Thesis, Maastricht University]. ROA.

https://doi.org/10.26481/dis.20200129sw

Document status and date:

Published: 01/01/2020

DOI:

10.26481/dis.20200129sw

Document Version:

Publisher's PDF, also known as Version of record

\section{Please check the document version of this publication:}

- A submitted manuscript is the version of the article upon submission and before peer-review. There can be important differences between the submitted version and the official published version of record.

People interested in the research are advised to contact the author for the final version of the publication, or visit the DOI to the publisher's website.

- The final author version and the galley proof are versions of the publication after peer review.

- The final published version features the final layout of the paper including the volume, issue and page numbers.

Link to publication

\footnotetext{
General rights rights.

- You may freely distribute the URL identifying the publication in the public portal. please follow below link for the End User Agreement:

www.umlib.nl/taverne-license

Take down policy

If you believe that this document breaches copyright please contact us at:

repository@maastrichtuniversity.nl

providing details and we will investigate your claim.
}

Copyright and moral rights for the publications made accessible in the public portal are retained by the authors and/or other copyright owners and it is a condition of accessing publications that users recognise and abide by the legal requirements associated with these

- Users may download and print one copy of any publication from the public portal for the purpose of private study or research.

- You may not further distribute the material or use it for any profit-making activity or commercial gain

If the publication is distributed under the terms of Article $25 \mathrm{fa}$ of the Dutch Copyright Act, indicated by the "Taverne" license above, 


\section{Human capital and}

employee entrepreneurship

The role of skills, personality characteristics and the work context 
(C) Sanne van Wetten, Maastricht 2020

All rights reserved. No part of this publication may be reproduced, stored in a retrieval system, or transmitted in any form, or by any means, electronic, mechanical, photocopying, recording, or otherwise, without the prior permission in writing, from the author.

This research project has been financed by the Netherlands Organisation for Scientific Research (NWO), grant 409-13-2IO.

Published by ROA

Postbus 6I6

6200 MD Maastricht

ISBN: $978-90-532 I-587-6$

Printed in the Netherlands by Canon 


\title{
Human capital and employee entrepreneurship The role of skills, personality characteristics and the work context
}

\author{
DISSERTATION
}

to obtain the degree of Doctor at Maastricht University,

on the authority of the Rector Magnificus,

Prof. dr. Rianne M. Letschert

in accordance with the decision of the Board of Deans,

to be defended in public on

Wednesday January 29, 2020, at I2:00 hours

by

Sanne Johanna Leontien van Wetten 


\section{Supervisor}

Prof. dr. Andries de Grip

\section{Co-supervisor}

Dr. Ruud Gerards

\section{Assessment Committee}

Prof. dr. Martin Carree (chairman)

Dr. Julia Kensbock

Prof. dr. Erik Stam, Utrecht University School of Economics

Dr. Jana Deprez, KU Leuven 


\section{Acknowledgements}

I started my $\mathrm{PhD}$ because I enjoy learning new things and finding answers to questions that are not answered yet. However, learning hurts, and is not always easy. Like many others that decide to start a $\mathrm{PhD}$ trajectory, I started the $\mathrm{PhD}$ quite naïve on what 'doing a PhD' actually means. Of course, I knew I was going to do research, and in the end I would need four papers for my dissertation. However, during the $\mathrm{PhD}$ process, I realised that 'doing a PhD' is not only about producing scientific knowledge. I remember my job interview somewhere around September 20I4. I prepared for this interview by reading about intrapreneurship, thinking about several possible projects and research approaches. A large part of the interview however, was not about research at all. Instead, my then-to-be supervisors Andries and Ruud asked me how I react in difficult situations, how I deal with adversity, insecurity and ambiguity. It was not until some time into the $\mathrm{PhD}$ process that I understood why they put such emphasis on these skills. As others surely recognise, the process that has led up to this thesis, was one full of ups and downs, absolutely loving and sometimes disliking what you do at the same time. I did not only learn about employee entrepreneurship, research methodology, presenting, writing and teaching. Mostly, I learned to persevere and recognise and use my own strengths, but also to accept mistakes, failures, and imperfections and ask for help when needed. I feel very grateful for having had the opportunity to learn these valuable lessons.

I am also very thankful for all the wonderful people I met throughout my $\mathrm{PhD}$ time. I thank all my current and past colleagues at ROA and SBE for the good talks, fun times and support. Of course, thank you, Andries and Ruud for your support, patience and trust throughout my $\mathrm{PhD}$ process. I am especially grateful to all the members of our Pomodoro writing club for providing the peer-pressure I needed to sit down and write. Kim, Inge, Marloes and Maja ("thank you very much, let's make a good one!”), thank you for all the support, advice, laughs, good food and our hilarious, awkwardly honest conversations. Maria and Merve, guapas, thank you for being the best office mates, for your strength and inspiration. Arjan, thank you for our numerous walks, discussions and coffees. Thank you to Mieke Jansen and the supporting staff at ROA and MILE; Mariëlle, thank you for your help with designing this book. Thank you also to Alexander D., Alexander H., Bart, Cécile, Charlotte, Christian, Corrie, Frauke, Jaro, Johannes, Julia, Kars, Katarina, Lidwien, Lin, Lynn, Maria P., Mariana, Martine, Max, Melline, Nardo, Nina, Pomme, Raginee, Rasmus, Raymond, Sander, Sean, Seher, Sergio, Shash, Stan, Stefan, Tim, Timo and Tobi. I am also thankful to Coen Rigtering and Chen Fleisher 
for their valuable advice. I would also like to thank Martin Carree, Julia Kensbock, Erik Stam and Jana Deprez for the effort and time spent on the assessment of my thesis and their useful comments.

Thank you to Sandra, Iris, Domeniek, Yonne and all my friends that are always there for laughs and good conversations. Michael, you have been my continuous champion and without you, I would never have thought about doing a PhD. Octave, thank you for your support. Kelly and Milou, I know I can always count on you; thank you for always being there throughout the good and the bad, even when we are miles apart. Thank you to my family, mama, Timo and Karlijn for supporting all my decisions. Faleminderit Geri im, for making me feel sane when others think I am crazy, being my add-buddy, dancing in the living room, giving me a hug when I need one and taking me out of my research bubble. Undoubtedly I did not express my gratitude to everyone that provided valuable advice, help or support; thank you to all other people I met along the way and did not mention here. 


\section{Contents}

I Introduction I

I.I Motivation 2

I.2 Aim of the thesis 5

I.3 Thesis outline and main results 6

2 Attracting entrepreneurial employees: Exploring job preferences of STEM students using a discrete-choice experiment 9

2.I Introduction IO

$\begin{array}{ll}\text { 2.2 Theoretical framework } & \text { I2 }\end{array}$

$\begin{array}{ll}\text { 2.2.I Recruitment of employees with specific characteristics } & \text { I2 }\end{array}$

2.2.2 Identifying entrepreneurs, intrapreneurs and non-entrepreneurial employees $\quad$ I3

2.2.3 Attracting prospective intrapreneurs $\quad$ I6

$\begin{array}{ll}2.3 \text { Methods } & \text { I7 }\end{array}$

2.3.I Sample selection and Experimental design $\quad$ I7

$\begin{array}{ll}2.3 .2 \text { Job attributes } & \text { I8 }\end{array}$

2.3.3 Person-Entrepreneurship fit 20

2.3.4 Entrepreneurial attitude: income expectations 2I

2.3.5 Worker type 2I

2.3.6 Control variables $2 \mathrm{I}$

2.3.7 Data collection and sample description 22

2.4 Econometric framework 24

2.5 Results 26

2.5.I STEM students' preferences for job attributes 27

2.5.2 Comparing job attribute preferences of prospective worker types 30

2.5.3 Master students' willingness to pay $3 \mathrm{I}$

2.6 Discussion 33

2.6.I Limitations and future research $\quad 34$

2.6.2 Implications for practitioners $\quad 36$

$\begin{array}{ll}2.7 \text { Conclusion } & 36\end{array}$

3 Are graduates' intrapreneurial skills optimally used for innovation? $\quad 37$

3.I Introduction 38

3.2 Literature review and hypotheses 40 
3.2.I Intrapreneurial skills: their role in innovation in STEM and business occupations

3.2.2 Skill mismatch and innovation $\quad 43$

3.3 Methods 44

3.3.I Data and sample 44

3.3.2 Dependent variable 45

3.3.3 Independent variables $\quad 47$

3.3.4 Self-assessment bias $\quad 5 \mathrm{I}$

3.3.5 Other control variables $\quad 52$

3.3.6 Descriptive statistics $\quad 53$

3.3.7 Empirical model and estimations strategy $\quad 56$

3.4 Results $\quad 57$

3.4.I Skill allocation to innovation $\quad 57$

3.4.2 Skill allocation to different types of innovation 59

3.4.3 Skill underutilization and allocation to innovative tasks 62

3.4.4 Control variables $\quad 62$

3.5 Conclusions $\quad 63$

3.5.I Implications for further research $\quad 65$

3.5.2 Implications for firms and higher education 66

$\begin{array}{ll}3.6 \text { Appendix } & 67\end{array}$

4 The relevance of the Big Five personality traits, risk tolerance and perceived organisational support for intrapreneurial behaviour 75

$\begin{array}{ll}\text { 4.I Introduction } & 76\end{array}$

$\begin{array}{ll}\text { 4.2 Literature review and hypotheses } & 78\end{array}$

4.2.I Intrapreneurship and intrapreneurial behaviour $\quad 78$

4.2.2 Personality and intrapreneurship $\quad 78$

4.2.3 Organisational support, personality and intrapreneurial behaviour 83

$\begin{array}{ll}4.3 \text { Methods } & 85\end{array}$

4.3.I Sample-selection model $\quad 85$

$\begin{array}{lr}\text { 4.3.2 Data and sample } & 87\end{array}$

4.3.3 Measurements $\quad 88$

4.3.4 Descriptive statistics 92

4.4 Results 95

4.4.I Personality, organisational support and intrapreneurial behaviour 95

4.4.2 Additional analyses 97

4.5 Discussion 99

$\begin{array}{ll}\text { 4.5.I Implications for practice } & 102\end{array}$

$\begin{array}{ll}\text { 4.5.2 Limitations and future research } & \text { IO2 }\end{array}$

$\begin{array}{ll}4.6 \text { Appendix } & \text { IO3 }\end{array}$ 
5 New Ways of Working and Intrapreneurship: the mediating role of

Transformational Leadership and Social Interaction

I09

5.I Introduction

5.2 Literature review and hypotheses

II2

5.2.I Intrapreneurship and intrapreneurial behaviour

II 2

5.2.2 New Ways of Working

II3

5.2.3 New Ways of Working and Intrapreneurship

II4

5.2.4 The mediating role of co-worker Social Interaction

II7

5.2.5 The mediating role of transformational leadership

II9

5.3 Methods

I2I

5.3.I Data and sample

I2I

5.3.2 Measures

I2I

5.3.3 Descriptives

I24

5.3.4 Estimation methodology

I26

5.4 Results

5.4.I Overall extent of New Ways of Working, and intrapreneurship

I26

5.4.2 New ways of working separate facets, and intrapreneurship

I26

I27

I29

I3O

I3I

I3I

I32

5.6 Appendix

6.3 Implications for practice

Bibliography

Curriculum Vitae

ROA Dissertation Series

I7I 



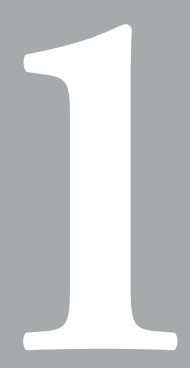

\section{Introduction}




\subsection{Motivation}

Entrepreneurs are important drivers of economic and technological change. They identify and exploit new business opportunities (Shane \& Venkataraman, 2000), and as such create employment, productivity growth and high-quality innovations (van Praag \& Versloot, 2007). However, entrepreneurship also takes place in existing organisations, which is then referred to as intrapreneurship. Intrapreneurs are employee entrepreneurs who instigate innovation (Pinchot, 1985) and strategic renewal within existing companies (Gawke et al, 20I7), create new internal ventures or enter new markets (Burgelman, 1983; de Jong et al., 20I5; Gawke et al, 2017). Several studies show that intrapreneurship is positively related to both short-term and long-term firm performance (Antoncic \& Hisrich, 2004; Vanacker et al., 2017; Zahra, I99I). However, Bosma et al. (2010) show that only five percent of all employees in highincome countries are involved in intrapreneurial activities.

This raises the challenge for firms as well as policy makers to increase employees' involvement in entrepreneurial activities within existing firms. This need is reflected in publications by for instance Ernst and Young (2010), Deloitte (2015) and PricewaterhouseCoopers (2019), which emphasise that fostering intrapreneurship is essential for innovation and firm growth. Furthermore, Dutch policy makers recently emphasised the importance of stimulating innovation and entrepreneurship in the context of tackling societal and environmental challenges ${ }^{\mathrm{I}}$. Indeed, a multitude of national and international policies aim to stimulate entrepreneurial skill development and innovative activities. As such, stimulating the development of entrepreneurial skills is mentioned as a priority within the European Commission's 'Entrepreneurship 2020 Action Plan' (European Commission, 2013). Moreover, in 2017, 30 of the 35 OECD countries and 2I of $28 \mathrm{EU}$ member states provide tax relief on Research and Development expenditures (OECD, 2018). For instance, in the Netherlands these policies include tax relief aiming to reduce (wage) costs and firms' expenses on Research and Development projects ('Wet Bevordering Speur- en Ontwikkelingswerk'), and tax relief on profits that result from innovation activities (the 'innovatie box') ${ }^{2}$. Moreover, research funding awarded to research projects on intrapreneurship by the Netherlands Organisation for Scientific Research (NWO) ${ }^{3}$

I see (in Dutch): https://www.rijksoverheid.nl/binaries/rijksoverheid/documenten/kamer stukken/2018/07/13/kamerbrief-naar-missiegedreven-innovatiebeleid-met-impact/Kamerbrief+ Naar+Missiegedreven+Innovatiebeleid+met+Impact.pdf

2 A list of other subsidies and benefits aimed at fostering innovative entrepreneurial initiatives funded by the European Union or the Dutch government is available (in Dutch) at https:// www.rvo.nl/subsidies-regelingen?f\% $\%$ Bo\% $\% \mathrm{D}=$ onderwerpen $\% 3 \mathrm{~A}_{3553}$

3 The research presented in this thesis is supported by the Netherlands Organisation for Scientific Research (NWO) as part of the project 'Intrapreneurship - Enabling talent for innovation' 
and the European Social Fund ${ }^{4}$ indicate the public interest for knowledge development on the topic of intrapreneurship.

Figure 1.1 - Number of published studies in the past 25 years containing the keyword 'intrapreneur*' included in the Web of Science database.

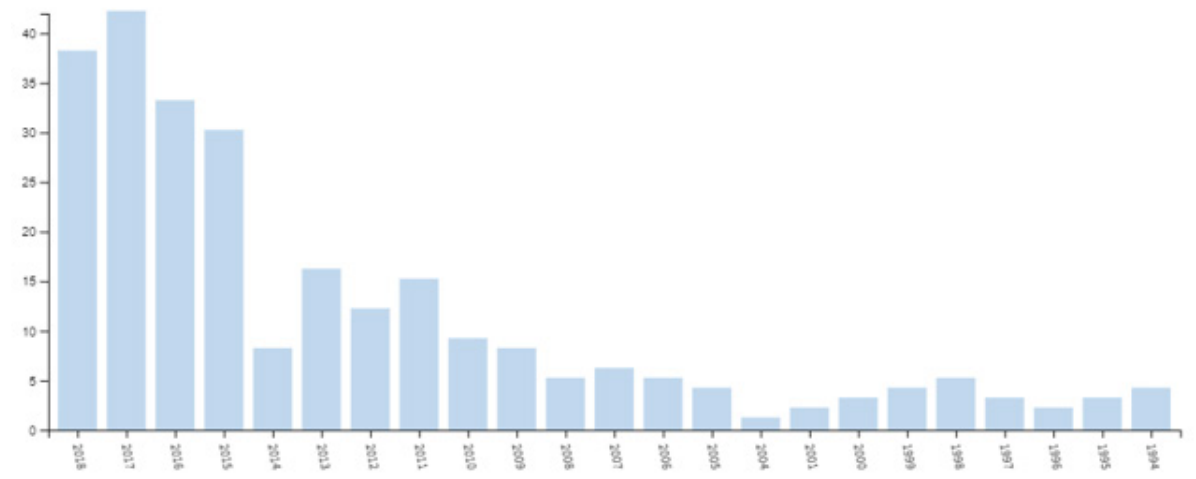

In the wake of the rise of firms' and governments' interest in promoting intrapreneurship, the topic of intrapreneurship recently gained research prominence, which is reflected in the emerging literature on intrapreneurship. As Figure I.I shows, especially the past decade has shown an increase in the number of scientific publications on intrapreneurships. The number of publications on intrapreneurship has rapidly grown to such magnitude, that the first review studies synthesising the scientific knowledge on employee intrapreneurship have recently emerged (see Blanka, 20I8; Fleisher et al., forthcoming; Mustafa et al., 20I8; Neessen et al., 20I8).

Individuals' human capital is an important driver of intrapreneurship (Blanka, 20I8; Hayton \& Kelley, 2006). Human capital related to intrapreneurship involves the knowledge, skills, abilities, and personality characteristics that enable employees to engage in intrapreneurship (e.g. Hayton \& Kelley, 2006). Previous research shows that there are several skills and abilities needed for intrapreneurship. These skills and

(NWO 409-I3-210); project description available at: https://www.nwo.nl/onderzoek-enresultaten/onderzoeksprojecten/i/63/II463.html

4 Project title 'Stimulating intrapreneurship - a transnational exploration'; project description is available at: https://ec.europa.eu/esf/transnationality/TPI-83.

5 Although intrapreneurship is regarded as an individual level concept in this thesis, the term is also often used as a synonym for firm level entrepreneurship, i.e. corporate entrepreneurship. Adding this literature would have led to an even larger number of published studies over the past 25 years. 
abilities depend on the two phases of development of the intrapreneurial project: (I) the idea development phase and (2) the idea implementation phase.

The first phase of idea development, requires employees to identify opportunities that create value for the firm (Kühn et al., 2016; Menzel et al., 2007; Vargas-Halabí et al., 2017). In order to identify new opportunities, workers should possess high levels of creative skills (Bjornali \& Støren, 20I2; Sinha \& Srivastava, 20I3). Creative skills comprise the ability to come up with new ideas, which in turn, requires workers to have both domain-specific knowledge and knowledge-brokering skills in order to acquire knowledge from inside and outside the organisation (Bjornali \& Støren, 20I2; Menzel et al., 2007; Razavi \& Ab Aziz, 2017). Here, domain-specific knowledge not only refers to technical or product knowledge, but also to market knowledge (Menzel et al., 2007; Vargas-Halabí et al., 2017).

Moving from the opportunity-identification phase to the implementation phase, intrapreneurial workers need to be able to identify resources, and to convince others in the organisation of the value of an idea (Vargas-Halabí et al., 20I7). This is referred to as championing skills, which includes high levels of interpersonal skills, commitment building and negotiation abilities (Bjornali \& Støren, 20I2; Boon et al., 2013; Menzel et al., 2007; Smith et al., 2016; Vargas-Halabí et al., 2017). Indeed, Bjornali and Støren (2012) show that highly educated workers with higher levels of creative, brokering and championing skills are more often involved in innovation activities in their firms.

In addition, previous research shows that several personality characteristics are related to intrapreneurship. Various studies investigate the relationship between the Big-Five personality traits and intrapreneurial behaviour in an Asian context. These studies find a positive relation between Extraversion and intrapreneurial behaviour (Farruhk et al., 2016; Sinha \& Strivastava, 2013). However, research findings on the other Big-Five personality traits are rather mixed. Sinha and Strivastava (2013) find a negative relation for Neuroticism with intrapreneurship and no relation of Openness to experience with intrapreneurship. In accordance with this finding, Farruhk et al. (2016) find positive relations between intrapreneurial behaviour and Emotional stability (i.e., reversed Neuroticism), but a positive relationship for Openness to experience. However, Woo (2018) finds no significant relation between Emotional stability and intrapreneurial behaviour. In addition, Farruhk et al. (20I6) find that Openness is positively, and Conscientiousness and Agreeableness are negatively related to intrapreneurial behaviour. Conversely, Woo (20I8) finds that Conscientiousness and Agreeableness have positive relations with intrapreneurial behaviour. Other personal characteristics that are found to be related to employees' intrapreneurial behaviour are risk tolerance (Douglas \& Fitzsimmons, 2013; Matthews et al., 2009), self-efficacy (Globocnik \& Salomo, 2015), persistence (Menzel et al., 2007; VargasHalabí et al., 20I7) and a need to control one's own destiny (Smith et al., 20I6). 
Apart from individuals' human capital, the work context appears to be an important determinant of intrapreneurial behaviour. Previous research shows that several contextual characteristics relating to employees' jobs and roles, their managers and their organisations can facilitate intrapreneurial behaviour (see Mustafa et al., 20I8 for a review). For instance, job characteristics such as decision-making autonomy (de Jong et al., 20I5; Kuratko et al., 2014) and time availability (Hornsby et al., 2009; Kuratko et al., 20I4; Puech \& Durand, 2017; Rigtering \& Weitzel, 2013) are positively associated with intrapreneurial behaviour. Furthermore, employees working in management and sales jobs appear to be more often involved in intrapreneurial behaviours than other employees (de Jong et al., 2015). In addition, managerial support (Dovey \& McCabe, 20I4; Smith et al., 20I6; Valsania et al, 20I6) and transformational leadership (Deprez \& Euwema, 20I7; Mariano et al., 20I4) play an important role in facilitating intrapreneurial behaviour. Moreover, higher levels of intrapreneurial behaviour are found in organisations that have an organisational culture that supports and facilitate employees' intrapreneurial behaviour (Hornsby et al., 2009; Kuratko et al., 1990; 20I4; Zampetakis et al., 2009).

Despite the growing body of research that investigates the human capital characteristics and characteristics of the work context that foster employee intrapreneurship, not much is known about the interplay between employees' intrapreneurial human capital and the work context. For instance, it is still unclear which job and organisational characteristics make organisations attractive for those who possess intrapreneurial human capital. Furthermore, it is not clear whether firms make optimal use of highly-educated workers' intrapreneurial human capital for innovation purposes. In addition, the question remains whether intrapreneurial skills are equally important for highly-educated workers across different occupational domains. Moreover, relatively few studies investigate what personality characteristics are conducive for intrapreneurial behaviour, and how characteristics of the organisation inhibit or facilitate expression of these characteristics in intrapreneurial behaviour. In addition, more research is needed that investigates the complexities in relationships between contextual determinants of intrapreneurial behaviour. Addressing these research gaps is relevant to improve our understanding of why some individuals behave intrapreneurial and some do not, and why we observe higher levels of intrapreneurial behaviour in some firms than in others.

\subsection{Aim of the thesis}

The aim of this thesis is to create more insight into the interplay between individuals' human-capital characteristics and characteristics of the work context in explaining employees' intrapreneurial behaviour within organisations. The thesis addresses the following research questions: 
- Chapter 2: Which firm and job characteristics are attractive for intrapreneurial talent?

- Chapter 3: How are intrapreneurial skills used in different occupations and are they optimally used?

- Chapter 4: What personality characteristics are important for intrapreneurial behaviour, and what is the role of the organisational environment in the relationship between personality and intrapreneurial behaviour?

- Chapter 5: How do characteristics of the job, management and internal communication networks simultaneously contribute to intrapreneurial behaviour?

\subsection{Thesis outline and main results}

Figure I.2 provides a conceptual overview of the four studies included in this thesis. Chapters 2 and 3 examine the interplay between human capital and the work context in explaining intrapreneurial behaviour by focussing on the allocation of talent to firms and jobs in workers' early careers. More specifically, Chapter 2 investigates preferences for job and organisational characteristics of master students with intrapreneurial characteristics, contributing to the overall aim of this thesis by providing valuable insights into the role of the work context in attracting intrapreneurial talent to organisations. Chapter 3 investigates the use of higher-education graduates' intrapreneurial skills for intrapreneurial activities, and in different occupations. This chapter contributes to the overall aim of the thesis by investigating the interplay between employees' intrapreneurial skills and their occupational characteristic and skill demands. Chapters 4 and 5 focus on the entire working population and investigate how intrapreneurial talent is affected by the work context. Chapter 4 investigates what personality characteristics are conducive for intrapreneurial behaviour in a sample of the Dutch working population, and how perceptions of the organisational environment affect the relations between personality characteristics and intrapreneurial behaviour. As such, Chapter 4 contributes to the aim of this thesis by providing insight into the interplay between personality characteristics and organisational characteristics in explaining employees' intrapreneurial behaviour. Chapter 5 contributes to the aim of this thesis by examining the relationships of various work contextual characteristics with employees' intrapreneurial behaviour. Specifically, Chapter 5 investigates the influence of a bundle of human resource management practices and job characteristics, in addition to transformational leadership and social interaction on intrapreneurial behaviour in a sample of the Dutch working population. 
Figure 1.2 - Conceptual overview of the thesis

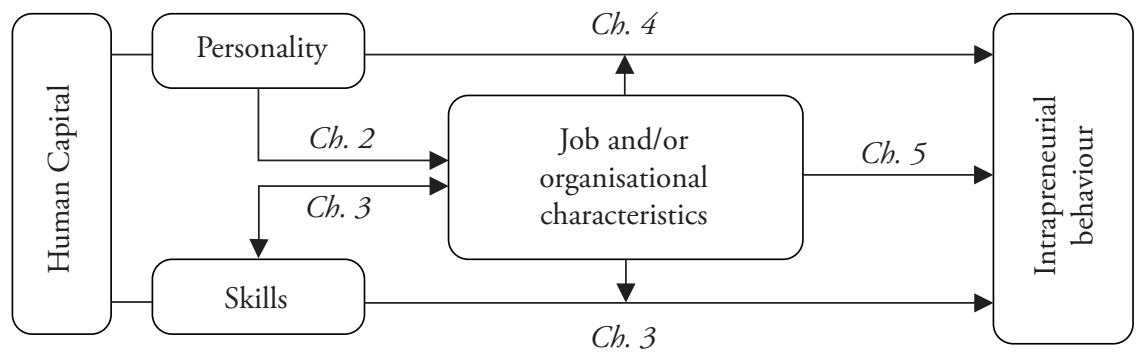

More specifically, Chapter 2 exploits data from a discrete-choice experiment and investigates how intrapreneurial talent is attracted to organisations. Building on personentrepreneurship fit theory and entrepreneurial-intention models, we use personality traits and attitudes towards entrepreneurship to distinguish between prospective entrepreneurs, intrapreneurs, and non-entrepreneurial employees. In a sample of 855 master's students in the fields of science, technology, engineering and mathematics (STEM), we elicit preferences for eight job attributes and explore how preferences relate to entrepreneurial talent. Our results indicate that prospective intrapreneurs have stronger preferences for firms that focus on innovation and/or corporate social responsibility and/or sustainability than non-entrepreneurial employees. Both prospective intrapreneurs and entrepreneurs are less averse to high workloads and have stronger preferences for management positions than non-entrepreneurial employees have. In addition, we find that prospective intrapreneurs have a stronger preference for team-based performance pay than other workers do.

Chapter 3 studies the extent to which higher-education graduates with higher intrapreneurial skills - creative, brokering, and championing skills - are more involved in innovative activities in their organisations. Crucially, we differentiate between graduates employed in STEM occupations and those employed in business occupations. Using data on higher-education graduates from in European countries, we find that, in both STEM and business occupations, high levels of creative skills are important to involvement in innovation. Higher levels of brokering skills are particularly important for graduates employed in STEM occupations, whereas higher levels of championing skills are particularly important for those in business occupations. However, we find that the innovative potential of graduates whose intrapreneurial skills are higher than is required in their jobs, is not optimally utilized for innovation.

Chapter 4 investigates the relation between the Big-Five personality traits, risk tolerance as well as the influence of employees' perception of organisational support for intrapreneurship on intrapreneurial behaviour. We use data from the Longitudinal Internet Studies for the Social Sciences (LISS) panel, and find in a 
sample of I,557 workers in dependent and independent employment that those employees with higher levels of Extraversion, those with a higher level of Openness to experience and risk tolerance have higher levels of intrapreneurial behaviour one year later. Furthermore, employees who perceive higher levels of organisational support for intrapreneurship have higher levels of intrapreneurial behaviour. Moreover, the relation between Openness to experience and intrapreneurial behaviour is positively moderated by employees' perceptions of organisational support for intrapreneurship. Additionally, we find that highly intrapreneurial employees have higher levels of both Openness and Conscientiousness than entrepreneurs.

Chapter 5 investigates the relation between a bundle of human resource management practices termed New Ways of Working (NWW) and intrapreneurial behaviour, while testing transformational leadership and social interaction as mediators. We use a sample of 254 employees of the Dutch working population and apply the Preacher and Hayes' (2008) bootstrap method for multiple mediation to test our hypotheses. We find that NWW are positively related to intrapreneurial behaviour. This relation is partially mediated by transformational leadership. Although NWW are positively related to social interaction, we find no relation between social interaction and intrapreneurial behaviour. More specifically, we find that the NWW facets 'time- and location-independent work' and 'management on output' drive the positive relation between NWW and intrapreneurial behaviour.

Chapter $\mathbf{6}$ concludes and provides a summary of the main results and contributions of this thesis. In addition, the chapter reflects on practical implications of the findings presented in this thesis and provides avenues for future research. 


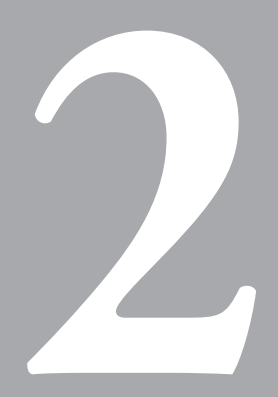

\section{Attracting entrepreneurial employees: Exploring job preferences of STEM students using a discrete-choice experiment}

This chapter is joint work with Arjan Non. We thank Martin Carree, Andries de Grip, Rund Gerards, Julia Kensbock and participants of the EURAM 2018 conference and ENESER Small Group Meeting 2018 for helpful comments and suggestions. 


\subsection{Introduction}

Entrepreneurs are often considered to be important drivers of economic and technological change. Entrepreneurs identify and exploit new opportunities, and by doing so generate employment, productivity growth and high-quality innovations (van Praag \& Versloot, 2007). The identification and exploitation of opportunities is however not restricted to independent entrepreneurs, but also takes place within established organizations. This phenomenon is referred to as intrapreneurship (Sharma \& Chrisman, 1999). Intrapreneurs are employees that instigate innovation in existing companies (Pinchot, 1985), create new internal ventures and enter new markets (de Jong et al., 2015; Gawke et al, 2017). In advanced economies, intrapreneurship is more prevalent than independent entrepreneurship (Stam, 2013).

Intrapreneurs are an important source of competitive advantage (Leiponen, 2005). Several studies show that intrapreneurship is positively related to both short-term and long-term firm performance (Antoncic \& Hisrich, 2004; Zahra, 1991; Vanacker, Zahra \& Holmes, 20I7). An important question is therefore how organizations can attract intrapreneurial talent. This question is particularly important for organizations that operate in an environment where continuous innovation is vital for their performance. This particularly holds for the fields of science, technology, engineering and mathematics (STEM), see Atkinson \& Mayo (20I0), Langdon et al. (20II), and Winters (20I4). Intrapreneurial activities of workers in those fields are also important for the society at large. More generally, workers in STEM fields are considered essential drivers of technology-intensive economic growth (Murphy et al., 199I).

In this chapter, we investigate the preferences of Master of Science (MSc) students in the STEM fields with respect to eight job and firm characteristics, and how these preferences differ for those with intrapreneurial talent. We conduct a discrete-choice experiment among 855 MSc students from a renowned Dutch technical university ${ }^{6}$. Students choose among three hypothetical jobs in five different choice sets. This allows us to infer their preferences for the eight job and organizational characteristics included in the choice experiment. In addition, we collect data on personality characteristics and attitudes that are associated with entrepreneurial activity. Based on this information, we classify students as prospective entrepreneurs, intrapreneurs and non-entrepreneurial employees. We define prospective intra- and entrepreneurs as those who possess an entrepreneurial personality: high levels of risk tolerance, openness to experience and generalized self-efficacy. Prospective entrepreneurs

6 Non et al. (2019) study the impact of the mission of the company on job choice of STEM MSc students on the same sample, plus additional data from another Dutch technical university. However, they do not investigate how job attributes can attract entrepreneurial talent.

7 We use the term 'prospective' as we do not observe students' future worker type or employment status. 
differ from intrapreneurs by their attitude towards independent entrepreneurship: entrepreneurs are characterised by higher expectations of generating an income from independent entrepreneurship. Prospective non-entrepreneurial employees possess low levels of entrepreneurial personality and have low expectations of acquiring an entrepreneurial income ${ }^{8}$. We then explore differences in the preferences of prospective intrapreneurs, entrepreneurs and non-entrepreneurial employees for job and organizational characteristics.

We find that STEM students who are prospective intrapreneurs are most attracted to organizations that focus on innovation, CRS and sustainability than to organizations with a strong profit focus. Moreover, prospective intrapreneurs have a stronger preference for non-profit organisations than prospective entrepreneurs. Intrapreneurs and entrepreneurs both have a stronger preference for management occupations and are more willing to work overtime than non-entrepreneurial employees. Unlike entrepreneurs, intrapreneurs also have a stronger preference for team-based performance pay over a fixed salary than non-entrepreneurial employees.

The unique contribution of this chapter is that we examine how (high tech) companies can attract graduates of STEM studies with intrapreneurial characteristics. Only few previous studies investigate targeted recruitment, i.e. how organizations can attract individuals who possess the specific human capital a given vacancy requires (Breaugh, 2008, 2013; Evertz \& Süß, 2017; Hunter et al., 2012; Non et al., 2019), and none of those studies investigate how workers with intrapreneurial talent can be attracted. A noteworthy exception is Moser et al. (2017), who investigate how recently formed ventures can attract entrepreneurial employees. One of the differences with the study presented in this chapter is that they focus on self-selection of entrepreneurial talent into newly founded organizations only, whereas we focus on established organizations. In addition, Non et al. (2019) also investigate the job preferences of STEM students. However, this study is the first that distinguishes between job preferences of entrepreneurs, intrapreneurs and non-entrepreneurial employees. As such, we contribute to the emerging literature on the relationship between job and organizational characteristics and individuals' intrapreneurial behaviour (e.g. de Jong et al., 20I5; Gawke et al., 2017; Rigtering \& Weitzel, 2013) - not by investigating how job characteristics stimulate intrapreneurial behaviour, but how they attract those with intrapreneurial talent.

The remainder of this chapter is structured as follows. In Section 2.2, we review the literature on recruitment of different types of workers and intrapreneurial employees in particular. Next, in Sections 2.3 and 2.4, we describe our methods and our empirical model. Section 2.5 presents our results. Then, in Section 2.6, we reflect

8 In addition, we classify students who possess low levels of entrepreneurial personality but have high expectations of receiving an entrepreneurial income as prospective incongruent worker types. See the Methods section for a more elaborate explanation. 
on the implications of our results for both research and recruitment practice. Section 2.7 concludes.

\subsection{Theoretical framework}

In this Section, we first review the literature on attraction of different types of workers and the literature on the characteristics of entrepreneurial employees, respectively. We draw on entrepreneurship-fit theory and entrepreneurial intention models to create a typology of three types of workers: I) the entrepreneur 2) the intrapreneur 3) the non-entrepreneurial employee. Finally, we consider which job and company characteristics attract intrapreneurs.

\subsubsection{Recruitment of employees with specific characteristics}

According to Breaugh (2008, pp.IO3-IO4) recruitment refers to: "an employer's actions that are intended to (I) bring a job opening to the attention of potential job candidates who do not currently work for the organization, (2) influence whether these individuals apply for the opening, (3) affect whether they maintain interest in the position until a job offer is extended, and (4) influence whether a job offer is accepted". Recruitment that is designed to attract a particular type of job applicant is referred to as targeted recruitment (Breaugh, 2008).

Attracting the attention of targeted prospective applicants is an essential element in the early stages of the recruitment process (Breaugh, 2013). If organizations do not appeal to the types of individuals they intend to hire, they might fail to attract an applicant pool that possesses the personal attributes that fit to their organizational objectives (Evertz \& Süß, 20I7). Consequently, the organization must understand what attracts the type of envisioned job applicant.

In a recent review, Evertz and Süß (20I7) find that most studies on individual differences in the attraction of applicants, focus on differences in applicant perceptions during various elements of the recruitment process (e.g. Judge \& Cable, 1997; Cable \& Judge, I994; Carless, 2005). Other studies focus on the effect of socialisation and experience (e.g. Schreurs et al., 2009a; Crant \& Bateman, 1990), biographical characteristics (e.g. Cho et al., 2013; Casper et al., 2013), motivation (e.g. Vroom, 1966; Larsen \& Philips, 2002), personality traits (e.g. Schreurs et al., 2009b; Lievens et al., 200I; Cable \& Judge, 1994), values and attitudes (e.g. Avery et al., 2013; Olsen et al., 2015), ability (e.g. Blume et al., 2013; Trank et al., 2002) or emotions and moods (Chen et al., 2013) on applicant attraction. Although previous research shows that individual differences matter for applicant attraction, it is still unclear how organizations can attract applicants that possess specifically job relevant characteristics (Evertz \& Süß, 20I7; Breaugh, 20I3; Hunter et al., 20I2). We contribute to filling this gap by investigating the extent to which in entrepreneurs, intrapreneurs 
and non-entrepreneurial employees are attracted by different job and organizational characteristics.

\subsubsection{Identifying entrepreneurs, intrapreneurs and non-entrepreneurial employees}

Intrapreneurship and entrepreneurship are closely related concepts that revolve around the entrepreneurial process. The entrepreneurial process constitutes the recognition of business opportunities, the assessment of the value of the opportunity and finally the exploitation of this opportunity (Shane \& Venkataraman, 2000). While entrepreneurship entails independent business ownership, intrapreneurs are considered employee entrepreneurs within an existing company (Pinchot 1985, p.15). ${ }^{9}$

In the literature, there is no consensus on how to identify potential intrapreneurs. ${ }^{10}$ Some studies take a behavioural approach to identify intrapreneurial talent. For instance, Moser et al. (2017) investigate how recently formed ventures can attract entrepreneurial employees. They identify entrepreneurial talent based on applicants' level of intrapreneurial behaviour, specifically innovative, proactive and risk-taking behaviours. However, the measures they use are based on individuals' past workplace behaviour which does not necessarily capture their potential and overlooks differences in opportunities individuals had in their past work.

Other studies identify intrapreneurs by the competencies they possess, such as their knowledge, skills, personality and attitudes. For instance, Hayton and Kelley (2006) develop a competency profile for intrapreneurs and propose the knowledge, skills and personality traits needed for intrapreneurs based on four roles in the innovation process: I) the technical innovator, 2) knowledge broker, 3) the idea champion and 4) the sponsor of the idea. Although, this model has not been empirically tested, Bjornali and Støren (20I2) show that higher education graduates with higher levels of intrapreneurial skills related to creativity, knowledge brokering and idea championing are more often involved in innovation. In addition, in Chapter 3 of this dissertation, we show that the level of these more specific intrapreneurial skills needed for technological innovation differs between higher education graduates in business occupations and those in STEM occupations. Graduates in business occupations were found to need higher levels of championing skills for innovation, whereas graduates in STEM occupations need higher levels of brokering skills.

In this chapter we, however, build on person-entrepreneurship fit theory and entrepreneurial intention models to determine the characteristics that help us identify intrapreneurs and differentiate between different types of workers.

9 More formally, Stam et al. (2012, p. 43) define intrapreneurship as the identification and exploitation of opportunities by individual workers to (also) advance their organization, which is generally characterized by employees' innovation, proactive and risk taking behaviours'.

We refer to Blanka (20I8) for a systematic literature review on the topic of intrapreneurship. 


\section{Person - entrepreneurship fit theory}

According to person-organization and person-job fit theories, (e.g. Kristof, 1996; Kristof-Brown et al., 2005), applicants seek a fit with an organization or job. Applicants' evaluations of fit to an organization or job depend on their own personal characteristics and needs and the characteristics of organizations and jobs. Rooted in person-organization fit theory, person-entrepreneurship fit theory (Markman \& Baron, 2003) suggests that the higher the extent to which individuals possess characteristics that are relevant to the entrepreneurial role, the more likely they are successful entrepreneurs. As such, person-entrepreneurship fit theory aims to discriminate between those with entrepreneurial talent and those without.

In support of person-entrepreneurship fit theory, several personality characteristics that are related to the entrepreneurial role have been found to be important drivers of entrepreneurial intentions, the decision to start a business and business success (Caliendo et al., 20I4; Davidsson, 2004; Holland, I997; Markman \& Baron, 2003; Zhao, Seibert \& Lumpkin, 2010). Most research on the role of personality characteristics as predictors of entrepreneurship focuses on the role of the Big Five personality traits and risk propensity (Zhao, Seibert \& Lumpkin, 20Io). Research shows that especially openness to experience (Caliendo et al., 20I4; Zhao, Seibert \& Lumpkin, 20IO), and risk propensity (Caliendo et al., 20I4; Cramer, et al., 2002; Rauch \& Frese, 2007) are related to entrepreneurial intentions and success. In addition, other personality characteristics that have been related to entrepreneurial success are self-efficacy (Markman \& Baron, 2003; Rauch \& Frese, 2007), locus of control (Caliendo et al., 20I4), innovativeness, stress tolerance, need for autonomy, and proactive personality (Rauch and Frese, 2007).

Intrapreneurs are seen as entrepreneurs in existing organizations (Pinchot, 1985) and should therefore share traits with entrepreneurs (Menzel et al., 2007). Indeed, Matthews, Schenkel, Ford and Human (2009) show that entrepreneurs and intrapreneurs are similar in risk tolerance levels, while Douglas and Fitzsimmons (2013) show that self-efficacy is an antecedent of both entrepreneurship and intrapreneurship.

\section{Entrepreneurial intentions}

Whereas person-entrepreneurship fit theory discriminates between those with, and those without entrepreneurial talent, entrepreneurial intention models identify individuals who are likely to start their own businesses instead of choosing for dependent employment (Krueger, 2009). Several models have been developed to explain the emergence of entrepreneurial intentions which we can roughly divide into two types of models. One of the earliest models to explain entrepreneurial intentions is the entrepreneurial event model (EEM; Shapero, 1975). This model proposes that entrepreneurial intentions develop through an individual's propensity to act and perceptions of both the feasibility and desirability of starting one's own business. 
Another widely used model to explain entrepreneurial intentions is based on the theory of planned behaviour (TPB; Azjen, I99I), which proposes that entrepreneurial intentions develop through individuals' attitude towards entrepreneurship, social norms about entrepreneurship and perceived behavioural control (Krueger \& Carsrud, I993).

Schlaegel and Koenig (2014) develop an integrative model of entrepreneurial intentions encompassing elements from both EEM and TPB. They show that the development of entrepreneurial intentions is best explained by a function of four types of attitudes. First, individual attitudes towards entrepreneurial behaviour, are determined by the outcomes they expect from entrepreneurial behaviour, such as income and wellbeing. Second, apart from their own attitude towards entrepreneurship, individuals take social norms regarding entrepreneurship into account in their decision making. Social norms refer to the support and expectations of an individual's social environment (e.g. family and friends) for showing entrepreneurial behaviour,. Third, perceived behavioural control refers to an individual's assessment of the feasibility of starting an entrepreneurial venture. Individuals assess for instance if they possess the knowledge, skills, and abilities to perform the tasks necessary to be a successful entrepreneur (Krueger et al., 2000). Fourth, an individual's perceived desirability of entrepreneurship refers to the extent to which an individual is attracted to entrepreneurship (Schlaegel \& Koenig, 20I4). Both individuals' own attitudes towards entrepreneurship and perceived social norms towards entrepreneurship are expected to determine the desirability of independent entrepreneurship over dependent employment (Krueger, Reilly \& Carsrud, 2000; Segal, Borgia \& Schoenfeld, 2005) ${ }^{\text {II }}$.

Entrepreneurial intention models suggest that individuals' entrepreneurial personality influences their attitudes towards entrepreneurship and consequently their intentions and behaviour (Azjen, I99I; Baum \& Locke, 2004; Caliendo et al., 20I4; Schlaegel \& Koenig, 20I4). However, these models also suggest that some individuals may have the predisposition for entrepreneurship, without forming positive attitudes towards entrepreneurship or forming intentions to pursue entrepreneurship in the near future. This enables us to distinguish intrapreneurs from entrepreneurs by their entrepreneurial attitudes. Intrapreneurs have lower levels of entrepreneurial attitudes than entrepreneurs.

II Another strand of literature on entrepreneurial career choices distinguishes between negative 'push' and positive 'pull' factors in explaining why people opt for an entrepreneurial career (e.g. Amit \& Muller, 1995; Dawson \& Henley, 20I2; Gilad \& Levine, 1986; Schjoedt \& Shaver, 2007). For instance, being fired from a job might 'push' people into an entrepreneurial career out of necessity whereas expectation of increased life satisfaction might 'pull' individuals towards an entrepreneurial career. 
Table 2.I gives an overview of the different worker types we distinguish, based on the levels of person-entrepreneurship fit and entrepreneurial attitudes. We define entrepreneurs as those who possess high levels of person-entrepreneurship fit and high levels of entrepreneurial attitudes. Next, we define intrapreneurs as those who possess high levels of person-entrepreneurship fit and low levels of entrepreneurial attitudes. Finally, we define non-entrepreneurial employees as those with low levels of entrepreneurship-fit and low levels of entrepreneurial attitudes.

Table 2.1 - A definition of worker types

\begin{tabular}{l|l|l} 
& Person-Entrepreneurship fit & Entrepreneurial attitudes \\
\hline Entrepreneur & High & High \\
Intrapreneur & High & Low \\
Non-entrepreneurial employee & Low & Low \\
\hline
\end{tabular}

\subsubsection{Attracting prospective intrapreneurs}

According to person-organization and person-job fit theories, individuals are more likely to be attracted to organizations and jobs when their perceived fit to an organization or job is high (Chapman et al., 2005). We may therefore expect that entrepreneurs, intrapreneurs and non-entrepreneurial employees differ in their preferences for job and organizational characteristics.

Although to the best of our knowledge, there is no study that specifically investigates the job preferences of intrapreneurs, previous research suggests that employees with entrepreneurial characteristics self-select into jobs and companies with characteristics that they find particularly desirable. For instance, several studies show that higher levels of job autonomy are related to higher levels of intrapreneurial behaviour (de Jong et al., 2015; Globocnik \& Salomo, 2015). In addition, de Jong et al. (2015) find that employees in management and sales jobs display higher levels of intrapreneurial behaviour as compared to those in other jobs. Bjornali and Støren (20I2) and the results of Chapter 3 of this dissertation show that employees with higher levels of intrapreneurial skills are more often involved in innovations whereas Rigtering and Weitzel (2013) find that higher level of intrapreneurial behaviour is found in firms with horizontal participation and with more available financial and time resources.

However, we do not formulate specific hypotheses for each attribute we include in this chapter as a lack of previous research on this topic makes it difficult to formulate specific hypotheses concerning what job and company characteristics are considered attractive by intrapreneurs. Moreover, the selection of firm and company attributes we investigate in this chapter is practice-based. As we more elaborately discuss in the Methods section, we focus on attributes and levels which are present in recruitment advertisements and suggested by HR practitioners involved in recruitment and selection. 


\subsection{Methods}

\subsubsection{Sample selection and Experimental design}

Our discrete-choice experiment is explicitly designed for MSc students in the STEM fields. Focusing on this group of young and highly educated individuals has a number of advantages. First, Parker (2OII) shows that younger workers are more likely to be intrapreneurial than those in later stages of their career. Second, MSc students are about to enter the labour market. It is therefore likely that they are highly engaged with the choices to be made. In their study on the validity of discrete-choice experiments, Hainmüller et al. (2015) conclude that respondent engagement is a key factor for the reliability of the results. Finally, students are a homogeneous group in terms of age and stage of their career, which facilitates the interpretation of the results.

Discrete-choice experiments have some important advantages over naturally occurring revealed preference data. First, discrete-choice experiments allow the researcher to exogenously vary job attributes, while exogenous variation in choice options is rarely observed in naturally occurring data. Second, in experimental data all available choice options are observed, including the options that are not chosen. Studies on actual behaviour are typically not able to identify all options available for the individual.

The core of our discrete-choice experiment consists of the choices respondents make among three hypothetical jobs in five different choice sets. Specifically, we ask respondents to rank order three jobs, which they do so five times. We prefer a rankorder over ratings, since we want to force individuals to make choices. ${ }^{\mathrm{I} 2}$ Figure 2.I shows a screenshot to illustrate how choice options are presented to respondents. Respondents are confronted with a screen such as the one depicted in Figure 2.I five times.

Jobs differ in eight job and organizational attributes that are exogenously varied. All respondents evaluate different choice sets, as all jobs are randomly generated. The values of each job attribute are randomly drawn from the set of possible levels. The randomization is subject to two intuitive constraints. First, we rule out that a job attribute takes on three times the same value in a set of three jobs. This ensures that there is variation in each attribute within each choice set, which increases the information implicit in respondents' choices. ${ }^{13}$ Second, we rule out two implausible combinations. If work is conducted on one's own, pay-for-performance is never based on team performance. Vice versa, if work is conducted in teams, performance pay is not based on individual performance. To ensure that students' ranking of jobs will

I2 It is of course possible to impose that respondents rate jobs unequally, but this increases complexity without much additional information.

I3 Note that this procedure does not preclude the possibility that subjects incidentally see the same job twice in a choice set, but this happened only twice (out of 7490 choice sets). 
not be influenced by their responses to other questions, all other questions (except for basic demographics) were asked after the ranking task in the survey.

One might be concerned that respondents find it daunting to compare jobs that differ in eight dimensions. The effects of job attributes on attractiveness would be attenuated. However, the advantage of such an extensive choice set is that we collect information on several potentially important job attributes, which adds realism as in practice jobs also differ along several dimensions.

Figure 2.1 - Screenshot of ranking task

\begin{tabular}{|c|c|c|c|}
\hline & Job A & Job B & Job C \\
\hline Salary & 1800 euro net per month & 2000 euro net per month & 1800 euro net per month \\
\hline Work environment & $\begin{array}{l}\text { Work is conducted in teams } \\
\text { where people have the same } \\
\text { expertise }\end{array}$ & $\begin{array}{l}\text { Work is conducted on one's } \\
\text { own }\end{array}$ & $\begin{array}{l}\text { Work is conducted in teams } \\
\text { where people have the same } \\
\text { expertise }\end{array}$ \\
\hline Workload & $\begin{array}{l}\text { Workload can usually be } \\
\text { accomplished in regular } \\
\text { working time }\end{array}$ & $\begin{array}{l}\text { Workload can usually be } \\
\text { accomplished in regular } \\
\text { working time }\end{array}$ & $\begin{array}{l}\text { High workload requires } \\
\text { frequently working unpaid } \\
\text { overtime }\end{array}$ \\
\hline Control over work & $\begin{array}{l}\text { You have no influence on } \\
\text { what you do and how you } \\
\text { do it }\end{array}$ & $\begin{array}{l}\text { You have no influence on } \\
\text { what you do and how you } \\
\text { do it }\end{array}$ & $\begin{array}{l}\text { You decide on what you do } \\
\text { and how you do it }\end{array}$ \\
\hline Composition salary & Fixed Salary & $\begin{array}{l}10 \% \text { higher or lower wage } \\
\text { per month depending on } \\
\text { individual performance }\end{array}$ & Fixed Salary \\
\hline Focus of company & $\begin{array}{l}\text { For profit organization with } \\
\text { a strong focus on innovation }\end{array}$ & Non-profit organization & Non-profit organization \\
\hline Occupation & Research and development & Research and development & Management \\
\hline Job security & Permanent contract & Permanent contract & $\begin{array}{l}2 \text { year temporary contract } \\
\text { with } 80 \% \text { chance on } \\
\text { permanent contract }\end{array}$ \\
\hline
\end{tabular}

\subsubsection{Job attributes}

Table 2.2 provides an overview of the job attributes included in the discrete-choice experiment and the corresponding levels. Jobs differ in the following attributes, which can be grouped into three categories:

I. Mission of the company: focus of the company

2. Job design: autonomy, teamwork, occupation, workload

3. Contractible characteristics: salary, performance pay, job security. 
Table 2.2 - Overview of job attributes and their levels in the discrete-choice experiment

\begin{tabular}{|c|c|}
\hline Attribute & Levels \\
\hline \multicolumn{2}{|l|}{ Mission } \\
\hline Focus of the company & $\begin{array}{l}\text { 1. For profit organization that is strongly profit orientated } \\
\text { 2. For profit organization with a strong focus on innovation } \\
\text { 3. For profit organization with a strong focus on corporate } \\
\text { social responsibility and sustainability } \\
\text { 4. Non-profit organization }\end{array}$ \\
\hline \multicolumn{2}{|l|}{ Job design } \\
\hline Autonomy & $\begin{array}{l}\text { 1. You have no influence on what you do and how you do it } \\
\text { 2. You have no influence on what you do, but you decide } \\
\text { on how you do it } \\
\text { 3. You decide on what you do and how you do it }\end{array}$ \\
\hline Teamwork & $\begin{array}{l}\text { 1. Work is conducted on one's own } \\
\text { 2. Work is conducted in multidisciplinary teams } \\
\text { 3. Work is conducted in teams where people have the } \\
\text { same expertise }\end{array}$ \\
\hline Occupation & $\begin{array}{l}\text { 1. Research and development } \\
\text { 2. Management } \\
\text { 3. Sales }\end{array}$ \\
\hline Workload & $\begin{array}{l}\text { 1. High workload requires frequently working unpaid } \\
\text { overtime } \\
\text { 2. Workload can usually be accomplished in regular } \\
\text { working time }\end{array}$ \\
\hline \multicolumn{2}{|l|}{ Contractible attributes } \\
\hline Salary & $\begin{array}{l}\text { 1. } € 1800 \text { net per month } \\
\text { 2. } € 2000 \text { net per month } \\
\text { 3. } € 2200 \text { net per month }\end{array}$ \\
\hline Pay for performance & $\begin{array}{l}\text { 1. Fixed salary } \\
\text { 2. } 10 \% \text { higher or lower wage per month depending on } \\
\text { individual performance } \\
\text { 3. } 10 \% \text { higher of lower wage per month depending on } \\
\text { team performance }\end{array}$ \\
\hline Job security & $\begin{array}{l}\text { 1. } 2 \text { year temporary contract with } 20 \% \text { chance on } \\
\text { permanent contract } \\
\text { 2. } 2 \text { year temporary contract with } 80 \% \text { chance on } \\
\text { permanent contract } \\
\text { 3. Permanent contract }\end{array}$ \\
\hline
\end{tabular}

We based our selection of job attributes on practical relevance for this segment of the labour market. We screened job advertisements in the Netherlands targeted at Master's students in the STEM fields. We specifically screened how approximately I2O organisations advertise themselves at one of the largest job fairs for students and recent graduates in engineering in the Netherlands, which took place at the Technical University of Eindhoven in spring 20I5. By doing so we obtain a good 
impression what job attributes organisations emphasize to attract recent graduates in engineering. We used this information to discuss relevant characteristics with recruiters from various companies in the high-tech sector. In addition, we designed attribute levels in such a way that they are realistic and sufficiently specific to allow for meaningful comparisons. For example, it would be hard to meaningfully interpret the choice between either a job with an 'average salary' and 'average workload' or a job with 'above average salary' and 'above average workload'. Hence, we quantified job attributes as much as possible. To ensure realism, we discussed with HR-practitioners working in the Dutch high-tech sector what variation in attribute levels would be realistic. For example, starting salaries in the sector typically hoover between 1800 and 2200 euro net per month. Likewise, performance pay components, when present, usually make up for IO\% of the wages in this sector in the Netherlands.

\subsubsection{Person-Entrepreneurship fit}

To determine individuals' level of person-entrepreneurship fit, we selected three variables that according to the literature have been consistently related to the probability of starting new ventures and venture success: Openness to experience, risk tolerance and generalized self-efficacy. We create a measure of person-entrepreneurship fit using the first principal component of these three variables, which results in a standardised weighted sum-score of the three variables.

General self-efficacy: We measure general self-efficacy with a selection of items from the New General Self-Efficacy Scale (Chen, Gully \& Eden., 20or). We use the following three items: I) "I will be able to achieve most of the goals that I have set for myself", 2) "I will be able to successfully overcome many challenges", and 3) "Compared to other people, I can do most tasks very well" which are rated on a 5-point Likert scale. Exploiting questionnaire data which we collected as part of an unrelated laboratory experiment, these three items jointly show a 0.95 correlation with the original I4-item scale. We measure general self-efficacy instead of entrepreneurial self-efficacy because this better reflects a stable personality characteristic and has been shown to be higher among entrepreneurs (Markman et al., 2002) whereas entrepreneurial self-efficacy is highly malleable (e.g. Zhao et al., 2005).

Risk tolerance: We measure individuals' attitude towards risk by a widely used subjective risk question (see Falk et al., 2016 and Dohmen et al., 20II for validation of this measure). Respondents indicate on a continuous scale from o-Io to what extent the following statement applies to them: "How do you see yourself: are you a person who is generally willing to take risks, or do you try to avoid taking risks?"

Openness to Experience: We included a short 2-item scale of Openness to Experience based on the Io-item NEO-FFI (Gosling, Rentfrow \& Swann, 2003). Participants assess how they score on 2 statements using a 5-point Likert scale: I) "has an active imagination", and 2) "has few artistic interests". 


\subsubsection{Entrepreneurial attitude: income expectations}

We measure individuals' attitude towards entrepreneurship by asking them to rate the likelihood of obtaining their primary income from entrepreneurship in the next five years on a Likert scale ranging from o-Io. As such, this question taps into students' expectation of becoming an entrepreneur and earning an entrepreneurial income (Krueger et al., 2000; Schleagel \& Koenig, 20I4). The higher individuals' rating on this scale, the more likely we expect them to have entrepreneurial intentions.

\subsubsection{Worker type}

We differentiate between worker types depending on students' level of personentrepreneurship fit and students' expectation of obtaining an income from independent entrepreneurship. We create a categorical variable which indicates whether the student is a prospective intrapreneur $(=0)$, an entrepreneur $(=\mathrm{I})$, non-entrepreneurial employee $(=2)$, or an incongruent $(=3)$ worker type.

More specifically, we formally define an individual as a prospective entrepreneur when that individual reports person-entrepreneurship fit above the sample median, and entrepreneurial income expectations of at least the scale average (i.e. 5). This category represents therefore students who not only possess predispositions for entrepreneurship, but also are relatively likely to choose independent over dependent employment. Specifically, their answer to the question "How likely is it that entrepreneurship will become your primary source of income in the coming 5 years?" is closer to Io, which is defined as "definitely", than to o, which stands for "certainly not". Note that using the scale average implies a cut-off close to the $70^{\text {th }}$ percentile, which makes it a stricter criterion than the sample median.

Next, we formally define prospective intrapreneurs as those who have a personentrepreneurship fit above the sample median, but have entrepreneurial income expectations below the scale average. Thus, this category represents students that have predispositions for entrepreneurship, but nevertheless are most likely to choose dependent over independent employment.

In addition, we formally define an individual as a prospective non-entrepreneurial employee when that individual displays below median levels of person-entrepreneurship fit and below scale average income expectations. Finally, we also define a category of individuals who have below median levels of person-entrepreneurship fit, but nevertheless have above scale average entrepreneurial income expectations as incongruents.

\subsubsection{Control variables}

We collect information on a number of background characteristics such as gender and nationality (defined as country of birth). In addition, we measure academic achievement with the grade obtained in the master program so far. Grades in the Netherlands are always expressed on a scale I (lowest) to Io (highest), where 5.5 is the 
minimum passing grade. Only $2.4 \%$ of the sample reports an average grade below 5.5, and about 50\% of all grades are between 7 and 8 (bounds included).

\subsubsection{Data collection and sample description}

Our sample consists of MSc students in science and engineering from one of the largest technical universities in the Netherlands. MSc programs in those disciplines take two years. We include both first and second-year master students. The survey was conducted in July 2016 and distributed via the university's regular mailing system. We collected 855 valid responses (IO\% of the approached population). Table 2.3 provides descriptive statistics of the main variables. Most students classify themselves as second-year master students. ${ }^{14}$ Students with Dutch nationality are somewhat underrepresented (6r\% in the sample vs $68 \%$ in the population), while women are overrepresented (36\% in the sample vs $27 \%$ in the population). Non-Dutch students predominantly come from China and India ( $13 \%$ ) and other European countries (IO\%).

Table 2.4 reports correlations between variables. Risk tolerant individuals score higher on self-efficacy and openness to experience, while self-efficacy and openness to experience are not correlated. As predicted by person-entrepreneurship theory, risk tolerance, self-efficacy and openness to experience are all positively correlated to entrepreneurial income expectations. As expected, self-efficacy and grades are positively correlated. Women tend to have lower expectations of earning an entrepreneurial income than men, although they do not seem to differ on levels of self-efficacy, risk tolerance and openness to experience. Dutch students appear less risk tolerant, have lower expectations of earning an entrepreneurial income and aspire less often to entrepreneurial careers than students from other countries. This is not very surprising since by choosing to study in The Netherlands, the Dutch students have made a study-choice that is relatively low in risk as compared to the choice of the students coming from other countries.

I4 This may reflect selection because the survey topic is more interesting for students closer to the completion of their studies. However, it may also simply reflect that many students take longer than two years to finish their studies, implying that there are more 2nd year than ist year MSc students in the population. 
Table 2.3 - Descriptive Statistics by worker type

\begin{tabular}{|c|c|c|c|c|c|}
\hline & Intrapreneur & Entrepreneur & Employee & Incongruents & Total \\
\hline \multicolumn{6}{|l|}{ Personality } \\
\hline Self-Efficacy & $\begin{array}{l}4.28 \\
(0.40)\end{array}$ & $\begin{array}{l}4.31 \\
(0.44)\end{array}$ & $\begin{array}{l}3.62^{* * *} \\
(0.54)\end{array}$ & $\begin{array}{l}3.65^{* * *} \\
(0.45)\end{array}$ & $\begin{array}{l}3.96 \\
(0.58)\end{array}$ \\
\hline Risk tolerance & $\begin{array}{l}7.52 \\
(1.21)\end{array}$ & $\begin{array}{l}7.78^{*} \\
(1.31)\end{array}$ & $\begin{array}{l}4.77^{* * *} \\
(1.86)\end{array}$ & $\begin{array}{l}5.44^{* * *} \\
(1.75)\end{array}$ & $\begin{array}{l}6.29 \\
(2.08)\end{array}$ \\
\hline Openness & $\begin{array}{l}3.67 \\
(0.74)\end{array}$ & $\begin{array}{l}3.69 \\
(0.70)\end{array}$ & $\begin{array}{l}3.24^{* * *} \\
(0.81)\end{array}$ & $\begin{array}{l}3.49 * * \\
(0.68)\end{array}$ & $\begin{array}{l}3.49 \\
(0.78)\end{array}$ \\
\hline Person-entrepreneurship fit & $\begin{array}{l}0.84 \\
(0.58)\end{array}$ & $\begin{array}{l}0.97^{*} \\
(0.60)\end{array}$ & $\begin{array}{l}-0.99^{* * *} \\
(0.81)\end{array}$ & $\begin{array}{l}-0.64^{* * *} \\
(0.61)\end{array}$ & $\begin{array}{l}0.00 \\
(1.14)\end{array}$ \\
\hline Entrepreneurial intentions & & & & & \\
\hline Income expectations & $\begin{array}{l}2.12 \\
(1.25)\end{array}$ & $\begin{array}{l}6.57^{* * * *} \\
(1.41)\end{array}$ & $\begin{array}{l}1.73^{* * *} \\
(1.25)\end{array}$ & $\begin{array}{l}6.31^{* * *} \\
(1.30)\end{array}$ & $\begin{array}{l}3.36 \\
(2.50)\end{array}$ \\
\hline Academic performance & & & & & \\
\hline Grade (1-10) & $\begin{array}{l}7.66 \\
(0.68)\end{array}$ & $\begin{array}{l}7.66 \\
(0.54)\end{array}$ & $\begin{array}{l}7.50^{* * *} \\
(0.67)\end{array}$ & $\begin{array}{l}7.43^{* * *} \\
(0.88)\end{array}$ & $\begin{array}{l}7.57 \\
(0.68)\end{array}$ \\
\hline Demographics & & & & & \\
\hline Age & $\begin{array}{l}24.87 \\
(2.21)\end{array}$ & $\begin{array}{l}25.70^{* * * *} \\
(2.47)\end{array}$ & $\begin{array}{l}24.64 \\
(2.01)\end{array}$ & $\begin{array}{l}25.26 \\
(2.16)\end{array}$ & $\begin{array}{l}24.99 \\
(2.22)\end{array}$ \\
\hline Gender (\% woman) & $40 \%$ & $26 \% * * *$ & $35 \%$ & $36 \%$ & $35 \%$ \\
\hline Nationality: Dutch (\%) & $63 \%$ & $49 \% * * *$ & $71 \%^{* *}$ & $44 \% * * *$ & $61 \%$ \\
\hline Second-year MSc (\%) & $72 \%$ & $75 \%$ & $70 \%$ & & $71 \%$ \\
\hline $\mathrm{N}$ & 253 & 178 & 330 & 94 & 855 \\
\hline
\end{tabular}

Note: Standard deviations between brackets. Person-entrepreneurship fit is the first principal component of self-efficacy, risk tolerance and openness. Comparisons performed by regression analysis with reference category intrapreneur for all comparisons. Stars indicate significance: ${ }^{*} p<0.10,{ }^{* *} p<0.05,{ }^{* * *} p<0.01$

Table 2.4 - Correlations between individual characteristics

\begin{tabular}{ll|l|l|l|l|l|l|l|l|l|l|l}
\hline 1. & Self- efficacy & 1 & 1.000 & & 3 & 4 & 6 & 7 & 8 & 9 & 10 & 11 \\
2. & Risk tolerance & $0.271^{* * *}$ & 1.000 & & & & & & & & \\
3. & Openness & 0.026 & $0.103^{* * *}$ & 1.000 & & & & & & & \\
4. & P-E fit & $0.748^{* * *}$ & $0.792^{* * *}$ & $0.335^{* * *}$ & 1.000 & & & & & & \\
5. & Income exp. & $0.170^{* * *}$ & $0.276^{* * * *}$ & $0.112^{* *}$ & $0.295^{* * *}$ & 1.000 & & & & & \\
6. & Grade & $0.207^{* * *}$ & 0.060 & 0.008 & $0.157^{* * *}$ & 0.006 & 1.000 & & & & \\
7. & Age & 0.034 & $0.099^{* * *}$ & $0.104^{* *}$ & $0.107^{* *}$ & $0.156^{* * *}$ & $-0.101^{* *}$ & 1.000 & & & \\
8. & Female & -0.020 & 0.019 & 0.045 & 0.012 & $-0.097^{* * *}$ & 0.006 & -0.064 & 1.000 & & \\
9. & Dutch & -0.025 & $-0.157^{* * *}$ & 0.013 & $-0.107^{* *}$ & $-0.205^{* * *}$ & -0.050 & $-0.172^{* * * *}$ & 0.014 & 1.000 & \\
10. Study year & $0.080^{*}$ & -0.030 & 0.041 & 0.038 & -0.034 & $0.072^{*}$ & $0.191^{* * *}$ & -0.001 & $0.111^{* *}$ & 1.000 \\
\hline
\end{tabular}

Note: $P$-E fit $=$ person-entrepreneurship fit; represents the first principal component of self-efficacy, risk tolerance and openness. ${ }^{*} p<0.05,{ }^{* *} p<0.01,{ }^{* * *} p<0.001$ 


\subsection{Econometric framework}

We estimate mixed rank-ordered logit models to assess the value of job attributes. ${ }^{15}$ The point of departure is that individuals choose the alternative that maximizes their utility. The utility function consists of a systematic and stochastic part. Specifically, utility of alternative $\mathrm{j}$ in choice situation $\mathrm{t}$ for individual $\mathrm{n}$ is described by:

$$
\mathrm{U}_{\mathrm{njt}}=\beta^{\prime}{ }_{\mathrm{n}} \mathrm{X}_{\mathrm{j}}+\gamma^{\prime} \mathrm{Xj \textrm {j }}_{\mathrm{t}} * \mathrm{Z}_{\mathrm{n}}+\varepsilon_{\mathrm{njt}},
$$

where $\beta_{\mathrm{n}}$ and $\gamma$ are coefficient vectors, $\mathrm{x}_{\mathrm{jt}}$ is a vector that describes the job attributes, $\mathrm{z}_{\mathrm{n}}$ is a vector that describes individual characteristics, and $\varepsilon_{\mathrm{njt}}$ is an error term. The error term $\varepsilon_{\mathrm{njt}}$ is independent and identically (iid) extreme-value distributed. The coefficient of interest is the interaction between job characteristics and individual characteristics $(\gamma)$, in particular the classification of individuals as intrapreneurs, entrepreneurs, or non-entrepreneurs. This interaction shows how the valuation of job characteristics differs between these groups. The mixed rank-ordered logit model allows the valuation of job attributes, captured by $\beta_{\mathrm{n}}$, to differ over individuals. The coefficients vary over individuals with density $\mathrm{f}\left(\beta_{\mathrm{n}} \mid \theta\right)$, which is assumed to be a normal distribution with parameters of the distribution (mean and variance) described by $\theta$. This is the main difference with the standard rank-ordered logit model, which assumes that $\beta_{n}$ is the same for all individuals, i.e. $\beta_{n}=\beta$. The aim is to estimate the model parameters $\gamma$ and $\theta$, where $\theta$ represents the mean and standard deviation of the preferences.

By assuming that preferences for job attributes vary over individuals we take into account that individuals' choices are correlated across different choice situations. When an individual has a very strong preference for one attribute, this preference could influence his or her choices in all choice situations. Since individuals' preferences for job attributes are also likely to be correlated, we allow the individual-specific parameters to be correlated. ${ }^{16}$ Failure to take this correlation into account could lead to over- or underestimation of the marginal rates of substitution. Compared to standard logit models, mixed logit models allow for more efficient estimation when individuals make repeated choices and relax the independence of irrelevant alternatives (IIA) assumption (see Revelt \& Train, 1998). Moreover, the estimated variance gives an estimate of preference heterogeneity in the sample.

I5 Useful introductions to mixed logit models are Revelt and Train (1998), Hensher and Greene (2003), Layton (2000) and Lancsar et al. (2017).

I6 For instance, consider an individual who greatly cares about making a difference in the life of others (job meaning). It is likely that this individual cares more than average about both focus of the company and job autonomy. See Hess and Train (2017) for further examples. 
Individuals choose alternative $\mathrm{j}$ from choice set $\mathrm{t}$ when alternative $\mathrm{j}$ gives the highest utility relative to other alternatives in the choice set. The probability that individual $\mathrm{n}$ prefers alternative $j$ over all alternatives $i$ in the choice set $t$ conditional on preferences $\beta_{\mathrm{n}}$, denoted $\mathrm{P}_{\mathrm{nit}}\left(\beta_{\mathrm{n}}\right)$, is therefore described by:

$$
P_{\text {nit }}=\operatorname{Pr}\left(U_{n j t}-U_{n i t}>0\right), \quad \forall i \neq j
$$

As utility depends on the iid extreme-value distributed error term $\varepsilon_{\mathrm{njt}}$, the probability that individual $n$ chooses alternative $\mathrm{j}$ takes the familiar logit form:

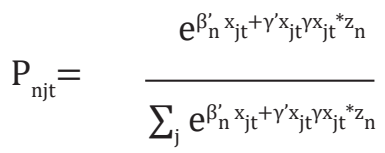

The sequence of choices made by individual $\mathrm{n}$ occurs with probability

$$
S_{n}=\prod_{t=1}^{T} \frac{e^{\beta_{n}^{\prime} x_{j t}+\gamma^{\prime} x_{j t} y^{1} x_{j t}{ }^{*} z_{n}}}{\sum_{j} e^{\beta_{n}^{\prime} x_{j t}+\gamma^{\prime} x_{j t} x_{j t}{ }^{*} z_{n}}}
$$

which is the product of the probabilities of choices. As $\beta_{\mathrm{n}}$ is unobserved and we aim to estimate the parameters $\theta$ of the preference distribution, we average over $\beta_{n}$ to obtain the unconditional probability for the sequence of choices:

$$
S_{n}(\theta)=\int S_{n}\left(\beta_{n}\right) f\left(\beta_{n} \mid \theta\right) d \beta_{n}
$$

We estimate the parameters $\theta$ that best describe the observed choices. Specifically, summing over individuals, we estimate $\theta$ to maximize the likelihood function $\operatorname{LL}(\hat{\theta})=\sum_{n} S_{n}(\hat{\theta})$, where $\hat{\theta}$ is the estimated $\theta$. Since this expression has no closedform solution, we approximate this probability using simulated maximum likelihood (Revelt \& Train, 1998). In particular, we approximate $S_{n}(\hat{\theta})$ by summation of $S_{n}\left(\beta_{n}\right)$ over randomly drawn values of $\beta_{n}$. Each value of $\beta_{n}$ is drawn from the distribution $\mathrm{f}\left(\beta_{\mathrm{n}} \mid \hat{\theta}\right)$ and the corresponding probability $\mathrm{S}_{\mathrm{n}}\left(\beta_{\mathrm{n}}\right)$ is calculated. This process is repeated for many draws, so that the average of the resulting $S_{n}\left(\beta_{n}\right)$ 's approximates:

$$
S_{n}^{\operatorname{sim}}(\theta)=\frac{1}{R} \sum_{r=1}^{R} S_{n}\left(\beta_{n}^{r \mid \hat{\theta}}\right)
$$

where $\mathrm{R}$ is the number of draws, and $\beta_{\mathrm{n}}^{\mathrm{r}} \mathrm{e}^{\hat{\theta}}$ is the $\mathrm{r}$-th draw from $\mathrm{f}\left(\beta_{\mathrm{n}} \mid \hat{\theta}\right)$. Summing over individuals gives the simulated likelihood function. In all our reported estimations 
we use 500 draws generated by a Halton sequence, see Lancsar et al. (2017) for a discussion of the trade-offs involved in choosing the number of draws.

We do not allow all coefficients to differ between individuals for two reasons. First, models with all parameters varying can be unstable (Revelt \& Train, 1998). Second, it is convenient to keep wage coefficients fixed, because we use the wage as a common metric to compute the implied monetary value of job attributes. Also, we control for order effects to obtain more precise estimates: we include dummy variables that indicate whether a job is presented on the left of the screen, in the centre, or on the right. ${ }^{17}$ Finally, identification requires that the interaction between job attributes and individual characteristics is the same for all individuals.

The rank-ordered logit is also referred to as exploded logit, because the ranking process is assumed to be sequential. Respondents are assumed to first choose the most attractive job out of the three alternatives, and then choose the most attractive option out of the remaining alternatives. The data is 'exploded' to represent this choice process, meaning that the dataset is transformed to record the preferred option among the three alternatives as well as among the two remaining alternatives. In our case, this implies that we have 5 observations per choice set. As each individual is confronted with five choice sets, the total number of observations in the estimations is equal to 25 times the number of respondents. The mixed rank-ordered logit model is estimated as mixed logit on the 'exploded' data, while the rank-ordered logit can be estimated as conditional logit on 'exploded' data, see Lancsar et al. (20I7) for a clear description.

\subsection{Results}

Table 2.5 presents our estimation results of the mixed rank-ordered logit model. We firstly estimate a model without worker-type comparisons. The results of this estimation are presented in columns Ia and $\mathrm{Ib}$, where column Ia shows the estimated average coefficients of the job attributes and column ib the standard deviations of the individual coefficients. We then estimate a model in that includes interactions between job attributes and the control variables gender, grade, and nationality. By doing so we allow for systematic differences in the valuation of job attributes by gender, grade, and nationality. The results of this estimation are presented in columns $2 \mathrm{a}$ and $2 \mathrm{~b}$, where column $2 \mathrm{a}$ reports the estimated average coefficient for a Dutch male with average grades. Next, in addition to the control variables we include interactions between the various job attributes and the worker types. The estimation results

I7 In other words, dummies indicate whether a job was presented as job A, B, or C (see Figure 2.I). We do not allow these order effects to differ over individuals, and find that order effects are small in magnitude and not statistically significant. 
of this model are presented in columns $3 \mathrm{a}-3 \mathrm{e}$. Columns $3 \mathrm{a}$ and $3 \mathrm{~b}$ show the main effects of the job attributes and the standard deviations of the individual coefficients, respectively. Columns 3c, 3d and 3e show the interaction effects between the job attributes and worker types, comparing the preferences of intrapreneurs (column $3 \mathrm{c}$ ), entrepreneurs (column 3d) and incongruent individuals (column 3e) with those of non-entrepreneurial employees.

\subsubsection{STEM students' preferences for job attributes}

Column ra shows the estimated main effects, indicating the average contribution of each job attribute to job attractiveness. Column $\mathrm{ib}$ reports the variation in preferences between individuals, i.e. the standard deviation of the individual coefficients. The sizeable and statistically significant standard deviations of the individual coefficients in column $\mathrm{Ib}$ indicate that there is substantial variation of preferences between individuals. In several cases, the estimated standard deviation is much larger than the average coefficient.

With respect to the mission of the company we find that, on average, STEM students prefer working in companies that focus on innovation or CSR and sustainability, as well as prefer to work in non-profit organizations over working in firms with a strict focus on profit.

Next, with regard to the job design category, we find that STEM students positively value job autonomy, work in multidisciplinary teams, R\&D occupations, and a healthy work-life balance. Specifically, we find that STEM students generally prefer higher levels of autonomy than no autonomy in their jobs. In addition, working in teams, and especially multidisciplinary teams, is preferred over working alone. As can be expected, students also prefer working in R\&D jobs and, to a lesser extent, management jobs as compared to sales jobs. Furthermore, on average students prefer to work in jobs that include workloads that can be accomplished in regular working time over high workloads that require frequent unpaid overtime. 


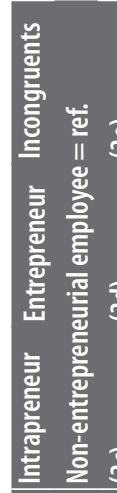

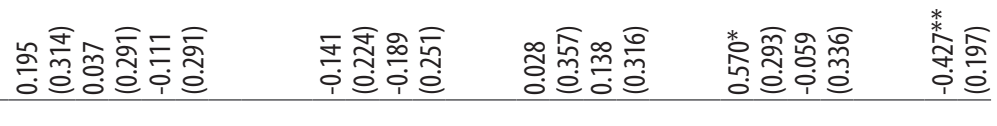

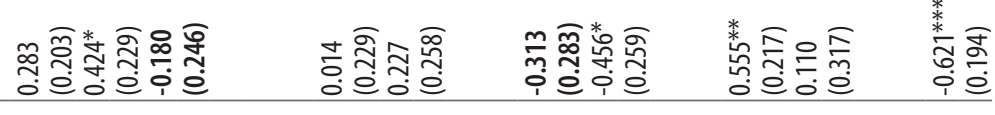

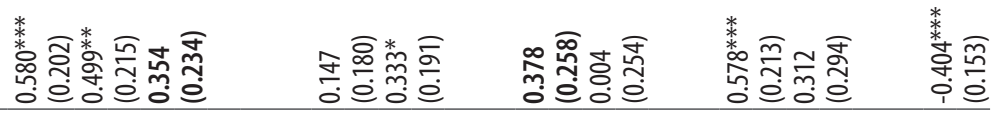

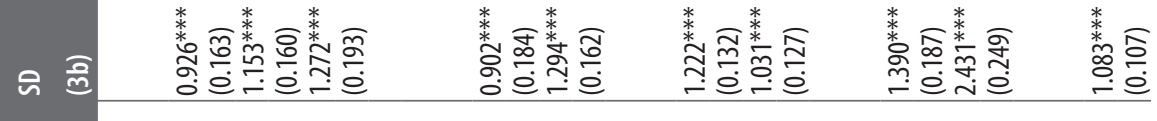

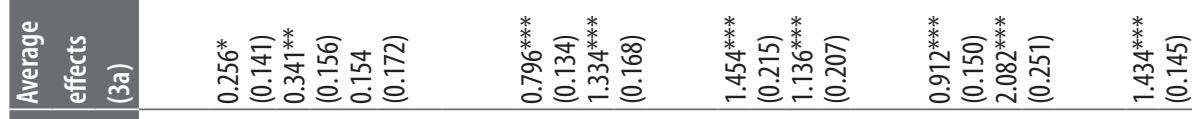

ทิ ลิ

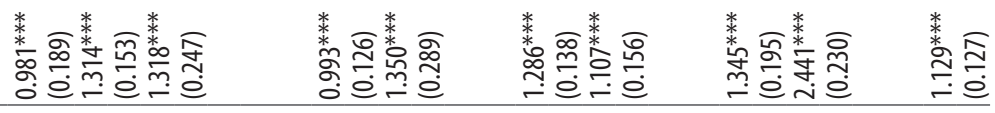

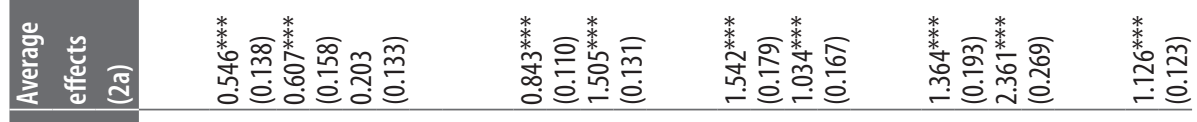

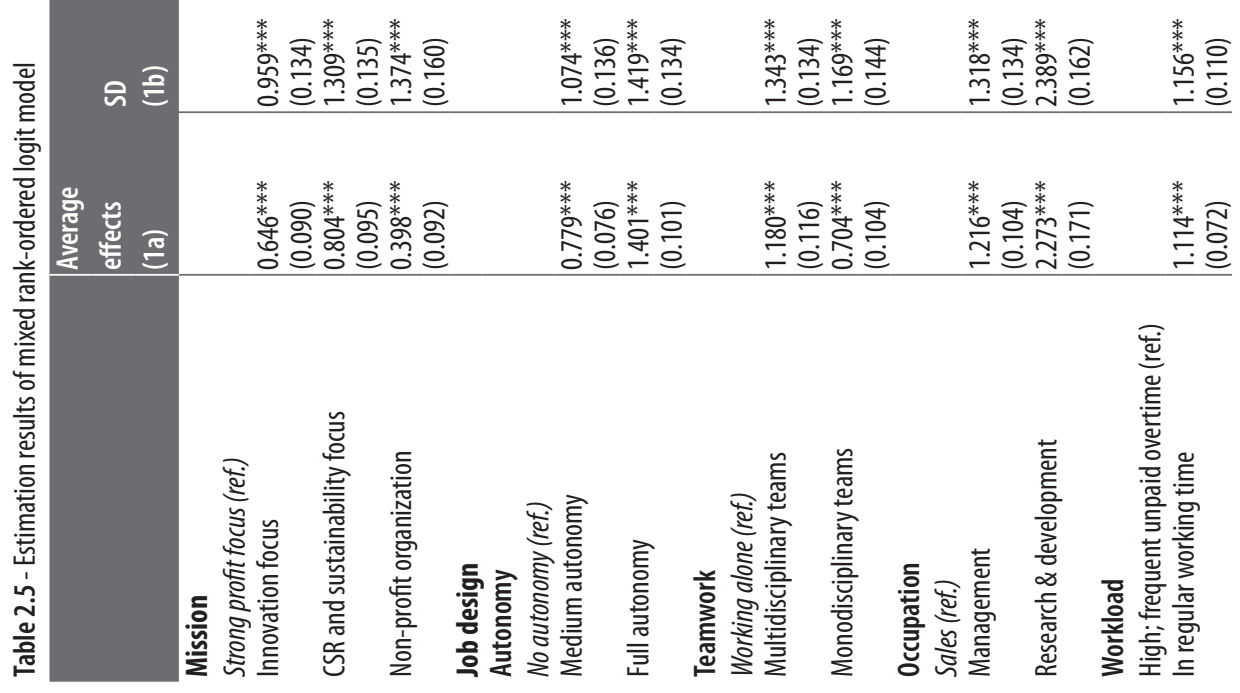




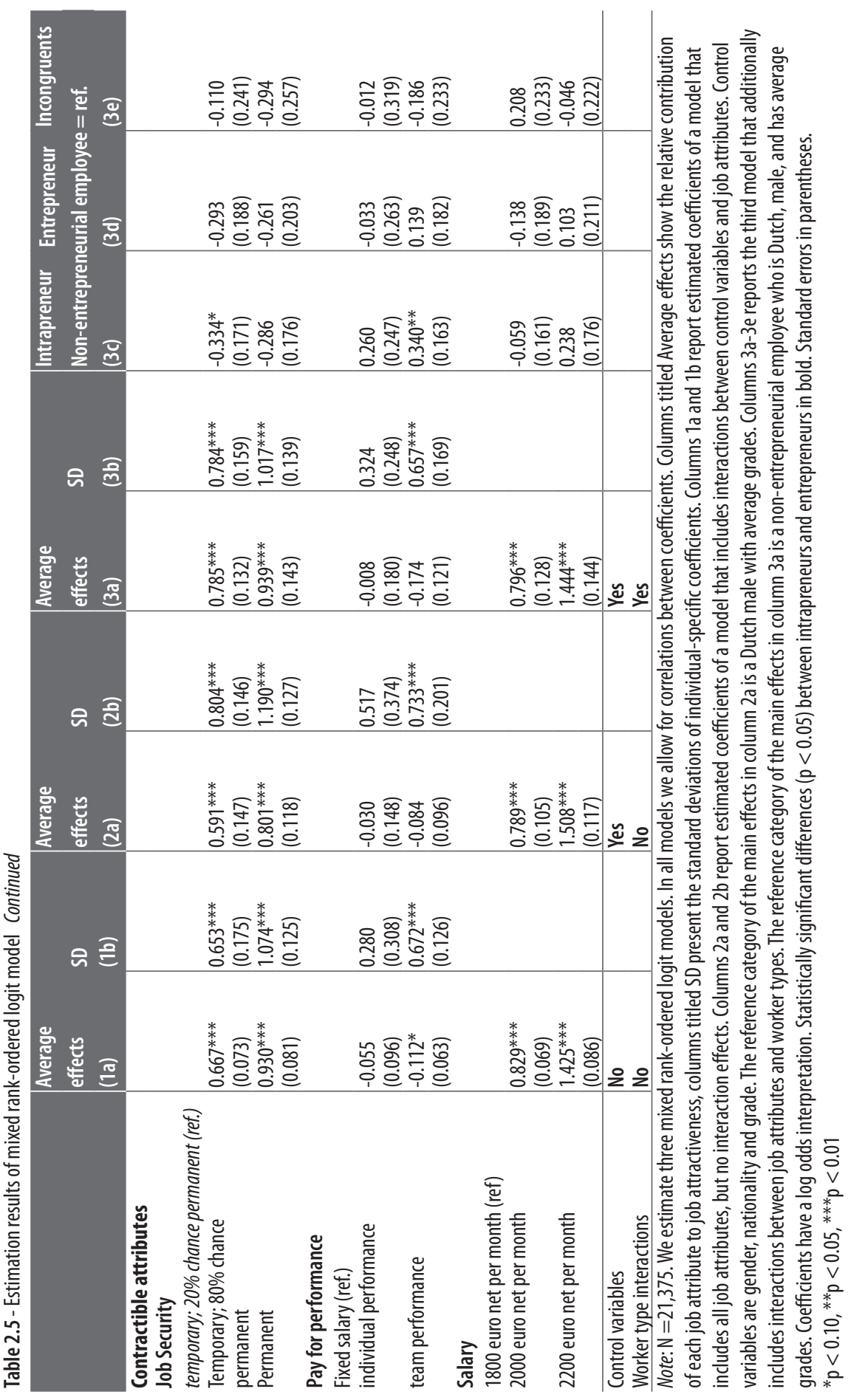


Concerning contractible attributes, the results suggest that, as expected, STEM students prefer high job security and high salaries. Specifically, jobs that offer a permanent contract, or a temporary contract with high chances of obtaining a permanent contract, are preferred over jobs that offer temporary contracts with low chances of a permanent contract. In addition, students do not express a statistically significant preference for pay for performance over a fixed salary, regardless whether the performance pay is based on team or individual performance.

Columns $2 \mathrm{a}$ and $2 \mathrm{~b}$ show the estimated main effects and variation in preferences between individuals when we interact job characteristics with the control variables gender, nationality, and grade. By doing so we change the reference category to a male Dutch student with average grades. The coefficients in column $2 \mathrm{a}$ are comparable to those in column ra. The estimation results are similar to those of Non et al. (2019) who study the impact of mission of the company on job attractiveness on the same sample, plus additional data from a different Dutch technical university.

\subsubsection{Comparing job attribute preferences of prospective worker types}

Columns 3a-3e in Table 2.5 present the estimation results for the model including control variables and worker type comparisons. Columns $2 \mathrm{a}$ and $2 \mathrm{~b}$ present the main effects of the job attributes and the standard deviations of the individual coefficients, respectively. Note that these coefficients represent the average individual of our sample: a student who is male, of average ability, Dutch and a non-entrepreneurial worker type. Comparing the coefficients in column 3 a with those in columns ia and 2a makes clear that the outcomes of all three estimations are comparable.

In column 3c, we compare prospective intrapreneurs with non-entrepreneurial employees. Our results show that prospective intrapreneurs have a stronger preference for companies with a focus on innovation, and a focus on CSR and sustainability compared to companies with merely a profit focus than non-entrepreneurial employees. In addition, prospective intrapreneurs have a stronger preference for management positions than prospective non-entrepreneurial employees. Moreover, intrapreneurs are less averse to working unpaid overtime than non-entrepreneurial employees. Furthermore, intrapreneurs are more attracted to jobs that include performance pay based on team performance. There are however no significant differences between intrapreneurs and non-entrepreneurial employees in preferences for teamwork and salary.

In column $3 \mathrm{~d}$, we compare prospective entrepreneurs with prospective non-entrepreneurial employees. Like intrapreneurs, entrepreneurs have a stronger preference for firms that focus on CSR and sustainability as well for a management job. Moreover, they are also more willing to work overtime as compared to non-entrepreneurial employees. However, different than intrapreneurs, entrepreneurs do not have a significantly stronger preference for companies with a focus on innovation than non-entrepreneurial employees. 
In column 3 e, we compare non-entrepreneurial employees with the incongruent group. By and large, incongruent employees have similar preferences as non-entrepreneurial employees, with preferences for workload as a noteworthy exception. Like prospective intrapreneurs and entrepreneurs, incongruent workers are more willing than non-entrepreneurial employees to frequently work unpaid overtime.

In addition, we test the differences between intrapreneurs and entrepreneurs by estimating a rank ordered mixed logit model with intrapreneur as reference category ${ }^{18}$. In Table 2.5, the coefficients that significantly $(\mathrm{p}<0.05)$ differ between the entrepreneurs and intrapreneurs are indicated in bold in column $3 \mathrm{c}$ and $3 \mathrm{~d}$. As compared to entrepreneurs, intrapreneurs have a stronger preference for working in non-profit organizations over strongly profit-oriented companies, and to work in multidisciplinary teams over working alone ${ }^{19}$.

\subsubsection{Master students' willingness to pay}

To provide more insight into the relative value of the various attributes, we calculate the monetary value, i.e. the 'willingness to pay' (WTP; Revelt \& Train, 1998), of all job attributes for intrapreneurs, entrepreneurs and employees. The assumption is that workers can be compensated with a higher salary for accepting a job with less attractive attribute levels, or conversely, are willing to accept a lower salary in exchange for attractive attribute levels. ${ }^{20}$

Figures $2.2 \mathrm{a}$ to $2.2 \mathrm{~g}$ depict the monetary value of different levels of job design, company mission and contractible attributes for intrapreneurs, entrepreneurs and employees, respectively. Note that the monetary value of each attribute level indicates the value relative to the reference category of that attribute. For instance, Figure 2.2a makes clear that intrapreneurs are willing to pay 239 euro's for medium levels of job autonomy as compared to no autonomy, and 423 euro's for a job that gives them full autonomy rather than no autonomy.

I8 Estimation results can be obtained from the author.

I9 We also checked sensitivity of our results to a change in the cut-off to categorize worker types. We categorized students as prospective intrapreneurs (entrepreneurs) when their level of P-E fit was I standard deviation above the mean and when their income expectations was below (above) the scale mean. Results are similar for entrepreneurs, but not for intrapreneurs. Specifically, we find that only the difference between employees and intrapreneurs in preference for workload is robust to a change in cut-off level.

20 We calculate average WTP for a given level of a job attribute relative to the reference category per worker type as follows: WTP $=(200 / \text { average coefficient of a } 200 \text { euro salary increase })^{*}$ (average attribute coefficient + type-specific attribute coefficient). For each of the worker types we calculate the average coefficient of a 200- euro increase in salary as follows: $0.5^{*}$ (coefficient of 2000 euro salary $+0.5^{*}$ coefficient of 2200 euro salary). 
Figure 2.2 - Willingness to pay
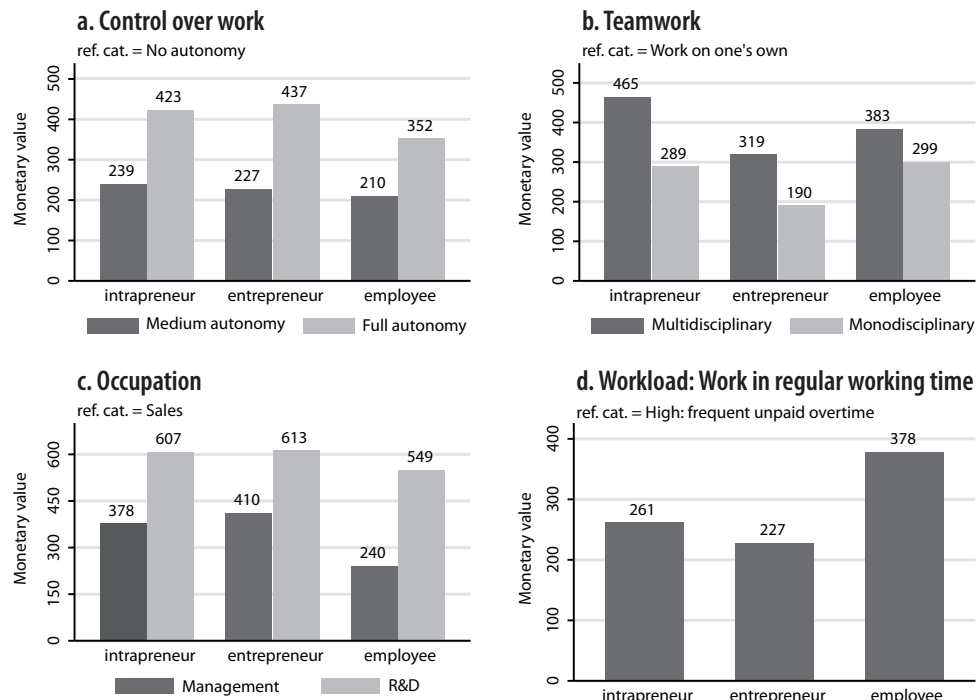

d. Workload: Work in regular working time
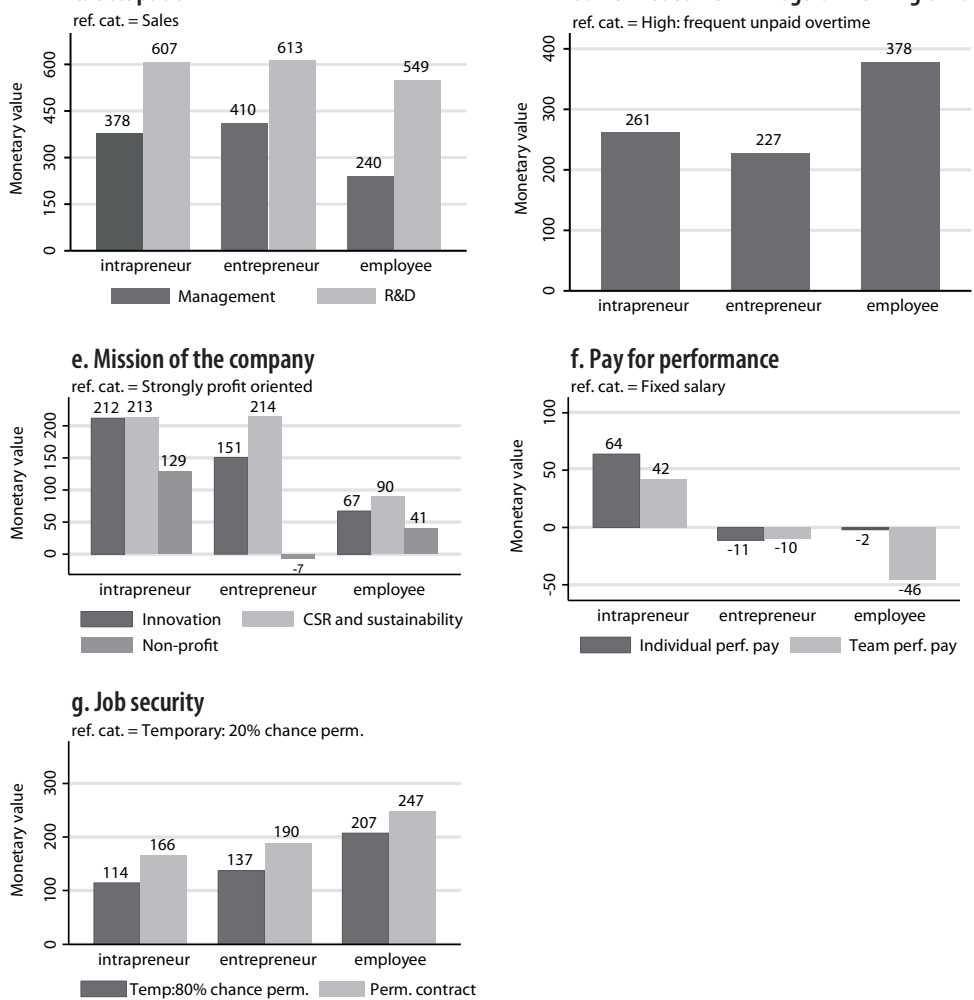

Note: Rounded monetary values (in Euros) displayed above each bar

Figure 2.2 illustrates that all prospective worker types attach the highest monetary value to working in an R\&D job. Workers are willing to give up 600 euro of their monthly salary to work in R\&D instead of sales. An interesting observation in Figure $2.2 \mathrm{e}$ is also that prospective non-entrepreneurial employees attach relatively low monetary value to attributes relating to the mission of the company as compared to prospective entrepreneurs and intrapreneurs. 


\subsection{Discussion}

Using a discrete-choice experiment, we explored preference heterogeneity between prospective intrapreneurs, entrepreneurs and non-entrepreneurial employees for several job and organizational characteristics in a sample of STEM MSc students. Our results indicate differences in preference for several job attributes between prospective intrapreneurs and non-entrepreneurial employees, and non-entrepreneurial employees and entrepreneurs. More specifically, we find that intrapreneurs differ from non-entrepreneurial employees with regard to preferences for company mission, type of occupation, workload and performance pay.

As intrapreneurship includes innovation and renewal, not surprisingly prospective intrapreneurs prefer jobs in firms that share their focus on innovation. Our findings are therefore in line with Moser et al. (20I7), who find that job seekers with higher levels of entrepreneurial behaviour relating to innovativeness are more attracted to start-ups that have a clear innovation aim. In addition, they find that specifically job seekers with low work experience but high levels of entrepreneurial behaviours relating to risk and proactiveness are more attracted to start-ups that have a clear innovation aim and a culture that supports creativity. In addition, several studies point towards the middle manager as a key employee in the intrapreneurial process. Middle managers have a position in organizations that allows them to collect new ideas from lower level employees and develop these ideas through their connections with higher level managers (Burgelman, 1983; de Jong et al., 2015; Hornsby et al., 2002; Kanter, 1982, 1985; Kuratko et al., 2002). Our results show that prospective intrapreneurs are indeed more attracted to management occupations as compared to other employees. As such, our results are in line with person-organization fit theory (Kristof-Brown, 2005). Furthermore, in line with Hamermesh (1990) and Kolvereid (1996) we find that prospective intrapreneurs and entrepreneurs differ from non-entrepreneurial employees with respect to their preferences for workload: they are more willing to work overtime.

This chapter makes contributions to the literature in various fields. Firstly, we are the first to define the prospective intrapreneur based on person-entrepreneurship fit theory and entrepreneurial intention models. Specifically, we use individual differences in entrepreneurial personality traits and attitudes towards entrepreneurship to $a$ priori identify prospective intrapreneurs, and to differentiate between (prospective) entrepreneurs, intrapreneurs and non-entrepreneurial employees. Although some studies propose that individual differences in personality and attitudes may be useful to identify intrapreneurs (e.g. Hayton \& Kelley, 2006), previous empirical studies on intrapreneurship at the individual level have mainly operationalised intrapreneurship by either work-related behaviours such as innovative work behaviour, proactive work behaviour and risk taking (e.g. de Jong et al., 20I5; Rigtering \& Weitzel, 20I3; Moser et al., 20I7), or by employees' involvement in innovation activities (e.g. Rigtering \& 
Weitzel, 20I3). The advantage of our approach to identify prospective intrapreneurs is that it is independent of the opportunities workers have for displaying intrapreneurial behaviours in their current job or had in previous positions.

Secondly, we contribute to a growing body of research on intrapreneurship at the individual level in two ways. There are few studies that compare intrapreneurs and entrepreneurs. Several studies investigate the antecedents or determinants for entrepreneurship and intrapreneurship in terms of skills, personality, attitudes and motivations (Douglas \& Fitzsimmons, 20I3; Martiarena; 20I3; Matthews et al. (2009); Monsen, Patzelt \& Saxton, 20I0), demographics (Adachi \& Hisada, 20I7) or characteristics of the business opportunity (Parker, 20II). However, to the best of our knowledge, there is no study that compares the organizational and job preferences of entrepreneurs, intrapreneurs and non-entrepreneurial employees. By comparing their preferences for several organizational and job characteristics, our research contributes to understanding the sorting along entrepreneurial personality traits and attitudes into different types of firms and jobs. Specifically, our results suggest that those with intrapreneurial talent more often than prospective non-entrepreneurial employees may choose employment in firms that focus on innovation, CSR and sustainability, management occupations as well as in jobs that include higher workloads and teambased performance pay.

In addition, we contribute to the recruitment literature, by investigating differences in job and firm preferences between prospective entrepreneurs, intrapreneurs and non-entrepreneurial employees. Few previous studies have investigated how specific types of workers can be attracted to organizations (Breaugh, 20I3), and to our knowledge only one previous study specifically investigates recruitment of entrepreneurial employees (Moser et al., 2017). We add to this literature by showing that STEMstudents' preferences for organizational and job characteristics differ depending on their entrepreneurial personality and attitudes towards entrepreneurship.

\subsubsection{Limitations and future research}

We recognise several limitations of our study. First, our methodology has a number of limitations. The first limitation is that although choices in vignette studies predict outcomes in real life (Hainmüller et al., 20I5), we do not observe actual behaviour of our participants. Second, the results may be sensitive to the design of the vignette. Despite the fact that our choice of job attributes and their levels are grounded in practice, other attributes might be important as well. Moreover, the attribute levels in our experiment do not represent the full array of possible variation. Future research could therefore investigate whether intrapreneurs differ in their preferences for other attributes than the attributes included in our experiment. Examples include geographical location, learning opportunities, and flexibility in both working time and location.

Second, although in reality applicants also face choices between jobs and organizations with many different characteristics, the inclusion of eight attributes in 
our experiment could cause a high cognitive load among survey respondents, resulting in measurement error. In addition, the order of the attributes was not randomized in our experiment, which may affect the results to the extent that survey participants are sensitive to several cognitive biases. However, it is reassuring that job choices are not sensitive to whether a job was presented on the left, middle, or right of the screen.

Third, in reality applicants do not always have information on all characteristics of jobs and organizations and may therefore use specific observable characteristics as a signal for unobserved characteristics. For instance, the coincidence of pay for performance with a high salary could signal a competitive work environment. This is particularly important to keep in mind when interpreting the WTP estimates of job attributes.

Fourth, we use broad personality factors and a coarse measure of entrepreneurial attitude to formally define and differentiate prospective intrapreneurs, entrepreneurs and employees. Different measures to distinguish between worker types (e.g. more specific personality traits, skill measures or experience) might produce different findings. Future research could therefore investigate the relationship between the measure used in this chapter for identifying different types of workers and other measures of intrapreneurship (behaviour, involvement in innovation), and how to best identify intrapreneurial types of students or workers and how to distinguish them from entrepreneurial and non-entrepreneurial types.

Finally, our sample only includes MSc students from the STEM fields in a Dutch university. Results may therefore not be generalized to prospective workers with other educational backgrounds or other national contexts. In addition, our student sample had no or only limited work experience they can relate to, and may develop other preferences once employed. Perceptions of company and job attractiveness can change over time (Evertz \& Süß, 2017). By construction of the worker type categories, the differences between intrapreneurs and employees are likely mostly driven by entrepreneurial personality characteristics, whereas differences between intrapreneurs and entrepreneurs are most likely driven by attitudes or expectations. As personality is relatively stable across the life span the differences in job preferences between intrapreneurs and employees are probably also mostly stable. By contrast, entrepreneurial attitudes are highly malleable and can be affected by many factors, including for instance training, experience and availability of financial and social capital (Blumberg \& Pfann, 20I6). Future research could therefore repeat our experiment with a sample that has work experience. Ideally, we would repeat the experiment in a couple of years with the same sample as is used in the present study. Such a longitudinal design would yield information on the stability of STEM students' preferences for job and company characteristics during their working careers. In addition, collecting field data on their current jobs would provide more information on the self-selection mechanisms and outcomes for intrapreneurs. 


\subsubsection{Implications for practitioners}

Firms can use our results to target entrepreneurial talent by highlighting their mission and employer brand in the recruitment process. As compared to other employees, prospective intrapreneurs have a particularly strong preference for working in companies that focus on innovation, CSR and sustainability. The same holds for highlighting the career opportunities into management positions. Moreover, intrapreneurs are more attracted to jobs that include team-based performance pay than non-entrepreneurial employees. This suggests that firms that offer teambased performance pay are more likely to attract intrapreneurial talent. However, intrapreneurs do regard this job attribute as very important.

\subsection{Conclusion}

We investigate how preferences for job and company characteristics drive the job choice for intrapreneurial, entrepreneurial and non-entrepreneurial MSc STEM students. As such, the study presented in this chapter is a first study that investigates specifically how entrepreneurial talent can be attracted to established organizations. Using a discrete-choice experiment, we find several differences in job preferences between intrapreneurs and non-entrepreneurial employees. As compared to prospective non-entrepreneurial employees, intrapreneurs are more attracted to jobs in firms that focus on innovation, CSR and sustainability, management positions, and team-based performance pay. In addition, prospective intrapreneurs mind less to work overtime. As compared to prospective non-entrepreneurial employees, prospective entrepreneurs are more attracted to management positions and mind less to work overtime. We contribute to research on intrapreneurship, applicant attraction and targeted recruitment, and we provide more insight into the role of entrepreneurial personality and attitudes in sorting along job and company preferences. We suggest further research to explore alternatives using longitudinal designs, more diverse samples and more specific firm and job characteristics.

Attracting entrepreneurial talent to organizations represents an important way for organizations to create a competitive advantage. However, as much research on organizational behaviour suggests, it is pivotal to facilitate workers to display desired behaviour. For instance, human resource practices (Hayton, 2005), leadership (Moriano et al., 20I4), management support (Dovey \& McCabe, 20I4), formal structures (Globocnik \& Salomo, 20I5) and job design (de Jong et al. 20I5; Globocnik \& Salomo, 20I5; Rigtering \& Weitzel, 2013) have all been shown to be important factors in facilitating or hindering employees intrapreneurial behaviour. In addition, apart from attracting entrepreneurial talent in the first place, retaining this valuable human capital is the next challenge organizations face. 


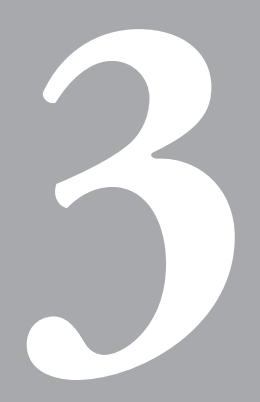

\section{Are graduates' intrapreneurial skills optimally used for innovation?}

This chapter is joint work with Rund Gerards and Andries de Grip, and is currently resubmitted at Technovation. We thank Kim van Broekhoven, Martin Carree, Maria Ferreira Sequeda, Julia Kensbock, Ken Mayhew, Christoph Meng, Raymond Montizaan, Arjan Non, Coen Rigtering, and the participants of the Maastricht University TIID seminar, the 2017 CGHRM conference in Gothenburg, and the 2017 EURAM conference in Glasgow for helpful comments and suggestions on earlier versions of this chapter. 


\subsection{Introduction}

Various studies show that human capital is a major enabler of innovation (Anderson et al., 20I4; Leiponen, 2005) and thus provides a basis for creating competitive advantage for firms (Lepak \& Snell, 1999; McGuirk et al., 20I5) and economic growth (Freeman, 1995). Although workers' human capital levels have increased over the past decades (OECD, 20I7), the question remains whether firms make optimal use of highly educated workers' skills for innovation. In addition, it is not clear whether skills that are relevant for innovation are equally important for highly educated workers across different occupational domains. Concomitantly, it is unclear whether policies and practices aimed at increasing innovation should accommodate differential skill demands for workers in different occupations. We address these issues by studying (I) how the level of intrapreneurial skills of recent higher education graduates who work in science, technology, engineering, and mathematics (STEM) or business occupations relates to their involvement in innovation and (2) to what extent the (mis)match of their skills with their job requirements is related to their involvement in innovation. Our focus on intrapreneurial skills is congruent with the trend to move beyond human capital measures focusing only on employees' level of education (McGuirk et al., 20I5).

Building on Hayton and Kelley (2006), who developed a skill profile for intrapreneurs, and Bjornali and Støren (20I2), we distinguish three intrapreneurial skills: creative skills, brokering skills, and championing skills. Creative skills refer to creativity and opportunity recognition, brokering skills refer to accessing and disseminating new knowledge, and championing skills refer to convincing people in the organisation of the potential impact of an innovation project and facilitating the project. Both creative and brokering skills thus pertain to the creative stage of innovation, whereas championing skills pertain to the implementation stage of innovation. Bjornali and Støren (20I2) show that young graduates with higher levels of skills related to creativity, brokering, and championing are more often involved in innovation.

Higher levels of intrapreneurial skills positively affect innovation (Bjornali \& Støren, 20I2) and firms can utilize their human capital pool strategically by allocating employees with higher levels of intrapreneurial skills to innovative tasks (Lepak \& Snell, 1999). However, the misallocation of intrapreneurial skills can occur when either firms do not allocate their employees to innovative tasks according to their intrapreneurial skill levels or employees sort themselves into tasks that are above or below their own skill levels (Weis, 1995). Then, employee skills do not match the job skill requirements, resulting in either skill deficits or underutilization. Studies suggest the consequences of skill mismatch (e.g. Hartog, 2000) can be detrimental to innovation; however, no previous study has investigated the consequences of intrapreneurial skill mismatches for innovation. Therefore, we consider whether the 
(mis)match between employees' intrapreneurial skills and their jobs' intrapreneurial skill requirements is related to their involvement in innovation. This chapter specifically focuses on the underutilization of intrapreneurial skills.

In addition, previous research suggests that the demand for intrapreneurial skills can differ across various occupational domains (Hunter et al., 20I2). Mumford et al. (20I0) show, for instance, that different levels of creative skills are needed in different occupational domains. However, what is unknown is whether the importance of intrapreneurial skills for workers' allocation to innovative tasks differs depending on their occupation.

In this chapter, we considers two types of occupations to be relevant to innovation. First, workers in science, technology, engineering and mathematics (STEM) occupations are seen as crucially important for innovation (Atkinson \& Mayo, 20IO; Langdon et al., 20II; Winters, 20I4). Winters (20I4) finds, for instance, that, contrary to other types of workers, workers in STEM occupations increase innovation intensity in metropolitan areas in the United States. Indeed, innovation studies often focus on research and development $(\mathrm{R} \& \mathrm{D})$ departments, where technical employees are most involved in the creation and development of innovations (Menzel et al., 2007), or use R\&D expenditures as an innovation indicator (e.g. Stam, 2013).

Second, other studies emphasise the role of business occupations in management and sales in innovation. De Jong et al. (2015) find, for instance, that managers and sales workers are more involved in intrapreneurship than other employees are. Managers are said to be particularly uniquely positioned to stimulate employee creativity and provide support for intrapreneurial initiatives through their connections with higher management and lateral units (Burgelman, 1983; de Jong et al., 2015; Hornsby et al., 2002; Kanter, 1982, 1985). In addition, sales workers have been found to engage more in risk-taking behaviours related to innovation than other types of workers (de Jong et al., 20I5).

We therefore distinguish between those employed in STEM occupations and those in business occupations in management and sales and we investigate the extent to which the relevance of intrapreneurial skills differs for innovation, between higher education graduates in STEM occupations, and business occupations in management and sales.

We use data from the REFLEX European higher education graduate survey (Allen \& van der Velden, 20II), which includes information on higher education graduates' intrapreneurial skills, their involvement in innovation, and their current job. Our results show differences in the importance of intrapreneurial skills for innovation between STEM and business occupations. Furthermore, we find that the underutilization of intrapreneurial skills is related to lower involvement in innovation, suggesting that the potential of graduates with higher levels of intrapreneurial skills is not fully utilized for innovation. We thus contribute to understanding the role of human capital and skill mismatch for innovation. 
The remainder of this chapter is structured as follows. In Section 3.2, we review the relevant literature from which we derive our hypotheses. Section 3.3 describes the data, our model, and the variables in more detail. We present our results in Section 3.4. Section 3.5 concludes the chapter and discusses the relevance and implications of our findings.

\subsection{Literature review and hypotheses}

\subsubsection{Intrapreneurial skills: their role in innovation in STEM and business occupations}

High levels of human capital are essential for innovation. ${ }^{21}$ For instance, Taggar (2002) finds that general cognitive ability is positively related to creative performance. Furthermore, using longitudinal data, Zwick et al. (20I7) find that individuals' educational level and skills acquired during their careers are related to their innovative performance. Although the innovation process requires both the generation and implementation of ideas, most studies on the relation between human capital and innovation focus on either the process of individual creative idea generation or the implementation of these ideas (Anderson et al., 20I4). This chapter, however, focuses on a set of skills that encompasses both these stages: the skills required to be an intrapreneur.

We highlight two definitions of intrapreneur(ship) before we discuss the skills required in STEM and business occupations. Pinchot (1985) offers an early definition, considering intrapreneurs as entrepreneurs within an existing company. Sharma and Chrisman (1999) define intrapreneurship as a process in which one or more employees create a new organization or initiate renewal or innovation in an existing organization. Intrapreneurs are pivotal to innovation and even more important than entrepreneurs for national innovation levels (Stam, 2013).

While the skills related to the success of new entrepreneurial ventures have received considerable attention (e.g. Baum et al., 200I; Mitchelmore \& Rowley, 20IO), far less research has been devoted to those needed for being an intrapreneur. A notable exception is the work of Hayton and Kelley (2006), who have developed a competency framework for intrapreneurship that includes relevant knowledge, skills, and personality factors. They describe four roles employees can take on as an intrapreneur, covering both the creative stage and the implementation stage of innovation, where each of these roles requires its own set of knowledge, skills, abilities, and personality. These roles are I) the innovator, referring to creativity and opportunity recognition; 2) the knowledge broker, accessing and disseminating

2I For a comprehensive review of the determinants of innovation at the individual level, see Anderson et al. (20I4). 
new knowledge; 3) the idea champion, convincing people in the organization about the benefits of the intrapreneurial project, and 4) the sponsor, providing resources and legitimacy for the project. We label the skills pertaining to these four roles as, respectively, creative skills, brokering skills, championing skills, and sponsoring skills. Since sponsoring can be seen as purely a top management task, we focus our analyses only on the creative, brokering, and championing skills.

First, the creative idea generation stage of innovation requires creative skills, such as the generation of effective and novel solutions to problems (Cropley, 2016) and the assessment of the value of ideas (Farr et al., 2003; Hunter et al., 20I2). Therefore, this first innovation stage requires opportunity recognition, that is, having creative insight about combinations of information and their potential value (Block \& MacMillan, I993; Hayton \& Kelley, 2006; Maidique, I980; Vila et al., 20I2).

Second, the creative idea generation stage of innovation requires the use of brokering skills, such as accessing new information and knowledge, crossing boundaries, disseminating knowledge, and combining different sources (Amabile, I988; Hargadon, 2002; Hayton \& Kelley, 2006; West et al., 20I4). Bjornali and Støren (20I2) find that employees with brokering skills related to the internal communication of knowledge and external networking relate especially positively to being involved in innovation.

Research on creative idea generation (what is often known as creativity) often focuses on samples of workers whose need for problem solving is apparent (Mumford \& McIntosh, 20I7), most frequently workers in STEM occupations (e.g. Cropley, 2016; Scott \& Bruce, 1994; Simonen \& McCann, 2008; Unsworth \& Clegg, 20IO). For instance, Cropley (2016) argues that creativity is essential for workers in engineering occupations, since they are specifically concerned with generating solutions to technical problems. Thus, coming up with new ideas and solutions and further developing them are often part of STEM workers' daily activities.

Generating effective and novel solutions is fostered by knowledge brokering activities such as accessing new information sources and combining them with existing knowledge (Amabile, 1988). Workers in highly skilled jobs characterized by fast technological changes face rapid depreciation of their knowledge (Murillo, 20II; Neuman \& Weiss, 1995). Therefore, they must continuously acquire new information to keep their technical knowledge up-to-date (van Loo et al., 200I). Knowledge brokering skills are therefore essential in STEM occupations.

In sum, the above-mentioned studies suggest that higher education graduates who are employed in STEM occupations need creativity and knowledge brokering to contribute successfully to innovation. However, unlike in STEM occupations, those employed in business occupations (management and sales) are arguably not concerned on such a daily basis with the generation of effective novel solutions to technical problems. Therefore, creative and brokering skills are expected to be less 
important for their involvement in innovation, compared to graduates employed in STEM occupations. We therefore formulate the following hypothesis.

HI: Creative and brokering skills are more important for involvement in innovation in STEM occupations than in business occupations.

Third, for an innovation to come to fruition, the creative idea must pass the implementation stage, which means that the intrapreneur must convince others in the organization of the value of the creative idea. Successful implementation of a creative idea depends on obtaining support throughout the organization (Mumford, 2000). This requires championing skills, such as creating a vision around an innovation and actively supporting the innovation to commercialization (Hayton \& Kelley, 2006; Hunter et al., 20I2; Maidique, I980; Schon, I963; Shane, 1994; Vila et al., 20I2). Howell and Shea (200I) show that championing skills, such as expressing confidence in a project, motivating others, and persistence, positively relate to the success of product innovation.

Research suggests that especially those employed in business occupations have an important role in the implementation phase of the innovation process (e.g. Damanpour \& Schneider, 2008). Santamaría et al. (2009) conclude that many activities that lead to the implementation of innovations go beyond activities such as $\mathrm{R} \& \mathrm{D}$, which are mostly the domain of STEM occupations. De Jong et al. (20I5) find that workers in management and sales jobs are more often involved in roles that foster innovation than other types of workers are.

For those in management occupations, the greater likelihood of being involved in innovation roles could be explained by their position in the organization, which makes it possible to easily spot new opportunities and connect with key stakeholders in the organization (Burgelman, 1983; de Jong et al., 2015; Hornsby et al., 2002; Kanter, 1982, 1985; Kuratko et al., 2005; Mom et al., (2007). Connecting with key stakeholders in the organization is important for managers to convince stakeholders in the organization of the value of a creative idea and to acquire the necessary resources for the development of this new idea. For instance, Kanter (1982, p. I54) states, 'When managers believe in something, they will eagerly leverage their own staff and budget and even bootleg resources from their subordinates' budgets. But innovations usually require a manager to search for additional supplies elsewhere in the organization'. In addition, Mumford (2000) proposes that, for managers, leadership skills - particularly the ability to communicate their vision - are important in the innovation process. Thus, we can conclude that championing skills are essential for managers' involvement in the innovation process.

In addition, the main activity of those employed in sales occupations is to sell products or services to either other businesses or consumers. Through these customer contacts, they learn about new or changing customer needs and are therefore 
particularly well positioned to signal particular needs for innovation (Stam et al., 20I2). Therefore, graduates in sales occupations have an important role in recognizing new opportunities and advocating the need for innovation within their organization. Important skills for performance in sales occupations naturally include sales skills, comprising interpersonal skills, product knowledge, and sales presentation abilities (Rentz et al., 2002; Wachner et al., 2009). Specifically sales presentation skills (Johlke, 2006), such as identifying customers and their needs, the ability to handle customer's objections, and negotiation on offered solutions, products, or transactions, are essential for successful championing efforts in the innovation process.

In sum, this suggests that in business occupations, graduates' contributions to innovation stem mainly from their championing skills, such as providing leadership, expressing confidence, and convincing others inside the organization of the new idea. Therefore, we formulate the following hypothesis.

H2: Championing skills are more important for involvement in innovation in business occupations than in STEM occupations.

\subsubsection{Skill mismatch and innovation}

Although higher levels of human capital are known to foster innovation (Anderson et al., 20I4), no research exists on the extent to which workers' skills are optimally utilized for innovation. For instance, workers could possess the skills necessary for innovation but not have tasks that enable them to use these skills. Research in labour economics concerned with the consequences of skill mismatch in the labour market shows complex relations between workers' skill levels and employee and firm outcomes, depending on the match between workers' skills and job requirements.

Generally, a distinction can be made between workers who are well matched, workers with skill deficits, and those whose skills are underutilized (e.g. Allen \& van der Velden, 200I). When workers possess higher skill levels than they use in the workplace, they are overskilled; their skills are underutilized. Conversely, when workers possess lower levels of skills than are required in their jobs, they are underskilled and have a skill deficit. Mismatches can be defined by either educational level or more specific skill levels. However, educational and skill mismatches are two distinct phenomena (e.g. Allen \& Van der Velden, 200I; Mavromaras et al., 20I2). Since we are specifically concerned with the use of intrapreneurial skills, we focus on skill mismatches. More specifically, we focus on the relation between intrapreneurial skill underutilization and involvement in innovation.

Generally, workers whose skills are underutilized face a depreciation of the skills they are not using (De Grip et al., 2008; Perry et al., 20I4). In addition, skill underutilization has a detrimental effect on job satisfaction (Allen \& van der Velden, 20oI), which can negatively affect work performance (Judge et al., 200I). Moreover, workers whose skills are underutilized have an increased likelihood of voluntarily quitting their 
job (Allen \& van der Velden, 20oI) and experience fewer learning opportunities in their jobs (van der Velden \& Verhaest, 20I7). Furthermore, workers whose skills are underutilized earn lower wages than those with comparable skill levels working at their own skill level (Allen \& van der Velden, 200I; Green \& McIntosh, 2007).

Explaining the negative wage effects of skill underutilization, assignment theory ${ }^{22}$ (Sattinger, 1993) suggests that every job has a productivity potential attached to it, independent of the productivity potential of the worker in the job. Workers employed in jobs that are below their skill level are therefore faced with a productivity ceiling and can only use their skills up to the productivity level attached to the job. This, in turn, results in lower wages compared to workers with comparable skill levels who are well matched to their jobs. With regard to workers' engagement in innovative tasks, Choi (2004) similarly argues that if people have abilities to perform these tasks very well, they can only fully apply these abilities if their job involves them in innovative tasks. Thus, when graduates with high intrapreneurial skills are employed in jobs in which they are not involved in innovation, they cannot optimally use their intrapreneurial skills. Those who underutilize their intrapreneurial skills are therefore expected to be less often involved in innovation compared to graduates whose intrapreneurial skills are well matched to their job. We formulate the following hypothesis.

$\mathrm{H}_{3}$ : Graduates whose intrapreneurial skills are underutilized are less often involved in innovation than well-matched graduates are.

\subsection{Methods}

\subsubsection{Data and sample}

We use data from the REFLEX higher education graduate survey. The survey was conducted in 2005 in 16 countries among higher education graduates who graduated in 1999/2000 (Allen \& van der Velden, 20II). Consequently, our sample consists of young professionals who are, on average, 4.5 years into their professional career. The survey targeted graduates at the bachelor's and master's or equivalent level (i.e. ISCED 5A level). Highly educated graduates are very suitable for the purpose of this study, since those with higher levels of education are most involved in innovation (e.g. Alpkan et al., 20IO; Janssen, 2000; Stam et al., 20I2). In addition, workers who just entered the labour market experience an especially higher incidence of overeducation (Quintini, 20Ira) and are therefore more at risk of the negative consequences of mismatch.

22 For formal models of mismatch as a source of unemployment, see Şahin et al. (2014) and Shimer (2007). 
We focus exclusively on those employed in the private profit sector in II Western and Southern European countries included in the REFLEX study. ${ }^{23}$ Table 3.I displays the number of graduates per country. Our sample $(n=4, \mathrm{II} 8)$ includes only those graduates employed in either a STEM or a business occupation. The mean age of the graduates in our sample is 30.9 years, with a standard deviation of 3.7 years.

Table 3.1 - Number of graduates per country

\begin{tabular}{l|r|r}
\hline Country & N & Percentage of total sample \\
\hline Austria & 342 & 8.31 \\
Belgium & 283 & 6.87 \\
Finland & 549 & 13.33 \\
France & 283 & 6.87 \\
Germany & 340 & 8.26 \\
Italy & 441 & 10.71 \\
Netherlands & 516 & 12.53 \\
Norway & 308 & 7.48 \\
Portugal & 138 & 3.35 \\
Switzerland & 651 & 15.81 \\
United Kingdom & 267 & 6.48 \\
\hline Total & 4,118 & 100.00 \\
\hline
\end{tabular}

Although the REFLEX survey is conducted in the early 2000's, it still holds value. The REFLEX survey data contains unique information that is not available in any other dataset. Despite its age, the REFLEX survey is the only international survey that includes information about intrapreneurial skills, skill requirements, occupations and individuals' involvement in innovation. Although we acknowledge that the value of certain skills (e.g. soft skills and analytical skills) has increased over time (Weinberger, 20I4), the stages of the innovation process still require the generation and implementation of new ideas. However, additional analyses on a proprietary dataset presented in the Appendix (Tables A3.I and A3.2), show that intrapreneurial skill levels among the working population have not increased over time. In addition, the relations we find between intrapreneurial skills and innovation using data from 2016 are comparable to the relations we find in this chapter. This suggests that the REFLEX data is still relevant for the purposes of this chapter.

\subsubsection{Dependent variable}

The REFLEX survey contains questions regarding graduates' perception of the extent of different types of innovation in their organization and, crucially, a question on

23 Eastern European countries were excluded to allow for a sample of European countries of comparable economic development. 
each graduate's own involvement in innovation. Specifically, the graduates were first asked to indicate the extent of innovation in their organization in I) products and services, 2) technology, tools, or instruments, and 3) knowledge or methods. ${ }^{24}$ The answers were given on a five-point Likert scale ranging from one for very low to five for very high. Next, for each of the three innovation types, the graduates were asked to indicate if they played a role in introducing these innovations. ${ }^{25}$ We create three binary variables that indicate whether each graduate was involved in each of the three types of innovation.

In addition, we construct a binary variable to capture overall involvement in innovation that takes the value of one if the graduate indicated having been involved in introducing innovation in any one or more of the three innovation types and zero otherwise. We do not formulate hypotheses for different types of innovation, as research suggests that there are complementarities as well as differences between on the one hand product and service innovations and on the other hand process innovations (e.g. Damanpour, 1988; Damanpour \& Gopalakrishnan, 200I; Martinez-Roz, 2000). Moreover, the contribution of employees' ideas to firms' innovative performance has been shown to depend on whether product/service or process innovation is desired (Andries \& Czarnitzki, 20I4). Therefore, we exploit the presence of this distinction in the data and test our hypotheses both for the general measure of involvement in innovation and for being involved in different types of innovation.

The use of a single-item measure of the graduates' involvement in innovation is appropriate for several reasons. Fuchs and Diamantopoulos (2009) argue that a single-item measure can be used when the research objective is to obtain a general impression of a construct. Here, we are interested in graduates' general involvement in innovation, as opposed to the quality of innovative behaviours. Therefore, the use of one item is suited to our research objectives. Moreover, a single item measure is appropriate when measuring highly complex constructs. In our heterogeneous sample, the characteristics of innovation are expected to be diverse and complex. Determining relevant a priori indicators for involvement in innovation in this case would imply selecting criteria for involvement in innovation that would be suitable in multiple sectors of industry and firm contexts. Such a broadly formulated item, however, allows graduates to determine if they have or have not been involved in innovation in their specific situation (Fuchs \& Diamantopoulos, 2009).

24 In this article, we sometimes refer to the latter two combined as process innovations.

25 Respondents indicating that no innovation activities take place in their respective firms were excluded from the estimation sample $(n=223)$. 


\subsubsection{Independent variables}

\section{Intrapreneurial skills}

The REFLEX survey covers is skills for which the graduates were asked to evaluate their own level on a seven-point Likert scale ranging from one for very low to seven for very high. These skills originate from an investigation of indispensable skills for higher education graduates (Allen \& van der Velden, 20II). We use exploratory factor analysis to create the skill variables of interest. We determine the number of factors by applying the Kaiser criterion, that is, retaining the number of factors with eigenvalues greater than one and by inspecting the pattern coefficients to assess the meaningfulness of the items and factors. Since intrapreneurial skills are expected to be correlated not only with each other but also, possibly, with other skills, we apply an oblique rotation to allow for correlation between the factors and for ease of interpretation. To assess whether the items are meaningful, a lower limit of 0.3 for factor loadings is often applied; however, we use a stricter criterion, retaining only skill items with factor loadings of 0.4 or greater after rotation. This results in the exclusion of two skill items relating to the ability to write reports and memos and foreign language abilities. After this exclusion, we repeat the analysis until a satisfactory final solution is reached. Our final factor solution shows three factors, which we term championing skills, creative skills, and non-intrapreneurial skills. Table 3.2 depicts the factor loadings of the 17 retained skills ${ }^{26}$.

The item loadings show that the creative skills factor entails relevant knowledge, the ability to acquire this knowledge, critical thinking about ideas, the ability to come up with new ideas, and computer use abilities. This result is in line with the definitions of creative skills of Block and MacMillan (1993), Hayton and Kelley (2006), and Maidique (1980). The championing skills factor includes the ability to negotiate effectively, mobilize the capacity of other people, and coordinate activities, in line with the definitions of championing skills of Hayton and Kelley (2006), Maidique (1980), Schon (1963), and Shane (1994). Also included in this factor is alertness to new opportunities, which is regarded as a core entrepreneurial skill (Mitchelmore \& Rowley, 20IO). The non-intrapreneurial skills factor represents skills that are important for performing one's job on a day-to-day basis but which are not specifically relevant for innovation purposes.

26 It should be noted that these skill items have not been specifically designed for measuring intrapreneurial skills. Nevertheless, as Bjornali and Støren (20I2) show, these skill items load onto factors that largly represent the intrapreneurial skill-set. 
Table 3.2 - Rotated factor loadings of intrapreneurial and non-intrapreneurial skills

\begin{tabular}{l|r|r|r}
\hline Skill item & $\begin{array}{r}\text { Championing } \\
\text { skills }\end{array}$ & $\begin{array}{r}\text { Creative } \\
\text { skills }\end{array}$ & $\begin{array}{r}\text { Non- } \\
\text { intrapreneurial } \\
\text { skills }\end{array}$ \\
\hline Ability to negotiate effectively & 0.7061 & 0.0629 & 0.0939 \\
Alertness to new opportunities & 0.4835 & 0.2285 & 0.1043 \\
Ability to mobilize capacities of others & 0.6491 & 0.0381 & 0.2123 \\
Ability to make your meaning clear to others & 0.5679 & 0.0716 & 0.1874 \\
Ability to assert your authority & 0.7515 & 0.0594 & 0.0728 \\
Ability to present products, ideas or reports to an audience & 0.6357 & 0.1799 & 0.0969 \\
Mastery of own fields or discipline & 0.0164 & 0.5874 & 0.0782 \\
Mastery of other fields or discipline & 0.3225 & 0.5080 & 0.2426 \\
Analytical thinking & 0.0363 & 0.6776 & 0.0804 \\
Ability to rapidly acquire new knowledge & 0.0239 & 0.5602 & 0.2993 \\
Ability to use computers and the internet & 0.2900 & 0.6601 & 0.1655 \\
Ability to come up with new ideas and solutions & 0.3130 & 0.6130 & 0.1011 \\
Willingness to question your own and others ideas & 0.3511 & 0.4720 & 0.0536 \\
Ability to perform well under pressure & 0.2007 & 0.1482 \\
Ability to coordinate activities & 0.3441 & 0.0347 & 0.5195 \\
Ability to use time efficiently & 0.0093 & 0.0304 & 0.5377 \\
Ability to work productively with others & 0.1493 & 0.7838 \\
\hline
\end{tabular}

Note: The values in bold indicate the highest loading on a factor for every item. The original survey covers 19 skill items, 17 of which were retained for use in this chapter. Excluded items are a) the ability to write reports, memos, or documents and b) the ability to write and speak in a foreign language.

Although the REFLEX survey does not contain questions directly related to brokering skills, it does contain questions relating to brokering as a role graduates can adopt. These items were selected based on the definition of Hayton and Kelley (2006), who state that brokering skills include the ability to establish knowledge networks outside the organization, as well as share newfound knowledge with others inside the organization. The survey items selected to proxy as the level of brokering skill, answered on a five-point Likert scale, are as follows: 'Professional colleagues rely on me as an authoritative source of advice', 'I keep my professional colleagues informed about new developments in my field of work', and 'I take initiative in establishing professional contacts with experts outside of the organization'. To investigate if we can indeed group these three items to proxy for a graduate's level of brokering skills, we perform an exploratory factor analysis. The result of this analysis yields a clear one-factor solution.

Next, we calculate the factor scores for the skill variables. We use a regression scoring method to calculate an index for each factor. This method allows for items to contribute to the overall factor score of multiple factors by assigning weights to each item's respective contribution. The factor scores for all the skill variables are 
thus calculated by regressing the standardised items on the respective factors. This procedure results in standardised skill variables with a mean of zero and a standard deviation of one (Kucel et al., 2016).

\section{STEM and business occupations}

Using the 1988 International Standard Classification of Occupations (ISCO-88; ILO, 1989) we classify graduates' occupations with a binary variable distinguishing STEM jobs (= I) from business jobs (= o). The ISCO-88 classification regards each occupation as a group of jobs that include highly similar tasks and duties but it does not specifically differentiate between STEM and business management jobs. Therefore, we manually construct these two occupational categories.

In line with Langdon et al. (20II), we consider occupations STEM jobs if they include professional and technical support occupations in the fields of computer science and mathematics, engineering, and life and physical sciences. Tasks shared by STEM occupations relate to research, the application of scientific knowledge, and technical work. STEM occupations include the ISCO-88 sub-major group physical, mathematical, and engineering science professionals within the major group professionals. Furthermore, from the major group technicians and associate professionals, we include those within the sub-major group physical and engineering science associate professionals (excluding safety and quality inspectors). Moreover, we include graduates from the minor (three-digit) group life science technicians and related associate professionals within the sub-major group life science and health associate professionals.

We label occupations as business jobs if they include occupations in management, business, or sales. Tasks shared by business jobs relate to advising, policy formulation and/or implementation, or business organization and the analysis of business opportunities or to performing a supportive role in this process. The graduates included in business occupations are employed in an occupation in the sub-major (two-digit) groups corporate managers and general managers or in related professions in the sub-major groups other professionals and other associate professionals. Of the sub-major group other professionals, the minor (three-digit) group business professionals is also included, whereas the sub-major group other associate professionals and the minor groups finance and sales and associate professionals, business service agents and trade brokers, and administrative associate professionals are included. Table 3.3 shows the occupations at the ISCO- 88 minor group-level that are included in STEM and business occupations.

It should be noted that we do not focus on the fields of study of the graduates but on the occupations where they find employment. This is in line with our expectation that the job in which a graduate is employed determines the possible role in innovative processes. However, STEM graduates may be employed in non-STEM jobs, and vice versa. Graduates who are employed in STEM occupations mostly graduated within the fields of Engineering, manufacturing and construction (66.7\%) 
and Science, mathematics and computing (20.3\%). Graduates who are employed in business occupations mostly graduated within the fields of Social sciences, business and law (65.8\%), and in Engineering, manufacturing and construction (I2.4\%). Only $5.5 \%$ of those classified in STEM occupations and I0.3\% of those classified in business occupations indicate that their job requires a totally different field of education than their own.

Table 3.3 - ISCO-88 minor groups (3 digit level) occupations in groups of graduates in STEM and business occupations

\begin{tabular}{l|r|r} 
& Frequency & Percent \\
STEM & & \\
Physical, mathematical and engineering & 4 & 0.21 \\
Physicists, chemists and related professionals & 7 & 0.37 \\
Mathematicians, statisticians and related professionals & 21 & 1.11 \\
Computing professionals & 522 & 27.68 \\
Architects, engineers and related professionals & 1056 & 55.99 \\
Technicians and associate professionals & 8 & 0.42 \\
Physical and engineering science associate professionals & 7 & 0.37 \\
Physical and engineering science technicians & 154 & 8.17 \\
Computer associate professionals & 89 & 4.72 \\
Ship and aircraft controllers and technicians & 4 & 0.21 \\
Life science technicians and related associate professionals & 14 & 0.74 \\
\hline Total & 1,886 & 100.00 \\
& & \\
Business & & 1.30 \\
Corporate managers & 29 & 1.25 \\
Directors and chief executives & 28 & 6.54 \\
Production and operations managers & 146 & 13.84 \\
Other specialist managers & 309 & 3.09 \\
Managers of small enterprises & 69 & 0.22 \\
Professionals & 5 & 47.13 \\
Business professionals & 1052 & 19.00 \\
Finance and sales associate professionals & 424 & 2.78 \\
Business services agents and trade brokers & 62 & 4.84 \\
Administrative associate professionals & 108 & 100.00 \\
\hline Total & 2,232 & \\
\hline
\end{tabular}

\section{Skill mismatch}

How to best measure skill mismatch is still a topic of academic debate and we refer to Quintini (20Irb), Perry et al. (20I4), and McGuinness et al. (2017) for elaborate discussions on methods of measuring skill mismatch. Skill mismatch is most often measured by using respondents' self- reported information on their skill levels and skill use in their jobs (Perry et al., 20I4). However, Sánchez-Sánchez and McGuinness (2015) find that general measures of overskilling are weakly related to more specific direct overskilling measures. 
Here, we adopt a skill use-based approach of measuring skill mismatch with regard to intrapreneurial skills. We thereby derive separate skill mismatch measures for creative skills as well as championing skills. We do so by comparing graduates' acquired skill levels with their levels of utilization in their current job. Similarly, we derive a skill mismatch indicator for non-intrapreneurial skills for additional reference in the analysis. The REFLEX survey covers the (self-assessed) required skill level for graduates' jobs for the same in skills for which the graduates were asked to evaluate their own levels of skill. Graduates indicated the required level of these skills in their current jobs on a seven-point Likert scale ranging from one for very low to seven for very high. We calculate the average required creative, championing, and non-intrapreneurial skill levels using the same item weights as for the graduates' own levels of skills.

A limitation of using self-reported data for measuring skill use is that the graduates could be biased (Hartog, 2000; Perry et al., 20I4). Another limitation of our approach is that we can only calculate these values for required levels of creative, championing, and non-intrapreneurial skills, since the data contain no information on self-assessed required brokering skills. Therefore, we cannot assess skill use for innovation for all intrapreneurial skills.

We measure skill use in the same way as Allen et al., (2013). First, we subtract the standardised measures for required creative, championing, and non-intrapreneurial skill levels from the graduates' actual skill levels. We then construct three categorical variables for skill mismatch where we define the graduates' skills to be well matched if the calculated difference between the graduates' level of skills and the skills required in their jobs is less than I.5 points. Graduates' skills are considered to be underutilized if their skill levels exceed those required for their job by I.5 points or more and graduates are considered to experience a skill deficit if their skill level is I.5 points or more below the level of skills required for their job. For creative, championing, and non-intrapreneurial skills, we include the skill mismatch category indicating skill utilization as the measure of interest to test $\mathrm{H}_{3}$, whereas skill deficits are included as a control variable to take into account any potential differences between graduates who face a skill deficit and those employed in a well-matched job.

\subsubsection{Self-assessment bias}

Note that all skill variables and required skill levels are measured by means of graduates' self-assessment, a method that could have disadvantages (e.g. Hartog, 2000; Perry et al., 20I4; Podsakoff et al., 2003). If graduates do not indicate their true skill levels, measurement error will increase. This can have multiple causes, such as social desirability, unclear question formulation, or an inability of individuals to assess their skill levels (Allen \& van der Velden, 2005). However, there is no reason to expect that a self-assessment bias would be different for intrapreneurial and non-intrapreneurial skills. Therefore, self-assessment bias cannot explain our results. Moreover, skill self- 
assessment methods have been shown to reliably predict, for example, entrepreneurial performance (Mitchelmore \& Rowley, 2010).

Nevertheless, we explore if self-assessment bias is problematic is the following way. We investigate if our mismatch classification may have been affected by the DunningKruger effect (Kruger \& Dunning, 1999). This is a cognitive bias that leads those that are actually low in ability to rate themselves as high in ability, while not being aware of their own incompetence. If this is the case, we would falsely classify those that are low in ability as 'underutilized'. We therefore assess differences in objective ability (graduates' average study grade) between graduates that are overskilled and matched in their jobs. If our skill-mismatch measures would be affected by the DunningKruger effect, we would observe lower objective ability for those graduates that we classify as overskilled as compared to those that are matched in their jobs. As Appendix Table A3.3 shows, we do not find systematic differences in objective ability between the mismatch categories.

\subsubsection{Other control variables}

At the individual level, we control for gender $($ male $=0$, female $=\mathrm{I})$ and tenure. Tenure is measured as the number of years the graduate has been employed in his or her current job. In addition, a squared term of tenure is added to control for possible time trends. We do not control for age, since the graduates are all in the same age category, ${ }^{27}$ and time in the labour market since graduation is the same for all graduates.

Apart from individual characteristics, job and educational characteristics can also influence a graduate's involvement in innovation. For instance, high job autonomy is related to higher levels of employee innovation (Stam et al., 20I2). Therefore, we construct a control variable for job autonomy by averaging the following two items measured on a five-point Likert scale: 'To what extent are you responsible for setting goals for your own work?' and 'To what extent are you responsible for deciding how you do your own job?' (Cronbach's $\alpha=0.69$ ). In addition, we control for differences related to graduates' leadership position by including a dummy variable indicating whether the graduate supervises other workers $(=\mathrm{I})$ or not $(=0)$. Furthermore, we include a variable for the extent to which graduates' educational program provided a basis for the development of entrepreneurial skills.

To account for differences in the probability of being involved in innovation due to the context a graduate is working in, we include several common control variables. Company size is included as a categorical variable based on the number of employees. We control for sector-specific characteristics by including sector dummies based on the International Standard Industrial Classification (revision 3.I). Finally,

27 Estimations including a control variable for age show no significant relation of age with involvement in innovation nor does this influence the general outcomes and conclusions. 
we include country dummies to control for country-specific characteristics (e.g. culture, legislation).

\subsubsection{Descriptive statistics}

Tables 3.4 to 3.6 display our sample and variable descriptives. Table 3.4 shows the correlations between nonstandardised variables. All three intrapreneurial skills are positively correlated with each other and with involvement in all types of innovation. The non-intrapreneurial skills are not significantly correlated with innovation involvement, indicating that these skills are not specifically relevant to innovation. However, the non-intrapreneurial skills are positively correlated with the intrapreneurial skills. Thus, although graduates with high intrapreneurial skills also score high on non-intrapreneurial skills, having only high intrapreneurial skills is significantly positively related to involvement in innovation. Table 3.4 also shows that the extent of entrepreneurial education is positively related to graduates' level of creative, brokering and championing skills as well as to their level of non-intrapreneurial skills. This suggests that more focus on entrepreneurial education in the curriculum contributes to intrapreneurial skills without any trade-off for other skills.

From Tables 3.4 and 3.5, we see that graduates in STEM occupations have, on average, higher creative skills as well as higher creative skill requirements in their jobs but lower championing skills and championing skill requirements. Graduates who are employed in STEM occupations also have, on average, lower non-intrapreneurial skills and non-intrapreneurial skill requirements than those employed in business occupations. There is, however, no difference in brokering skill levels between the two occupational groups. Furthermore, there are no differences in intrapreneurial skill matches between graduates employed in STEM and business occupations. However, graduates employed in business occupations more often experience a good match between their non-intrapreneurial skill levels and the non-intrapreneurial skills requirements in their jobs and less often experience skill deficits for non-intrapreneurial skills.

Table 3.6 shows that $75.9 \%$ of all graduates have been involved in at least one type of innovation. This percentage is higher among graduates employed in STEM occupations $(80.8 \%)$ than among those employed in business occupations (7I.7\%). Specifically, those employed in STEM occupations are significantly more often involved in product and service innovation as well as in process innovation in technology, tools, and instruments at the $5 \%$ and $\mathrm{i} \%$ levels, respectively. This suggests that there is indeed a difference in the involvement in innovation between graduates working in STEM versus business occupations. Finally, the table shows that graduates in both STEM and business occupations are most often involved in process innovations related to knowledge and methods. 


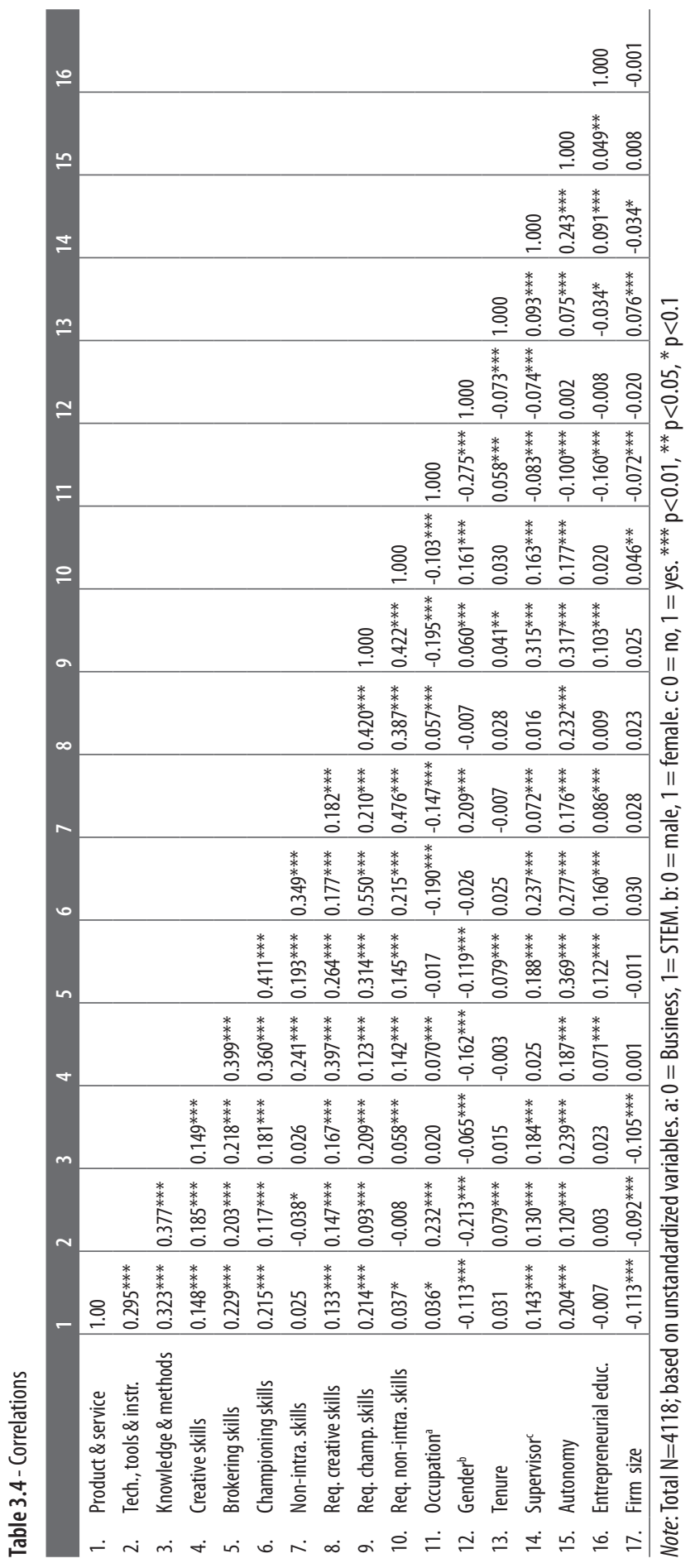


Table 3.5 - Means and standard deviations for required skill levels, and skill (mis)match proportions for graduates in STEM and business occupations and total sample

\begin{tabular}{|c|c|c|c|c|}
\hline & $\begin{array}{c}\text { STEM } \\
\text { occupations }\end{array}$ & $\begin{array}{l}\text { Business } \\
\text { occupations }\end{array}$ & & Total sample \\
\hline (Required) Skill levels & Mean (SD) & Mean (SD) & p(t-statistic) & Mean (SD) \\
\hline Creative skill & $8.27(1.00)$ & $8.13(1.00)$ & $<0.01$ & $8.20(1.00)$ \\
\hline Required level & $7.74(1.32)$ & $7.58(1.37)$ & $<0.01$ & $7.65(1.35)$ \\
\hline Brokering skill & $3.30(0.82)$ & $3.33(0.85)$ & n.s. & $3.31(0.84)$ \\
\hline Championing skill & $5.59(1.28)$ & $6.07(1.19)$ & $<0.01$ & $5.85(1.25)$ \\
\hline Required level & $5.40(1.60)$ & $6.03(1.53)$ & $<0.01$ & $5.74(1.59)$ \\
\hline Non-intrapreneurial skills & $6.43(1.07)$ & $6.74(1.02)$ & $<0.01$ & $6.60(1.06)$ \\
\hline Required level & $6.56(1.28)$ & $6.83(1.26)$ & $<0.01$ & $6.71(1.28)$ \\
\hline Skill (mis)match proportions & $\%$ & $\%$ & p(z-statistic) & $\%$ \\
\hline Creative skills & & & & \\
\hline Match & 85.47 & 84.23 & n.s. & 84.80 \\
\hline Underutilized & 8.54 & 8.96 & n.s. & 8.77 \\
\hline Deficit & 6.00 & 6.81 & n.s. & 6.44 \\
\hline \multicolumn{5}{|l|}{ Championing skills } \\
\hline Match & 89.40 & 90.32 & n.s. & 89.90 \\
\hline Underutilized & 5.57 & 5.11 & n.s. & 5.32 \\
\hline Deficit & 5.04 & 4.57 & n.s. & 4.78 \\
\hline \multicolumn{5}{|l|}{ Non-intrapreneurial skills } \\
\hline Match & 85.95 & 88.04 & $<0.05$ & 87.08 \\
\hline Underutilized & 6.26 & 6.41 & n.s. & 6.34 \\
\hline Deficit & 7.79 & 5.56 & $<0.01$ & 6.58 \\
\hline $\mathrm{N}$ & 1,886 & 2,232 & & 4,118 \\
\hline
\end{tabular}

Note: In this table, n.s. stands for not significant. Innovating and championing skills are measured on a seven-point Likert scale and brokering skills are measured on a five-point Likert scale. Skill level scores represent nonstandardised weighted sum scores. 
Table 3.6 - Involvement in innovations for graduates in STEM and business occupations

\begin{tabular}{|c|c|c|c|c|c|c|c|c|}
\hline \multirow[b]{3}{*}{ Occupation } & \multirow{2}{*}{\multicolumn{2}{|c|}{$\begin{array}{l}\text { Any type of } \\
\text { Innovation }\end{array}$}} & \multirow{2}{*}{\multicolumn{2}{|c|}{$\begin{array}{l}\text { Product \& service } \\
\text { innovation }\end{array}$}} & \multicolumn{4}{|c|}{$\begin{array}{c}\text { Process } \\
\text { innovation }\end{array}$} \\
\hline & & & & & \multicolumn{2}{|c|}{$\begin{array}{l}\text { Technology, tools \& } \\
\text { instruments }\end{array}$} & \multicolumn{2}{|c|}{$\begin{array}{l}\text { Knowledge \& } \\
\text { methods }\end{array}$} \\
\hline & $\mathrm{N}$ & $\%$ & $\mathbf{N}$ & $\%$ & $\mathrm{~N}$ & $\%$ & $\mathrm{~N}$ & $\%$ \\
\hline STEM & 1,524 & $80.8^{* * *}$ & 965 & $55.2^{* *}$ & 1,017 & $59.2^{* * *}$ & 1,138 & 64.8 \\
\hline Business & 1,601 & 71.7 & 1,074 & 51.6 & 705 & 36.0 & 1,300 & 62.9 \\
\hline Total & 3,125 & 75.9 & 2,039 & 53.3 & 1,722 & 46.9 & 2,438 & 63.8 \\
\hline
\end{tabular}

Note: The percentages are calculated for occupational groups and for the total sample. Tests results for the equality of innovation involvement indicated as follows: ${ }^{* *} p<0.05,{ }^{* * *} p<0.01$

\subsubsection{Empirical model and estimations strategy}

Involvement in innovation is denoted as $\mathrm{Y}$ and takes the value of one when a graduate indicates involvement in introducing (at least one type of) innovation and the value of zero when graduates indicate that they have not been involved in innovation of any type:

$$
\mathrm{Y}= \begin{cases}1 & \text { involvement in (any) type of innovation } \\ 0 & \text { no involvement in (any) type of innovation }\end{cases}
$$

We estimate equation (3.I) by a linear probability model ${ }^{28}$ that estimates the probability that a graduate has been involved in innovation as follows:

$$
\begin{aligned}
& \mathrm{P}(\mathrm{Y}=1)=\alpha+\beta_{1} \text { skills }+\beta_{2} \text { occupation }+\beta_{3} \text { occupation* }{ }^{*} \text { skills }+\beta_{4} \text { skillmatch } \\
& +\beta_{5} \text { controls }+\varepsilon
\end{aligned}
$$

28 Models with binary outcomes are often estimated with logit models. However, the interpretation of interaction terms in logit models is often problematic and does not allow for assessing differences in the coefficients between different occupational groups. For a discussion on interpreting interaction effects in logit models, see Ai and Norton (2003) and Long and Freese (20I4). However, logit estimations have outcomes similar to those of the linear probability model we use here (see Table $\mathrm{A}_{3.4}$ in the Appendix). The consequence of estimating an LPM is that predicted probabilities can fall outside the O-I probability range. To investigate the extent to which this is the case for the estimations we present in the next section, we calculate the percentage of observations with predicted probabilities that are below o or above I. We do this for the estimations presented in column 5 of Table 3.6, as well as those presented in columns I, 2 and 3 of Table 3.7. The percentages of observations with predicted probabilities that are below 0 are $0.02 \%, 0.81 \%, 0.33 \%$ and $0.13 \%$, respectively. The percentages of observations with predicted probabilities that are above I are: $6.7 \%, 0.03 \%, 0.03 \%$ and $2.4 \%$, respectively. 
where skills denotes a vector of a graduate's level of creative, championing, brokering, and non-intrapreneurial skills; occupation denotes the graduate's occupation type, that is, either a STEM occupation or a business occupation; occupation *skills denotes the interaction between the type of occupation and (non-)intrapreneurial skills; skillmatch denotes a vector of categorical variables indicating whether the graduates are matched or experience skill underutilization or skill deficits in their jobs with respect to their creative, championing, and non-intrapreneurial skills; and controls denotes a vector of control variables for gender, tenure, supervisor position, level of job autonomy, firm size, industrial sector, and country.

\subsection{Results}

\subsubsection{Skill allocation to innovation}

Table 3.7 shows the estimation results when we consider involvement in any type of innovation. Model I includes only the control variables, Model 2 includes only a dummy for job type, Model 3 only includes the skill variables, Model 4 includes all the variables, and Model 5 adds the interactions between occupation type and (non-) intrapreneurial skills.

Table 3.7 shows that all three intrapreneurial skills are significantly positively related to the probability of being involved in at least one type of innovation (Model 3), even when we account for various characteristics related to the individual, job, organization, sector, and country (Model 4). However, non-intrapreneurial skills are significantly negatively related to involvement in innovation in all models. Therefore, as expected, high levels of intrapreneurial skills increase the likelihood of being involved in innovation, whereas high levels of non-intrapreneurial skills decrease that likelihood.

Next, the positive coefficient for STEM occupations in all models shows that graduates employed in STEM occupations are significantly more often involved in innovation than those employed in business occupations are. To investigate whether there is a difference in the importance of the skill variables between graduates in STEM versus business occupations, Model 5 also includes the interaction effects between the type of occupation and creative, brokering, championing, and non-intrapreneurial skills. The estimation results show that the coefficients of these interaction terms are not significant. This indicates that the relations between the levels of the three intrapreneurial skills and the probability of being involved in innovation do not differ between STEM and business occupations. However, as shown in Section 3.4.2, we do find differences between these occupations when we distinguish between different types of innovation. 
Table 3.7 - LPM estimation results for being involved in any type of innovation

\begin{tabular}{|c|c|c|c|c|c|}
\hline & (1) & (2) & (3) & (4) & (5) \\
\hline Skills & & & & & \\
\hline Creative skills & & & $\begin{array}{c}0.048^{* * *} \\
(0.008)\end{array}$ & $\begin{array}{c}0.064^{* * *} \\
(0.008)\end{array}$ & $\begin{array}{c}0.067^{* * * *} \\
(0.011)\end{array}$ \\
\hline Brokering skills & & & $\begin{array}{c}0.097^{* * *} \\
(0.010)\end{array}$ & $\begin{array}{c}0.076^{* * *} \\
(0.011)\end{array}$ & $\begin{array}{c}0.085^{* * * *} \\
(0.014)\end{array}$ \\
\hline Championing skills & & & $\begin{array}{c}0.050^{* * *} \\
(0.008)\end{array}$ & $\begin{array}{c}0.046^{* * * *} \\
(0.009)\end{array}$ & $\begin{array}{c}0.055^{* * * *} \\
(0.012)\end{array}$ \\
\hline Non-intrapreneurial skills & & & $\begin{array}{c}-0.037^{* * * *} \\
(0.007)\end{array}$ & $\begin{array}{c}-0.033^{* * *} \\
(0.008)\end{array}$ & $\begin{array}{c}-0.041^{* * *} \\
(0.010)\end{array}$ \\
\hline Occupation & & & & & \\
\hline STEM, ref. $=$ Business & & $\begin{array}{c}0.091^{* * * *} \\
(0.013)\end{array}$ & & $\begin{array}{c}0.101^{* * * *} \\
(0.014)\end{array}$ & $\begin{array}{c}0.102^{* * * *} \\
(0.014)\end{array}$ \\
\hline Interactions & & & & & \\
\hline STEM*creative skills & & & & & $\begin{array}{l}-0.009 \\
(0.015)\end{array}$ \\
\hline STEM*brokering skills & & & & & $\begin{array}{l}-0.021 \\
(0.019)\end{array}$ \\
\hline STEM ${ }^{*}$ championing skills & & & & & $\begin{array}{l}-0.020 \\
(0.016)\end{array}$ \\
\hline STEM*non-intrapreneurial skills & & & & & $\begin{array}{c}0.018 \\
(0.014)\end{array}$ \\
\hline Skill mismatch, ref. $=$ match & & & & & \\
\hline Creative skills, underutilized & & & & $\begin{array}{c}-0.099^{* * *} \\
(0.025)\end{array}$ & $\begin{array}{c}-0.099^{* * *} \\
(0.025)\end{array}$ \\
\hline Championing skills, underutilized & & & & $\begin{array}{c}-0.104^{* * *} \\
(0.032)\end{array}$ & $\begin{array}{c}-0.104^{* * *} \\
(0.032)\end{array}$ \\
\hline Non-intrap. skills, underutilized & & & & $\begin{array}{c}0.026 \\
(0.028)\end{array}$ & $\begin{array}{c}0.026 \\
(0.028)\end{array}$ \\
\hline Control variables & & & & & \\
\hline Creative skills, deficit & & & & $\begin{array}{l}0.057^{*} \\
(0.029)\end{array}$ & $\begin{array}{l}0.056^{*} \\
(0.029)\end{array}$ \\
\hline Championing skills, deficit & & & & $\begin{array}{l}-0.004 \\
(0.034)\end{array}$ & $\begin{array}{l}-0.006 \\
(0.034)\end{array}$ \\
\hline Non-intrap. skills, deficit & & & & $\begin{array}{c}-0.055^{* * *} \\
(0.028)\end{array}$ & $\begin{array}{l}-0.052^{*} \\
(0.028)\end{array}$ \\
\hline Supervisor, ref. $=$ No supervisor & $\begin{array}{c}0.075^{* * *} \\
(0.013)\end{array}$ & & & $\begin{array}{c}0.055^{* * *} \\
(0.014)\end{array}$ & $\begin{array}{c}0.054^{* * * *} \\
(0.014)\end{array}$ \\
\hline Female, ref.=Male & $\begin{array}{c}-0.106^{* * * *} \\
(0.015)\end{array}$ & & & $\begin{array}{c}-0.046^{* * * *} \\
(0.015)\end{array}$ & $\begin{array}{c}-0.043^{* * *} \\
(0.015)\end{array}$ \\
\hline Autonomy & $\begin{array}{c}0.091^{* * *} \\
(0.007)\end{array}$ & & & $\begin{array}{c}0.055^{* * * *} \\
(0.008)\end{array}$ & $\begin{array}{c}0.055^{* * * *} \\
(0.008)\end{array}$ \\
\hline Tenure & $\begin{array}{l}-0.001 \\
(0.004)\end{array}$ & & & $\begin{array}{l}-0.002 \\
(0.004)\end{array}$ & $\begin{array}{l}-0.002 \\
(0.004)\end{array}$ \\
\hline Tenure $^{2}$ & $\begin{array}{l}-0.000 \\
(0.000)\end{array}$ & & & $\begin{array}{l}-0.000 \\
(0.000)\end{array}$ & $\begin{array}{l}-0.000 \\
(0.000)\end{array}$ \\
\hline Entrepreneurial education & $\begin{array}{l}-0.002 \\
(0.007)\end{array}$ & & & $\begin{array}{l}-0.006 \\
(0.007)\end{array}$ & $\begin{array}{l}-0.006 \\
(0.007)\end{array}$ \\
\hline Constant & $\begin{array}{c}0.970^{* * * *} \\
(0.058)\end{array}$ & $\begin{array}{c}0.717^{* * *} \\
(0.010)\end{array}$ & $\begin{array}{c}0.758^{* * *} \\
(0.006)\end{array}$ & $\begin{array}{c}0.978^{* * *} \\
(0.060)\end{array}$ & $\begin{array}{c}0.980^{* * *} \\
(0.060)\end{array}$ \\
\hline $\begin{array}{l}\text { Controls firm size, sector, country } \\
\text { Observations } \\
\text { R-squared }\end{array}$ & $\begin{array}{c}\text { Yes } \\
4,118 \\
0.101\end{array}$ & $\begin{array}{c}\text { No } \\
4,118 \\
0.011\end{array}$ & $\begin{array}{c}\text { No } \\
4,118 \\
0.088\end{array}$ & $\begin{array}{c}\text { Yes } \\
4,118 \\
0.167\end{array}$ & $\begin{array}{c}\text { Yes } \\
4,118 \\
0.169\end{array}$ \\
\hline
\end{tabular}

Note: Robust standard errors in parentheses; Estimations performed with standardized independent variables. ${ }^{*} p<0.10$, ${ }^{* *} p<0.05,{ }^{* * *} p<0.01$ 


\subsubsection{Skill allocation to different types of innovation}

We also investigate whether our results differ by type of innovation. We here distinguish between the innovation of I) products and services, 2) technology, tools, or instruments, and 3) knowledge or methods. Table 3.8 presents the estimation results for product and service innovation and the two types of process innovation, respectively. The table shows that the relations between intrapreneurial skills and innovation indeed differ by type of innovation and type of occupation.

Models I to 3 show that, for all intrapreneurial skills, those with higher skills are significantly more often involved in product and service innovation, as well as in both types of process innovation. Since none of the interaction terms between creative skills and job types is significant, we can conclude that there is no difference in the importance of higher creative skills for being involved in innovation between those working in STEM and business occupations.

The interaction effect with brokering skills and job type in Model 2 indicates that higher levels of brokering skills increase the probability of being involved in innovations in technology, tools, and instruments more for those in STEM than for those in business occupations (see also Figure 3.Ia). Marginal predictions for both groups indicate that an increase of one standard deviation in brokering skills is associated with an increase of II.6 percentage points in being involved in this type of innovation for graduates in STEM occupations, whereas, for those in business occupations, this increase is only 6.5 percentage points. Thus, $\mathrm{H}_{\mathrm{I}}$ is partially supported.

In Model 2, the significant negative coefficient for the interaction of championing skills and job type indicates that higher levels of championing skills increase the probability of being involved in technology, tool, and instrument innovation more for graduates in business occupations compared to those employed in STEM occupations. Comparisons of marginal predictions show that, for graduates in business occupations, an increase of one standard deviation in championing skills relates to an increase in the probability of being involved in innovations in technology, tools, and instruments of 5.I percentage points. For those employed in STEM occupations, this increase is only I.o percentage points, which is not significantly different from zero. Thus, higher levels of championing skills only increase involvement in technology, tool, and instrument innovation for graduates employed in business occupations, but not for those employed in STEM occupations. Figure 3.Ib shows that this result could be explained by the already high involvement of graduates in STEM occupations in this type of innovation, even at low levels of championing skills. Therefore, $\mathrm{H}_{2}$ is supported. 
Table 3.8 - LPM estimation results for Product \& service innovation and Process innovation

\begin{tabular}{|c|c|c|c|}
\hline & Product \& service & Process & ons \\
\hline & & $\begin{array}{l}\text { Technology, tools } \\
\text { \& instruments }\end{array}$ & $\begin{array}{l}\text { Knowledge } \\
\text { \& methods }\end{array}$ \\
\hline & (1) & $(2)$ & (3) \\
\hline Skills & & & \\
\hline Creative skills & $\begin{array}{c}0.035^{* * *} \\
(0.013)\end{array}$ & $\begin{array}{c}0.072^{* * *} \\
(0.013)\end{array}$ & $\begin{array}{c}0.060^{* * *} \\
(0.013)\end{array}$ \\
\hline Brokering skills & $\begin{array}{c}0.090^{* * *} \\
(0.016)\end{array}$ & $\begin{array}{c}0.065^{* * *} \\
(0.016)\end{array}$ & $\begin{array}{c}0.099^{* * * *} \\
(0.016)\end{array}$ \\
\hline Championing skills & $\begin{array}{c}0.091^{* * *} \\
(0.013)\end{array}$ & $\begin{array}{c}0.051^{* * *} \\
(0.013)\end{array}$ & $\begin{array}{c}0.051^{* * *} \\
(0.013)\end{array}$ \\
\hline Non-intrapreneurial skills & $\begin{array}{c}-0.036^{* * *} \\
(0.012)\end{array}$ & $\begin{array}{c}-0.043^{* * *} \\
(0.012)\end{array}$ & $\begin{array}{c}-0.042^{* * *} \\
(0.012)\end{array}$ \\
\hline Occupation & & & \\
\hline STEM, ref. = Business & $\begin{array}{l}0.036^{* *} \\
(0.017)\end{array}$ & $\begin{array}{c}0.203^{* * *} \\
(0.018)\end{array}$ & $\begin{array}{l}0.034^{* *} \\
(0.017)\end{array}$ \\
\hline Interactions & & & \\
\hline STEM*creative skills & $\begin{array}{c}0.012 \\
(0.018)\end{array}$ & $\begin{array}{l}0.005 \\
(0.018)\end{array}$ & $\begin{array}{c}0.000 \\
(0.017)\end{array}$ \\
\hline STEM*brokering skills & $\begin{array}{c}0.001 \\
(0.022)\end{array}$ & $\begin{array}{l}0.051^{* *} \\
(0.022)\end{array}$ & $\begin{array}{l}-0.035 \\
(0.022)\end{array}$ \\
\hline STEM*championing skills & $\begin{array}{l}-0.028 \\
(0.017)\end{array}$ & $\begin{array}{c}-0.041^{* *} \\
(0.018)\end{array}$ & $\begin{array}{l}-0.022 \\
(0.018)\end{array}$ \\
\hline STEM*non-intrapreneurial skills & $\begin{array}{c}0.018 \\
(0.017)\end{array}$ & $\begin{array}{l}0.031^{*} \\
(0.017)\end{array}$ & $\begin{array}{c}0.023 \\
(0.016)\end{array}$ \\
\hline Skill mismatch, ref. $=$ match & & & \\
\hline Creative skills, underutilized & $\begin{array}{c}-0.076^{* * *} \\
(0.029)\end{array}$ & $\begin{array}{l}-0.047 \\
(0.030)\end{array}$ & $\begin{array}{c}-0.078^{* * *} \\
(0.028)\end{array}$ \\
\hline Championing skills, underutilized & $\begin{array}{c}-0.125^{* * *} \\
(0.037)\end{array}$ & $\begin{array}{l}-0.062^{*} \\
(0.037)\end{array}$ & $\begin{array}{c}-0.108^{* * *} \\
(0.038)\end{array}$ \\
\hline Non-intrap. skills, underutilized & $\begin{array}{l}0.071^{* *} \\
(0.034)\end{array}$ & $\begin{array}{c}0.039 \\
(0.034)\end{array}$ & $\begin{array}{c}0.007 \\
(0.033)\end{array}$ \\
\hline Control variables & & & \\
\hline Creative skills, deficit & $\begin{array}{l}0.070^{* *} \\
(0.034)\end{array}$ & $\begin{array}{c}0.118^{* * *} \\
(0.034)\end{array}$ & $\begin{array}{c}0.093^{* * *} \\
(0.034)\end{array}$ \\
\hline Championing skills, deficit & $\begin{array}{l}0.043 \\
(0.038)\end{array}$ & $\begin{array}{l}-0.012 \\
(0.037)\end{array}$ & $\begin{array}{c}0.045 \\
(0.036)\end{array}$ \\
\hline Non-intrap. skills, deficit & $\begin{array}{l}-0.033 \\
(0.033)\end{array}$ & $\begin{array}{l}-0.016 \\
(0.034)\end{array}$ & $\begin{array}{l}-0.063^{*} \\
(0.032)\end{array}$ \\
\hline Supervisor, ref.= No supervisor & $\begin{array}{c}0.048^{* * *} \\
(0.017)\end{array}$ & $\begin{array}{c}0.075^{* * *} \\
(0.017)\end{array}$ & $\begin{array}{c}0.090^{* * * *} \\
(0.016)\end{array}$ \\
\hline Female, ref. $=$ Male & $\begin{array}{c}-0.075^{* * *} \\
(0.018)\end{array}$ & $\begin{array}{c}-0.122^{* * *} \\
(0.018)\end{array}$ & $\begin{array}{l}-0.030^{*} \\
(0.017)\end{array}$ \\
\hline Autonomy & $\begin{array}{c}0.041^{* * *} \\
(0.009)\end{array}$ & $\begin{array}{c}0.013 \\
(0.009)\end{array}$ & $\begin{array}{c}0.065^{* * *} \\
(0.009)\end{array}$ \\
\hline Tenure & $\begin{array}{c}0.008 \\
(0.005)\end{array}$ & $\begin{array}{c}0.017^{* * * *} \\
(0.005)\end{array}$ & $\begin{array}{l}-0.009^{*} \\
(0.005)\end{array}$ \\
\hline Tenure $^{2}$ & $\begin{array}{l}-0.000 \\
(0.000)\end{array}$ & $\begin{array}{c}-0.001^{* *} \\
(0.000)\end{array}$ & $\begin{array}{c}0.000 \\
(0.000)\end{array}$ \\
\hline Entrepreneurial education & $\begin{array}{l}-0.012 \\
(0.008)\end{array}$ & $\begin{array}{c}0.006 \\
(0.008)\end{array}$ & $\begin{array}{c}0.001 \\
(0.008)\end{array}$ \\
\hline Constant & $\begin{array}{c}0.899^{* * * *} \\
(0.106)\end{array}$ & $\begin{array}{c}0.735^{* * *} \\
(0.107)\end{array}$ & $\begin{array}{c}0.961^{* * *} \\
(0.098)\end{array}$ \\
\hline $\begin{array}{l}\text { Controls firm size, sector, country } \\
\text { Observations } \\
\text { R-squared }\end{array}$ & $\begin{array}{c}\text { Yes } \\
3829 \\
0.156\end{array}$ & $\begin{array}{c}\text { Yes } \\
3674 \\
0.181\end{array}$ & $\begin{array}{c}\text { Yes } \\
3821 \\
0.153\end{array}$ \\
\hline
\end{tabular}

Note: Robust standard errors in parentheses; Estimations performed with standardised independent variables.

${ }^{*} p<0.10,{ }^{* *} p<0.05,{ }^{* * *} p<0.01$ 
Finally, the estimation results show that graduates with higher non-intrapreneurial skills are less often involved both in product and service and in process innovation. For process innovation in technology, tools, and instruments, the marginally significant positive coefficient for the interaction of non-intrapreneurial skills and occupation suggests that a higher level of these skills has a less negative impact on being involved in innovation for those in STEM occupations than for those employed in business occupations. Figure 3.IC shows that graduates employed in STEM occupations have high involvement in innovation in technology, tools, and instruments at each level of non-intrapreneurial skills, whereas involvement in this type of innovation decreases with increasing levels of non-intrapreneurial skills for graduates employed in business occupations.

Figure 3.1 - Linear predictions of being involved in innovations in Technology, tools \& instruments for graduates in STEM and business occupations two standard deviations around the mean skill level.
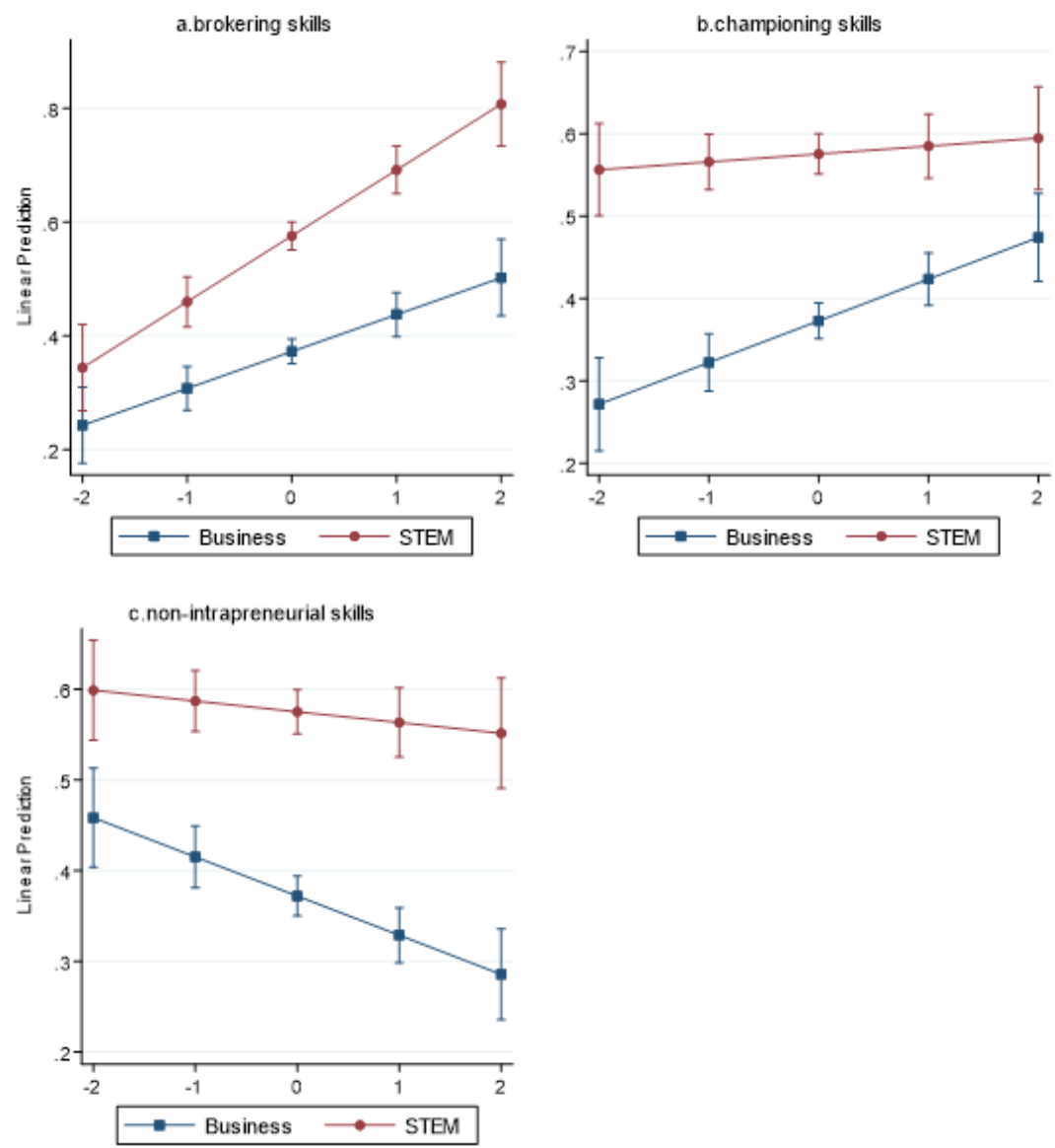

Note: Predictions calculated at mean levels of the other variables. 
Further comparing the two occupational groups, we see that graduates employed in STEM occupations are significantly more involved in all types of innovations, which is most likely due to specific task characteristics. STEM occupations are more or less inherently concerned with improving technology, whereas this is not the case for business occupations.

\subsubsection{Skill underutilization and allocation to innovative tasks}

Thus far, our results show that graduates with higher levels of intrapreneurial skills are more often involved in innovation. However, Tables 3.7 and 3.8 show that graduates who experience underutilization of their intrapreneurial skills are less often involved in innovation, compared to those whose skills match the skill demands in their jobs. This result suggests that the intrapreneurial potential of the former is not optimally utilized. Therefore, $\mathrm{H}_{3}$ is supported.

More specifically, graduates who experience underutilization of their creative skills are less often involved in product and service innovation and in process innovations in knowledge and methods compared to graduates whose jobs match their creative skills. However, although the coefficient has the expected negative sign, graduates experiencing underutilization of their creative skills are not significantly less involved in process innovations in technology, tools, and instruments.

Next, graduates who experience underutilization of their championing skills are less involved in product and service innovation and in both types of process innovations than well-matched graduates are. However, the negative coefficient for the underutilization of championing skills in innovations in technology, tools, and instruments is only marginally significant.

In addition, graduates who experience underutilization of their non-intrapreneurial skills are more involved in product and service innovation. Additional analyses not presented here indicate no heterogeneous effects of skill underutilization between graduates employed in STEM occupations and those employed in business occupations. $^{29}$

\subsubsection{Control variables}

Graduates who supervise other workers are more involved in all types of innovations than those who do not supervise others. Female graduates are less often involved in innovation than male graduates are. Since we include skill level, occupation, job requirements, autonomy, and supervisory position, this gender difference is not attributable to these factors or to sectorial or country differences. Therefore, the gender differences we find most probably points at gender differences in allocation to innovation tasks by the female graduates themselves and/or their employers (Adachi \& Hisada, 20I7; Parker, 20II).

29 The estimation results can be obtained from the author. 
Job autonomy is important in product and service innovation and in innovation in knowledge and methods. However, our results suggest that job autonomy does not play a role in innovation in technology, tools, and instruments. Our results also show that tenure increases the probability of a graduate's involvement in innovation in technology, tools, and instruments. The significant negative term for tenure squared indicates that this positive relation decreases with longer employment duration. This result suggests that the accumulation of specific human capital is important for this type of innovation, but less so for the other innovation types.

Finally, graduates experiencing creative skill deficits appear to be more involved in all types of innovation, compared to graduates whose creative skills match the required level in their jobs. However, this does not hold for graduates who experience championing skill deficits. In addition, graduates who experience non-intrapreneurial skill deficits are also less involved in process innovation in knowledge and methods. Additionally, we tested if skill mismatches are related to the level of entrepreneurial education graduates' received in their studies. The results of this analysis, presented in Appendix Table A3.5, show that graduates with skill deficits have lower levels of entrepreneurial education as compared to graduates who are matched in their jobs. This is the case for both intrapreneurial and non-intrapreneurial skill deficits. However, graduates whose intrapreneurial and non-intrapreneurial skills are underutilized do not differ from matched graduates in their studies' level of entrepreneurial education.

However, we think an elaborate exposition on skill deficits is less interesting here. As shown in Table 3.7, column 5, creative skills deficits particularly occur (marginally significant) when being involved in innovation, and non-intrapreneurial skill deficits occur (marginally significant) when not being involved in innovative activities. This merely supports our assumption and finding that intrapreneurial skills are demanded for innovative activities. Moreover, facing a skill deficit when being involved in innovation does not have to be a bad thing. As Allen and de Grip (20I2) show, skill deficits are inherent to being employed in a dynamic job and an important source for further learning.

Table A3.6 in the Appendix also includes the linear probability model estimations with detailed results for organizational size, sector, and country. For all types of innovations, employees are less likely to be involved in innovation in larger organizations. Our results also show differences between sectors and countries in employees' probability of being involved in innovation.

\subsection{Conclusions}

The aim of this chapter has been to investigate the extent to which graduates with higher intrapreneurial skills are more often involved in innovation and whether this differs between STEM and business occupations. In addition, we investigated 
the extent to which graduates are allocated to innovative tasks according to their intrapreneurial skill levels. In our analyses, we distinguish between product and service innovation and two types of process innovation: innovation in technology, tools, and instruments and in knowledge and methods.

Using data on higher education graduates from II European countries, we find that graduates' intrapreneurial skills are used for innovation in line with the specific skill requirements for innovation of STEM and business occupations. Moreover, we find that graduates whose intrapreneurial skills are underutilized are less involved in innovation, compared to graduates whose intrapreneurial skill levels match the requirements of their jobs.

In addition, there are considerable heterogeneous effects between graduates employed in STEM and those employed in business occupations and differences in the extent to which high levels of intrapreneurial skills are relevant to involvement in different types of innovation. Graduates working in STEM occupations are, on average, more involved in innovation than those employed in business occupations are. This holds for process innovation in particular. In addition, higher levels of brokering skill levels increase the probability of being involved in innovation in technology, tools, and instruments more for graduates employed in STEM occupations than for those employed in business occupations. Conversely, for graduates employed in business occupations, higher championing skill levels increase the probability of being involved in innovation in technology, tools, and instruments. However, this does not hold for those employed in STEM occupations.

Furthermore, our results indicate that the potential of graduates with higher levels of intrapreneurial skills is not fully utilized by involving them in the firm's innovation projects: both creative and championing skills are underutilized for innovation, specifically for product and service innovation and process innovation in knowledge and methods. This finding suggests that the allocation of graduates' intrapreneurial skills to innovative tasks is not optimal.

We contribute to the literature on the importance of human capital for innovation in three ways. First, we confirm the findings by Bjornali and Støren (2012) by showing that higher education graduates with higher intrapreneurial skills are more involved in innovation.

Second, we compare the importance of intrapreneurial and non-intrapreneurial skills with regard to innovation between STEM and business occupations. We thus add to the research on the importance of workers' skills for innovation (e.g. Bjornali \& Støren, 20I2; Hunter et al., 20I2; Mumford et al., 20IO; Vila et al. 20I2) by showing differences in the importance of specific intrapreneurial skills for involvement in innovation that arise from either the type of occupation or the type of innovation. Our findings suggest that studies concerned with workers' involvement in innovation in organizations should pay particular attention to possible heterogeneous effects depending on both graduates' occupations and the type of innovation being studied. 
Third, we show that the allocation of intrapreneurial skills is not always geared towards maximizing the involvement in innovation of graduates who have high intrapreneurial skills. We thus also add to the economic literature on the effects of skill mismatch (e.g. Allen \& van der Velden, 20oI; McGuinness et al., 20I7; SánchezSánchez \& McGuinness, 2015) by investigating skill misallocation with respect to graduates' involvement in innovative tasks.

\subsubsection{Implications for further research}

Our results provide a stepping stone for research on who to recruit for a given objective, which is, as far as we know, almost non-existent (Breaugh, 2008). This also holds for research on how to select talent for innovation (Hunter et al., 20I2). Therefore, future research should investigate the effects of recruitment focused on intrapreneurial skills by, for example, investigating the performance of new hires with different intrapreneurial skills in product and service innovation and process innovation.

In addition, future research should investigate the broader consequences of the underutilization of intrapreneurial skills for both employees and firms with regard to wages, promotions, turnover intention, voluntary job quits, job performance, and innovation. For instance, underutilization of intrapreneurial skills for innovation could be part of a transitory process for young graduates in the labour market. Humburg and van der Velden (20I5) show that, in the recruitment of recent graduates, creative and entrepreneurial skills are not regarded as essential skills by employers but do play an important role in promotion decisions in later career stages. Although skill underutilization is often quite persistent (Cedefop, 20I5; Mavromaras et al., 20I3), it would be interesting to see if intrapreneurial skill mismatches are, to some extent, resolved in later stages of graduates' careers.

Although not the focus of this chapter, we also showed that graduates who experience creative skill deficits are more often involved in all types of innovation, compared to graduates whose creative skills are well matched to their jobs' requirements. Future research could investigate why those with lower creative skill levels are allocated to innovative tasks. A possible mechanism is that graduates with a lower level of creative skills are challenged to involve themselves more than wellmatched graduates in learning activities (Allen \& de Grip, 20I2; van der Velden \& Verhaest, 20I7) that are beneficial for their involvement in innovation (Hargadon, 2002).

Moreover, our findings highlight the relevance of the context in which innovative behaviour arises. In this chapter, we take into account the match between the level of employees' intrapreneurial skills and the intrapreneurial skills required in their jobs and control for various job and company characteristics. However, since innovation activities in organizations mostly take place in teams, there is ample scope for future research to investigate the effects of allocation of intrapreneurial skills on innovation 
in different team settings with respect to, for example, the age/experience structure of the team and mono- versus multidisciplinary teams.

In addition, gender differences in the allocation of workers to innovation activities represent an interesting avenue for future research. From our analysis, it is not clear what factors drive these differences. In line with our results, Parker (20II) finds that women are generally less involved in both intrapreneurial and entrepreneurial activities, but the author does not explain this finding. Adachi and Hisada (2017) also find that women are less likely to be involved in intrapreneurial activities. Moreover, they find that factors related to women's work environment - but not family-related factors - can have a positive effect on closing this gender gap. However, their analysis also suggests that women's positions could be disadvantageous for their involvement in innovation. Future research could therefore aim to investigate what drives these gender differences.

\subsubsection{Implications for firms and higher education}

Our results also suggest that it could be beneficial for companies to invest in further developing the intrapreneurial skills of their higher-educated employees in both STEM and business occupations. However, our results suggest that this training should focus on different intrapreneurial skills for graduates in business occupations and those in STEM occupations. Moreover, this training should be further tailored by taking into account the intrapreneurial skill levels of the employees, the skills demands in their job, and the type of innovation envisioned.

Our finding that intrapreneurial skills are underutilized in firms' innovation processes suggests that firms could make more efficient use of their intrapreneurial talent by allocating more employees with higher levels of intrapreneurial skills to innovative tasks. Our results particularly suggest that firms can make more efficient use of employees with higher creative and championing skills in product and service innovation and in process innovation in knowledge and methods.

Finally, our results are relevant to those in charge of the design of study curricula in higher education by showing that the innovative potential of students could be increased by fostering their creativity, championing, and brokering skills. This holds particularly for students in STEM and business studies. 


\subsection{Appendix}

Table A3.1 - Skill levels in 2005 and 2016

\begin{tabular}{l|c|c} 
& Skill levels 2005 & $\begin{array}{c}\text { Skill levels 2016 } \\
\text { (highly educated) } \\
\text { Mean (SD) }\end{array}$ \\
Creative skills & Mean (SD) & 8.13 \\
Championing skills & 8.20 & $(1.26)$ \\
& $(1.00)$ & 5.97 \\
Non-intrapreneurial skills & 5.85 & $(1.34)$ \\
& $(1.25)$ & 6.22 \\
N & $6.60^{* * *}$ & $(1.04)$ \\
Data source & $(1.06)$ & 275 \\
& 4118 & Proprietary data gathered by \\
& REFLEX survey & author in collaboration with Etil \\
\end{tabular}

Note: Skills are constructed using the same items as in the REFLEX survey. ${ }^{*} p<0.10,{ }^{* *} p<0.05,{ }^{* * *} p<0.01$

Table A3.2 - 0LS regression of creative, championing and non-intrapreneurial skills on workers' involvement in innovation in 2016

\begin{tabular}{l|c|c} 
& $(1)$ & $(2)$ \\
Creative skills & All employees & Higher educated employees \\
Championing skills & $0.077^{* *}$ & $0.090^{* *}$ \\
& $(0.030)$ & $(0.046)$ \\
Non-intrapreneurial skills & $0.086^{* * *}$ & $0.096^{* * *}$ \\
& $(0.022)$ & $(0.036)$ \\
Age & $-0.048^{*}$ & -0.057 \\
& $(0.025)$ & $(0.044)$ \\
Female & 0.003 & 0.003 \\
Tenure & $(0.002)$ & $(0.003)$ \\
& -0.017 & -0.030 \\
Higher education & $(0.038)$ & $(0.064)$ \\
& 0.001 & 0.000 \\
Constant & $(0.002)$ & $(0.003)$ \\
& $0.175^{* * *}$ & \\
\hline Controls for sector & $(0.040)$ & \\
N & 0.114 & $0.292^{*}$ \\
\hline
\end{tabular}

Note: Robust standard errors in parentheses. Skills are constructed using the same items as in the REFLEX survey.

${ }^{*} p<0.10,{ }^{* *} p<0.05,{ }^{* * *} p<0.01$. Source: Proprietary data gathered by authors in collaboration with Etil research group. 


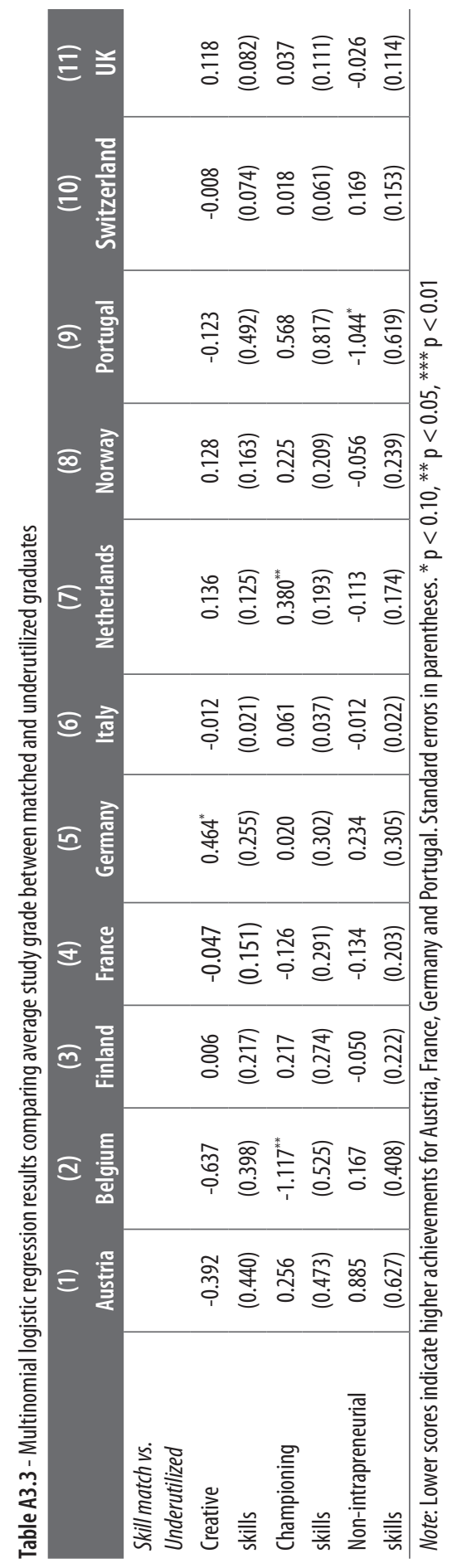


Table A3.4 - Logit estimations for being involved in (different types of) innovation

\begin{tabular}{|c|c|c|c|c|}
\hline & $\begin{array}{l}\text { Any type of } \\
\text { Innovation }\end{array}$ & $\begin{array}{c}\text { Product \& services } \\
\text { innovations }\end{array}$ & $\begin{array}{l}\text { Process inn } \\
\text { Technology, tools \& } \\
\text { instruments }\end{array}$ & $\begin{array}{l}\text { vations } \\
\text { Knowledge \& } \\
\text { methods }\end{array}$ \\
\hline Skills & (1) & $(2)$ & (3) & (4) \\
\hline Creative skills & $\begin{array}{c}0.424^{* * *} \\
(0.067)\end{array}$ & $\begin{array}{c}0.175^{* * *} \\
(0.063)\end{array}$ & $\begin{array}{c}0.364^{* * *} \\
(0.067)\end{array}$ & $\begin{array}{c}0.313^{* * *} \\
(0.066)\end{array}$ \\
\hline Brokering skills & $\begin{array}{c}0.479^{* * *} \\
(0.084)\end{array}$ & $\begin{array}{c}0.443^{* * *} \\
(0.079)\end{array}$ & $\begin{array}{c}0.350^{* * *} \\
(0.087)\end{array}$ & $\begin{array}{c}0.513^{* * *} \\
(0.081)\end{array}$ \\
\hline Championing skills & $\begin{array}{c}0.295^{* * *} \\
(0.071)\end{array}$ & $\begin{array}{c}0.443^{* * *} \\
(0.065)\end{array}$ & $\begin{array}{c}0.280^{* * *} \\
(0.069)\end{array}$ & $\begin{array}{c}0.263^{* * *} \\
(0.070)\end{array}$ \\
\hline $\begin{array}{l}\text { Non-intrapreneurial skills } \\
\text { Occupation }\end{array}$ & $\begin{array}{c}-0.228^{* * *} \\
(0.061)\end{array}$ & $\begin{array}{c}-0.173^{* * *} \\
(0.058)\end{array}$ & $\begin{array}{c}-0.232^{* * *} \\
(0.063)\end{array}$ & $\begin{array}{c}-0.213^{* * *} \\
(0.060)\end{array}$ \\
\hline $\begin{array}{l}\text { STEM, ref. = Business } \\
\text { Interactions }\end{array}$ & $\begin{array}{c}0.652^{* * *} \\
(0.101)\end{array}$ & $\begin{array}{l}0.167^{* * *} \\
(0.083)\end{array}$ & $\begin{array}{c}0.968^{* * *} \\
(0.087)\end{array}$ & $\begin{array}{l}0.130 \\
(0.087)\end{array}$ \\
\hline STEM $^{*}$ creative skills & $\begin{array}{l}-0.011 \\
(0.095)\end{array}$ & $\begin{array}{c}0.044 \\
(0.086)\end{array}$ & $\begin{array}{l}-0.004 \\
(0.089)\end{array}$ & $\begin{array}{l}-0.001 \\
(0.087)\end{array}$ \\
\hline STEM*brokering skills & $\begin{array}{l}-0.019 \\
(0.121)\end{array}$ & $\begin{array}{l}-0.024 \\
(0.108)\end{array}$ & $\begin{array}{c}0.184 \\
(0.114)\end{array}$ & $\begin{array}{l}-0.195^{*} \\
(0.109)\end{array}$ \\
\hline STEM $^{*}$ championing skills & $\begin{array}{l}-0.022 \\
(0.100)\end{array}$ & $\begin{array}{l}-0.151^{*} \\
(0.087)\end{array}$ & $\begin{array}{l}-0.231^{* *} \\
(0.090)\end{array}$ & $\begin{array}{l}-0.117 \\
(0.091)\end{array}$ \\
\hline STEM ${ }^{*}$ non-intrapreneurial skills & $\begin{array}{c}0.067 \\
(0.090)\end{array}$ & $\begin{array}{c}0.090 \\
(0.079)\end{array}$ & $\begin{array}{l}0.181^{* *} \\
(0.084)\end{array}$ & $\begin{array}{c}0.118 \\
(0.081)\end{array}$ \\
\hline Skill-job match, ref. = match & & & & \\
\hline Creative skills, underutilized & $\begin{array}{c}-0.623^{* * *} \\
(0.155)\end{array}$ & $\begin{array}{c}-0.363^{* * *} \\
(0.139)\end{array}$ & $\begin{array}{l}-0.235 \\
(0.146)\end{array}$ & $\begin{array}{c}-0.401^{* * *} \\
(0.141)\end{array}$ \\
\hline Championing skills, underutilized & $\begin{array}{c}-0.606^{* * *} \\
(0.186)\end{array}$ & $\begin{array}{c}-0.602^{* * *} \\
(0.178)\end{array}$ & $\begin{array}{l}-0.329^{*} \\
(0.186)\end{array}$ & $\begin{array}{c}-0.538^{* * *} \\
(0.183)\end{array}$ \\
\hline Non-intrap. skills, underutilized & $\begin{array}{c}0.142 \\
(0.179)\end{array}$ & $\begin{array}{l}0.337^{* *} \\
(0.160)\end{array}$ & $\begin{array}{c}0.205 \\
(0.166)\end{array}$ & $\begin{array}{c}0.036 \\
(0.164)\end{array}$ \\
\hline $\begin{array}{l}\text { Control variables } \\
\text { Creative skills deficit }\end{array}$ & $0394 * *$ & $0311^{*}$ & $0555^{* * *}$ & $0466 * * *$ \\
\hline & $(0.174)$ & $(0.161)$ & $(0.172)$ & $(0.172)$ \\
\hline Championing skills, deficit & $\begin{array}{l}-0.018 \\
(0.187)\end{array}$ & $\begin{array}{c}0.210 \\
(0.180)\end{array}$ & $\begin{array}{l}-0.058 \\
(0.190)\end{array}$ & $\begin{array}{c}0.235 \\
(0.181)\end{array}$ \\
\hline Non-intrap. skills, deficit & $\begin{array}{l}-0.324^{*} \\
(0.172)\end{array}$ & $\begin{array}{l}-0.149 \\
(0.156)\end{array}$ & $\begin{array}{l}-0.052 \\
(0.165)\end{array}$ & $\begin{array}{c}-0.316^{* *} \\
(0.161)\end{array}$ \\
\hline Supervisor, ref. $=$ No supervisor & $\begin{array}{c}0.398^{* * *} \\
(0.094)\end{array}$ & $\begin{array}{c}0.224^{* * *} \\
(0.079)\end{array}$ & $\begin{array}{c}0.351^{* * *} \\
(0.082)\end{array}$ & $\begin{array}{c}0.471^{* * *} \\
(0.083)\end{array}$ \\
\hline Female, $r e f .=$ Male & $\begin{array}{c}-0.262^{* * *} \\
(0.093)\end{array}$ & $\begin{array}{c}-0.354^{* * *} \\
(0.083)\end{array}$ & $\begin{array}{c}-0.591^{* * *} \\
(0.087)\end{array}$ & $\begin{array}{c}-0.157^{*} \\
(0.087)\end{array}$ \\
\hline Autonomy & $\begin{array}{c}0.310^{* * *} \\
(0.046)\end{array}$ & $\begin{array}{c}0.197^{* * *} \\
(0.043)\end{array}$ & $\begin{array}{c}0.067 \\
(0.045)\end{array}$ & $\begin{array}{c}0.315^{* * *} \\
(0.044)\end{array}$ \\
\hline Tenure & $\begin{array}{l}-0.012 \\
(0.028)\end{array}$ & $\begin{array}{c}0.037 \\
(0.025)\end{array}$ & $\begin{array}{c}0.083^{* * *} \\
(0.026)\end{array}$ & $\begin{array}{c}-0.044^{*} \\
(0.026)\end{array}$ \\
\hline Tenure $^{2}$ & $\begin{array}{l}-0.000 \\
(0.001)\end{array}$ & $\begin{array}{l}-0.002 \\
(0.001)\end{array}$ & $\begin{array}{l}-0.003^{* *} \\
(0.001)\end{array}$ & $\begin{array}{c}0.002 \\
(0.001)\end{array}$ \\
\hline Entrepreneurial education & $\begin{array}{l}-0.040 \\
(0.044)\end{array}$ & $\begin{array}{l}-0.058 \\
(0.039)\end{array}$ & $\begin{array}{c}0.031 \\
(0.040)\end{array}$ & $\begin{array}{c}0.009 \\
(0.040)\end{array}$ \\
\hline Constant & $\begin{array}{c}3.562^{* * *} \\
(1.078)\end{array}$ & $\begin{array}{c}2.067^{* * *} \\
(0.686)\end{array}$ & $\begin{array}{l}1.157^{*} \\
(0.595)\end{array}$ & $\begin{array}{c}2.678^{* * *} \\
(0.754)\end{array}$ \\
\hline $\begin{array}{l}\text { Controls } \\
\text { Observations } \\
\text { Pseudo R-squared }\end{array}$ & $\begin{array}{c}\text { Yes } \\
4112 \\
0.160\end{array}$ & $\begin{array}{c}\text { Yes } \\
3829 \\
0.123\end{array}$ & $\begin{array}{c}\text { Yes } \\
3674 \\
0.144\end{array}$ & $\begin{array}{c}\text { Yes } \\
3821 \\
0.127\end{array}$ \\
\hline
\end{tabular}

Note: Robust standard errors in parentheses. Estimations performed with standardized independent variables. ${ }^{*} p<0.10$,

${ }^{* *} p<0.05,{ }^{* * *} p<0.01$ 
Table A3.5 - Multinomial logistic regression results comparing the level of entrepreneurial education between mismatch categories.

\begin{tabular}{l|c|c|c}
\multicolumn{1}{c}{} & \multicolumn{1}{c}{$(1)$} & $(2)$ & $(3)$ \\
\multicolumn{1}{l}{ Creative skills } & \multicolumn{1}{c}{ Championing skills } & Non-intrapreneurial skills \\
Underutilized & & & \\
& 0.030 & -0.030 & 0.031 \\
Constant & $(0.048)$ & $(0.061)$ & $(0.056)$ \\
& $-2.350^{* * *}$ & $-2.749^{* * *}$ & $-2.705^{* * *}$ \\
Skills match vs. & $(0.142)$ & $(0.175)$ & $(0.165)$ \\
Skill deficit & & & \\
& $-0.198^{* * *}$ & $-0.154^{* *}$ & $-0.257^{* * *}$ \\
Constant & $(0.058)$ & $(0.066)$ & $(0.058)$ \\
& $-2.074^{* * *}$ & $-2.538^{* * *}$ & $-1.938^{* * *}$ \\
\hline $\mathrm{N}$ & $(0.154)$ & $(0.178)$ & $(0.151)$ \\
\hline
\end{tabular}

Note: Standard errors in parentheses ${ }^{*} p<0.10,{ }^{* *} p<0.05,{ }^{* * *} p<0.01$ 
Table A3.6 - LPM estimations for being involved in (different types of) innovation, full output.

\begin{tabular}{|c|c|c|c|c|}
\hline & Any type of & Product \& service & Process in & ovations \\
\hline & & & $\begin{array}{l}\text { Technology, tools } \\
\text { \& instruments }\end{array}$ & $\begin{array}{l}\text { Knowledge \& } \\
\text { methods }\end{array}$ \\
\hline & (1) & (2) & (3) & (4) \\
\hline Skills & & & & \\
\hline Creative skills & $\begin{array}{c}0.067^{* * * *} \\
(0.011)\end{array}$ & $\begin{array}{c}0.035^{* * *} \\
(0.013)\end{array}$ & $\begin{array}{c}0.072^{* * * *} \\
(0.013)\end{array}$ & $\begin{array}{c}0.060^{* * *} \\
(0.013)\end{array}$ \\
\hline Brokering skills & $\begin{array}{c}0.085^{* * *} \\
(0.014)\end{array}$ & $\begin{array}{c}0.090^{* * *} \\
(0.016)\end{array}$ & $\begin{array}{c}0.065^{* * * *} \\
(0.016)\end{array}$ & $\begin{array}{c}0.099^{* * *} \\
(0.016)\end{array}$ \\
\hline Championing skills & $\begin{array}{c}0.055^{* * *} \\
(0.012)\end{array}$ & $\begin{array}{c}0.091^{* * *} \\
(0.013)\end{array}$ & $\begin{array}{c}0.051^{* * *} \\
(0.013)\end{array}$ & $\begin{array}{c}0.051^{* * *} \\
(0.013)\end{array}$ \\
\hline Non-intrapreneurial skills & $\begin{array}{c}-0.041^{* * *} \\
(0.010)\end{array}$ & $\begin{array}{c}-0.036^{* * *} \\
(0.012)\end{array}$ & $\begin{array}{c}-0.043^{* * *} \\
(0.012)\end{array}$ & $\begin{array}{c}-0.042^{* * *} \\
(0.012)\end{array}$ \\
\hline Occupation & & & & \\
\hline $\begin{array}{l}\text { STEM, ref. = Business } \\
\text { Interactions }\end{array}$ & $\begin{array}{c}0.102^{* * * *} \\
(0.014)\end{array}$ & $\begin{array}{l}0.036^{* *} \\
(0.017)\end{array}$ & $\begin{array}{c}0.203^{* * * *} \\
(0.018)\end{array}$ & $\begin{array}{l}0.034^{* *} \\
(0.017)\end{array}$ \\
\hline STEM*creative skills & $\begin{array}{l}-0.009 \\
(0.015)\end{array}$ & $\begin{array}{c}0.012 \\
(0.018)\end{array}$ & $\begin{array}{c}0.005 \\
(0.018)\end{array}$ & $\begin{array}{c}0.000 \\
(0.017)\end{array}$ \\
\hline STEM*brokering skills & $\begin{array}{l}-0.021 \\
(0.019)\end{array}$ & $\begin{array}{c}0.001 \\
(0.022)\end{array}$ & $\begin{array}{l}0.051^{* *} \\
(0.022)\end{array}$ & $\begin{array}{l}-0.035 \\
(0.022)\end{array}$ \\
\hline STEM*championing skills & $\begin{array}{l}-0.020 \\
(0.016)\end{array}$ & $\begin{array}{l}-0.028 \\
(0.017)\end{array}$ & $\begin{array}{l}-0.041^{* *} \\
(0.018)\end{array}$ & $\begin{array}{l}-0.022 \\
(0.018)\end{array}$ \\
\hline STEM*non-intrapreneurial skills & $\begin{array}{l}0.018 \\
(0.014)\end{array}$ & $\begin{array}{l}0.018 \\
(0.017)\end{array}$ & $\begin{array}{l}0.031^{*} \\
(0.017)\end{array}$ & $\begin{array}{l}0.023 \\
(0.016)\end{array}$ \\
\hline Skill mismatch, ref. $=$ match & & & & \\
\hline Creative skills, underutilized & $\begin{array}{c}-0.099 * * * \\
(0.025)\end{array}$ & $\begin{array}{c}-0.076^{* * *} \\
(0.029)\end{array}$ & $\begin{array}{l}-0.047 \\
(0.030)\end{array}$ & $\begin{array}{c}-0.078^{* * *} \\
(0.028)\end{array}$ \\
\hline Championing skills, underutilized & $\begin{array}{c}-0.104^{* * * *} \\
(0.032)\end{array}$ & $\begin{array}{c}-0.125^{* * *} \\
(0.037)\end{array}$ & $\begin{array}{l}-0.062^{*} \\
(0.037)\end{array}$ & $\begin{array}{c}-0.108^{* * *} \\
(0.038)\end{array}$ \\
\hline Non-intrap. skills, underutilized & $\begin{array}{c}0.026 \\
(0.028)\end{array}$ & $\begin{array}{l}0.071^{* *} \\
(0.034)\end{array}$ & $\begin{array}{c}0.039 \\
(0.034)\end{array}$ & $\begin{array}{c}0.007 \\
(0.033)\end{array}$ \\
\hline Control variables & & & & \\
\hline Creative skills, deficit & $\begin{array}{l}0.056^{*} \\
(0.029)\end{array}$ & $\begin{array}{l}0.070^{* *} \\
(0.034)\end{array}$ & $\begin{array}{c}0.118^{* * * *} \\
(0.034)\end{array}$ & $\begin{array}{c}0.093^{* * *} \\
(0.034)\end{array}$ \\
\hline Championing skills, deficit & $\begin{array}{l}-0.006 \\
(0.034)\end{array}$ & $\begin{array}{c}0.043 \\
(0.038)\end{array}$ & $\begin{array}{l}-0.012 \\
(0.037)\end{array}$ & $\begin{array}{c}0.045 \\
(0.036)\end{array}$ \\
\hline Non-intrap. skills, deficit & $\begin{array}{l}-0.052^{*} \\
(0.028)\end{array}$ & $\begin{array}{l}-0.033 \\
(0.033)\end{array}$ & $\begin{array}{l}-0.016 \\
(0.034)\end{array}$ & $\begin{array}{l}-0.063^{*} \\
(0.032)\end{array}$ \\
\hline Supervisor, ref. $=$ No supervisor & $\begin{array}{c}0.054^{* * *} \\
(0.014)\end{array}$ & $\begin{array}{c}0.048^{* * *} \\
(0.017)\end{array}$ & $\begin{array}{c}0.075^{* * *} \\
(0.017)\end{array}$ & $\begin{array}{c}0.090^{* * * *} \\
(0.016)\end{array}$ \\
\hline Female, ref.=Male & $-0.043^{* * *}$ & $-0.075^{* * *}$ & $-0.122^{* * *}$ & $-0.030^{*}$ \\
\hline & $(0.015)$ & $(0.018)$ & $(0.018)$ & $(0.017)$ \\
\hline Autonomy & $\begin{array}{c}0.055^{* * *} \\
(0.008)\end{array}$ & $\begin{array}{c}0.041^{* * *} \\
(0.009)\end{array}$ & $\begin{array}{c}0.013 \\
(0.009)\end{array}$ & $\begin{array}{c}0.065^{* * *} \\
(0.009)\end{array}$ \\
\hline Tenure & $\begin{array}{l}-0.002 \\
(0.004)\end{array}$ & $\begin{array}{c}0.008 \\
(0.005)\end{array}$ & $\begin{array}{c}0.017^{* * *} \\
(0.005)\end{array}$ & $\begin{array}{l}-0.009^{*} \\
(0.005)\end{array}$ \\
\hline Tenure $^{2}$ & $\begin{array}{l}-0.000 \\
(0.000)\end{array}$ & $\begin{array}{l}-0.000 \\
(0.000)\end{array}$ & $\begin{array}{c}-0.001^{* *} \\
(0.000)\end{array}$ & $\begin{array}{c}0.000 \\
(0.000)\end{array}$ \\
\hline Entrepreneurial education & $\begin{array}{l}-0.006 \\
(0.007)\end{array}$ & $\begin{array}{l}-0.012 \\
(0.008)\end{array}$ & $\begin{array}{c}0.006 \\
(0.008)\end{array}$ & $\begin{array}{c}0.001 \\
(0.008)\end{array}$ \\
\hline
\end{tabular}


Table A3.6 - LPM estimations for being involved in (different types of) innovation, full output. Continued

\begin{tabular}{|c|c|c|c|c|}
\hline & \multirow{2}{*}{$\begin{array}{l}\text { Any type of } \\
\text { innovation }\end{array}$} & \multirow{2}{*}{$\begin{array}{l}\text { Product \& service } \\
\text { innovation }\end{array}$} & \multicolumn{2}{|c|}{ Process innovations } \\
\hline & & & $\begin{array}{l}\text { Technology, tools } \\
\text { \& instruments }\end{array}$ & $\begin{array}{l}\text { Knowledge \& } \\
\text { methods }\end{array}$ \\
\hline Organizational size, ref. $=<10$ & (1) & (2) & (3) & (4) \\
\hline $10-49$ & $\begin{array}{l}-0.013 \\
(0.027)\end{array}$ & $\begin{array}{l}-0.041 \\
(0.034)\end{array}$ & $\begin{array}{c}-0.115^{* * *} \\
(0.035)\end{array}$ & $\begin{array}{c}-0.088^{* * *} \\
(0.030)\end{array}$ \\
\hline $50-99$ & $\begin{array}{l}-0.018 \\
(0.031)\end{array}$ & $\begin{array}{c}-0.112^{* * *} \\
(0.038)\end{array}$ & $\begin{array}{c}-0.151^{* * *} \\
(0.040)\end{array}$ & $\begin{array}{c}-0.118^{* * *} \\
(0.035)\end{array}$ \\
\hline $100-249$ & $\begin{array}{l}-0.029 \\
(0.030)\end{array}$ & $\begin{array}{c}-0.107^{* * *} \\
(0.037)\end{array}$ & $\begin{array}{c}-0.163^{* * *} \\
(0.037)\end{array}$ & $\begin{array}{c}-0.146^{* * *} \\
(0.034)\end{array}$ \\
\hline 250-999 & $\begin{array}{l}-0.073^{* *} \\
(0.029)\end{array}$ & $\begin{array}{c}-0.157^{* * *} \\
(0.035)\end{array}$ & $\begin{array}{c}-0.185^{* * *} \\
(0.036)\end{array}$ & $\begin{array}{c}-0.200^{* * *} \\
(0.032)\end{array}$ \\
\hline$>1000$ & $\begin{array}{c}-0.071^{* * *} \\
(0.026)\end{array}$ & $\begin{array}{c}-0.200^{* * *} \\
(0.031)\end{array}$ & $\begin{array}{c}-0.215^{* * *} \\
(0.031)\end{array}$ & $\begin{array}{c}-0.189^{* * *} \\
(0.028)\end{array}$ \\
\hline $\begin{array}{l}\text { Sector, ref. = Agriculture, hunting and } \\
\text { forestry }\end{array}$ & & & & \\
\hline Fishing & $\begin{array}{c}0.061 \\
(0.077)\end{array}$ & $\begin{array}{c}-0.432^{* *} \\
(0.183)\end{array}$ & $\begin{array}{l}-0.317 \\
(0.253)\end{array}$ & $\begin{array}{c}0.031 \\
(0.224)\end{array}$ \\
\hline Mining and quarrying & $\begin{array}{c}-0.266^{* * *} \\
(0.087)\end{array}$ & $\begin{array}{l}-0.292^{* *} \\
(0.132)\end{array}$ & $\begin{array}{l}-0.255^{*} \\
(0.131)\end{array}$ & $\begin{array}{l}-0.128 \\
(0.118)\end{array}$ \\
\hline Manufacturing & $\begin{array}{c}-0.156^{* * *} \\
(0.056)\end{array}$ & $\begin{array}{l}-0.163 \\
(0.104)\end{array}$ & $\begin{array}{l}-0.184^{*} \\
(0.103)\end{array}$ & $\begin{array}{l}-0.160^{*} \\
(0.095)\end{array}$ \\
\hline Electricity, gas and water supply & $\begin{array}{c}-0.270^{* * *} \\
(0.083)\end{array}$ & $\begin{array}{l}-0.283^{* *} \\
(0.120)\end{array}$ & $\begin{array}{l}-0.158 \\
(0.117)\end{array}$ & $\begin{array}{l}-0.144 \\
(0.119)\end{array}$ \\
\hline Wholesale and retail trade & $\begin{array}{c}-0.322^{* * *} \\
(0.064)\end{array}$ & $\begin{array}{c}-0.381^{* * *} \\
(0.111)\end{array}$ & $\begin{array}{c}-0.304^{* * *} \\
(0.109)\end{array}$ & $\begin{array}{l}-0.225^{* *} \\
(0.100)\end{array}$ \\
\hline Hotels and restaurants & $\begin{array}{l}-0.152^{* *} \\
(0.060)\end{array}$ & $\begin{array}{l}-0.209^{*} \\
(0.108)\end{array}$ & $\begin{array}{l}-0.241^{* *} \\
(0.106)\end{array}$ & $\begin{array}{l}-0.175^{*} \\
(0.098)\end{array}$ \\
\hline Transport, storage and communication & $\begin{array}{l}-0.194^{*} \\
(0.105)\end{array}$ & $\begin{array}{l}-0.171 \\
(0.139)\end{array}$ & $\begin{array}{l}-0.206 \\
(0.150)\end{array}$ & $\begin{array}{l}-0.139 \\
(0.134)\end{array}$ \\
\hline Financial intermediation & $\begin{array}{c}-0.172^{* * *} \\
(0.059)\end{array}$ & $\begin{array}{l}-0.150 \\
(0.107)\end{array}$ & $\begin{array}{l}-0.155 \\
(0.106)\end{array}$ & $\begin{array}{l}-0.199^{* *} \\
(0.098)\end{array}$ \\
\hline Real estate, renting and business activities & $\begin{array}{c}-0.243^{* * *} \\
(0.058)\end{array}$ & $\begin{array}{c}-0.276^{* * *} \\
(0.106)\end{array}$ & $\begin{array}{l}-0.235^{* *} \\
(0.104)\end{array}$ & $\begin{array}{l}-0.215^{* *} \\
(0.096)\end{array}$ \\
\hline Public administration and defense & $\begin{array}{c}-0.249^{* * * *} \\
(0.055)\end{array}$ & $\begin{array}{l}-0.244^{* *} \\
(0.104)\end{array}$ & $\begin{array}{l}-0.260^{* *} \\
(0.102)\end{array}$ & $\begin{array}{l}-0.201^{* *} \\
(0.094)\end{array}$ \\
\hline Education & $\begin{array}{l}-0.251^{* *} \\
(0.112)\end{array}$ & $\begin{array}{l}-0.255 \\
(0.159)\end{array}$ & $\begin{array}{c}-0.443^{* * *} \\
(0.162)\end{array}$ & $\begin{array}{l}-0.091 \\
(0.145)\end{array}$ \\
\hline Health and social work & $\begin{array}{l}-0.140^{*} \\
(0.082)\end{array}$ & $\begin{array}{l}-0.287^{* *} \\
(0.139)\end{array}$ & $\begin{array}{l}-0.109 \\
(0.135)\end{array}$ & $\begin{array}{l}-0.252^{*} \\
(0.133)\end{array}$ \\
\hline $\begin{array}{l}\text { Other community, social and personal } \\
\text { service activities }\end{array}$ & $\begin{array}{l}-0.242^{* *} \\
(0.101)\end{array}$ & $\begin{array}{l}-0.069 \\
(0.142)\end{array}$ & $\begin{array}{l}-0.274^{*} \\
(0.148)\end{array}$ & $\begin{array}{l}-0.058 \\
(0.121)\end{array}$ \\
\hline Extraterritorial organizations and bodies & $\begin{array}{l}-0.180^{* *} \\
(0.082)\end{array}$ & $\begin{array}{l}-0.191 \\
(0.132)\end{array}$ & $\begin{array}{l}-0.333^{* *} \\
(0.129)\end{array}$ & $\begin{array}{l}-0.199^{*} \\
(0.117)\end{array}$ \\
\hline $\begin{array}{l}\text { Country, ref. = the Netherlands } \\
\text { Italy }\end{array}$ & $\begin{array}{c}0.006 \\
(0.028)\end{array}$ & $\begin{array}{c}-0.079^{* *} \\
(0.033)\end{array}$ & $\begin{array}{l}-0.028 \\
(0.033)\end{array}$ & $\begin{array}{c}0.030 \\
(0.032)\end{array}$ \\
\hline France & $\begin{array}{c}0.049 \\
(0.032)\end{array}$ & $\begin{array}{l}-0.022 \\
(0.038)\end{array}$ & $\begin{array}{l}0.037 \\
(0.039)\end{array}$ & $\begin{array}{l}0.031 \\
(0.037)\end{array}$ \\
\hline Austria & $-0.085^{* * *}$ & $-0.095 * * *$ & $-0.111^{* * *}$ & $-0.111^{* * *}$ \\
\hline
\end{tabular}


Table A3.6 - LPM estimations for being involved in (different types of) innovation, full output. Continued

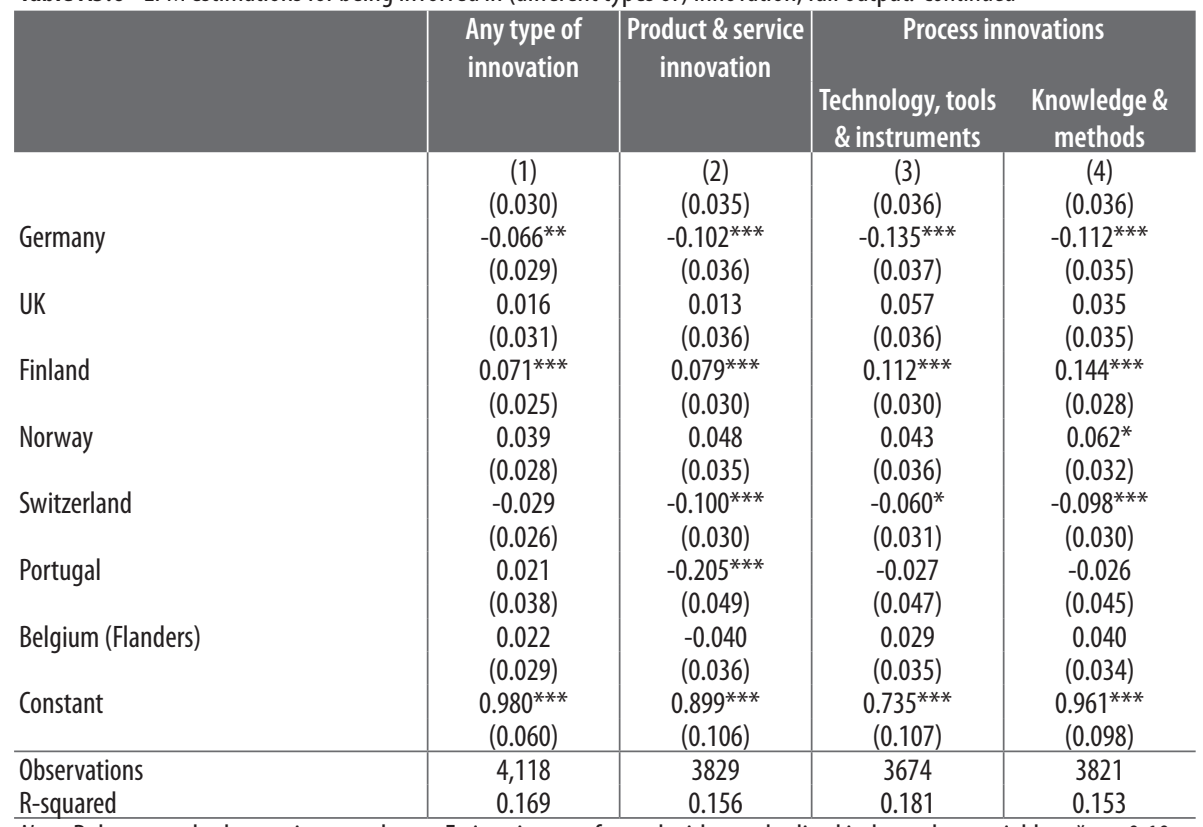

Note: Robust standard errors in parentheses. Estimations performed with standardized independent variables. * $\mathrm{p}<0.10$, ${ }^{* *} p<0.05,{ }^{* * *} p<0.01$ 



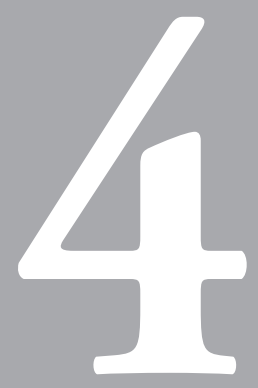

\section{The relevance of the Big Five personality traits, risk tolerance and perceived organisational support for intrapreneurial behaviour}

I thank Boris Blumberg, Andries de Grip, Ruud Gerards, Julia Kensbock, Bart de Koning, Miquelle Marchand, Pomme Theunissen and Nardo de Vries for helpful comments and suggestions. 


\subsection{Introduction}

Although entrepreneurship is usually associated with independent business ownership, entrepreneurship and entrepreneurial behaviour can also take place in the context of the established firm. This is then referred to as intrapreneurship (Pinchot, 1985). Stam (2013) finds that in advanced economies, intrapreneurship is even more prevalent than independent entrepreneurship. However, Bosma et al. (2010) show that only five percent of all employees are involved in intrapreneurial activities. In order to stimulate intrapreneurial behaviour among employees, it is essential to understand the interplay between individual and contextual drivers of intrapreneurship (e.g. Blanka, 20I8; Mustafa et al., 20I8). Therefore, we investigate whether the Big Five personality traits and risk tolerance are related to intrapreneurial behaviour. In addition, we investigate the relations between employees' perceptions of organisational support for intrapreneurship and their intrapreneurial behaviour and how these perceptions affect the relations between personality and intrapreneurial behaviour.

Personality traits are relevant in explaining individual differences in occupational choices (Holland, 1997) work behaviours and performance (Tett \& Burnett, 2003; Zhao \& Seibert, 2006). Many studies investigate the role of personality in workers' choice for entrepreneurship (e.g. Caliendo et al., 20I4; Zhao \& Seibert, 2006; Zhao et al., 20IO). In addition, several personality traits are considered to be indispensable elements of the intrapreneurial skillset (Hayton \& Kelley, 2006; Farruhk et al., 20I6).

Relatively few studies however, have empirically investigated the relation between personality traits and intrapreneurship. Several of these studies focus on the relation between the Big Five personality characteristics and intrapreneurship (e.g. Sinha \& Strivastava, 2013; Woo, 20I8). The outcomes of these studies show positive relations between Extraversion and and intrapreneurship, but are inconsistent for the relations of the other Big Five personality traits. In addition, these studies have all been conducted in the Asian context. However, since national cultures affect innovation outcomes at the national level (Shane, 1993) and effective organisational behaviours in the innovation process also differ across cultures (Shane, 1994), the relationships between personality characteristics and behavioural outcomes may also differ across national cultures (Sinha, 2009), making generalisability across cultural contexts problematic. Other studies investigate the relation between risk tolerance and intrapreneurship (e.g. Douglas \& Fitzsimmons, 2013). These studies find a positive relation of risk tolerance with intrapreneurship, but do not account for the Big Five personality traits in their analyses. We therefore investigate the relation between the Big Five and risk tolerance with intrapreneurial behaviour simultaneously using a sample from the Netherlands.

In addition, previous studies show that intrapreneurial behaviour is influenced by organisational factors such as management support for intrapreneurship, rewards and resource endowments (see Mustafa et al., 20I8, for a review). However, not much is 
known about the interplay between individual and contextual factors in explaining intrapreneurial behaviour. Therefore, we investigate the influence of perceived organisational support for intrapreneurship on intrapreneurial behaviour and how these perceptions affect the relations between personality and intrapreneurial behaviour. In doing so, we build on two models that attempt to explain behaviour in organisations. First, we build on the attraction-selection-attrition model (Schneider, 1987) which can be used to explain why we may observe differences in employee behaviours across organisations. Second, we build on trait activation theory (Tett \& Burnett, 2003), which suggests that the organisational environment is essential in explaining the relation between personality and employee level outcomes such as intrapreneurial behaviour.

We use data from a sample of $\mathrm{I}, 557$ workers of the Dutch population in dependent or independent employment whom are included in the LISS (Longitudinal Internet Studies for the Social sciences) household panel. Taking into account selection into dependent employment, the results of this chapter show that employees with higher levels of Openness, Extraversion and general and career related risk tolerance, show higher levels of intrapreneurial behaviour one year later. As expected, we find that employees who perceive higher levels of organisational support for intrapreneurship (i.e. rewards, time and financial resources), have higher levels of intrapreneurial behaviour. Moreover, we find that these perceptions moderate the relation between Openness and intrapreneurial behaviour. Additionally, we compare employees with high levels of intrapreneurial behaviour with entrepreneurs. We find that intrapreneurs have comparable levels of Neuroticism, Extraversion, Agreeableness and risk tolerance as entrepreneurs, but higher levels of Openness and Conscientiousness.

The findings of this chapter contribute to understanding the role of, and interplay between personality and employee perceptions of the organisational environment in intrapreneurial behaviour (e.g. Blanka et al., 20I8; Kuratko et al., 1990; 20I4; Mustafa et al., 20I8). Specifically, this is the first study that investigates the relations between the Big Five personality traits, risk tolerance and intrapreneurial behaviour in a Dutch context. In addition, we use an alternative manner of conceptualising intrapreneurial behaviour as new venture and strategic renewal behaviour (Gawke et al., 2019). Moreover, this chapter contributes to the literature by investigating the influence of the organisational culture on the relationship between employees' personality and intrapreneurial behaviour. We show that higher levels of perceived organisational support for intrapreneurship are associated with higher levels of intrapreneurial behaviour, and especially facilitate intrapreneurial behaviour for those employees with higher levels of Openness. In addition, this chapter is the first study that compares the Big Five personality traits of entrepreneurs and employees with high levels of intrapreneurial behaviour.

The remainder of this chapter is structured as follows. In Section 4.2 we provide a literature review and develop our hypotheses. Next, we describe our methods in 
Section 4.3 and Section 4.4 presents the results. Finally, in Section 4.5 we discuss the implications of the results.

\subsection{Literature review and hypotheses}

\subsubsection{Intrapreneurship and intrapreneurial behaviour}

Intrapreneurship is generally described as entrepreneurship within an existing organisation (Menzel, et al., 2007). The entrepreneurial process constitutes the recognition of business opportunities, the assessment of the value of the opportunity and the exploitation of this opportunity (Shane \& Venkataraman, 2000). This entrepreneurial process can also take place within an organisation, in which an employee or a group of employees instigate renewal, innovation or create new ventures (Sharma \& Chrisman, 1999). Intrapreneurs are therefore considered employee entrepreneurs within an existing company (Antoncic \& Hisrich, 2003; Blanka, 2018; Pinchot, 1985). Intrapreneurship researchers have predominantly focused on organisational level intrapreneurship, which is also known as corporate entrepreneurship (Antoncic \& Hisrich, 2003; Guth \& Ginsberg, I990; Zahra, I99I; Covin \& Slevin, I99I; Lumpkin \& Dess, 1996). The main antecedent of corporate entrepreneurship is employees' intrapreneurial behaviour (Mustafa et al., 20I8).

A growing body of research is concerned with the determinants of intrapreneurial behaviour (see Blanka, 20I8, and Mustafa et al., 20I8, for systematic literature reviews). Intrapreneurial behaviour relates to actions revolving around the recognition, evaluation and exploitation of entrepreneurial opportunities (Kuratko et al., 2005). However, there is no consensus on what these behaviours exactly entail. The most common approach is to conceptualise intrapreneurial behaviour as a set of innovative, proactive and risk taking behaviours (e.g. Stam et al., 2012; de Jong et al., 2015; Rigtering \& Weitzel, 2013). To distinguish intrapreneurs from other innovative employees, Gawke et al. (20I7) provide an alternative conceptualisation that matches more closely to entrepreneurship. They argue that what makes intrapreneurs unique, are behaviours that relate to new venture creation and strategic renewal. In this conceptualisation of intrapreneurial behaviour, new venture behaviour consists of an employee's agentic and anticipatory behaviour with the specific goal of creating new business or new organisations (Gawke et al., 20I7). In addition, strategic renewal behaviours are actions aimed at fostering an organisation's ability to react to both internal and external developments (Gawke et al., 20I7). It is this conceptualisation that we apply in this chapter.

\subsubsection{Personality and intrapreneurship}

According to trait theorists, people can be characterized in terms of relatively stable patterns of thoughts, feelings and actions (McCrae \& Costa, I999). More specifically, 
personality traits are defined as "differences among individuals in a typical tendency to behave, think or feel in some conceptually related ways, across a variety of relevant situations and across some fairly long period of time" (Ashton, 2007, p27-28).

The most commonly applied approach to personality is the Five Factor model of personality, also known as the Big Five (McCrae \& Costa, 1999). This taxonomy of personality consists of five broad factors that describe the personality traits Conscientiousness, Agreeableness, Extraversion, Neuroticism and Openness to Experience (McCrae \& John, I992; McCrae \& Costa, 1999). Next to the broadly defined Big Five personality traits, there are researchers that advocate a more narrow approach to personality. Although the Big Five is considered to exhaustively describe the breadth of personality (McCrae \& Costa, 1999), more narrow or specific traits could still be better predictors of a criterion when they are most relevant to that criterion (Ashton, 2007; Barrick \& Mount, 2005; Rauch \& Frese, 2007). Therefore, Rauch and Frese (2007) argue for investigating more specific personality traits to predict entrepreneurship.

As opposed to research in intrapreneurship, the investigation of personality traits has a long tradition in the study of entrepreneurship. For instance, Knight (192I) emphasises risk taking as an essential characteristic of entrepreneurs, whereas Schumpeter (1934) highlights creativity. However, observing mixed empirical results, researchers have questioned the predictive validity of personality traits for entrepreneurship. Gartner (1988) argues that asking "who is the entrepreneur?" is the wrong question. Instead of investigating personality traits of entrepreneurs, he advocates for a behavioural approach in the study of entrepreneurship. Aldrich (I999, p.76) even concludes that "research on personal traits seems to have reached an empirical dead end" in the study of entrepreneurship. However, the study of personality traits and entrepreneurship revived with the publication of several meta-analyses that find support for the predictive validity of personality traits for entrepreneurship (e.g. Rauch \& Frese, 2007; Zhao \& Seibert, 2006; Zhao et al., 20I0).

The predominant focus of personality studies in entrepreneurship has been on the broad Big Five personality traits and narrower trait of risk tolerance (Caliendo et al., 20I4; Zhao \& Seibert, 2006). For instance, Zhao and Seibert (2006) find that managers in dependent employment score lower on Conscientiousness and Openness, but higher on Neuroticism and Agreeableness as compared to entrepreneurs. However, they find no difference for Extraversion. Caliendo et al. (2014) however, analyse to what extent personality affects entrepreneurial decisions at certain points in time, instead of comparing self-employed with individuals in another type of employment. They find that employees have lower levels of Openness, Extraversion and risk tolerance, but higher levels of Agreeableness and Neuroticism. Moreover, entry into self-employment is predicted by higher levels of Openness and risk tolerance (at increasing rates) and lower levels of Neuroticism. They find no relation between 
Conscientiousness and entrepreneurial status, entry or exit. In this chapter we extend this line of research and attempt to integrate the two main streams of literature by focussing on personality traits as well as behaviour. Specifically, we focus on both the relation between the Big Five personality traits and intrapreneurial behaviour, and the relation between risk tolerance and intrapreneurial behaviour simultaneously.

\section{The Big Five personality traits and intrapreneurship}

Empirical evidence on the relation between the Big Five trait Extraversion with intrapreneurship consistently shows a positive relation. However, research findings on the other Big Five personality traits are mixed. Sinha and Strivastava (2013) investigate the relation of the Big Five personality traits with intrapreneurial orientation in a sample of executives working in the manufacturing sector in India. They find a positive relation for Extraversion and a negative relation for Neuroticism with intrapreneurship. No significant relations were found for Conscientiousness, Agreeableness and Openness. Conversely, Ahmed et al. (2013) find a positive relation between Openness and intrapreneurship in a sample of middle and line managers working in for-profit firms in Pakistan. In accordance with this finding, Farruhk et al. (2016) find positive relations between intrapreneurial behaviour and Openness, Extraversion and Emotional stability (reversed Neuroticism) in a sample of public sector university employees in Pakistan, In addition, they find that Conscientiousness and Agreeableness are negatively related to intrapreneurial behaviour. Finally, Woo (2018) finds that Extraversion and Agreeableness have positive relations with intrapreneurship, whereas the relations between intrapreneurship and Openness and Conscientiousness are positively and fully mediated by career adaptability for employees from a South Korean conglomerate. Woo (2018) finds no significant relations between Neuroticism and intrapreneurship.

\section{Risk tolerance and intrapreneurship}

Previous studies find a positive relation between risk tolerance and intrapreneurship, but yield mixed results concerning the differences between intrapreneurs and entrepreneurs. Monsen et al. (20I0) investigate what drives the decision to participate in corporate entrepreneurship projects, and find that the risk of job loss, and expected success and effort matter in the decision to get involved in corporate entrepreneurship projects. Matthews et al. (2009) find that intrapreneurs and entrepreneurs have comparable levels of risk tolerance, whereas Martiarena (2013) finds that intrapreneurs have higher levels of fear of failure as compared to entrepreneurs. Conversely, Douglas and Fitzsimmons (2013) find that attitudes to risk only relate to intrapreneurial intentions but not to entrepreneurial intentions. 


\section{Matching personality to intrapreneurial roles}

We develop our hypotheses by relating personality traits to intrapreneurial roles. As such, we follow Rauch and Frese (2007), who find that personality traits that are matched with entrepreneurial tasks and roles predict entrepreneurial behaviour better than personality traits that do not match these tasks.

We match the Big Five personality traits and risk tolerance to the four intrapreneurial roles distinguished by Hayton and Kelley (2006): I) the innovator, 2) the knowledge broker, 3) the champion and 4) the sponsor ${ }^{30}$. First, the innovator role involves opportunity recognition, where employees need the creative insight about particular combinations of knowledge and information, and understand what value these novel insights have for their organisation and customers (Hayton \& Kelley, 2006). Second, the knowledge broker role involves accessing and combining both new and existing sources of information and knowledge, and disseminating this knowledge within the organisation (Hayton \&Kelley, 2006; Hagardon, 2002). Third, the champion role involves creating support for the pursuit of an identified opportunity, by inspiring others with a vision of the potential of an innovation, showing extraordinary confidence and gaining the commitment of others to support the intrapreneurial project (Hayton \& Kelley, 2006; Howell \& Higgins, 1990). Fourth, the sponsor role involves providing advice, legitimacy and support for the project, and help with gaining access to necessary resources for the development of the project (Day, 1994; Hayton \& Kelley, 2006; Garud \& van de Ven, 1992). Next, we develop our hypotheses by matching each of the Big Five personality traits and risk tolerance to the four intrapreneurial roles.

\section{Big Five personality traits and intrapreneurial behaviour}

Individuals who are high on Openness are most likely to take on the role of innovator (Hayton \& Kelley, 2006). They are more willing to try new things, are more creative and curious, and are more likely to hold unconventional ideas (McCrae \& John, 1992). These individuals explore new ideas, have an ability for divergent thinking that enables the generation and exploration of new ideas (McCrae, 1987) and are therefore more likely to recognise business opportunities (Caliendo et al., 20I4). In addition, individuals with high levels of Openness are intrinsically curious, which may facilitate the search for new information. We therefore expect that individuals with higher levels of Openness have higher levels of intrapreneurial behaviour:

30 Matching personality with intrapreneurial tasks and roles guides us in developing hypotheses about the relationships between personality and intrapreneurial behaviour. However, our aim is not to directly investigate the relationships between personality and engagement in intrapreneurial roles. 
HI: Openness is positively related to intrapreneurial behaviour.

People who have high levels of Extraversion can be described as outgoing, sociable, talkative, enthusiastic and cheerful. In addition, people who are high in Extraversion enjoy social interactions and are also considered to be assertive and seeking leadership roles (McCrae \& John, 1992; Judge et al., 1999). These traits are helpful in the role of knowledge broker and seem particularly valuable for successful championing of an intrapreneurial idea. Individuals high in Extraversion easily establish social contacts which may help them to create organisational knowledge networks and gaining access to decision makers in the organisation. In addition, their assertiveness and enthusiasm may help in creating commitment and support for the intrapreneurial project among others. Therefore, we expect that higher levels of Extraversion are associated with higher levels of intrapreneurial behaviour:

$\mathrm{H}_{2}$ : Extraversion is positively related to intrapreneurial behaviour.

Neuroticism (also reversely named emotional stability), refers to the tendency to experience adverse emotions as moodiness, anxiety and anger (McCrae \& John, 1992). Neuroticism has been linked to higher levels of creativity and could therefore be linked to the innovator role. However findings concerning the relation between Neuroticism and creativity are mixed, showing positive (Burch et al., 2006), negative (Raja \& Johns, 20IO) and no relations (e.g. Batey et al., 20IO; Taggar, 2002). In a meta-analytical review, Feist (1998) finds that higher levels of Neuroticism are especially relevant for artistic creativity, but not for creativity in other domains. In addition, Judge et al. (1998) argue that those who have high levels of Neuroticism are anxious and lack the confidence to engage in novel situations. They therefore have a preference for low risk jobs that are structured and do not require any initiative (Judge \& Cable, 1997). High levels of Neuroticism are therefore not likely conducive for an intrapreneurial role. Contrarily, low levels of Neuroticism are associated with high levels of self-esteem and are able to manage stressful situations (Judge et al., 1999). Low levels of Neuroticism are therefore conducive for successful championing of new initiatives. Therefore, we hypothesise:

$\mathrm{H}_{3}$ : Neuroticism is negatively related to intrapreneurial behaviour.

Since the expected relations are ambiguous, we do not formulate hypotheses for the relations of both Agreeableness and Conscientiousness with intrapreneurial behaviour. Agreeableness describes an individual's interpersonal orientation and relates to the tendency to be sympathetic, kind and cooperative (McCrae \& John, 1992). The championing role requires employees to get other organisational members on board with the project. Highly sympathetic individuals may therefore be more 
successful in creating support for a project. In addition, as teamwork is important in most organisations, employees need to be cooperative. Employees also require a cooperative attitude for successfully building knowledge networks in and outside the organisation. However, high levels of Agreeableness are also related to conflict avoidance (Antonioni, 1998) which does not facilitate resolving interpersonal tensions that may arise from the introduction and championing of new ideas.

Conscientiousness entails the tendency to aim for achievement, to be organized, efficient, diligent, thorough and precise (McCrae \& John, I992). The relation of Conscientiousness with intrapreneurship is not straightforward. On the one hand, highly conscientious individuals aim for achievement, which may facilitate employees to successfully take on a championing role. On the other hand, one might expect a negative relation between Conscientiousness and intrapreneurial behaviour. A high level of Conscientiousness is especially conducive for efficiency and is therefore the best predictor of job performance (Judge et al., I999). However, efficiency is not a prerequisite for any intrapreneurial role. Moreover, since intrapreneurial behaviour can be seen as extra role behaviour which is not necessarily part of one's regular job description (Rigtering \& Weitzel, 2013), high job performance does not naturally translate into high levels of intrapreneurial behaviour.

\section{Risk tolerance and intrapreneurial behaviour}

Risk tolerance is essential for any entrepreneurial decision (Caliendo et al., 20I4) and is therefore likely to be relevant for intrapreneurship. However, the nature of risk that entrepreneurs and intrapreneurs face is different. Entrepreneurs risk losing a financial investment, whereas intrapreneurial behaviour is associated with career related risk (Kacperczyk, 20I2; Zenovia, 20II). Failure of an intrapreneurial endeavour might result in loss of reputation, demotion or dismissal. Championing and sponsoring an intrapreneurial project requires an employee to actively promote and support the project. Sponsoring an intrapreneurial idea additionally requires facilitating the allocation of organisational resources for development and implementation of the project. In case of project failure, any negative outcomes will therefore most likely be ascribed to those involved in the project championing and sponsoring. Indeed, Howell and Higgins (1990) find that champions exhibit higher levels of risk taking than non-champions. Consequently, we hypothesise:

$\mathbf{H}_{4}$ : Risk tolerance is positively related to intrapreneurial behaviour.

\subsubsection{Organisational support, personality and intrapreneurial behaviour}

Organisations that are supportive of intrapreneurship have higher levels of intrapreneurial behaviour (Mustafa et al., 20I8). Organisations can signal their support for intrapreneurship by for instance providing recognition and rewards (Hornsby et al., 2009; Kuratko et al., I990; 2014) and providing time and financial resources for 
intrapreneurial activities (Hornsby et al., 2009; Puech \& Durand, 20I7; Rigtering \& Weitzel, 2013). Indeed, employees that experience support for intrapreneurial initiatives show higher levels of intrapreneurial behaviour (Zampetakis et al., 2009).

This may be explained by selection of individuals with higher levels of personality traits that are conducive for intrapreneurship into organisations that are supportive of such behaviour. Indeed, the attraction-selection-attrition (ASA) model (Schneider, 1987) predicts that organisations with an organisational environment that is supportive of intrapreneurship attracts and selects employees with intrapreneurial personality traits. First, workers with these traits may be more attracted to jobs and organisations when they perceive a supportive organisational environment for intrapreneurship. Second, in those organisations that have a favourable environment for intrapreneurs, workers involved in selection of employees may prefer to employ individuals with personality traits that are conducive for intrapreneurship and will not employ those without these personality traits. This then leads to the observation of higher levels of intrapreneurial behaviour in organisations that support intrapreneurship.

Additionally, perceptions of the organisational environment may affect the expression of personality traits in behaviour (Hayton \& Kelley, 2006; Kuratko et al., 1990; 20I4; Mustafa et al., 2018). According to trait activation theory (Tett \& Burnett, 2003), the organisational environment provides cues that either constrain or strengthen the expression of personality into behaviour. Therefore, an organisation that lacks a supportive environment for intrapreneurship may employ many potential intrapreneurs, without actually observing intrapreneurial behaviour (Krueger \& Brazeal, 1994). Therefore, we expect that intrapreneurial behaviour of employees is higher in organisations in which employees perceive higher levels of organisational support for intrapreneurship, and that higher levels of perceived organisational support for intrapreneurship facilitates the expression of personality traits into intrapreneurial behaviour. We hypothesise:

H5a: Employees' perception of organisational support for intrapreneurship is positively related to intrapreneurial behaviour.

H5b: Employees' perceptions of organisational support for intrapreneurship positively moderates the relation between personality and intrapreneurial behaviour.

Figure 4.I provides an overview of the relations we expect in this chapter. 
Figure 4.1 - Overview of hypothesised relations.

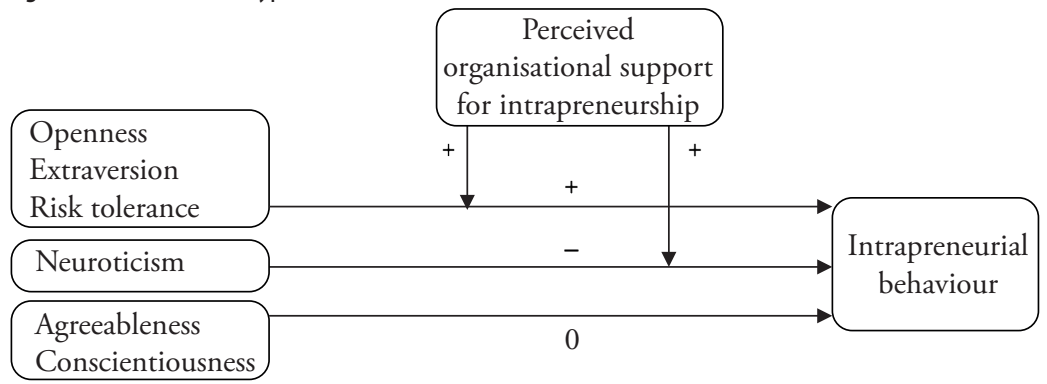

Note: + indicates a positive relationship; - indicates a negative relationship; 0 indicates no expected relationship.

\subsection{Methods}

\subsubsection{Sample-selection model}

We conceptualise a worker's involvement in intrapreneurship as follows. First, a worker chooses between entrepreneurship and dependent employment. Second, if a worker choses dependent employment, a worker may engage in intrapreneurship ${ }^{31}$. Intrapreneurship per definition only takes place within organisations and we can therefore only observe intrapreneurship when an individual has chosen to work in dependent employment. The choice for dependent versus independent employment is influenced by a workers' personality characteristics ${ }^{32}$ (e.g. Caliendo et al., 20I4; Zhao \& Seibert, 2006; Zhao et al., 2010). Personality, therefore, not only affects intrapreneurial behaviour, but also the probability that we observe a worker in a sample of employees.

3I Our conceptualisation differs from Parker (20II) who conceptualises the choice between entrepreneurship and intrapreneurship as a choice for start-up mode. In this conceptualisation, a worker firstly identifies an opportunity, and then chooses for exploitation of this opportunity either through intrapreneurship or entrepreneurship. This differs from our conceptualisation in which workers first choose for dependent or independent employment. These conceptualisations are not necessarily opposites however, and should be seen as complementary (c.f. Adachi \& Hisada, 20I7).

32 A common approach in the investigation of the role of personality in the choice for entrepreneurship is to compare entrepreneurs with managers in dependent employment (see Zhao \& Seibert, 2006). The reasoning behind this approach is that managers are similar to entrepreneurs in for instance the need for general business knowledge and exposure to business opportunities. By comparing entrepreneurs with managers in dependent employment, occupation specific differences in personality characteristics (Holland, 1987) are controlled for. 
Not correcting for self-selection into dependent employment increases the possibility of sample induced endogeneity, which could lead to biased results (Certo et al., 20I6). Hence, We correct for self-selection in dependent employment and estimate a Heckman selection model using a full information maximum likelihood estimator (Heckman, 1976), which assumes that there exists an underlying regression relationship

$$
y_{j}=x_{j} \beta+u_{j}^{1}
$$

However, outcome y is only observed for $j$ when

$$
\mathrm{z}_{\mathrm{j}} \gamma+\mathrm{u}_{\mathrm{j}}^{2}>0
$$

where

$$
\begin{aligned}
& \mathrm{u}^{1} \sim \mathrm{N}(0, \sigma) \\
& \mathrm{u}^{2} \sim \mathrm{N}(0,1) \\
& \operatorname{corr}\left(\mathrm{u}^{1}, \mathrm{u}^{2}\right)=\rho
\end{aligned}
$$

We estimate the outcome equation

$$
\mathrm{I}_{\mathrm{i}}=\mathrm{b}+\mathrm{X}_{\mathrm{i}}+\mathrm{Y}_{\mathrm{i}}+\mathrm{e}^{\mathrm{I}}
$$

and the selection equation

$$
E_{i}=a+Z_{i}+Y_{i}+e^{2}
$$

where $\mathrm{E}_{\mathrm{i}}$ is o when individual $i$ chooses to be an entrepreneur, i.e. work in independent employment, and $\mathrm{I}$ if individual $i$ chooses dependent employment. Conditional on $\mathrm{E}_{\mathrm{i}}$ $=\mathrm{I}$, We observe the level of intrapreneurial behaviour I for individual $i$. Thus, in the first stage we estimate whether an individual choses for paid employment and in the second stage we estimate who of those in paid employment engage in intrapreneurial behaviour.

$\mathrm{X}_{i}$ is a vector of explanatory variables affecting $\mathrm{I}_{i}$ but not $\mathrm{E}_{i}$, which includes perceived organisational support for intrapreneurship, specific human capital (tenure), functional background, job autonomy and sector. $\mathrm{Y}_{i}$ is a vector of explanatory variables affecting $\mathrm{E}_{i}$, and potentially $\mathrm{I}_{i}$ including personality, risk tolerance, gender, age, general human capital (educational level) and entrepreneurship training. $Z_{i}$ is the exclusion restriction, which is an exogenous explanatory variable that predicts whether or not a worker appears in our sample of employees (Certo et al., 2016) and should affect $\mathrm{E}_{i}$ but not $\mathrm{I}_{i}$. Here we include a variable indicating whether a worker 
has an entrepreneurial parent or not. This instrument is used to estimate weather someone enters paid employment rather than being self-employed.

We argue that having an entrepreneurial parent affects a worker's choice for entrepreneurship, but does not affect intrapreneurship. Having a self-employed parent is one of the most consistent predictors for entrepreneurship (e.g. Blumberg $\&$ Pfann, 20I6; Caliendo et al., 20I4; Chlosta et al., 20I2; Dunn \& Holtz-Eakin, 2000; Mungai \& Velamuri, 20II). Blumberg and Pfann (20I6) argue that a self-employed father provides the social capital, i.e. the resources individuals have access to through theirs social relationships, needed for workers' entrepreneurship. There are two possible mechanisms through which entrepreneurial parents affect their children's' choice for entrepreneurship (Blumberg and Pfann, 20ı6; Dunn \& Holtz-Eakin, 2000). Firstly, Dunn and Holtz-Eakin (2000) find that entrepreneurial parents may provide their children with financial capital to facilitate entrepreneurial endeavours. Secondly, they find that entrepreneurial parents may transfer entrepreneurial skills through their own work experience and other entrepreneurial human capital.

We do not expect that an entrepreneurial parent affects intrapreneurship. A clear difference between entrepreneurship and intrapreneurship is that intrapreneurship takes place in the organisational environment, where the organisation's structure, procedures and activities make up the ecosystem in which the intrapreneur operates (Burgelman, I99I; Kuratko et al., 20I4). Therefore, entrepreneurial parents can hardly to be expected to provide financial capital to facilitate an intrapreneurial project. In addition, successful intrapreneurship requires specific human and social capital, including knowledge about the organisation and access to key decision makers within the organisation (Hayton \& Kelley, 2006). It would be highly unlikely that employees' parents affect organisational processes, employees' knowledge about their organisation or provide them access to key decision makers in the organisation. However, we can imagine that an entrepreneurial parent transmits general cognitive skills and entrepreneurial personality traits that could facilitate intrapreneurial behaviour. Nevertheless, this is not problematic since we account for general cognitive skills and entrepreneurial non-cognitive skills by including both workers' educational level and personality in our model.

\subsubsection{Data and sample}

We use the LISS (Longitudinal Internet Studies for the Social sciences) panel administered by CentERdata (Tilburg University, The Netherlands). The LISS panel is a representative sample of Dutch individuals who participate in monthly Internet surveys. The panel is based on a true probability sample of households drawn from the population register and consists of 5000 households and 8,000 individuals. Households that could not otherwise participate are provided with a computer and Internet connection. A core survey is fielded in the panel every year, covering a large variety of domains including work, education, income, housing, time use, political 
views, values and personality. More information about the LISS panel can be found at: www.lissdata.nl.

In addition to the data on personality and several background variables included in the LISS panel, we collected additional data among panel members through a survey that was developed for the purpose of this chapter. This survey included questions about intrapreneurship, perceived organisational support for intrapreneurship and parental entrepreneurial experience. We include respondents who are between i8 years and 67 years old, in dependent or independent employment at the time of data collection. However, only those panel members in dependent employment were asked to answer questions about their level of intrapreneurship in their current jobs and perceived organisational support for intrapreneurship. Data was collected during July and August 20I8. As such, 3,356 panel members were eligible for inclusion in the current study and were invited to complete our survey. 2,804 individuals completed the survey, resulting in a response rate of $83.5 \%$. However, the LISS panel does not contain all required personality traits for all these individuals. Therefore, for our analyses we use a sample of I,557 workers in dependent and independent employment for whom all relevant information is available.

\subsubsection{Measurements}

\section{Intrapreneurial behaviour}

We measure intrapreneurial behaviour by the shortened version of the Employee Intrapreneurship Scale (EIS; Gawke et al., 2017; Gawke et al., 2019). The scale consists of 8 items divided in two subscales measuring strategic renewal and venturing behaviour (see Appendix Table A4.I). A sample item is "I undertake activities to realize change in my organisation". Respondents indicate the extent to which the statements apply to themselves in their current job by a 7 point Likert-scale, ranging from never (I) to always (7). Overall scale reliability is good $(\alpha=0.93)$.

We create one variable by calculating a sum-score for the total scale by regression scoring after a polychoric factor analyses (Holgado-Tello et al., 20IO). This continuous variable is used in the main analyses. In addition, we create a second dichotomous variable that takes value I when we classify an employee 'high' in intrapreneurial behaviour, i.e., when the sum-score for an employee's level of intrapreneurial behaviour is 4 or higher. As such, this category represents employees who are at least 'regularly' involved in intrapreneurial activities. Moreover, the variable takes value $\mathrm{o}$ when a worker is 'low' in intrapreneurial behaviour, i.e. when the sum-score for an employee's average level of intrapreneurial behaviour is lower than 4 . This category represents employees that are on average 'never' to 'sometimes' involved in intrapreneurial activities. This dichotomous variable is used in additional analyses. 


\section{Big Five personality traits}

We measure the Big Five personality traits - Openness, Conscientiousness, Extraversion, Agreeableness and Neuroticism - using 50 items from the International Personality Item Pool (IPIP) (Goldberg et al., 2006). Each Big Five subscale is measured by Io items containing statements describing people's behaviours. Respondents rate how accurately the statements describe them as they are now, on a 5-point Likert scale ranging from very inaccurate (I) to very accurate (5). Panel members fill in the personality items every year; we use the Big Five personality measures from March 2017.

Factor analysis on all 50 items show a clear five factor solution. However, we remove I item with a factor loading below 0.3 on all factors, and 4 items with factor loadings of 0.3 or higher on more than one factor. Scale reliability statistics are satisfactory for all Big Five personality facets. Cronbach's alpha for Neuroticism is 0.90, for Extraversion 0.89, for Agreeableness 0.85, for Openness 0.77, and for Conscientiousness 0.74. Example items are "I worry about things" for Neuroticism, "I feel good in the company of others" for Extraversion, "I sympathise with others' feelings" for Agreeableness, "I have a vivid imagination" for Openness, and "I am always prepared" for Conscientiousness. We calculate weighted sum-scores for each personality trait by using regression scoring after a polychoric factor analyses of the items that represent each personality trait. We standardise the sum-score of each of the Big Five traits to a mean of o and a standard deviation of $\mathrm{I}$.

\section{Risk tolerance}

We measure risk tolerance by a widely used subjective risk question (Falk et al., 20I6; Dohmen et al., 20II). In April 2017 panel members are asked if they see themselves as generally a person who is fully prepared to take risks, or as a person who tries to avoid taking risks. Respondents answer this question on an II-point Likert scale ranging from unwilling to take risk (o) to fully prepared to take risk (Iо). We standardise the score for this item to a mean of $\mathrm{o}$ and a standard deviation of $\mathrm{I}$.

\section{Perceived organisational support for intrapreneurship}

We measure perceived organisational support for intrapreneurship with 4 items adapted from the innovation support inventory developed by Lukes and Stephan (20I7). The inventory includes statements about time availability, reward structures and an organisation's resource availability for innovation. Respondents are asked to indicate their level of agreement with these statements on a 5 -point Likert scale ranging from strongly agree (I) to strongly disagree (5). An example item is "Our organisation provides employees time for putting ideas and innovations into practice". Cronbach's alpha for this scale is 0.77 . We create a sum-score for this scale by regression scoring after a polychoric factor analysis, and standardise the sum-score to a mean of $\mathrm{o}$ and a standard deviation of $\mathrm{I}$. 


\section{Entrepreneurial parent}

We asked respondents to indicate if their father, mother or both of their parents were ever self-employed or worked in a family business. We create a binary variable taking the value I when any of the respondent's parents were self-employed or working in a family business, and o when neither of the respondent's parent were involved in these activities.

\section{Control variables}

We include several control variables that have been shown to affect intrapreneurship. We control for workers' gender and include a dummy indicating if a worker is male $(=0)$ or female $(=\mathrm{I})$. In addition, we create a categorical variable that indicates a worker's educational level. We distinguish between elementary school level $(=\mathrm{I})$, secondary school level $(=2)$, vocational level $(=3)$ and Bachelor level or higher $(=4)$. We also include a dummy variable ( $\mathrm{O}=$ no; $\mathrm{I}=\mathrm{yes}$ ) indicating whether a worker ever received training in business and entrepreneurship. Furthermore, we control for workers' age and tenure in years. In addition, we include control variables for job autonomy (de Jong et al., 2015), job type (higher and intermediate positions in management and sales, academic professions, other white collar mental work such as accountants and administrative assistants, (semi-)skilled manual work, and unskilled manual work and agrarian professions) and sector.

We must note however, that the information on these contextual variables are collected in April-May 20I8, two months before we collect information about individuals' intrapreneurial behaviour. We cannot check if an employee changed employers or jobs in these months. However, we make sure to include only those individuals in the analyses that have the same work status (i.e. employee or entrepreneur) both in April-May and July 2018. 


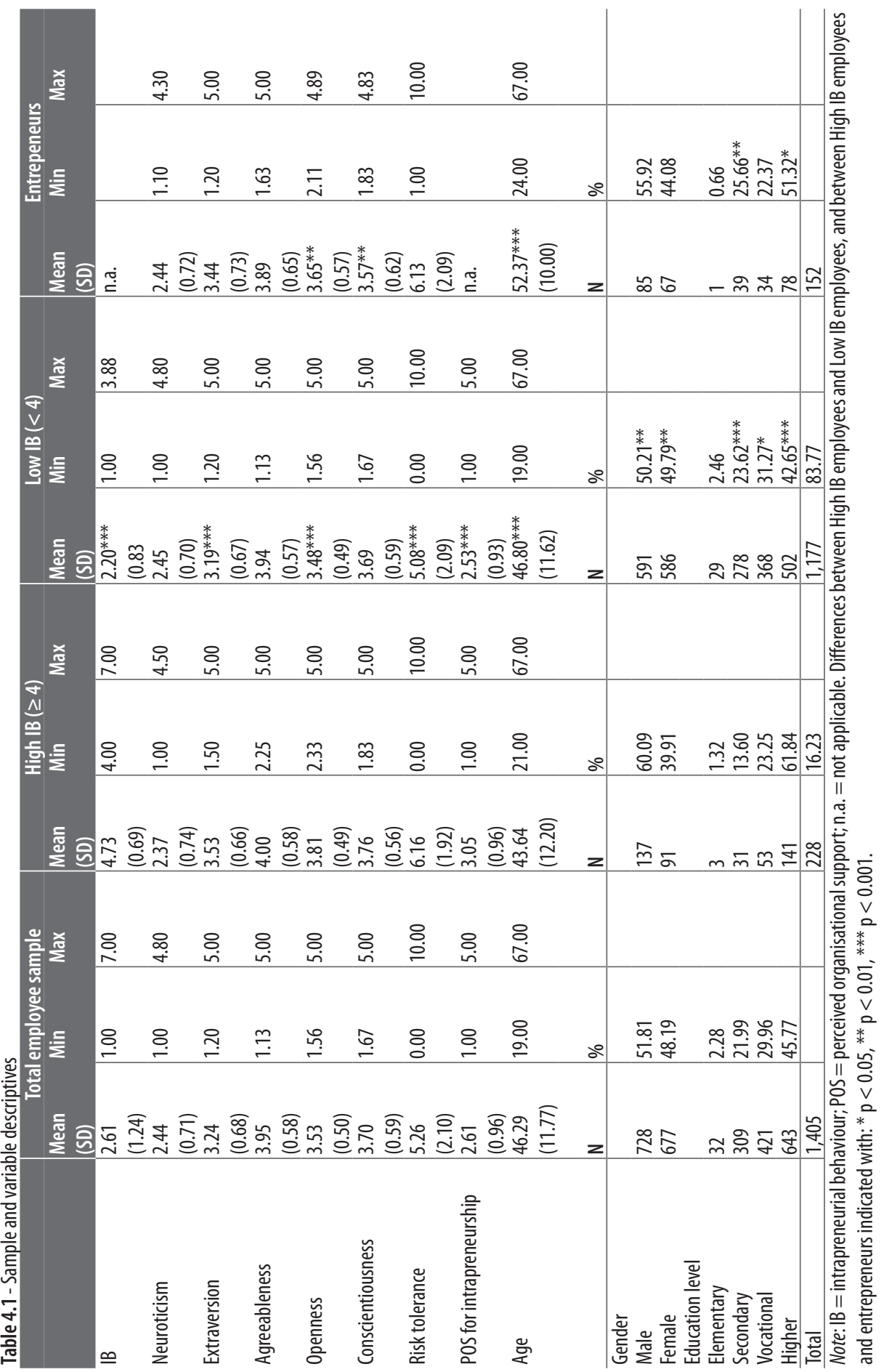




\subsubsection{Descriptive statistics}

Table 4.I displays the means and standard deviations for the continuous variables in this chapter, and frequencies for the categorical variables. Congruent with previous findings (Bosma et al., 2010), we find that the average level of intrapreneurial behaviour among all employees in our sample is quite low. This low average score indicates that on average, employees are at most sometimes involved in activities relating to strategic renewal and the creation of new ventures for their organisations. Only 228 (I6.2\%) of all employees have an average level of intrapreneurial behaviour of 4 or higher, i.e. are at least regularly involved in intrapreneurial activities. Indeed, Figure 4.2 shows that the distribution for the unstandardized sum score for intrapreneurial behaviour is quite skewed.

Furthermore, we compare the employees who we classified as high in intrapreneurial behaviour $(\geq 4)$ with those who we classified as low in intrapreneurial behaviour $(<4)$. Table 4.I shows that the average level of intrapreneurial behaviour for highly intrapreneurial employees is indeed significantly higher than the average level of intrapreneurial behaviour for employees who are low in intrapreneurial behaviour. In addition, highly intrapreneurial employees have higher levels of Extraversion, Openness and risk tolerance as compared to employees with lower levels of intrapreneurial behaviour. We find no significant differences in the average level of Neuroticism, Conscientious and Agreeableness between high and low intrapreneurial employees. Furthermore, highly intrapreneurial employees perceive higher levels of organisational support for intrapreneurship.

Figure 4.2 - Frequency distribution of the unstandardized sum score of intrapreneurial behaviour

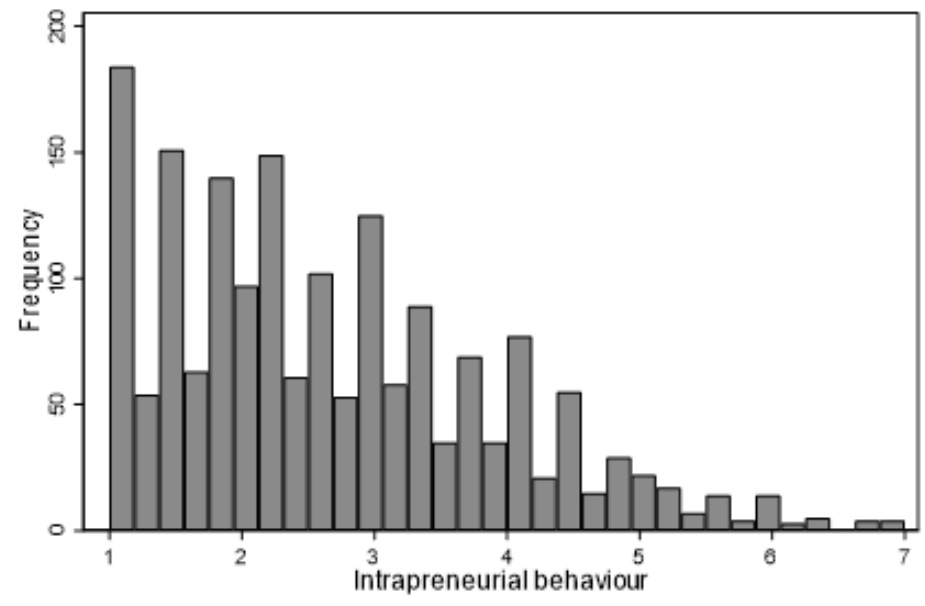


Moreover, we compare highly intrapreneurial employees with entrepreneurs. Table 4.I shows that highly intrapreneurial employees have higher levels of Openness and Conscientiousness than entrepreneurs. However, average levels of Neuroticism, Extraversion, Agreeableness, and risk tolerance do not differ between the two groups.

Table 4.2 shows the correlations between the main variables in this chapter, and the reliability statistics for the scales we use. The table shows that higher levels of Neuroticism are related to lower levels of intrapreneurial behaviour, whereas higher levels of Agreeableness, Extraversion, Openness and risk tolerance are related to higher levels of intrapreneurial behaviour. Here we can also see that employees have on average higher levels of Conscientiousness, but lower levels of Extraversion, Openness and risk tolerance as compared to entrepreneurs. Importantly, entrepreneurs more often have an entrepreneurial parent than employees. In addition, perceived organisational support for intrapreneurship is positively associated with intrapreneurial behaviour, Extraversion, Openness and risk tolerance, but negatively with Neuroticism. This suggest that organisations with higher levels of support for intrapreneurship employ workers with higher levels of personality traits that are also associated with intrapreneurial behaviour.

Table 4.2 - Correlations and reliability statistics

\begin{tabular}{|c|c|c|c|c|c|c|c|c|c|}
\hline & 1 & 2 & 3 & 4 & 5 & 6 & 7 & 8 & 9 \\
\hline 1. IB & $(0.93)$ & & & & & & & & \\
\hline 2. Neuroticism & $-0.077^{* *}$ & $(0.90)$ & & & & & & & \\
\hline 3. Extraversion & $0.275^{* * *}$ & $-0.182^{* * *}$ & $(0.89)$ & & & & & & \\
\hline 4. Agreeableness & $0.053^{*}$ & $-0.127^{* * * *}$ & $0.315^{* * *}$ & $(0.85)$ & & & & & \\
\hline 5. Openness & $0.357^{* * *}$ & $-0.158^{* * *}$ & $0.333^{* * *}$ & $0.199^{* * *}$ & $(0.77)$ & & & & \\
\hline 6. Conscientiousness & 0.026 & $-0.134^{* * *}$ & 0.043 & $0.198^{* * *}$ & $0.115^{* * *}$ & $(0.74)$ & & & \\
\hline 7. Risk tolerance & $0.286^{* * *}$ & $-0.151^{* * *}$ & $0.304^{* * *}$ & -0.012 & $0.218^{* * *}$ & $-0.081^{* *}$ & n.a. & & \\
\hline $\begin{array}{l}\text { 8. POS for } \\
\text { intrapreneurship }\end{array}$ & $0.319^{* * *}$ & $-0.077^{* *}$ & $0.091^{* * *}$ & -0.024 & $0.095^{* * *}$ & -0.002 & $0.174^{* * *}$ & $(0.77)$ & \\
\hline $\begin{array}{l}\text { 9. Entrepreneurial } \\
\text { parent }^{\mathrm{a}}\end{array}$ & 0.039 & 0.002 & 0.038 & -0.013 & 0.019 & -0.008 & $0.058^{*}$ & $0.060^{*}$ & n.a. \\
\hline 10. Worker type ${ }^{b}$ & n.a. & -0.001 & $-0.084^{* * *}$ & 0.035 & $-0.065^{*}$ & $0.064^{*}$ & $-0.122^{* * *}$ & & $-0.128^{* * *}$ \\
\hline
\end{tabular}

Note: $\mathrm{IB}=$ intrapreneurial behaviour; $\mathrm{POS}=$ perceived organisational support; $\mathrm{n} . \mathrm{a} .=$ not applicable.

$\mathrm{N}=1405$ for IB and organisational support; $\mathrm{N}=1557$ for all other variables. Correlations and reliability statistics calculated using the unstandardized sum-scores of all variables. Cronbach's alpha statistics in parentheses on the diagonal. a: yes $=1$, no $=0$; b :employee $=1$, entrepreneur $=0 ;{ }^{*} p<0.05,{ }^{* *} p<0.01,{ }^{* *} p<0.001$. 
Table 4.3 - Estimation results Heckman selection model and bias-uncorrected OLS.

\begin{tabular}{|c|c|c|c|c|c|c|}
\hline & \multicolumn{3}{|c|}{ Heckman selection model } & \multicolumn{3}{|c|}{ Bias-uncorrected OLS } \\
\hline & (1) & (2) & (3) & (4) & (5) & (6) \\
\hline & Selection: $\mathbf{E}_{\mathrm{i}}$ & Outcome: $I_{\mathrm{i}}$ & Outcome: $I_{i}$ & OLS & OLS & OLS \\
\hline \multirow[t]{2}{*}{ Neuroticism } & $-0.105^{* *}$ & 0.047 & 0.059 & 0.044 & 0.055 & 0.044 \\
\hline & $(0.052)$ & $(0.033)$ & $(0.036)$ & $(0.036)$ & $(0.036)$ & $(0.036)$ \\
\hline \multirow[t]{2}{*}{ Extraversion } & $-0.153^{* * *}$ & $0.134^{* * *}$ & $0.132^{* * *}$ & $0.130^{* * *}$ & $0.127^{* * *}$ & $0.131^{* * *}$ \\
\hline & $(0.056)$ & $(0.037)$ & $(0.037)$ & $(0.037)$ & $(0.037)$ & $(0.037)$ \\
\hline \multirow[t]{2}{*}{ Agreeableness } & $0.138^{* *}$ & -0.017 & -0.018 & -0.013 & -0.013 & -0.014 \\
\hline & $(0.054)$ & $(0.037)$ & $(0.038)$ & $(0.038)$ & $(0.038)$ & $(0.038)$ \\
\hline \multirow[t]{2}{*}{ Openness } & -0.052 & $0.287^{* * *}$ & $0.280^{* * *}$ & $0.285^{* * *}$ & $0.281^{* * *}$ & $0.281^{* * *}$ \\
\hline & $(0.056)$ & $(0.037)$ & $(0.038)$ & $(0.039)$ & $(0.039)$ & $(0.038)$ \\
\hline \multirow[t]{2}{*}{ Conscientiousness } & $0.086^{*}$ & 0.013 & 0.018 & 0.016 & 0.020 & 0.016 \\
\hline & $(0.048)$ & $(0.032)$ & $(0.033)$ & $(0.033)$ & $(0.033)$ & $(0.033)$ \\
\hline \multirow{2}{*}{ Risk tolerance } & $-0.161^{* * *}$ & $0.197^{* * *}$ & $0.209^{* * *}$ & $0.192^{* * *}$ & $0.202^{* * *}$ & $0.194^{* * *}$ \\
\hline & $(0.053)$ & $(0.034)$ & $(0.033)$ & $(0.033)$ & $(0.033)$ & $(0.034)$ \\
\hline \multirow[t]{2}{*}{ POS for intrapreneurship } & & $0.313^{* * *}$ & $0.314^{* * *}$ & $0.313^{* * *}$ & $0.311^{* * *}$ & $0.313^{* * *}$ \\
\hline & & $(0.032)$ & $(0.034)$ & $(0.035)$ & $(0.035)$ & $(0.035)$ \\
\hline \multicolumn{7}{|l|}{ POS for intrapreneurship* } \\
\hline \multirow[t]{2}{*}{ Neuroticism } & & & 0.050 & & 0.050 & \\
\hline & & & $(0.033)$ & & $(0.033)$ & \\
\hline \multirow[t]{2}{*}{ Extraversion } & & & 0.005 & & 0.005 & \\
\hline & & & $(0.037)$ & & $(0.038)$ & \\
\hline \multirow[t]{2}{*}{ Agreeableness } & & & -0.003 & & -0.002 & \\
\hline & & & $(0.036)$ & & $(0.037)$ & \\
\hline \multirow[t]{2}{*}{ Openness } & & & $0.093^{* * *}$ & & $0.095^{* * *}$ & \\
\hline & & & $(0.032)$ & & $(0.033)$ & \\
\hline \multirow[t]{2}{*}{ Conscientiousness } & & & -0.012 & & -0.012 & \\
\hline & & & $(0.033)$ & & $(0.034)$ & \\
\hline \multirow[t]{2}{*}{ Risk tolerance } & & & $0.061^{*}$ & & $0.060^{*}$ & \\
\hline & & & $(0.032)$ & & $(0.033)$ & \\
\hline \multirow[t]{2}{*}{ Entrepreneurial parent } & $-0.420^{* * *}$ & & & & & -0.064 \\
\hline & $(0.097)$ & & & & & $(0.070)$ \\
\hline \multirow[t]{2}{*}{ Female, male = ref. } & -0.163 & -0.064 & -0.076 & -0.069 & -0.082 & -0.067 \\
\hline & $(0.105)$ & $(0.078)$ & $(0.077)$ & $(0.078)$ & $(0.078)$ & $(0.079)$ \\
\hline \multirow[t]{2}{*}{ Age } & $-0.030^{* * *}$ & $-0.010^{* * *}$ & $-0.010^{* * *}$ & $-0.010^{* * *}$ & $-0.011^{* * *}$ & $-0.010^{* * *}$ \\
\hline & $(0.005)$ & $(0.003)$ & $(0.003)$ & $(0.003)$ & $(0.003)$ & $(0.003)$ \\
\hline \multirow{3}{*}{$\begin{array}{l}\text { Education, } B \text { A or higher }=\text { ref } \\
\text { elementary }\end{array}$} & & & & & & \\
\hline & 0.690 & -0.021 & -0.042 & -0.003 & -0.030 & -0.001 \\
\hline & $(0.464)$ & $(0.216)$ & $(0.230)$ & $(0.229)$ & $(0.231)$ & $(0.231)$ \\
\hline \multirow[t]{2}{*}{ secondary } & 0.009 & $-0.327^{* * *}$ & $-0.321^{* * *}$ & $-0.326^{* * *}$ & $-0.322^{* * *}$ & $-0.331^{* * *}$ \\
\hline & $(0.123)$ & $(0.093)$ & $(0.092)$ & $(0.092)$ & $(0.093)$ & $(0.093)$ \\
\hline \multirow[t]{2}{*}{ vocational } & 0.175 & $-0.260^{* * *}$ & $-0.260^{* * *}$ & $-0.254^{* * *}$ & $-0.256^{* * *}$ & $-0.256^{* * *}$ \\
\hline & $(0.120)$ & $(0.082)$ & $(0.084)$ & $(0.085)$ & $(0.085)$ & $(0.085)$ \\
\hline Business training, no=ref & $-0.382^{* * *}$ & $0.282^{* * *}$ & $0.274^{* * *}$ & $0.267^{* * *}$ & $0.256^{* * *}$ & $0.273^{* * *}$ \\
\hline & $(0.119)$ & $(0.096)$ & $(0.091)$ & $(0.094)$ & $(0.093)$ & $(0.094)$ \\
\hline Tenure & & -0.003 & -0.003 & -0.003 & -0.003 & -0.003 \\
\hline & & $(0.003)$ & $(0.003)$ & $(0.003)$ & $(0.003)$ & $(0.003)$ \\
\hline
\end{tabular}


Table 4.3 - Estimation results Heckman selection model and bias-uncorrected OLS. Continued

\begin{tabular}{|c|c|c|c|c|c|c|}
\hline & \multicolumn{3}{|c|}{ Heckman selection model } & \multicolumn{3}{|c|}{ Bias-uncorrected OLS } \\
\hline & (1) & (2) & (3) & (4) & (5) & (6) \\
\hline & Selection: $E_{i}$ & Outcome: $\mathrm{I}_{\mathrm{i}}$ & Outcome: $\mathrm{I}_{\mathrm{i}}$ & OLS & OLS & OLS \\
\hline Autonomy & & $\begin{array}{l}-0.023 \\
(0.044)\end{array}$ & $\begin{array}{l}-0.020 \\
(0.046)\end{array}$ & $\begin{array}{l}-0.023 \\
(0.046)\end{array}$ & $\begin{array}{l}-0.019 \\
(0.046)\end{array}$ & $\begin{array}{l}-0.024 \\
(0.047)\end{array}$ \\
\hline Job type, management/sales & & & & & & \\
\hline$=$ ref & & & & & & \\
\hline $\begin{array}{l}\text { Higher/intermediate } \\
\text { academic profession }\end{array}$ & & $\begin{array}{c}-0.647^{* * *} \\
(0.092)\end{array}$ & $\begin{array}{c}-0.648^{* * *} \\
(0.098)\end{array}$ & $\begin{array}{c}-0.648^{* * *} \\
(0.099)\end{array}$ & $\begin{array}{c}-0.644^{* * *} \\
(0.099)\end{array}$ & $\begin{array}{c}-0.650^{* * *} \\
(0.099)\end{array}$ \\
\hline $\begin{array}{l}\text { Other mental work (e.g. } \\
\text { accountant, admin assistant) }\end{array}$ & & $\begin{array}{c}-0.795^{* * *} \\
(0.097)\end{array}$ & $\begin{array}{c}-0.785^{* * *} \\
(0.101)\end{array}$ & $\begin{array}{c}-0.794^{* * *} \\
(0.102)\end{array}$ & $\begin{array}{c}-0.780^{* * *} \\
(0.102)\end{array}$ & $\begin{array}{c}-0.800^{* * *} \\
(0.102)\end{array}$ \\
\hline (Semi-)skilled manual work & & $\begin{array}{c}-0.883^{* * *} \\
(0.116)\end{array}$ & $\begin{array}{c}-0.892^{* * *} \\
(0.113)\end{array}$ & $\begin{array}{c}-0.881^{* * *} \\
(0.115)\end{array}$ & $\begin{array}{c}-0.887^{* * *} \\
(0.114)\end{array}$ & $\begin{array}{c}-0.887^{* * *} \\
(0.115)\end{array}$ \\
\hline $\begin{array}{l}\text { Unskilled manual work and } \\
\text { agrarian profession }\end{array}$ & & $\begin{array}{c}-0.849^{* * *} \\
(0.160)\end{array}$ & $\begin{array}{c}-0.882^{* * *} \\
(0.167)\end{array}$ & $\begin{array}{c}-0.849^{* * *} \\
(0.170)\end{array}$ & $\begin{array}{c}-0.880^{* * *} \\
(0.169)\end{array}$ & $\begin{array}{c}-0.851^{* * *} \\
(0.171)\end{array}$ \\
\hline Sector controls & & Yes & Yes & Yes & Yes & Yes \\
\hline Constant & $\begin{array}{c}3.080^{* * *} \\
(0.258)\end{array}$ & $\begin{array}{c}4.468^{* * *} \\
(0.325)\end{array}$ & $\begin{array}{c}4.492^{* * *} \\
(0.328)\end{array}$ & $\begin{array}{c}4.491^{* * *} \\
(0.332)\end{array}$ & $\begin{array}{c}4.496^{* * *} \\
(0.332)\end{array}$ & $\begin{array}{c}4.530^{* * *} \\
(0.334)\end{array}$ \\
\hline$\rho$ & & -0.113 & -0.119 & & & \\
\hline R2 & & & & 0.349 & 0.358 & 0.349 \\
\hline Observations & 1557 & 1405 & 1405 & 1405 & 1405 & 1405 \\
\hline
\end{tabular}

Note: Robust standard errors in parentheses. POS = perceived organisational support. Column (1) shows the results for the probit estimation of the probability of being employed in dependent employment, and columns (2) and (3) show the results of a bias-corrected 0LS estimation for intrapreneurial behaviour. ${ }^{*} p<0.10,{ }^{* *} p<0.05,{ }^{* * *} p<0.01$

\subsection{Results}

\subsubsection{Personality, organisational support and intrapreneurial behaviour}

Columns I and 2 in Table 4.3 show the estimation results of the Heckman selection model. We estimate a model with a continuous measure of intrapreneurial behaviour, including only the main effects for the dependent variables. The first stage estimation results (estimating $\mathrm{E}_{\mathrm{i}}$ ) of this model are presented in column I of Table 4.3. We first assess the appropriateness of the exclusion restriction. Having an entrepreneurial parent appears to be significantly negatively related to being in dependent employment. This indicates that having an entrepreneurial parent is a good predictor for the choice of independent over dependent employment. Furthermore, following Certo et al (2016), we estimate an OLS regression of all variables, including the variable for having an entrepreneurial parent on intrapreneurial behaviour. The results presented in column 6 of Table 4.3 show that having an entrepreneurial parent is not significantly related to intrapreneurial behaviour, which gives an indication of the validity of the exclusion restriction. 
Next, column I of Table 4.3 shows that Neuroticism, Extraversion and Risk tolerance, and higher levels of Agreeableness are significantly associated with those in dependent employment. These results suggest that personality traits play a role in workers' selection into dependent employment.

Column 2 in Table 4.3 presents the results of the second stage of the model, $\mathrm{I}_{\mathrm{i}}$, with intrapreneurial behaviour as the dependent variable. Here we see that $\rho$, indicating the correlation between the error terms in the first- $\left(\mathrm{E}_{\mathrm{i}}\right)$ and second-stage estimation $\left(\mathrm{I}_{\mathrm{i}}\right)$, is insignificant. Consequently, we can expect that OLS does not produce biased results, even though there is self-selection into dependent employment. The results in columns 2 show that Extraversion and Openness are positively related to intrapreneurial behaviour. Furthermore, we find that risk tolerance is also positively related to intrapreneurial behaviour. Therefore, hypotheses I, 2 and 4 are supported. In addition, we find no significant relation between intrapreneurial behaviour and Neuroticism, Conscientiousness, and Agreeableness. Consequently, hypothesis 3 is not supported. As expected, the results show that perceived organisational support for intrapreneurship is positively related to intrapreneurial behaviour. Therefore, hypothesis 5 a is supported.

Next, we investigate the moderating effect of organisational support on the relations between the personality traits and intrapreneurial behaviour. We estimate a model with interactions between the personality traits and organisational support. Column 3 presents the results of the second stage of the model, $I_{i}$, including interaction terms between the personality traits and perceived organisational support for intrapreneurship. The estimation results of first stage of the model, $\mathrm{E}_{\mathrm{i} \text {, }}$ are identical to those presented in column I and are therefore not presented here. The results show that perceived organisational support for intrapreneurship strengthens the positive relation between Openness as well as the positive relation between risk tolerance and intrapreneurial behaviour. However, the latter is only marginally significant, and we do not find significant moderation effects between perceived organisational support for intrapreneurship and the other personality traits. Therefore, we find only partial support for hypothesis $5 \mathrm{~b}$.

Columns 4 and 5 in Table 4.3 present the uncorrected OLS estimator of $I_{i}$. Comparing columns 2 and 3 with columns 4 and 5 , we can see that the OLS estimator does indeed not produce biased results.

\section{Control variables}

Columns 2, 3 and 4 in Table 4.3 show consistent results for all control variables. We find that the average level of intrapreneurial behaviour does not differ between males and females. Furthermore, we find that older workers have lower levels of intrapreneurial behaviour and that highly educated employees have higher levels of intrapreneurial behaviour as compared to those with secondary or vocational education. Moreover, the results show that employees who have received business training have higher 
levels of intrapreneurial behaviour as compared to those who did not receive this training. However, higher tenure is not related to intrapreneurial behaviour, suggesting that firm specific human capital may not be related to intrapreneurial behaviour. Surprisingly, we do not find that higher levels of job autonomy increase intrapreneurial behaviour. Furthermore, we find that employees in management and sales jobs have higher levels of intrapreneurial behaviour than those in all other types of jobs we distinguish.

\subsubsection{Additional analyses}

\section{The probability to be a highly intrapreneurial employee}

As a robustness analysis, we investigate whether the results would be different when we estimate the probability to be a highly intrapreneurial employee. Results from estimations of linear probability models and probit models are presented in Appendix Table A4.3. Estimation results of linear probability models are similar to the OLS estimator reported in Table 4.3. However, probit estimation results of a model including interactions between the personality variables and perceived organisational support for intrapreneurship do not show any significant interactions.

\section{Career related risk tolerance}

Furthermore, as intrapreneurial behaviour presents a possible career risk for employees that engage in this behaviour (Kacperczyk, 20I2; Zenovia, 20II), we investigate whether the results are affected when we replace general risk tolerance with a more specific measure of risk tolerance related to career risk (see Fouarge et al., 20I4). Appendix Table 4.3 shows that career risk tolerance is positively related to intrapreneurial behaviour. However, the coefficient of career risk is smaller than the coefficient for general risk tolerance. Therefore, general risk tolerance appears to be a stronger predictor for intrapreneurial behaviour than career related risk tolerance. In addition, we find that higher levels of organisational support do not increase the positive effect of career related risk tolerance on intrapreneurial behaviour.

\section{Comparing intrapreneurs and entrepreneurs}

An interesting question remains: Are personality traits that are predictive for being an entrepreneur also predictive for higher levels of intrapreneurial behaviour. Table 4.4 shows the estimation results of a probit model in which we compare personality traits of highly intrapreneurial employees with those of entrepreneurs. The dependent variable is a dichotomous variable that takes I when we classify an employee high in intrapreneurial behaviour $(\geq 4)$, and o when a worker is an entrepreneur. Apart from the Big Five personality characteristics and risk tolerance, we also include age, gender, educational level, business training and having an entrepreneurial parent in the model. 
Table 4.4 - Differences between intrapreneurs and entrepreneurs

\begin{tabular}{|c|c|c|}
\hline & $\begin{array}{c}(1) \\
\text { Probit }\end{array}$ & $\begin{array}{c}(2) \\
\text { Probit }\end{array}$ \\
\hline Neuroticism & $\begin{array}{l}-0.027 \\
(0.078)\end{array}$ & $\begin{array}{l}-0.034 \\
(0.078)\end{array}$ \\
\hline Extraversion & $\begin{array}{l}-0.058 \\
(0.085)\end{array}$ & $\begin{array}{l}-0.054 \\
(0.085)\end{array}$ \\
\hline Agreeableness & $\begin{array}{c}0.117 \\
(0.081)\end{array}$ & $\begin{array}{c}0.110 \\
(0.081)\end{array}$ \\
\hline Openness & $\begin{array}{l}0.179^{* *} \\
(0.080)\end{array}$ & $\begin{array}{l}0.189^{* *} \\
(0.079)\end{array}$ \\
\hline Conscientiousness & $\begin{array}{c}0.203^{* * *} \\
(0.074)\end{array}$ & $\begin{array}{c}0.201^{* * *} \\
(0.074)\end{array}$ \\
\hline Risk tolerance & $\begin{array}{c}0.019 \\
(0.081)\end{array}$ & \\
\hline Career risk tolerance & & $\begin{array}{l}-0.037 \\
(0.082)\end{array}$ \\
\hline Age & $\begin{array}{c}-0.050^{* * * *} \\
(0.007)\end{array}$ & $\begin{array}{c}-0.050^{* * *} \\
(0.007)\end{array}$ \\
\hline Female, male=ref. & $\begin{array}{c}-0.416^{* *} \\
(0.165)\end{array}$ & $\begin{array}{l}-0.422^{* *} \\
(0.165)\end{array}$ \\
\hline $\begin{array}{l}\text { Education, BA or higher = ref. } \\
\text { elementary }\end{array}$ & $\begin{array}{c}0.529 \\
(0.719)\end{array}$ & $\begin{array}{c}0.565 \\
(0.711)\end{array}$ \\
\hline secondary & $\begin{array}{l}-0.220 \\
(0.203)\end{array}$ & $\begin{array}{l}-0.215 \\
(0.202)\end{array}$ \\
\hline vocational & $\begin{array}{l}-0.040 \\
(0.181)\end{array}$ & $\begin{array}{l}-0.047 \\
(0.181)\end{array}$ \\
\hline Business training, $n 0=r e f$ & $\begin{array}{l}-0.214 \\
(0.176)\end{array}$ & $\begin{array}{l}-0.207 \\
(0.176)\end{array}$ \\
\hline Entrepreneurial parent, no=ref & $\begin{array}{c}-0.645^{* * *} \\
(0.157)\end{array}$ & $\begin{array}{c}-0.644^{* * *} \\
(0.157)\end{array}$ \\
\hline Constant & $\begin{array}{c}3.078^{* * *} \\
(0.377)\end{array}$ & $\begin{array}{c}3.096^{* * *} \\
(0.381)\end{array}$ \\
\hline $\begin{array}{l}\text { Observations } \\
\text { Pseudo R2 }\end{array}$ & $\begin{array}{c}380 \\
0.196\end{array}$ & $\begin{array}{c}380 \\
0.197\end{array}$ \\
\hline
\end{tabular}

Note: The dependent variable takes value 1 when the sum-score of an employee's level of intrapreneurial behaviour is 4 or higher. The dependent variable takes value 0 when a worker is independently employed. Robust standard errors in parentheses. ${ }^{*} p<0.10,{ }^{* *} p<0.05,{ }^{* * *} p<0.01$

Concerning personality differences, column I shows that the probit estimation yields highly similar results as the mean comparisons in Table 4.I. We find that highly intrapreneurial employees have higher levels of Openness and Conscientiousness 
as compared to entrepreneurs. In addition, as compared to entrepreneurs, highly intrapreneurial employees are younger, less likely to be female or to have an entrepreneurial parent. However, intrapreneurs and entrepreneurs do not differ in their level of Neuroticism, Agreeableness, Extraversion and risk tolerance. Comparing these results with those in column I of Table 4.3, we notice that, although higher levels of Neuroticism, Extraversion and risk tolerance, and lower levels of Agreeableness, are related to being in independent employment, intrapreneurs do not differ from entrepreneurs in these traits. Moreover, highly intrapreneurial employees do not differ from entrepreneurs in their education level or likelihood of having undergone training in business and entrepreneurship. Openness is not related to being in independent or dependent employment, but intrapreneurs have higher levels of this trait than entrepreneurs. Higher levels of Conscientiousness are (marginally significantly) related to being in dependent employment, and therefore highly intrapreneurial employees have higher levels of Conscientiousness than entrepreneurs.

Furthermore, we estimate a model in which we replace general risk tolerance with career related risk tolerance. The results of this estimation, presented in column 2 of Table 4.4, show that there is also no difference between entrepreneurs and intrapreneurs in their levels of career related risk tolerance.

\subsection{Discussion}

We investigated the relation between the Big Five personality traits, risk tolerance and intrapreneurial behaviour. In addition, we investigated how employees' perceptions of the support for intrapreneurship of the organisations where they are employed affects these relations. Congruent with earlier studies (e.g. Caliendo et al., 20I4; Holland, I976), we find that workers sort into dependent and independent employment along personality traits. In addition, we find that employees with higher levels of Extraversion, Openness and risk tolerance have higher levels of intrapreneurial behaviour. Furthermore, employees who perceive higher levels of support for intrapreneurship in their organisations have higher levels of intrapreneurial behaviour. Moreover, we find that the positive relation between Openness on intrapreneurial behaviour increases when employees are working in organisations in which they perceive higher levels of organisational support for intrapreneurship. We additionally show that highly intrapreneurial employees are more similar to entrepreneurs than other employees in terms of their personality traits are.

Our findings are in line with Ahmed et al. (2013), Sinha and Strivastava (2013), Farruhk et al. (2016) and Woo (2018), who show that Extraversion is positively related to intrapreneurial behaviour, and with Ahmed et al. (2013), Farruhk et al. (2016) and Woo (2018), who show that Openness is positively related to intrapreneurial behaviour. Our findings therefore suggest that these relations are consistent across Asian and 
Dutch cultural contexts. Furthermore, our findings are in line with Monsen et al. (2010) and Douglas and Fitzsimmons (2013) who find that risk tolerance is positively related to intrapreneurial behaviour. Moreover, in line with Sinha and Strivastava (2013), we find no significant relations between Conscientiousness or Agreeableness and intrapreneurial behaviour. This is contrary to Woo (2018), who finds positive relations between both Agreeableness and Conscientiousness and intrapreneurial behaviour. However, in line with Woo (2018), we find no significant relation between Neuroticism and intrapreneurial behaviour. This is contrary to Sinha \& Strivastava (2013) and Farruhk et al., (2016), who find negative relations between Neuroticism and intrapreneurial behaviour.

Our findings are valuable for understanding (self-) selection mechanisms into intrapreneurial activities and add to the accumulating evidence for the positive relation between Extraversion, Openness, risk tolerance and intrapreneurship (Ahmed et al., 2013; Douglas \& Fitzsimmons, 2013; Farruhk et al., 2016; Sinha \& Strivastava, 2013; Woo, 2018). There may be several possible reasons for the observed mixed results for the relations of the other Big Five personality traits and intrapreneurship across different studies. These mixed findings may not only be related to differences in cultural contexts, but also could be due to the different ways in which intrapreneurial behaviour is measured. For instance, in this study, we use a measure of intrapreneurial behaviour that assesses behaviours related to new venture creation and strategic renewal, whereas Farruhk et al. (2016) measure intrapreneurial behaviour as a composite of innovative behaviour and risk taking behaviour, and Woo (2018) measures intrapreneurial behaviour as a composite measure of behaviours related to new business creation, product innovation, process and technological innovation and renewal.

We find that some personality traits that are predictive for being an entrepreneur, are also predictive for higher levels of intrapreneurial behaviour. More specifically, in line with Matthews et al. (2009), we find that both higher levels of Extraversion and risk tolerance are related to both being an entrepreneur and showing higher levels of intrapreneurial behaviour. These finding are contrary to Martiarena (2013) and Douglas and Fitzsimmons (2013) who find that intrapreneurs are less risk tolerant than entrepreneurs. However, although levels of Neuroticism do not differ between highly intrapreneurial employees and entrepreneurs in our sample, higher levels of Neuroticism appear to set workers up for entrepreneurship, whereas higher levels of Openness are only related to higher levels of intrapreneurial behaviour. Differences we find between entrepreneurs and highly intrapreneurial employees with regard to their level of Conscientiousness may be explained by our finding that workers with higher levels of Conscientiousness are more likely to sort into dependent employment. In addition, we find that highly intrapreneurial employees are younger than entrepreneurs. An explanation for this findings may be that highly intrapreneurial employees do not have the social or financial capital needed 
to start their own business, and therefore remain in dependent employment. This interpretation is congruent with Blumberg and Pfann (2017) whose findings suggest that workers who become self-employed without taking over a family business, do so later in their careers, after acquiring sufficient entrepreneurial capital.

In addition, this is the first study that investigates the role of organisational culture for the relationship between employees' personality and intrapreneurial behaviour. As such, our findings contribute to understanding the influence of the organisational environment on intrapreneurial behaviour (e.g. de Jong et al., 20I5; Kuratko et al., I990; 20I4; Mustafa et al., 20I8). The results show that higher levels of intrapreneurial behaviour can be found in organisations in which employees perceive that they are rewarded for intrapreneurship and financial and time resources are available to pursue intrapreneurship. Pairwise correlational analyses show that employees with higher levels of personality traits that are conducive for intrapreneurship - Extraversion, Openness, and risk tolerance - are employed in organisations in which they perceive higher levels of support for intrapreneurship. This suggests that workers with higher levels of personality traits that are conducive for intrapreneurship self-select into organisations that allow for expression of these personality traits into intrapreneurial behaviour. This finding is congruent with the finding in Chapter 2 of this dissertation that Master students with entrepreneurial dispositions, but who do not plan on starting their own business, are especially attracted to organisations that focus on innovation.

This may also explain why we find only some support for trait activation theory (Tett $\&$ Burnett, 2003). Trait activation theory predicts that the organisational environment provides cues that can either hinder or facilitate the expression of personality traits into behaviour. In support of trait activation theory, we find that when employees perceive that the organisation is supportive of these activities, those with higher levels of Openness have even higher levels of intrapreneurial behaviour. However, we do not find that perceptions of organisational support for intrapreneurship increases the involvement of employees with higher levels of Extraversion, and only marginally for employees with high levels of risk tolerance.

Furthermore, the relationships of the control variables with intrapreneurial behaviour are largely in line with previous research findings. In accordance with Parker (20II), we find that older workers have lower levels of intrapreneurial behaviour. In addition, in line with Parker (20II) and Adachi and Hisada (20I7) we find that highly educated employees have higher levels of intrapreneurial behaviour as compared to those with secondary or vocational education. Moreover, in line with Martiarena (2013) we find that employees who have received business training have higher levels of intrapreneurial behaviour as compared to those who did not receive this training. In accordance with de Jong et al. (2015), we find that employees in management and sales jobs have higher levels of intrapreneurial behaviour than those in all other types of jobs we include. However, contrary to de Jong et al. (2015) we do not find that 
higher levels of job autonomy increase intrapreneurial behaviour. Contrary to Adachi and Hisada (2018) but in line with Martiarena (2013), our results show no gender differences in the average level of intrapreneurial behaviour.

\subsubsection{Implications for practice}

First, our results can inform those who are responsible for recruitment and selection procedures. Workers with higher levels of Extraversion, Openness and risk tolerance are more likely to show intrapreneurial behaviour. These traits can therefore be assessed during selection procedures. Furthermore, our results suggest that organisations that signal a supportive work environment for innovative activities are more successful in attracting employees with higher intrapreneurial potential. Therefore, organisations can highlight their support for intrapreneurship in their employer branding and during the recruitment process.

Second, our findings suggest that providing supportive measures for intrapreneurship does not incentivise all employees to engage in intrapreneurial behaviour. Providing employees with rewards, time and organisational resources for intrapreneurship may provide incentives for increased intrapreneurial behaviour for employees with higher levels of Openness. However, this is not the case for employees with higher levels of Extraversion and risk tolerance.

Third, organisations could provide intrapreneurial training to their employees. We show that employees who have experience with training in business creation or entrepreneurship have higher levels of intrapreneurial behaviour. Menzel et al. (2007) advise that training programs aimed at intrapreneurship should be multidisciplinary in nature, involve multiple stakeholders, and combine theory and practice by means of scenario-based simulations and role-playing. In addition, they suggest that these trainings should address planning, collaboration, and reflection.

\subsubsection{Limitations and future research}

A first limitation of the study presented in this chapter is that we do not observe intrapreneurial behaviour over time. As such, we cannot distinguish between successful and unsuccessful intrapreneurial behaviour. Related to this point, personality traits may have different effects depending on the phase within the intrapreneurial process. For instance, in the case of entrepreneurship, Caliendo et al. (20I4) show that although Conscientiousness is not related to workers' entry into entrepreneurship, higher levels of Conscientiousness are conducive for successful entrepreneurship. Future research could therefore investigate the influence of the phase of the intrapreneurial project on the relations between personality traits and intrapreneurial behaviour, and how personality traits relate to successful and unsuccessful intrapreneurship.

A second limitation of our study is that we focus on the broad factors of the Big Five personality traits. We do not distinguish between sub-dimensions of the personality traits, nor do we include more specific personality traits. Analyses 
including different subdimensions of the Big Five personality traits may yield more fine-grained insights into the relation between personality and intrapreneurial behaviour. For instance, the available data did not allow us to distinguish between subdimensions of Conscientiousness relating to achievement orientation on the one hand and efficiency on the other hand. One may expect that these sub-dimensions are differentially related to intrapreneurial behaviour. Future research can therefore investigate the relations between relevant subdimensions of the Big Five personality traits and intrapreneurial behaviour.

Third, we use a sample of workers from the Dutch population. Therefore, it is not evident that the results presented in this chapter are generalisable to other cultural contexts. Further investigations are needed with regard to the influence of cultural context on the relations between personality traits and intrapreneurial behaviour.

\subsection{Appendix}

Table A4.1 - Employee intrapreneurship scale (shortened 8-item scale)

\section{Strategic renewal behaviour}

1. I undertake activities to realise change in my organisation.

2. I undertake activities to change the current products/services of my organisation.

3. I contribute ideas for strategic renewal for my organisation.

4. I conceptualise new ways of working for my organisation.

\section{Venturing behaviour}

5. I undertake activities to set up new business units.

6. I undertake activities to reach a new market or community with my organisation.

7. I undertake activities that result in new departments outside of my organisation.

8. I actively establish new collaborations with experts outside of my own profession.

Source: Gawke et al. (2017; 2019). 
Table A4.2 - The probability to be a highly intrapreneurial employee

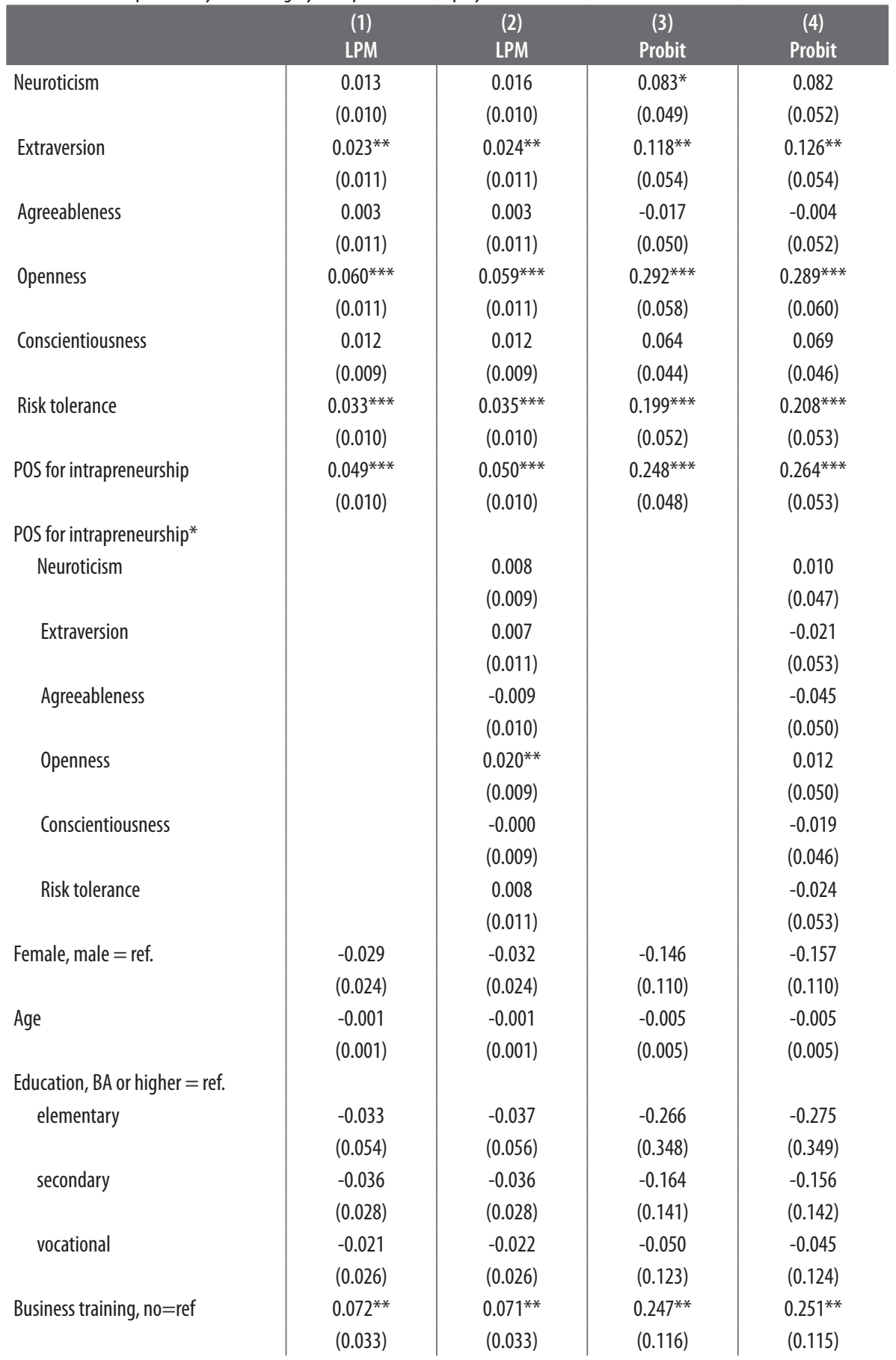


Table A4.2 - The probability to be a highly intrapreneurial employee Continued

\begin{tabular}{|c|c|c|c|c|}
\hline & $\begin{array}{c}(1) \\
\text { LPM }\end{array}$ & $\begin{array}{c}(2) \\
\text { LPM }\end{array}$ & $\begin{array}{c}\text { (3) } \\
\text { Probit }\end{array}$ & $\begin{array}{c}(4) \\
\text { Probit }\end{array}$ \\
\hline Tenure & $\begin{array}{l}-0.001 \\
(0.001)\end{array}$ & $\begin{array}{l}-0.001 \\
(0.001)\end{array}$ & $\begin{array}{l}-0.008 \\
(0.005)\end{array}$ & $\begin{array}{l}-0.008 \\
(0.005)\end{array}$ \\
\hline Autonomy & $\begin{array}{l}0.003 \\
(0.014)\end{array}$ & $\begin{array}{c}0.004 \\
(0.014)\end{array}$ & $\begin{array}{c}0.028 \\
(0.067)\end{array}$ & $\begin{array}{c}0.027 \\
(0.067)\end{array}$ \\
\hline & & & & \\
\hline $\begin{array}{l}\text { Higher/intermediate } \\
\text { academic profession }\end{array}$ & $\begin{array}{c}-0.156^{* * *} \\
(0.033)\end{array}$ & $\begin{array}{c}-0.156^{* * *} \\
(0.033)\end{array}$ & $\begin{array}{c}-0.571^{* * *} \\
(0.124)\end{array}$ & $\begin{array}{c}-0.576^{* * *} \\
(0.124)\end{array}$ \\
\hline $\begin{array}{l}\text { 0ther mental work (e.g. } \\
\text { accountant, admin assistant) }\end{array}$ & $\begin{array}{c}-0.139^{* * *} \\
(0.032)\end{array}$ & $\begin{array}{c}-0.136^{* * *} \\
(0.032)\end{array}$ & $\begin{array}{c}-0.530^{* * *} \\
(0.136)\end{array}$ & $\begin{array}{c}-0.530^{* * *} \\
(0.136)\end{array}$ \\
\hline (Semi-)skilled manual work & $\begin{array}{c}-0.172^{* * *} \\
(0.034)\end{array}$ & $\begin{array}{c}-0.173^{* * *} \\
(0.034)\end{array}$ & $\begin{array}{c}-0.819^{* * *} \\
(0.175)\end{array}$ & $\begin{array}{c}-0.827^{* * *} \\
(0.175)\end{array}$ \\
\hline $\begin{array}{l}\text { Unskilled manual work and } \\
\text { agrarian profession }\end{array}$ & $\begin{array}{l}-0.042 \\
(0.048)\end{array}$ & $\begin{array}{l}-0.047 \\
(0.048)\end{array}$ & $\begin{array}{l}-0.070 \\
(0.219)\end{array}$ & $\begin{array}{l}-0.061 \\
(0.219)\end{array}$ \\
\hline Sector controls & Yes & Yes & Yes & Yes \\
\hline Constant & $\begin{array}{c}0.294^{* * *} \\
(0.094)\end{array}$ & $\begin{array}{c}0.293^{* * *} \\
(0.094)\end{array}$ & $\begin{array}{l}-0.716 \\
(0.455)\end{array}$ & $\begin{array}{l}-0.695 \\
(0.455)\end{array}$ \\
\hline (Pseudo) R2 & 0.162 & 0.167 & 0.194 & 0.196 \\
\hline Observations & 1405 & 1405 & 1405 & 1405 \\
\hline
\end{tabular}

Note: Robust standard errors in parentheses. POS = perceived organisational support. The dependent variable takes 1 when the sum-score of an employee's level of intrapreneurial behaviour is 4 or higher, and 0 when an employee's intrapreneurial behaviour is lower than $4 .{ }^{*} p<0.10,{ }^{* *} p<0.05,{ }^{* * *} p<0.01$ 
Table A4.3 - Career related risk tolerance and intrapreneurial behaviour

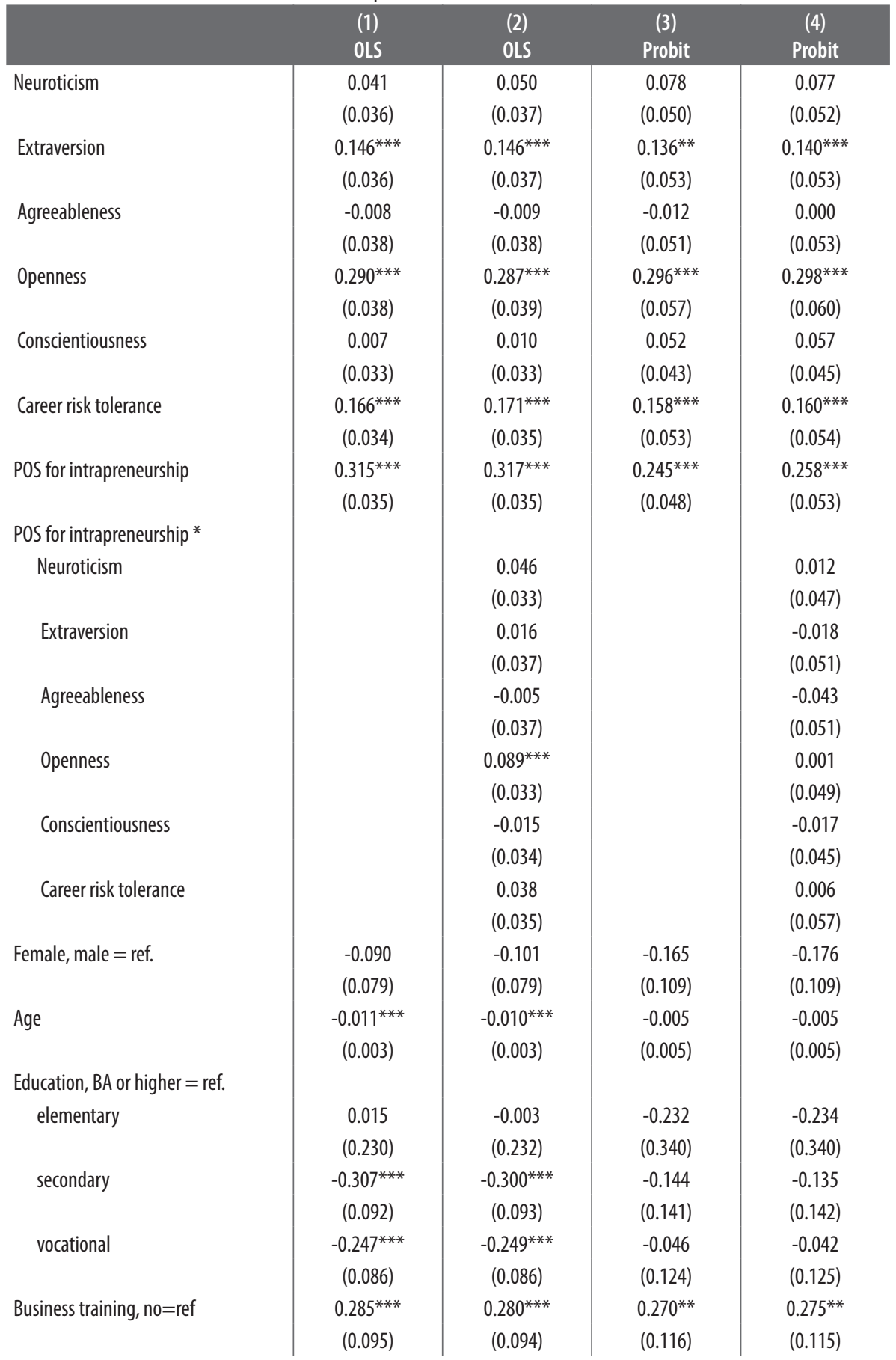


Table A4.3 - Career related risk tolerance and intrapreneurial behaviour Continued

\begin{tabular}{l|c|c|c|c}
\multicolumn{1}{c}{$(1)$} & $(2)$ & $(3)$ & (4) \\
& OLS & PLS & Probit & -0.006 \\
Tenure & -0.001 & -0.001 & -0.006 & $(0.005)$ \\
Autonomy & $(0.003)$ & $(0.003)$ & $(0.005)$ & 0.033 \\
& -0.016 & -0.013 & 0.035 & $(0.067)$ \\
Job type, management/sales =ref & $(0.047)$ & $(0.047)$ & $(0.067)$ & \\
Higher/intermediate & & & & $-0.555^{* * *}$ \\
academic profession & $-0.636^{* * *}$ & $-0.634^{* * *}$ & $-0.555^{* * *}$ & $(0.124)$ \\
Other mental work (e.g. & $(0.100)$ & $(0.100)$ & $(0.124)$ & $-0.513^{* * *}$ \\
accountant, admin assistant) & $-0.780^{* * *}$ & $-0.764^{* * *}$ & $-0.516^{* * *}$ & $(0.135)$ \\
(Semi-)skilled manual work & $(0.103)$ & $(0.103)$ & $(0.136)$ & $-0.798^{* * *}$ \\
Unskilled manual work and & $-0.853^{* * *}$ & $-0.857^{* * *}$ & $-0.790^{* * *}$ & $(0.175)$ \\
agrarian profession & $(0.116)$ & $(0.116)$ & $(0.174)$ & -0.063 \\
Sector controls & $-0.840^{* * *}$ & $-0.876^{* * *}$ & -0.073 & $(0.219)$ \\
Constant & $(0.169)$ & $(0.169)$ & $(0.218)$ & 1405 \\
\hline (Pseudo) R2 & & & & Yes \\
\hline Observations & Yes & Yes & Yes & -0.727 \\
\hline
\end{tabular}

Note: Robust standard errors in parentheses. POS = perceived organisational support. The dependent variable in column (3) and (4) takes 1 when the sum-score of an employee's level of intrapreneurial behavior is 4 or higher, and 0 when an employee's intrapreneurial behaviour is lower than $4 .{ }^{*} p<0.10,{ }^{* *} p<0.05,{ }^{* * *} p<0.01$ 



\section{New Ways of Working and Intrapreneurship: the mediating role of Transformational Leadership and Social Interaction}

This chapter is joint work with Ruud Gerards and Cecile van Sambeek, and is under revise and resubmit at Review of Managerial Science. We thank Evert Webers from Etil Research for his assistance in the survey design and data collection, and Martin Carree, Julia Kensbock, Coen Rigtering and Andries de Grip for helpful comments and suggestions on earlier versions of this chapter. 


\subsection{Introduction}

Innovation is a crucial aspect of business success and societal development (Cefis \& Marsili, 2006; Mumford, 2000). Employees can contribute to the firm's success by pursuing innovation and entrepreneurial activities bottom-up (Rigtering \& Weitzel, 2013; Rigtering et al., 2019; Sharma \& Chrisman, 1999). These entrepreneurial employees are known as intrapreneurs (Pinchot, 1985) and instigate new internal ventures, strategic renewal, and enter new markets (de Jong et al., 20I5; Gawke et al., 2017). For intrapreneurship to flourish, organisations should be organised in a way that promotes openness to innovation and entrepreneurship (Kuratko et al, 20I4; Kuratko et al, 1990; Mustafa et al., 20I8). New Ways of Working (NWW) have been implemented by an increasing number of organisations with the aim of improving both efficiency and innovativeness (Bijl, 2009; Brunia et al., 20I6; Nijp et al., 20I6; Kingma, 20I8).

NWW are a bundle of human resource management practices that affect employees' physical workspace, technology, organisation and management, and the work culture (Blok et al., 20I2; Gerards et al., 20I8a). NWW enable employees to work anytime and anywhere they want. This could be in an open-plan office, specifically designed to foster collegial encounters, but also from home, enabled by information and communications technologies (ICT) that offer unlimited accessibility and connectivity with colleagues as well as organisational networks. In addition, NWW implies that instead of the monitoring of work processes, employees are managed according to their performance and output. Moreover, NWW entails the freedom for employees to prioritise and organise their employment relation in such a way that suits their personal situation, ambition and lifestyle (Gerards et al., 20I8a). In sum, NWW aims to grant employees more flexibility, autonomy and freedom with the support of electronic communication (Peters et al., 20I4).

We build on social exchange theory (Blau, I964; Emerson, 1976; Homans, 1958) and theorise that NWW affect intrapreneurship by altering the social exchanges at various levels in an organisation: between the organisation and its employees, between individual employees, and employees and their managers. Using social exchange theory will help us form expectations about the relations between NWW and employee intrapreneurship, because these relations do not follow unambiguously from prior literature. For instance, recommendations from the literature on facilitating employee intrapreneurship often focus on increasing the NWW related job resources of flexibility, autonomy and freedom (e.g. de Jong et al., 20I5; Kuratko et al., 1990; Kuratko et al., 2014; Martins \& Terblanche, 2003). However, autonomy in NWW entails the absence of direct supervision and a focus on outputs that - if not supported by a suitable leadership style - might not be conducive for intrapreneurial behaviour. For instance, in fear of negative reciprocal consequences (Jung et al., 2003), employees will not engage in taking initiatives when organisations and leaders 
emphasise efficiency without making mistakes, even when they are given autonomy (Jung et al., 2003; Yukl, 200I).

Therefore, a suitable leadership style to support NWW and intrapreneurship is transformational leadership (Gerards et al., 20I8a). Transformational leadership is associated with positive social exchanges between leaders and their followers (Graen \& Uhl-Bien, 1995) and concerns leaders who create trust, inspire employees, and provide a vision and common goal for all employees to work towards (Bass, 1999). It is known to facilitate employee intrapreneurship (Moriano et al., 20I4). Moreover, Gerards et al. (2018a) elaborate how NWW may actually help push a managerial change towards transformational leadership. Therefore, we include transformational leadership as potential mediator in our analysis of the relation between NWW and intrapreneurship.

Similarly, organizational communication networks are essential for intrapreneurial behaviour (e.g. Heinze \& Weber, 20I6; Rigtering \& Weitzel, 20I3) and the social exchanges that occur in these networks facilitate the development of novel ideas (Fried et al., 2007; Russell, 1999) and concomitantly employee intrapreneurship. However, employees' flexibility in work location and time, in number of working hours and the increased reliance on communications technology entailed in NWW can simultaneously make for obstruction and facilitation of social exchanges between employees and between employees and their managers (Gerards et al., 20I8a). High quality social exchanges between co-workers are characterised by mutual support and high levels of interactions (Fried et al., 2007). We use the concept of 'social interaction' to capture these relations between co-workers (Gerards et al., 20I8a), and we employ it as another potential mediator in our analyses, next to transformational leadership.

For our empirical analyses, we use a sample of 254 employees across various economic sectors and occupations in the Netherlands. We find that an organisation's extent of NWW adoption is positively related to intrapreneurship. As expected, this relation is partially mediated by transformational leadership. However, social interaction does not mediate the relation between NWW and intrapreneurship. Although NWW are positively related to social interaction in the workplace, we find no relation between social interaction and intrapreneurship. Finally, we find that particularly the NWW facets that relate to granting employees autonomy in choosing when, where and how to work drive the positive relation between NWW and intrapreneurship.

We contribute to the literature in two ways. First, we contribute to the budding literature on the effects of NWW. Given the increasing number of organisations that adopt NWW, it is remarkable that there is only limited understanding of its effect on employee outcomes (Blok et al., 20I2; Nijp et al., 20I6; Gerards et al., 20I8a). Recent studies show, however, that NWW affect employee outcomes, such as informal learning efforts (Gerards et al., 20I8b) and work engagement (Gerards 
et al., 2018a). We contribute to this line of research by investigating the relation between NWW and employee intrapreneurship. Second, we contribute to the research that investigates organisational- and individual-level determinants of employee intrapreneurship. Previous studies on this relation show for instance that organisational structure (Kuratko et al., 20I4) and job design (e.g. de Jong et al., 20I5; Rigtering \& Weitzel, 2013) affect employee intrapreneurship. We add to this strand of literature by showing that NWW contributes to employee intrapreneurship, while controlling for individual-level determinants of intrapreneurship.

The remainder of this chapter is structured as follows. In Section 5.2 we review the literature on intrapreneurship and NWW, and develop our hypotheses. Section 5.3 describes our methods and Section 5.4 presents the estimation results. In Section 5.5 we reflect on the implications of our results for both research and practice.

\subsection{Literature review and hypotheses}

\subsubsection{Intrapreneurship and intrapreneurial behaviour}

Intrapreneurship is generally described as entrepreneurship within an existing organisation (Menzel, et al., 2007) and relates to a process in which one or more employees instigate renewal, innovation or create a new organisation in an existing organisation (Sharma \& Chrisman, 1999). Intrapreneurs are therefore often described as entrepreneurial employees (Antoncic \& Hisrich, 200I; Blanka, 20I8; Pinchot, 1985).

Contrary to entrepreneurs, intrapreneurs operate in an organisational environment which allows them to make use of organisational resources and networks, and enjoy greater support and flexibility in case of failure (Zenovia, 20II). However, the organisational environment can also entail restrictions with regard to autonomy and flexibility as they are subject to existing policies, regulations and bureaucracy (Zenovia, 20II). Indeed, previous research shows that contextual factors such as job and organizational characteristics are important determinants of employee intrapreneurship (see Mustafa et al., 20I8, for a review). Moreover, in contrast to entrepreneurs, employees' contracts usually translate into limited potential rewards for the intrapreneurial individual. However, as the ownership of the idea and the inherent financial risk of pursuing an entrepreneurial opportunity remain with the organisation, employees are shielded from these and instead carry career related risk in case of project failure (Kacperczyk, 20I2).

Although intrapreneurship refers to individual employees, research on intrapreneurship has mainly focused on the antecedents and consequences of intrapreneurship at the organisational level, which is known as corporate entrepreneurship (Antoncic \& Hisrich, 2003; Covin \& Slevin, 199I; Guth \& Ginsberg, 1990; Lumpkin \& Dess, 1996; Zahra, 199I). However, a growing body of 
research investigates intrapreneurship at the employee level (see Blanka, 20I8, for a review) and attempts to uncover the drivers of intrapreneurial employee behaviour (e.g. de Jong et al., 2015; Rigtering et al., 2019).

Intrapreneurial behaviour is usually conceptualised as employees' innovative, proactive and risk taking behaviours (e.g. de Jong et al., 20I5; Rigtering \& Weitzel, 2013; Stam et al., 2012). However, from this definition it remains unclear what is specifically intrapreneurial about these behaviours. Therefore, Gawke et al. (2017) conceptualise that, what sets intrapreneurs apart from other innovative and proactive employees, are behaviours that specifically revolve around new venture creation and strategic renewal. New venture creation involves the development of new businesses or new organisations (Gartner, 1985). New venture behaviour consists of an employee's agentic and anticipatory behaviours with the goal of creating new business or new organisations for an existing organisation (Gawke et al., 20I7). Strategic renewal entails the process, content and outcome of attributes of an organisation being refreshed or replaced, with the potential of affecting long-term prospects (Agarwal \& Helfat, 2009). Strategic renewal behaviour includes behaviours that aim to increase an organisation's ability to react to internal and external developments (Gawke et al., 20I7).

\subsubsection{New Ways of Working}

New Ways of Working are a recent phenomenon that arguably started with a speech and white paper by Bill Gates in 2005 titled 'The New World of Work'33 (Bijl, 2009). It has been enabled by rapid advances in ICT - notably the internet (Bijl, 2009) and aims to simultaneously recruit and retain a diverse workforce that increasingly varies in preferences, while boosting innovation and productivity, and cutting costs (Nijp et al., 20I6). It consists of a bundle of HRM practices enabling employees to work independent of time and place, supported by a flexible work environment that is facilitated by ICT (de Leede, 20I6). NWW grant employees more freedom and autonomy (Peters, et al., 20I4) through five facets distinguished by Gerards et al. (20I8a; 20I8b) based on their overview of the literature: I) time- and locationindependent work, 2) management on output, 3) access to organisational knowledge, 4) flexibility in working relations, and 5) a freely accessible open workplace. Note that each of the five NWW facets can be implemented independently in an organisation, but all facets contribute to an organisations' overall extent of NWW adoption. We now provide a brief explanation of these five facets and refer to Gerards et al. (20I8a) for more details.

Time- and location-independent work constitutes working independently of time and location. Employees are not bound by a work schedule and as such have a higher level of autonomy in choosing when and where to work. Management on output relates to the management of employees and their work processes. As office presence

33 https://news.microsoft.com/2005/05/r9/gates-outlines-new-world-of-work-at-ceo-summit/ 
is no longer required, management focusses on acquired results and output rather than how employees organise their work. The latter is left to the discretion of the employee. Modern ICT systems enable the facet access to organisational knowledge, which entails that employees have access to all knowledge in the organisation and can easily and quickly connect, communicate, and share their own knowledge with colleagues and supervisors. Flexibility in working relations relates to workers' influence over their work-life balance, for which employees might have different preferences depending on for instance their career stage or household structure (Darcy et al., 20I2; ten Brummelhuis \& van der Lippe, 20IO). This facet allows employees to design their job in a way that suits their private situation with regard to household and family activities, lifestyle or professional ambition. The freely accessible open workplace entails open-plan offices designed in such a way that they encourage communication and cooperation by fostering encounters between colleagues (Gerards et al., 20I8a).

\subsubsection{New Ways of Working and Intrapreneurship}

Social exchange theory (SET) states that social interactions are mutually reinforcing (Homans, 1958). In addition, an employee's behaviour is motivated by the rewards an employee expects to gain from this behaviour (Blau, 1964). Furthermore, positive social exchange relationships motivate employees to engage in behaviours that reward and reinforce those positive relationships (Cropanzano \& Mitchell, 2005; Hughes et al., 20I8). Here, rewards are not only economic but can also be socio-emotional. Importantly, the reciprocity principle (Blau, 1964; Cropanzano \& Mitchell, 2005; Homans, 1958; Meeker, 197I) entails that positive social exchange relationships urge employees to perform their tasks in new and better ways, triggering innovative behaviours (Bednall et al., 20I8; Hughes et al., 20I8; Scott \& Bruce, 1994) and likely also intrapreneurial behaviour.

Social exchanges also affect trust, which in turn affects behaviour (Tanghe et al., 20IO). In turn, trust sustains social exchange and can facilitate actions that entail risk taking such as intrapreneurial behaviour (Hughes et al., 20r8; Mayer et al., 1995; Rigtering \& Weitzel, 2013). As intrapreneurial behaviour entails career related risk for the employee (Kacperczyk, 20I2), without trust in the organisation, employees are likely to avoid these risks (Colquitt et al., 20II) and forego intrapreneurial behaviour. Therefore, we argue that the implementation of NWW signals an organisation's trust in their employees to execute job tasks effectively, even while working at a time and location of their choosing and in the absence of direct supervision. In return, employees reciprocate with intrapreneurial behaviour.

Next, we discuss the empirical evidence for the relation between NWW and intrapreneurship per facet. The first NWW facet time- and location-independent work grants employees autonomy in when and where to work. Autonomy is defined as "the degree to which the job provides substantial freedom, independence, and discretion to the individual in scheduling the work and in determining the procedures to be 
used in carrying it out" (Hackman \& Oldham, 1976, p. 258). Time- and locationindependent work relates mainly to employees' autonomy in scheduling and as such relates naturally to time availability, which is the degree to which jobs are structured and schedules are created in the workplace (Kuratko et al., 20I4). Time availability is crucial for employees to explore and realise new ideas (Deprez et al., 20I8; Kuratko et al., 20I4; Puech \& Durand, 20I7; Rigtering \& Weitzel, 2013). For instance, Puech and Durand (2017) find that intrapreneurial ideas and opportunities are mostly identified during daily tasks. However, when employees do not have available time for the exploration and development of new intrapreneurial projects, these projects are likely to fail before they even go beyond the idea phase. Therefore, Puech and Durand suggest that especially the exploration of the value of the new idea requires autonomy for employees to organise part of their work themselves. Accordingly, we argue that the autonomous and flexible scheduling that is associated with the NWW facet time- and location-independent work may facilitate employees to allocate time to intrapreneurial activities and as such may facilitate intrapreneurial behaviour. However, as working outside the office has been shown in some studies to negatively affect social exchange relationships ${ }^{34}$, time- and location-independent work - via this route - could also hinder intrapreneurial behaviour. However, Gerards et al. (2018a) in a comparable context to this chapter do not find any significant relation between the NWW facet time- and location-independent work and social interactions. Therefore, we argue that the potential negative influence on intrapreneurial behaviour of timeand location-independent work via social exchange relationships - if present at all - is probably outweighed by the positive influence of time availability. We formulate the following hypothesis:

Hra: Time- and location-independent work is positively related to intrapreneurial behaviour.

The second NWW facet, management on output, is also likely to foster intrapreneurial behaviour. Employees' intrapreneurial behaviour is facilitated when an organisation provides employees with work discretion, i.e. provides employees with freedom in the way in which they do their work, refutes excessive supervision and allows for decision making freedom (de Jong et al., 2015; Kuratko et al., 20I4). The facet management of output is therefore likely to foster intrapreneurship by allowing for procedural and decision-making autonomy. By managing output rather than input and focussing on results rather than processes, managers can grant employees the autonomy they need for intrapreneurial behaviour. Managers have to support intrapreneurs, not manage their processes, and provide them some leeway for changes (de Jong et al.,

34 See the discussion in Gerards et al. (2018a, pp. 520) on the ambiguous evidence of teleworking on social exchange relationships. 
20I5; Fry, 1987). In addition, fewer management control helps the communication of intrapreneurial ideas (Deprez et al., 20I8). We therefore expect that:

Hib: Management on output is positively related to intrapreneurial behaviour.

The third NWW facet, access to organisational knowledge, is likely to support the creative process of intrapreneurs. Freely accessible information is one of what Kanter (1985) describes as the 'power tools' in facilitating intrapreneurship. By providing employees with access to all organisational knowledge at any time, the flexibility of organisational boundaries is increased, which enhances information flows between individuals, departments, the organisation and the external environment (Kuratko et al, 20I4). In addition to providing access to knowledge, IT applications often support the development of organisational knowledge networks through facilitating interactions between team members, managers and colleagues from other departments. These knowledge networks increase employees' access to new perspectives and insights, which helps them to generate new ideas by combining information and knowledge from various sources (Perry-Smith, 2006; Perry-Smith \& Shalley, 2003), which is an essential element of intrapreneurship (Hayton \& Kelley, 2006). Therefore, we formulate the following hypothesis:

Hic: Access to organisational knowledge is positively related to intrapreneurial behaviour.

The fourth NWW facet, flexibility in working relations, concerns the adaptability of working hours and as such adds another layer of flexibility of how much to work. Both the mere availability and the actual use of this flexibility have been shown to relate positively to work engagement ( $\mathrm{Bal} \&$ De Lange, 20I5), which in turn is positively related to intrapreneurial behaviour (Gawke et al., 20I7), too. Moreover, if this flexibility is used to temporarily work more hours, it may help employees develop intrapreneurial projects (Peuch \& Durand, 2017). However, the common use of this flexibility is to reduce workload in response to personal or family circumstances (e.g. caring for a family member) or when personal preferences tend more towards leisure ( $\mathrm{Bal} \& \mathrm{De}$ Lange, 2015). As intrapreneurial behaviour is known to relate positively to the number of hours worked (Adachi \& Hisada, 20I7), the reduced workload commonly associated with flexibility in working relations may decrease intrapreneurial initiatives. However, since we operationalize this facet in terms of its availability and not in terms of its actual use (see Section 5.3.2.2), we expect that flexibility in working relations in this context relates positively to intrapreneurial behaviour. 
HId: Flexibility in working relations is positively related to intrapreneurial behaviour.

We also expect that the fifth NWW facet, a freely accessible worksplace, is positively related to intrapreneurship. The design of the workspace affects the behaviour of its users, and open-plan offices are specifically designed to foster communication and collaboration (Elsbach \& Bechky, 2007). Indeed, although open-plan offices can also be experienced to disturb the work process, there is a widespread belief that open-plan offices facilitate social exchanges (Kim \& de Dear, 2013). Moreover, the physical work environment is known to influence employees' creativity (Dul et al., 20II). Openplan offices in particular, foster employee creativity by increasing communication and interaction (Lewis \& Moultrie, 2005). The informal setting provided by freely accessible workspaces also provides employees with opportunity to mention and discuss ideas casually, lowering perceived risk of voicing a new idea (Deprez et al., 2018). In addition, Heinze and Weber (2016) find that intrapreneurs do not act on their own and that successful intrapreneurship depends on the employees' ability to recruit others for their ideas. Freely accessible workplaces create the opportunity for intrapreneurs to easily connect with likeminded individuals. Therefore, we expect that the facet freely accessible workplace is positively related to intrapreneurial behaviour.

Hre: A freely accessible workplace are positively related to intrapreneurial behaviour.

In sum, we expect that the bundle of HRM practises that constitute NWW create a positive exchange relation between the organisation and its employees, where all five facets of NWW help to build the right organisational environment for intrapreneurship to flourish. We therefore hypothesise that the higher the extent to which NWW practices are adopted in an organisation, the higher employees' level of intrapreneurial behaviour in that organisation:

HIf: An organisation's extent of NWW adoption is positively related to intrapreneurial behaviour.

\subsubsection{The mediating role of co-worker Social Interaction}

\section{NWW and co-worker social interaction}

Social interaction is central to social exchanges in any organisation; it shapes norms and values, and is at the basis of networks of employees that are cooperating to achieve a common goal (Cohen \& Prusak, 200I). Social exchange relationships between employees are likely to change with the implementation of NWW, but the direction of the change is not a priori clear from existing evidence (Gerards et al., 20I8a). 
The NWW facets time- and location-independent work, management on output and access to organisational knowledge contribute to extending communication beyond regular office hours and the physical office, and promote online communication instead of real life interaction. This could facilitate social interaction as it provides employees with a broader range of communication options (Boswell \& OlsenBuchanan, 2007; Diaz et al., 20II). These NWW facets are also common themes in the literature on flexible work design, teleworking or telecommuting (Gerards et al., 2018a). For instance, Halford (2005) provides examples of how telework affects organisational relationships and interactions in positive as well as negative ways. Some other studies however, emphasise the positive effects of these work designs on the quality of co-worker communication (e.g. ten Brummelhuis et al., 20I2; ter Hoeven \& van Zoonen, 20I5). In addition, empirical evidence points towards a positive relationship between the fourth NWW facet, flexibility in working relations, and social interaction. Kossek and Lee (2008) find for instance that working less hours because of a reduced workload, is positively related to communication between colleagues. In addition, Branine (2003) finds that workers in flexible work arrangements experience mutual support from their colleagues. The open-plan offices central to the fifth NWW facet, freely accessible open workplace, are especially designed to foster social interactions and are therefore naturally related to social interaction (Brunia et al., 20I6; Gerards et al., 2018a).

However, flexible work, intensive use of ICT and open-plan offices could also obstruct social interactions. As there is no designated place and time for employees to be available, colleagues might struggle to cooperate due to asynchronous and dispersed work habits. Moreover, working from home or elsewhere using IT can also contribute to social isolation of professionals (Cooper \& Kurland, 2002; Kurland \& Cooper, 2002). Morganson et al. (2010) show for instance a negative relation between working outside the office and social interaction at work. Similarly, Kingma (2018) describes an example how some workers turned the option to work from home into a right; claiming a fixed day for home-working and therewith actually reducing their flexibility to be available for office-based meetings. Lastly, open-plan offices have downsides of loss of privacy and increased noise (Kim \& de Dear, 2013).

To our knowledge, the only existing direct analysis of NWW facets on social interaction, Gerards et al. (2018a), find that only access to organisational knowledge and freely accessible workplaces are positively related to social interaction.

\section{Co-worker social interaction and intrapreneurship}

Research is more consistent concerning the relation between co-worker social interaction and employee intrapreneurship. Social interaction forms a key element of the intrapreneurial process as it is at the core of intrapreneurial networking activities. Organisational networks are essential for employees to gather and link new information and knowledge, and to find new opportunities for the organisation 
(Bjornali \& Støren, 20I2; Hayton \& Kelley, 2006; Rigtering \& Weitzel, 2013). These networks also play a pivotal role in accessing and convincing superiors and key decision makers in the organisation of the value of the new opportunity, which paves the way for further development and implementation (Hayton \& Kelley, 2006). Thus, social interaction helps employees to create an appropriate network for developing an intrapreneurial idea (Castrogiovanni et al., 20II). In sum, social interaction is essential for intrapreneurs in order to be able to gather information, recognise opportunities and convince people in the organisation to support their initiative. Based on the literature discussed above we hypothesise that the relation between NWW and intrapreneurship is positively mediated by social interaction. We expect however that this mediation is only partially, as Gerards et al. (20I8a) show that only two of the five NWW facets (access to organisational knowledge and freely accessible workplaces) are positively related to social interaction:

H2: Co-worker social interaction positively mediates the relation between NWW and intrapreneurial behaviour partially.

\subsubsection{The mediating role of transformational leadership}

\section{NWW and transformational leadership}

NWW also affects social exchange relations between managers and their employees. As NWW entail management according to output rather than work processes, and allow a considerable level of autonomy to employees, managers in the organisation need to adapt their management style accordingly (Gerards et al., 20I8a; Johnson, 2004; Peters \& Den Dulk, 2003; Wright \& Oldford, 1993). The introduction of NWW eliminates the need for managers to see their employees daily. Consequently, managers need to change from direct supervision to managing on output (de Leede \& Krajenbrink, 20I4). As such, Peters et al. (20I4) argue that the implementation of NWW prompts managers to show behaviours associated with transformational leadership.

Transformational leadership describes leaders who raise and broaden the interest of their followers. They provide direction and a vision to work towards common goals, and inspire and motivate employees to aim for successful outcomes. Transformational leaders are charismatic, provide intellectual stimulation and have consideration for the individual situation of the employee (Bass, 1999). They manage their teams by setting objectives and giving frequent feedback, which improves motivation, satisfaction and performance (Hertel et al., 2005). Therefore, transformational leadership entails positive social exchange relationships between managers and their employees.

Several studies find that transformational leadership mediates between NWW and employee level outcomes. For instance, de Leede and Kraijenbrink (2014) find that trust, which is an essential element of transformational leadership and an outcome 
of positive social exchange relationships (Tanghe et al., 20IO), mediates the relation between NWW and employee performance. Similarly, Gerards et al. (2018a) find that transformational leadership positively mediates the relation between NWW and work engagement. Importantly, in testing transformational leadership as a moderator (as opposed to a mediator), de Leede and Heuver (2016) do not find a significant effect of managers' transformational leadership qualities on the relation between NWW and organisational commitment. Therefore, following Gerards et al. (2018a) and de Leede and Kraijenbrink (20I4), we include transformational leadership as mediator between NWW and our employee level outcome, intrapreneurship.

\section{Transformational leadership and intrapreneurship}

Mutual trust and obligations are created as the relation quality between managers and employees progresses to transformational qualities (Graen \& Uhl-Bien, 1995). These positive exchange relationships between employees and their managers stimulate employees to engage in innovative activity that goes beyond role prescriptions (Bammens 20I6; Hughes et al., 20I8). We therefore expect that employees may reciprocate the positive social exchange relations associated with transformational leadership with intrapreneurial behaviour. In addition, transformational leaders communicate clear visions, that may guide employees in recognising opportunities for their organisations, and stimulate employees in coming up with new ideas (Howell \& Higgins, 1990; Moriano et al., 20I4). Furthermore, leaders play an important role in facilitating employees' new ideas (Deprez et al., 20I8; Heinze \& Weber, 20I6). New initiatives often go against the status quo in an organisation and are therefore likely met with resistance from other organisational members (Deprez et al., 20I8; Heinze \& Weber, 20I6). Transformational leaders provide employees' with the leverage needed to overcome organisational boundaries and find organisational support for their ideas (Rosing et al., 20II).

Indeed, empirical evidence shows that transformational leadership stimulates intrapreneurial behaviour (Moriano et al., 20I4). Moreover, Kuratko et al. (20I4) show that the encouragement and empowerment that a transformational leader provides coincides with the management support intrapreneurs need, and Deprez and Euwema (2017) show that intrapreneurs expect their managers to portray transformational leadership behaviours. They find that intrapreneurs expect their managers to provide, for instance, autonomy, trust, a personal connection and sufficient feedback. Therefore, we hypothesise that transformational leadership positively mediates the relation between NWW and intrapreneurship:

H3: Transformational leadership positively mediates the relation between NWW and intrapreneurial behaviour partially.

Figure 5.I provides a graphic overview of our research model and hypotheses. 
Figure 5.1 - Research model and hypotheses

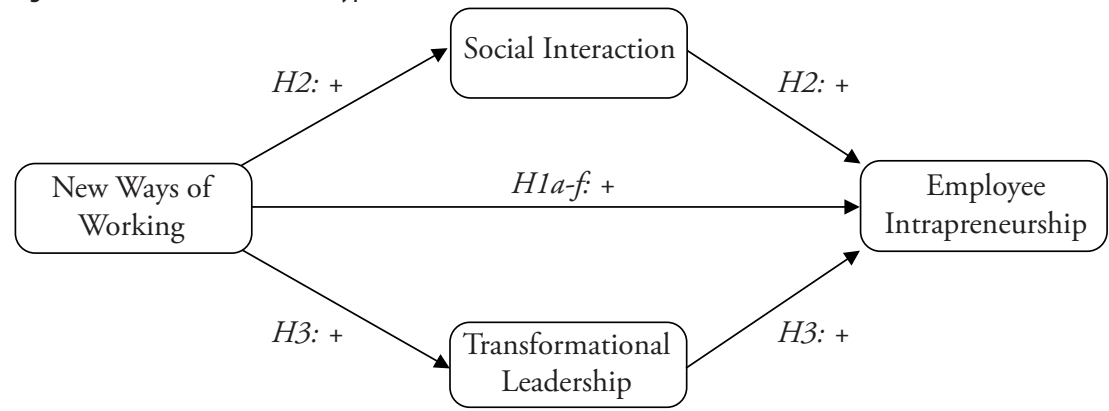

\subsection{Methods}

\subsubsection{Data and sample}

We developed a survey for the purpose of this chapter. In the spring of 20I8, we approached 13,665 members of the Dutch population via an online panel ${ }^{35}$. 629 individuals responded positively to the request to partake in the survey. Of these 629 , only those who indicated to be in paid employment were routed to continue the survey. This led to the exclusion of 329 respondents not in paid employment. In total 300 individuals completed the survey. For our analyses, we excluded 46 participants who were older than 67 years - which is the official retirement age in the Netherlands - or indicated not to have a manager or supervisor or not to work in a building. Our final sample consists of 254 individuals working in 13 different economic sectors.

\subsubsection{Measures}

\section{Employee intrapreneurship}

We measure intrapreneurial behaviour using the Dutch 15 -item version of the 'Employee Intrapreneurship Scale' (EIS; Gawke et al., 20I9). The EIS consists of fifteen items measuring employees' strategic renewal behaviours (eight items) and new venture behaviours (seven items). Table A5.I in the Appendix lists all items of this scale. Example items are "I undertake activities to realise change in my organisation" and "I actively establish new collaborations with experts outside of my own expertise." Respondents rated all items on a 7-point Likert scale ranging from I (Never) to 7

35 Data collection has been performed by the Dutch market research company Etil (https://www. etil.nl). 
(Always). Cronbach's alpha of the total scale is high $(\alpha=0.97)^{36}$. We perform a polychoric factor analysis (Holgado-Tello et al., 20IO) and subsequently calculate the total scale score by means of regression scoring. In addition, we standardise the total scale scores before our analyses.

\section{New Ways of Working}

We regard NWW as a formative (causal) construct (Fleuren et al., 20I8; Jarvis et al., 2003), where each of the five facets covers a different aspect of NWW. An organisation's overall extent of NWW adoption can be expressed through an aggregate measure of the HRM practices (i.e. NWW facets) that together constitute NWW.

We measure the extent to which the NWW facets are present in employees' organisations building on the NWW scale developed by Gerards et al., (2018a). This scale consists of five subscales measuring the five NWW facet of 'time- and locationindependent work', 'management on output', 'Access to organisational knowledge', 'flexibility in working relations', and 'freely accessible open workplace'. However, some of their subscales consist of only one or few items. In an effort to increase the reliability of the subscales, we added items to some subscales. Table A5.2 in the Appendix provides an overview of all items originating from Gerards et al. (2018a) and the new items we added. Respondents were asked to indicate the degree to which each statement applied to their current jobs on a 5-point Likert scale ranging from I (not at all) to 5 (to a very high extent). We calculate sum scores of the total extent of NWW adoption as well sum scores for the separate facets using regression scoring after a polychoric factor analysis (Holgado-Tello et al., 20 oro.

The Gerards et al. (2018a) subscale for the NWW facet time- and locationindependent work consisted of two items, to which we added one new item ("I am able to work from home if I want to"). Cronbach's alpha for these three items in our sample is high $(\alpha=0.86)$, indicating high internal consistency of this subscale. This is an improvement over the original two item subscale $(\alpha=0.78)$.

36 This high Cronbach's alpha value of the total EIS is consistent with previous studies. Using the I5-item version of the EIS, Gawke et al. (2019) calculate Cronbach's alpha values of 0.9I and 0.87 for strategic renewal behaviour and new venture behaviour, respectively. Furthermore, Gawke et al. (2018) who administered an 8-item version of this scale in a sample of Dutch employees from various sectors calculate a Cronbach's alpha value of 0.96 for the total scale. In addition, in Chapter 4 of this thesis, we calculated a Cronbach's alpha value of 0.93 for the 8 -item version of the EIS. We investigated whether these high values are due to non-varying answering patterns (i.e. a respondent giving the same responses to all scale items). We find that the average within-person item response variation is I.02 and non-varying responses across the fifteen items for seven respondents. Excluding these seven respondents does not affect the scale's Cronbach's alpha value (0.97). 
The Gerards et al. (2018a) subscale for the NWW facet management on output consisted of only one item. We added two new items "My supervisor does not get involved with the way I do my job" and "My supervisor evaluates me on the quality of the work I deliver, not the way I worked". Cronbach's alpha for these three items is 0.73 , which is satisfactory.

We added one new item ("I have access to all necessary information everywhere, at any time") to the original Gerards et al. (2018a) four item scale for the NWW facet access to organisational knowledge in order to more fully capture the scope of this facet. Cronbach's alpha for the new five item scale is satisfactory $(\alpha=0.79)$ and slightly improved over the original four item subscale $(\alpha=0.78)$.

Gerards et al. (20I8a)'s measurement of the subscale flexibility in working relations consisted of only one item, to which we added one new item ("I have the possibility to work more or fewer hours"). Cronbach's alpha for these two items is sufficient ( $\alpha$ $=0.69$ ).

The NWW subscale freely accessible open workplace consisted of two items $(\alpha=$ o.82) to which we added one more item ("The building is arranged in such a way that I enjoy working there"). Although this three item scale results in the same Cronbach's alpha $(\alpha=0.82)$ we retain this item as it also contributes to increasing the internal consistency of NWW as a bundle, discussed next.

\section{Transformational Leadership}

We measure transformational leadership using six items from Carless et al. (2000). Respondents are asked to indicate the extent to which the six items apply to their supervisor on a 5-point Likert scale ranging from I (never) to 5 (always). Example items are "My supervisor communicates a clear and positive vision of the future" and "My supervisor treats staff as individuals, supports and encourages their development". Cronbach's alpha of the scale is high $(\alpha=0.96)$.

\section{Social Interaction}

We measure social interaction using the two statements from Gerards et al. (2018a). One statement concerns the cooperation between colleagues ("I find working with my colleagues pleasant"). The other statement concerns the speed at which the respondent is helped by colleagues when he or she faces problems ("When facing problems, I quickly receive help from colleagues"). Respondents rate their agreement with these items on a 5-point Likert scale ranging from I (not at all) to 5 (to a very high degree). Cronbach's alpha of the scale is satisfactory $(\alpha=0.79)^{37}$.

37 Using a single source for the measurement of our main variables could lead to common method variance (e.g. Podsakoff et al. (2003) for a review and Spector (2006) for a critical discussion), possibly causing inflated correlations between the variables. However, Harman's one-factor tests did not produce one single factor that accounted for most of the variance between the variables. 


\section{Control variables}

We include several individual level control variables. First, we control for employees' education level. Previous studies show an ambiguous relation of education level with intrapreneurship. De Jong et al. (2015) and Urbano and Turró (2013) find a positive relation with intrapreneurship in a Dutch consultancy firm and in various sectors in nine European countries, respectively. However, Camelo-Ordaz et al. (20I2), find a negative relation between education level and intrapreneurship in Spanish small creative firms. We construct a categorical variable indicating an employee's lower $(=\mathrm{I})$, middle $(=2)$ or higher $(=3)$ education level.

Second, previous research indicates that older employees and those with longer organisational tenure are less involved in intrapreneurship (Camelo-Ordaz et al., 20I2; Parker, 20II). We therefore control for age and organisational tenure. Third, women appear to be less involved in intrapreneurship than men (Adachi \& Hisada, 20I7; Parker, 20II). Therefore, we include a gender dummy variable (I if female). Fourth, Adachi and Hisada (20I7) show that employees working part-time are less involved in intrapreneurship. We therefore include a dummy indicating part-time $(=I)$, i.e. a maximum of 32 hours per week, or full-time employment $(=0)$, i.e. more than 32 hours per week.

Last, we control for employees' personality by including measures for all Big Five personality traits. Some earlier studies investigate the relationship between personality traits and intrapreneurship. These studies find that the Big Five traits openness to experience (Farruhk et al., 20I6) and extraversion (Farruhk et al., 20I6; Sinha \& Srivastava, 20I3) are positively related to intrapreneurship. Contrarily, neuroticism (Sinha \& Srivastava, 2013), agreeableness (Farruhk et al., 2016) and conscientiousness appear to be negatively related to intrapreneurship. We use the I5-item Big-Five measure by Lang et al. (20II) that includes statements as "I see myself as extraverted, enthusiastic" and "I see myself as open to new experiences, complex". All items are rated on a 5 -point Likert scale ranging from I (completely disagree) to 5 (completely agree).

\subsubsection{Descriptives}

Table 5.I contains summary statistics of the variables in this chapter. Noteworthy are the relatively high mean on the facet access to organisational knowledge and the relatively low means on the facets time- and location-independent work and flexible working relations. This shows that access to organisational knowledge is much more widespread than the other NWW facets. In addition, the mean for intrapreneurship is quite low, indicating a skewed distribution of intrapreneurship scores in our sample. 
Table 5.1 - Summary statistics of all variables

\begin{tabular}{|c|c|c|c|c|}
\hline & Mean & SD & Min & Max \\
\hline \multicolumn{5}{|l|}{ Intrapreneurship } \\
\hline Strategic renewal behaviour & 2.74 & 1.30 & 1.00 & 6.50 \\
\hline New venture behaviour & 2.00 & 1.15 & 1.00 & 6.00 \\
\hline Total intrapreneurship & 2.40 & 1.16 & 1.00 & 6.00 \\
\hline \multicolumn{5}{|l|}{ NWW variables } \\
\hline Time- and location-independent independent work & 2.37 & 1.06 & 1.00 & 5.00 \\
\hline Management on output & 3.18 & 0.86 & 1.00 & 5.00 \\
\hline Access to organisational knowledge & 3.47 & 0.75 & 1.00 & 5.00 \\
\hline Flexibility in working relations & 2.79 & 0.99 & 1.00 & 5.00 \\
\hline Freely accessible open workplaces & 3.50 & 0.97 & 1.00 & 5.00 \\
\hline New ways of working total & 3.13 & 0.69 & 1.00 & 4.88 \\
\hline \multicolumn{5}{|l|}{ Mediating variables } \\
\hline Transformational leadership & 3.12 & 1.09 & 1.00 & 5.00 \\
\hline Social Interaction & 3.74 & 0.77 & 1.00 & 5.00 \\
\hline \multicolumn{5}{|l|}{ Control variables } \\
\hline Neuroticism & 2.60 & 0.77 & 1.00 & 4.67 \\
\hline Extraversion & 3.39 & 0.68 & 1.67 & 5.00 \\
\hline Openness & 3.22 & 0.66 & 1.33 & 5.00 \\
\hline Agreeableness & 3.79 & 0.62 & 2.00 & 5.00 \\
\hline Conscientiousness & 3.89 & 0.64 & 1.67 & 5.00 \\
\hline Age (in years) & 49.34 & 10.50 & 25 & 67 \\
\hline Organisational tenure (in years) & 14.53 & 11.51 & 0.08 & 45.83 \\
\hline Total N & 254 & & & \\
\hline
\end{tabular}

Note: Summary statistics based on unweighted and unstandardized sum-scores for the items of each scale.

This is consistent with previous studies that find a low prevalence of intrapreneurship among employees (Bosma et al., 20IO). Most individuals in our sample are highly educated $(53.9 \%)$ and more than half are male (55.9\%).

Table 5.2 shows the correlations between all variables. All NWW facets and NWW as a bundle are positively correlated with intrapreneurship, transformational leadership and social interaction. In addition, both transformational leadership and social interaction are positively correlated with intrapreneurship. 
Table 5.2 - Correlations between main variables

\begin{tabular}{l|l|l|l|l|l|l|l|l|l} 
& 1 & 2 & 3 & 4 & 5 & 6 & 7 & 8 \\
1. Time- and location-independent work & 1.000 & & & & & & \\
2. Management of output & $0.521^{* * *}$ & 1.000 & & & & & & \\
3. Access to organisational knowledge & $0.453^{* * *}$ & $0.583^{* * *}$ & 1.000 & & & & & \\
4. Flexibility in working relations & $0.621^{* * *}$ & $0.537^{* * *}$ & $0.499^{* * *}$ & 1.000 & & & & \\
5. Freely accessible open workplace & $0.282^{* * *}$ & $0.327^{* * *}$ & $0.515^{* * *}$ & $0.391^{* * *}$ & 1.000 & & & \\
6. NWW total & $0.753^{* * *}$ & $0.769^{* * *}$ & $0.837^{* * *}$ & $0.760^{* * *}$ & $0.671^{* * *}$ & 1.000 & & \\
7. Employee intrapreneurship & $0.373^{* * *}$ & $0.350^{* * *}$ & $0.272^{* * *}$ & $0.232^{* * *}$ & $0.313^{* * *}$ & $0.408^{* * *}$ & 1.000 & \\
8. Transformational leadership & $0.271^{* * *}$ & $0.394^{* * *}$ & $0.418^{* * *}$ & $0.386^{* * *}$ & $0.505^{* * *}$ & $0.518^{* * *}$ & $0.312^{* * *}$ & 1.000 \\
9. Social interaction & $0.185^{* *}$ & $0.358^{* * *}$ & $0.460^{* * *}$ & $0.332^{* * *}$ & $0.361^{* * *}$ & $0.451^{* * *}$ & $0.145^{*}$ & $0.436^{* * *}$ \\
\hline
\end{tabular}

Note: NWW = New ways of working. Correlations based on unweighted and unstandardized sum-scores for the items of each scale. ${ }^{*} p<0.05,{ }^{* *} p<0.01,{ }^{* * *} p<0.001$

\subsubsection{Estimation methodology}

We test our hypotheses using the multiple mediation bootstrap method by Preacher and Hayes (2008). This method uses OLS regressions to estimate all coefficients, and bootstrapping to determine the confidence intervals for the direct and indirect effects. As such, this method allows us to test the existence of indirect effects, which are only inferred when we would apply a causal steps approach (Baron \& Kenny, I986; Hayes, 2009).

\subsection{Results}

We estimate two models: First we estimate a model with the overall extent of NWW as independent variable, and second a model with the five NWW specific facets.

\subsubsection{Overall extent of New Ways of Working, and intrapreneurship}

Figure 5.2 shows the result of the first model. The total relation $c$ of the NWW bundled variable with intrapreneurship is positive and statistically significant $(\beta=$ 0.25 , p<0.oI). NWW are also positively related to both transformational leadership $(\beta=0.49, \mathrm{p}<0.0 \mathrm{I})$ and social interaction $(\beta=0.44, \mathrm{p}<0 . \mathrm{OI})$. However, there is no discernible mediation of the relation between NWW and intrapreneurship through social interaction, as social interaction has no significant relation with intrapreneurship $(\beta=-0.02, \mathrm{p}>0 . \mathrm{I})$.

Transformational leadership is positively related to intrapreneurship $(\beta=0.15$, $\mathrm{p}<0.05$ ), which suggests that the relation between NWW and intrapreneurship is partially mediated by transformational leadership. The indirect effect of NWW through transformational leadership is significant $(\beta=0.07, \mathrm{p}<0.05)$ and accounts for $28 \%$ of the total relation between NWW and intrapreneurship. After accounting for mediation, there remains a positive and significant direct relation $c$ ' between the 
overall extent of NWW and intrapreneurship ( $\beta=0.19, \mathrm{p}<0.0 \mathrm{I})$. Therefore, hypothesis If is supported. The total indirect effect however, is not significant $(\beta=0.06, \mathrm{p}>0 . \mathrm{I})$.

Figure 5.2 - Multiple mediation model of direct and indirect effects of NWW on intrapreneurship.

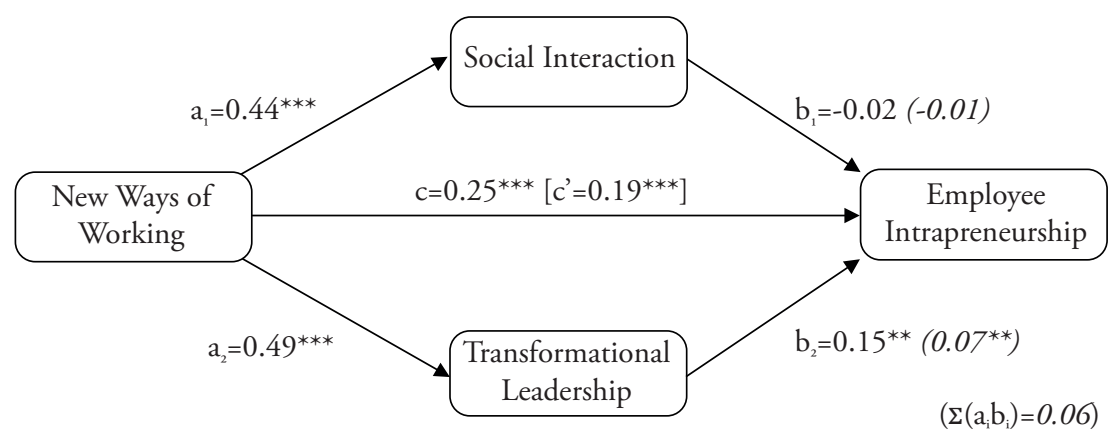

Note: Indirect effects $\left(a_{i} b_{j}\right)$ and total indirect effect $\left(\Sigma\left(a_{i} b_{i}\right)\right)$ are shown in italics in parentheses. Direct effect of NWW accounting for mediation is shown in brackets. Total effect $c=\Sigma\left(a_{i} b_{i}\right)+c^{\prime} .{ }^{*} p<0.1,{ }^{* *} p<0.05,{ }^{* * *} p<.01$

Furthermore, in line with the literature discussed in paragraph 5.3.2., we find that male workers, those in management or sales jobs, and employees in full-time employment have significantly higher levels of intrapreneurship than women, employees in other types of jobs and those in part-time employment, respectively. In addition, openness to experience is positively related to intrapreneurship. However, contrary to our expectations, the other control variables have no significant relation with intrapreneurship. ${ }^{38}$ The total model including control variables accounts for $39 \%$ of the variance in employee intrapreneurship and is highly significant $(\mathrm{p}<0.00)$.

\subsubsection{New ways of working separate facets, and intrapreneurship}

Figure 5.3 shows the estimation results of the relations between the separate NWW facets and intrapreneurship. The estimation results show that the facets time- and location-independent work $(\beta=0.16, p<0.05)$, management on output $(\beta=0.17$, $\mathrm{p}<0.05)$ and freely accessible open workplaces $(\beta=0.12$, $\mathrm{p}<0 . \mathrm{I})$ have a positive relation with intrapreneurship before accounting for mediation. The other NWW facets show no significant relation with intrapreneurship. Therefore, we find support for hypotheses Ia, Ib and Ie. However, we do not find support for hypotheses Ic and Id.

In addition, not all NWW facets are related to transformational leadership and social interaction. Only the facets management on output $(\beta=0.16, \mathrm{p}<0.05)$ and

38 A full table of results including control variables in included in the Appendix Table A5.3 (column I). 
freely accessible open workplaces $(\beta=0.33, \mathrm{p}<\mathrm{O} . \mathrm{OI})$ have a significant positive relation with transformational leadership. ${ }^{39}$

Furthermore, we find that access to organisational knowledge $(\beta=0.35, \mathrm{p}<\mathrm{O} .0 \mathrm{I})$, freely accessible open workplaces $(\beta=0.15, \mathrm{p}<0.0 \mathrm{I})$ and flexibility in working relations $(\beta=0.12, p<0.05)$ are positively related to social interaction. ${ }^{40}$

Equal to the model using the NWW bundled variable, of the expected mediators only transformational leadership $(\beta=0.15, \mathrm{p}<0 . \mathrm{OI})$ is significantly related to intrapreneurship. Hypothesis 2 is therefore not supported. While the mediating effect of transformational leadership renders the direct effect of freely accessible open workplaces on intrapreneurship insignificant after accounting for mediation $(\beta=0.07, p>0 . I)$. The indirect effect of freely accessible open workplaces $(\beta=0.05$, $\mathrm{p}<\mathrm{O} . \mathrm{I})$ on intrapreneurship through transformational leadership is only marginally significant. However, this indirect effect accounts for $41.7 \%$ of the total effect of the freely accessible open workplace. We find no other significant mediation effects, and as a result the direct effects of the facets time- and location-independent work and management on output on intrapreneurship show little to no change in size or significance after accounting for mediation ${ }^{41}$. Therefore, Hypothesis 3 is only partially supported.

39 These findings differ somewhat from Gerards et al. (2018a) who find that, in addition to freely accessible open workplace, also time- and location-independent work and access to organisational knowledge positively affect transformational leadership. Additional analyses not presented here show that this difference is partly due to the inclusion of new items to measure the NWW facets. When using the same items as Gerards et al. (2018a) to measure the NWW facets, we also find a positive relation between access to organizational knowledge and transformational leadership, but no significant relationship between time- and locationindependent work and transformational leadership.

This is in line with Gerards et al. (2018a), except for the positive relation between flexibility in working relations, which they did not observe. Note that we use expanded scales for the NWW facets in this chpater as compared to Gerards et al. (2018a). Additional analyses not presented here show that this difference is due to the introduction of new items to measure the facet flexibility in working relations.

4I We further analysed if these results differ for the two subscales of intrapreneurship. Figures A5.I and A5.2 in the Appendix show the results for the relations between the NWW bundled variable and strategic renewal and new venture behaviour, respectively. The only noteworthy difference is that the relation between NWW and strategic renewal behaviour is mediated more by transformational leadership than the relation between NWW and new venture behaviour, making the latter relation a relatively more direct one. Figures A5.3 and A5.4 in the Appendix show the results for the relations between the separate NWW facets and strategic renewal and new venture behaviour, respectively. Most noteworthy is that, after accounting for mediation, time and location independent work is significantly related to new venture behaviour ( $\beta=$ 
Figure 5.3 - Multiple mediation model of direct and indirect effects of NWW facets on intrapreneurship.

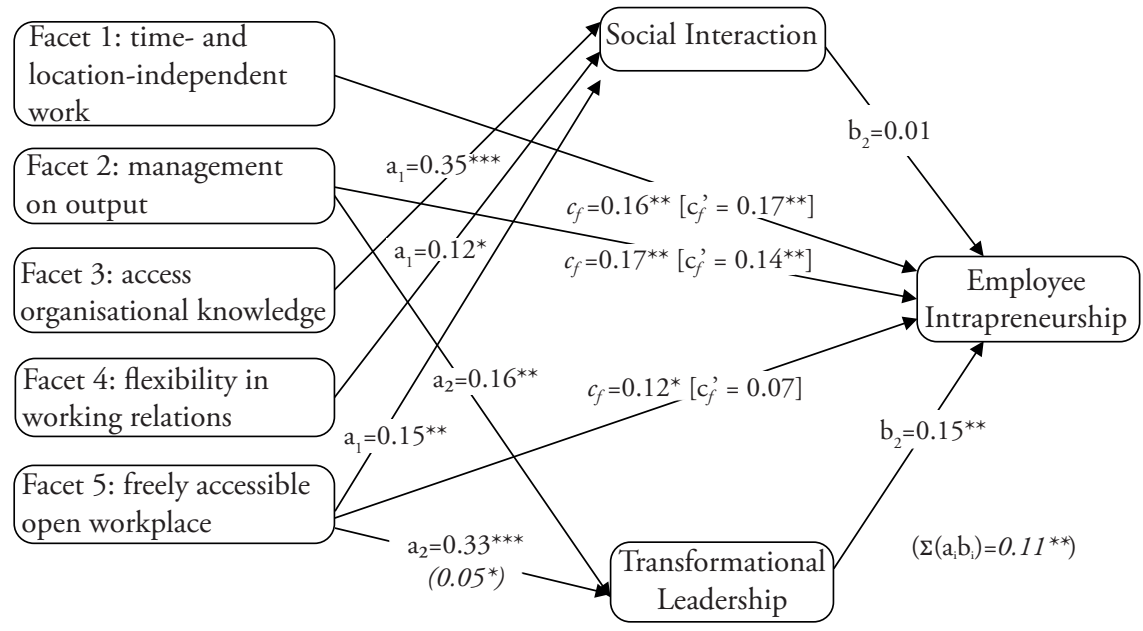

Note: Indirect effects $\left(a_{i} b_{i}\right)$ and total indirect effects $\left(\sum\left(a_{i} b_{i}\right)\right)$ are shown in italics parentheses. Direct effect of NWW facets accounting for mediation is shown in brackets. We show only significant relationships. Total effect per facet ' $f$ ' is $c f=$ $\Sigma\left(\mathrm{a}_{\mathrm{i}, \mathrm{f}}{ }^{*} \mathrm{~b}_{\mathrm{i}}\right)+c f .{ }^{*} \mathrm{p}<0.1,{ }^{* *} \mathrm{p}<.05,{ }^{* * *} \mathrm{p}<.01$

Altogether, the estimated model explains $4 \mathrm{I} \%$ of the variance in intrapreneurship and is highly significant $(\mathrm{p}<0.00)$. The control variables in this model ${ }^{42}$ have the same relations with intrapreneurship as in the model including the bundled NWW measure, except that we find no gender differences in the model that includes the separate NWW facets.

\subsection{Discussion}

In this chapter, we investigate the relation between NWW and intrapreneurship and the mediating effects of both social interaction and transformational leadership, while controlling for employees' age, education level, organisational tenure, gender and personality. We find that NWW are positively related to employee intrapreneurship, and that this relation is partially mediated by transformational leadership. This indicates that a proportion of the effect of NWW on intrapreneurship is explained by the implementation of transformational leadership practices.

$0.20, \mathrm{p}<0.05)$, but only marginally significantly to strategic renewal behaviour $(\beta=0.13, \mathrm{p}<0 . \mathrm{I})$.

Moreover, management on output is significantly related to strategic renewal behaviour $(\beta=$ $0.20 \mathrm{p}<0.0 \mathrm{I})$, but not to new venture behaviour $(\beta=0.04$, $\mathrm{p}>0 . \mathrm{I})$.

42 A full table of results including control variables is included in Appendix Table A5.3 (column 2). 
Contrary to our expectations, we find no relation between co-worker social interaction and employees' level of intrapreneurship. Thus, co-worker social interaction does not mediate between NWW and intrapreneurship. This unexpected result could be explained by the relatively focused way we measure social interaction. The measure we apply concerns the speed at which employees are helped by colleagues and managers, and how pleasant employees experience the cooperation with their colleagues. While these are important aspects of social interaction for intrapreneurship, these do not directly incorporate the quality or content of social interactions between colleagues.

Analyses using the five NWW facets separately reveal that the positive relation between NWW and intrapreneurship is mainly driven by three facets: timeand location-independent work, management on output and freely accessible open workplaces. However, the facet time- and location-independent work is positively and significantly related to intrapreneurship but not to the mediators. Management of output is positively related to both intrapreneurship and the mediator transformational leadership. However, as there is no significant indirect effect of management on output via transformational leadership, the coefficient of management of output on intrapreneurship hardly drops after accounting for the mediators. Next, we find that the relation between a freely accessible open workplace and intrapreneurship is fully mediated by transformational leadership. In brief, the NWW facets time- and location-independent work and management of output are the only facets that directly relate to intrapreneurship (in a positive way), without being mediated by transformational leadership or social interaction.

Additional analyses show that the facet management on output positively affects the strategic renewal behaviour aspect of intrapreneurship, but not the new venture behaviour aspect. They also show that time and location independent work positively affects new venture behaviour, but not strategic renewal behaviour.

\subsubsection{Contributions to the literature}

The study presented in this chapter is the first to investigate the relation between NWW and intrapreneurship. As such, we add to both the literature on the organisational antecedents of employee intrapreneurship and to the literature on employee outcomes of NWW. We add to the literature on the organisational antecedents of intrapreneurship by showing that NWW is positively related to intrapreneurship. Thus, NWW should be added to the ways in which organisations can influence employee intrapreneurship, such as job design (de Jong et al., 20I5; Rigtering \& Weitzel, 2013) and management style (Moriano et al., 20I4). Furthermore, our finding that time- and location- independent work and management on output positively relate to intrapreneurship - for our sample of employees from $\mathrm{I} 3$ different sectors in the Netherlands - strengthens the finding of de Jong et al.'s (20I5) single firm study that job autonomy is particularly important for stimulating employee intrapreneurship. In addition, we show that positive social exchange relations 
between managers and employees are more important than the social exchanges between co-workers for stimulating intrapreneurial behaviour. Moreover, we add to an increased understanding of the influence of personality on intrapreneurship (e.g. Sinha \& Srivastava, 20I3) by including the Big Five personality traits in our analyses. We find that openness to experience positively relates to intrapreneurship, whereas the other Big Five traits do not.

In addition, we contribute to the literature on the effects of NWW on employee outcomes, such as Peters et al. (20I4), de Leede and Kraijenbrink (20I4), de Leede and Heuver (2017), Gerards et al. (2018a) and Gerards et al. (2018b) who find positive relations between NWW and work-related flow, employee performance and productivity, work engagement, and informal learning, respectively. In fact, work engagement could provide an interesting perspective for further investigating the relation between NWW and intrapreneurship, as Gawke et al. (2017) find evidence for a positive and cyclical relation between employee intrapreneurship, personal resources and work engagement. Implementing NWW practices may provide a way to instigate this positive gain cycle.

\subsubsection{Practical implications}

Implementing NWW can help organisations to foster intrapreneurial behaviour of their employees. Giving employees the autonomy to work independent of time and location and to determine their own work processes are shown to relate to intrapreneurial behaviour. Moreover, the positive relation between our mediator transformational leadership and intrapreneurship, confirms that transformational leadership in itself also promotes intrapreneurship (see also Deprez and Euwema (2017) and Moriano et al., (2014)). In addition, since part of the relation between NWW and intrapreneurship runs via transformational leadership, organisations that implement NWW should consider actively promoting a more transformational leadership style alongside the introduction of NWW. In particular, creating a freely accessible open workplace only contributes to intrapreneurship if facilitated by a transformational leadership style.

However, not all NWW facets increase intrapreneurship. Our findings show that access to organisational knowledge and flexibility in working relations do not positively relate to intrapreneurship. This suggests that investments in information technology to allow for access to organisational knowledge should be carefully considered when an organisation aims at fostering employee intrapreneurship. Similarly, providing employees with the opportunity to adjust their contractual working hours does not seem an effective strategy for fostering intrapreneurship.

\subsubsection{Limitations and future research}

The main limitation of this study is that we use cross-sectional data, which makes causal inferences about the relations in our study problematic. For instance, although 
the literature suggests that NWW facilitates intrapreneurship (e.g. Martins \& Terblanche, 2003), organisations with NWW might also be particularly attractive for intrapreneurial employees, i.e., intrapreneurs could self-select into firms that implemented NWW, and already display high levels of transformational leadership.

Moreover, using cross-sectional data makes that we cannot take account of the fact that NWW includes facets that probably require time to become embedded after implementation. Similarly, the level of intrapreneurship is hardly expected to change overnight with the introduction of NWW practices. To investigate the causal effects of NWW on intrapreneurship, future research could therefore use longitudinal data or field experiments where the introduction of NWW and the effects on employee intrapreneurship are observed over time.

Another limitation concerns our sample. We conducted this study using a sample of employees from the Dutch working population. Consequently, our findings are not necessarily generalizable to other national and cultural settings. Future research is needed to investigate whether the relations between NWW and intrapreneurship we found hold in other cultures.

\subsection{Appendix}

Table A5.1 - Employee intrapreneurship scale (15-item version)

\section{Strategic renewal behaviour}

1. I undertake activities to realise change in my organisation.

2. I undertake activities to change the current products/services of my organisation.

3. I contribute ideas for strategic renewal for my organisation.

4. I conceptualise new ways of working for my organisation.

5. I utilise insights of other experts to innovate in my organisation.

6. I undertake activities that change the structure of my organisation.

7. I undertake activities that change the work practices of my organisation.

8. I exploit opportunities in the labour market or society to renew my organisation.

\section{Venturing behaviour}

9. I undertake activities to set up new business units.

10. I undertake activities to reach a new market or community with my organisation.

11. I undertake activities that result in new departments outside of my organisation.

12. I conceptualise new ways of service for my organisation.

13. I undertake activities that result in new projects within my organisation.

14. I actively establish new collaborations with experts outside of my own profession.

15. I conceptualise new products for my organisation.

Source: Gawke et al. (2019). 
Table A5.2 - New Ways of Working scale: original and new items

Facet 1: time- and location-independent work

1. I am able to set my own working hours

2. I am able to determine where I work

3. I am able to work from home if I want to

Facet 2: management on output

4. I am able to determine the way I work

5. My supervisor does not get involved with the way I do my job

6. My supervisor evaluates me on the quality of the work I deliver, not the way I worked

Facet 3: access to organisational knowledge

7. I can access all necessary information on my computer, smartphone, and/or tablet

8. I am able to reach colleagues within the team quickly

9. I am able to reach managers quickly

10. I am able to reach colleagues outside the team quickly

11. I have access to all necessary information everywhere, at any time

\section{Facet 4: flexibility in working relations}

12. I have the ability to adapt my working scheme to my phase of life and ambitions

13. I have the possibility to work more or fewer hours

\section{Facet 5: freely accessible open workplaces}

14. The building is arranged so that colleagues are easily accessible

15. The building is arranged so that managers are easily accessible

16. The building is arranged such that I enjoy working there

Note: Newly added items in italics. 
Table A5.3 - OLS regression results of aggregate NWW and NWW facets on intrapreneurship

\begin{tabular}{|c|c|c|}
\hline & (1) & (2) \\
\hline \multicolumn{3}{|l|}{ Main variables } \\
\hline NWW aggregate & $\begin{array}{l}0.188^{* * *} \\
(0.061)\end{array}$ & \\
\hline Time- and location-independent work & & $\begin{array}{l}0.168^{* *} \\
(0.067)\end{array}$ \\
\hline Management on output & & $\begin{array}{l}0.142^{* *} \\
(0.068)\end{array}$ \\
\hline Access to organisational knowledge & & $\begin{array}{l}-0.045 \\
(0.071)\end{array}$ \\
\hline Flexibility in working relations & & $\begin{array}{l}-0.089 \\
(0.069)\end{array}$ \\
\hline Freely accessible open workplace & & $\begin{array}{c}0.070 \\
(0.062)\end{array}$ \\
\hline Social interaction & $\begin{array}{l}-0.023 \\
(0.059)\end{array}$ & $\begin{array}{c}0.007 \\
(0.061)\end{array}$ \\
\hline Transformational leadership & $\begin{array}{l}0.150^{* *} \\
(0.061)\end{array}$ & $\begin{array}{l}0.149^{* *} \\
(0.062)\end{array}$ \\
\hline Control variables & & \\
\hline Female (ref. $=$ male) & $\begin{array}{l}-0.119 \\
(0.126)\end{array}$ & $\begin{array}{l}-0.119 \\
(0.125)\end{array}$ \\
\hline Age & $\begin{array}{l}-0.005 \\
(0.006)\end{array}$ & $\begin{array}{l}-0.006 \\
(0.006)\end{array}$ \\
\hline Management or sales job & $\begin{array}{l}0.605^{* * *} \\
(0.116)\end{array}$ & $\begin{array}{c}0.560^{* * *} \\
(0.116)\end{array}$ \\
\hline Tenure & $\begin{array}{l}-0.004 \\
(0.005)\end{array}$ & $\begin{array}{l}-0.003 \\
(0.005)\end{array}$ \\
\hline Part-time (ref. = full-time) & $\begin{array}{c}-0.274^{* *} \\
(0.121\end{array}$ & $\begin{array}{c}-0.255^{* *} \\
(0.120)\end{array}$ \\
\hline Lower level education (= ref.) & & \\
\hline Middle level education & $\begin{array}{l}-0.072 \\
(0.187)\end{array}$ & $\begin{array}{l}-0.093 \\
(0.186)\end{array}$ \\
\hline Higher level education & $\begin{array}{l}0.309^{*} \\
(0.188)\end{array}$ & $\begin{array}{l}0.255 \\
(0.189)\end{array}$ \\
\hline Neuroticism & $\begin{array}{l}0.060 \\
(0.057\end{array}$ & $\begin{array}{c}0.051 \\
(0.056)\end{array}$ \\
\hline Extraversion & $\begin{array}{l}-0.012 \\
(0.055)\end{array}$ & $\begin{array}{l}-0.003 \\
(0.055)\end{array}$ \\
\hline Openness to experience & $\begin{array}{c}0.201^{* * *} \\
(0.053)\end{array}$ & $\begin{array}{c}0.203^{* * *} \\
(0.053)\end{array}$ \\
\hline Agreeableness & $\begin{array}{c}0.020 \\
(0.056)\end{array}$ & $\begin{array}{l}-0.003 \\
(0.056)\end{array}$ \\
\hline Conscientiousness & $\begin{array}{c}0.041 \\
(0.054)\end{array}$ & $\begin{array}{c}0.062 \\
(0.055)\end{array}$ \\
\hline $\begin{array}{l}\text { Observations } \\
\text { R-squared }\end{array}$ & $\begin{array}{l}254 \\
0.39\end{array}$ & $\begin{array}{l}254 \\
0.41\end{array}$ \\
\hline
\end{tabular}


Table A5.4 - Mediation effect of NWW on intrapreneurship via social interaction and transformational leadership

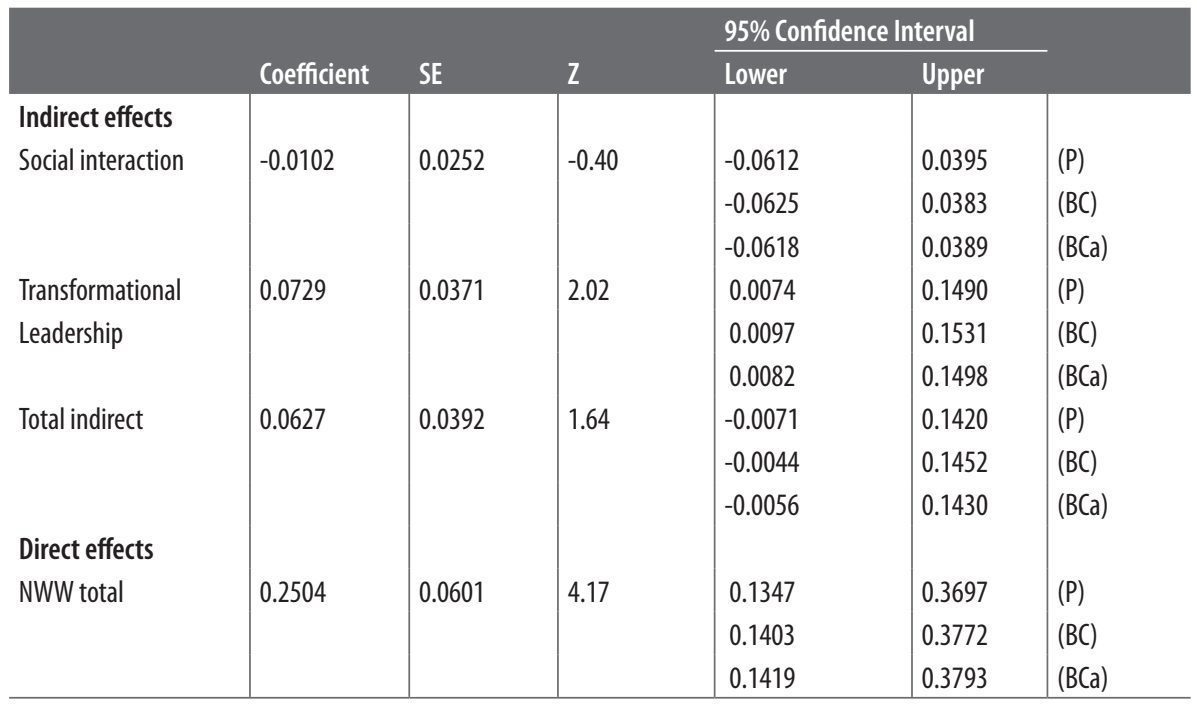

Note: NWW = New ways of working; P, percentile; $\mathrm{BC}$, bias-corrected; $\mathrm{BC}$, bias-corrected and accelerated. Results based on 4,999 bootstrap samples. 
Table A5.5 - Mediation effect of NWW facets on intrapreneurship via social interaction and transformational leadership

\begin{tabular}{|c|c|c|c|c|c|c|}
\hline \multirow{2}{*}{ Indirect effects } & \multirow[b]{2}{*}{ Coefficient } & \multirow[b]{2}{*}{ SE } & \multirow[b]{2}{*}{ Z } & \multicolumn{2}{|c|}{$95 \%$ Conf. Interval } & \\
\hline & & & & Lower & Upper & \\
\hline \multirow[t]{3}{*}{ Facet 1 via Social Interaction (a1b1) } & -0.0008 & 0.0082 & -0.10 & -0.0200 & 0.0155 & $(\mathrm{P})$ \\
\hline & & & & -0.0222 & 0.0139 & (BC) \\
\hline & & & & -0.0222 & 0.0139 & $(\mathrm{BCa})$ \\
\hline \multirow[t]{3}{*}{ Facet 2 via Social Interaction (a1b1) } & 0.0005 & 0.0061 & 0.08 & -0.0121 & 0.0144 & $(\mathrm{P})$ \\
\hline & & & & -0.0099 & 0.0177 & (BC) \\
\hline & & & & -0.0100 & 0.0175 & (BCa) \\
\hline \multirow[t]{3}{*}{ Facet 3 via Social Interaction (a1b1) } & 0.0026 & 0.0220 & 0.12 & -0.0414 & 0.0477 & (P) \\
\hline & & & & -0.0414 & 0.0477 & (BC) \\
\hline & & & & -0.0410 & 0.0479 & $(\mathrm{BCa})$ \\
\hline \multirow[t]{3}{*}{ Facet 4 via Social Interaction (a1b1) } & 0.0009 & 0.0086 & 0.11 & -0.0172 & 0.0198 & (P) \\
\hline & & & & -0.0154 & 0.0221 & $(B C)$ \\
\hline & & & & -0.0153 & 0.0222 & $(\mathrm{BCa})$ \\
\hline \multirow[t]{3}{*}{ Facet 5 via Social Interaction (a1b1) } & 0.0011 & 0.0105 & 0.11 & -0.0197 & 0.0239 & $(\mathrm{P})$ \\
\hline & & & & -0.0185 & 0.0251 & (BC) \\
\hline & & & & -0.0185 & 0.0251 & $(\mathrm{BCa})$ \\
\hline \multirow[t]{3}{*}{ Facet 1 via Transformational Leadership (a2b2) } & -0.0028 & 0.0113 & -0.25 & -0.0241 & 0.0227 & $(P)$ \\
\hline & & & & -0.0280 & 0.0182 & (BC) \\
\hline & & & & -0.0280 & 0.0181 & $(\mathrm{BCa})$ \\
\hline \multirow[t]{3}{*}{ Facet 2 via Transformational Leadership (a2b2) } & 0.0240 & 0.0162 & 1.49 & -0.0006 & 0.0622 & $(\mathrm{P})$ \\
\hline & & & & 0.0018 & 0.0718 & (BC) \\
\hline & & & & 0.0018 & 0.0712 & $(\mathrm{BCa})$ \\
\hline \multirow[t]{3}{*}{ Facet 3 via Transformational Leadership (a2b2) } & 0.0145 & 0.0138 & 1.06 & -0.0071 & 0.0471 & $(\mathrm{P})$ \\
\hline & & & & -0.0028 & 0.0554 & (BC) \\
\hline & & & & -0.0033 & 0.0535 & $(\mathrm{BCa})$ \\
\hline \multirow[t]{3}{*}{ Facet 4 via Transformational Leadership (a2b2) } & 0.0161 & 0.0142 & 1.14 & -0.0064 & 0.0497 & (P) \\
\hline & & & & -0.0025 & 0.0578 & $(B C)$ \\
\hline & & & & -0.0025 & 0.0579 & $(\mathrm{BCa})$ \\
\hline \multirow[t]{3}{*}{ Facet 5 via Transformational Leadership (a2b2) } & 0.0498 & 0.0255 & 1.95 & 0.0045 & 0.1050 & (P) \\
\hline & & & & 0.0085 & 0.1117 & (BC) \\
\hline & & & & 0.0072 & 0.1087 & (BCa) \\
\hline \multirow[t]{2}{*}{ Total indirect effect } & 0.1059 & 0.0537 & 1.97 & 0.0070 & 0.2180 & $(\mathrm{P})$ \\
\hline & & & & 0.0106 & 0.2223 & (BC) \\
\hline
\end{tabular}


Table A5.5 - Mediation effect of NWW facets on intrapreneurship via social interaction and transformational leadership Continued

\begin{tabular}{|c|c|c|c|c|c|c|}
\hline \multirow[b]{2}{*}{ Indirect effects } & \multirow[b]{2}{*}{ Coefficient } & \multirow[b]{2}{*}{ SE } & \multirow[b]{2}{*}{ Z } & \multicolumn{2}{|c|}{ 95\% Conf. Interval } & \\
\hline & & & & Lower & Upper & \\
\hline Total effects & & & & 0.0085 & 0.2204 & (BCa) \\
\hline \multirow[t]{3}{*}{ Total effect NWW facet 1} & 0.1645 & 0.0747 & 2.20 & 0.0191 & 0.3123 & (P) \\
\hline & & & & 0.0184 & 0.3119 & $(\mathrm{BC})$ \\
\hline & & & & 0.0163 & 0.3089 & (BCa) \\
\hline \multirow[t]{3}{*}{ Total effect NWW facet 2} & 0.1667 & 0.0709 & 2.35 & 0.0274 & 0.3035 & (P) \\
\hline & & & & 0.0367 & 0.3130 & $(\mathrm{BC})$ \\
\hline & & & & 0.0370 & 0.3145 & (BCa) \\
\hline \multirow[t]{3}{*}{ Total effect NWW facet 3} & -0.0278 & 0.0627 & -0.44 & -0.1450 & 0.0977 & (P) \\
\hline & & & & -0.1480 & 0.0941 & $(\mathrm{BC})$ \\
\hline & & & & -0.1483 & 0.0932 & (BCa) \\
\hline \multirow[t]{3}{*}{ Total effect NWW facet 4} & -0.0722 & 0.0674 & -1.07 & -0.2025 & 0.0587 & (P) \\
\hline & & & & -0.2020 & 0.0587 & $(\mathrm{BC})$ \\
\hline & & & & -0.1986 & 0.0610 & (BCa) \\
\hline \multirow[t]{3}{*}{ Total effect NWW facet 5} & 0.1214 & 0.0670 & 1.81 & -0.0125 & 0.2495 & (P) \\
\hline & & & & -0.0092 & 0.2525 & (BC) \\
\hline & & & & -0.0117 & 0.2498 & (BCa) \\
\hline
\end{tabular}

Note: $\mathrm{SI}=$ Social Interaction; $\mathrm{TL}=$ Transformational Leadership. P, percentile; $\mathrm{BC}$, bias-corrected; $\mathrm{BC}$, bias-corrected and accelerated. Results based on 4,999 bootstrap samples.

Figure A5.1 - Multiple mediation model of direct and indirect effects of NWW on Strategic Renewal behaviour.

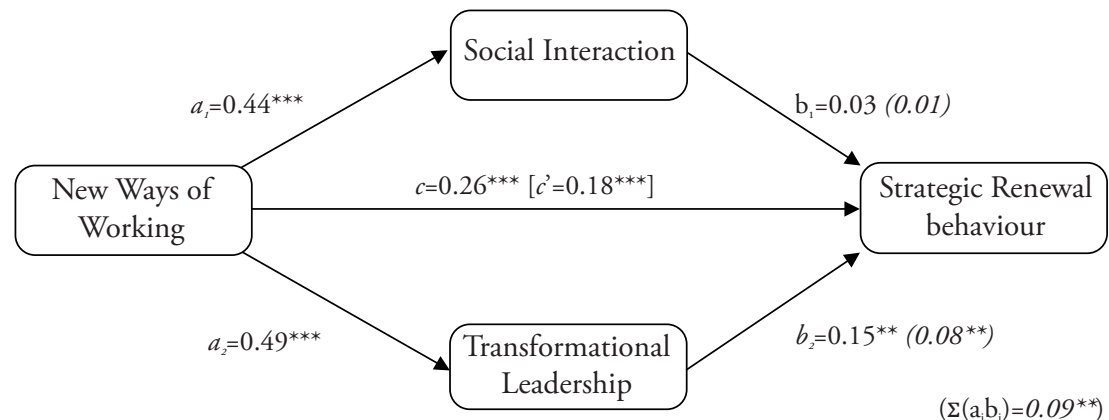

Note: Indirect effects $\left(a_{i} b_{i}\right)$ and total indirect effect $\left(\Sigma\left(a_{i} b_{i}\right)\right)$ are shown in italics in parentheses. Direct effect of NWW accounting for mediation is shown in brackets. Total effect $c=\Sigma\left(a_{i}{ }^{*} b_{i}\right)+c^{\prime} .{ }^{*} p<0.1,{ }^{* *} p<0.05,{ }^{* * *} p<.01$. 
Figure A5.2 - Multiple mediation model of direct and indirect effects of NWW on New Venture behaviour.

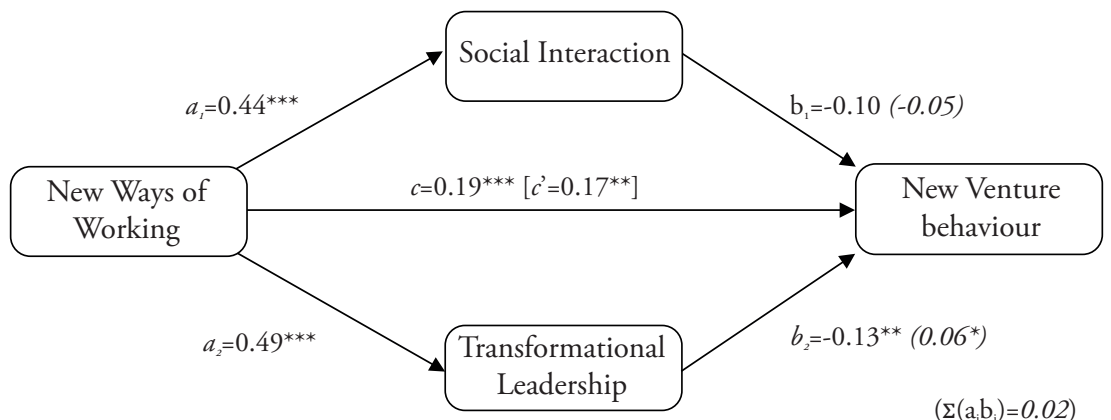

Note: Indirect effects $\left(a_{i} b_{i}\right)$ and total indirect effect $\left(\Sigma\left(a_{i} b_{i}\right)\right)$ are shown in italics in parentheses. Direct effect of NWW accounting for mediation is shown in brackets. Total effect $c=\sum\left(a_{i}^{*} b_{i}\right)+c^{\prime} .{ }^{*} p<0.1,{ }^{* *} p<0.05,{ }^{* * *} p<.01$.

Figure A5.3 - Multiple mediation model of direct and indirect effects of NWW facets on Strategic Renewal behaviour.

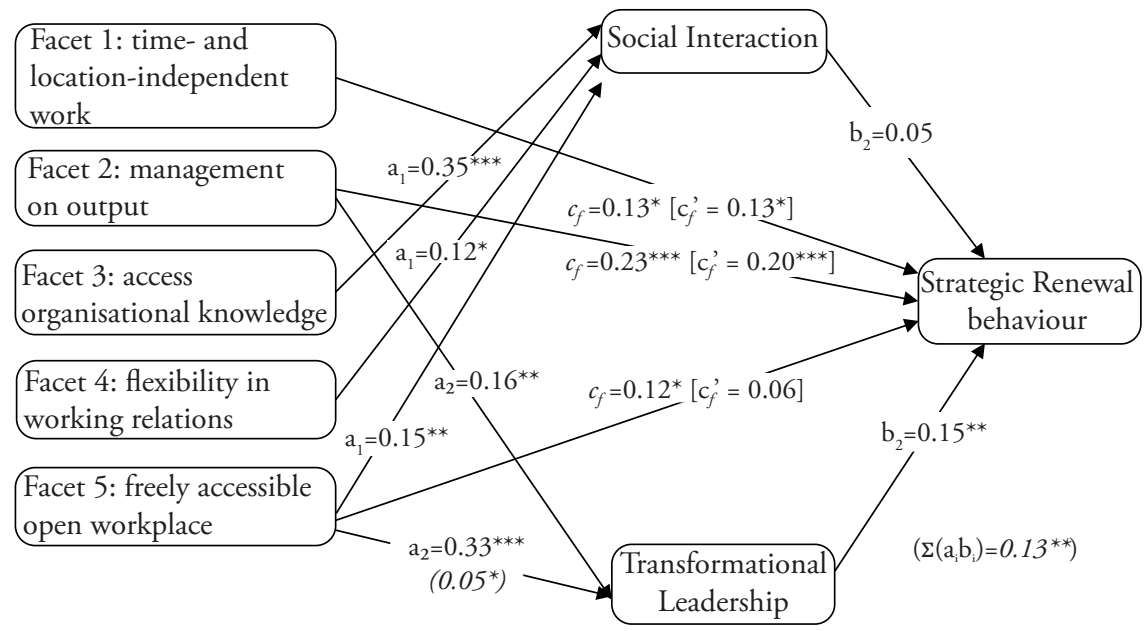

Note: Indirect effects $\left(a_{\mathrm{i}} \mathrm{b}_{\mathrm{i}}\right)$ and total indirect effects $\left(\sum\left(\mathrm{a}_{\mathrm{i}} \mathrm{b}_{\mathrm{i}}\right)\right)$ are shown in italics parentheses. Direct effect of NWW facets accounting for mediation is shown in brackets. We show only significant relationships. Total effect per facet ' $f$ ' is $(f=$ $\Sigma\left(\mathrm{a}_{\mathrm{i}, \mathrm{f}}{ }^{*} \mathrm{~b}_{\mathrm{i}}\right)+\left(f .{ }^{*} \mathrm{p}<0.1,{ }^{* *} \mathrm{p}<.05,{ }^{* * *} \mathrm{p}<.01\right.$. 
Figure A5.4 - Multiple mediation model of direct and indirect effects of NWW facets on New Venture behaviour.

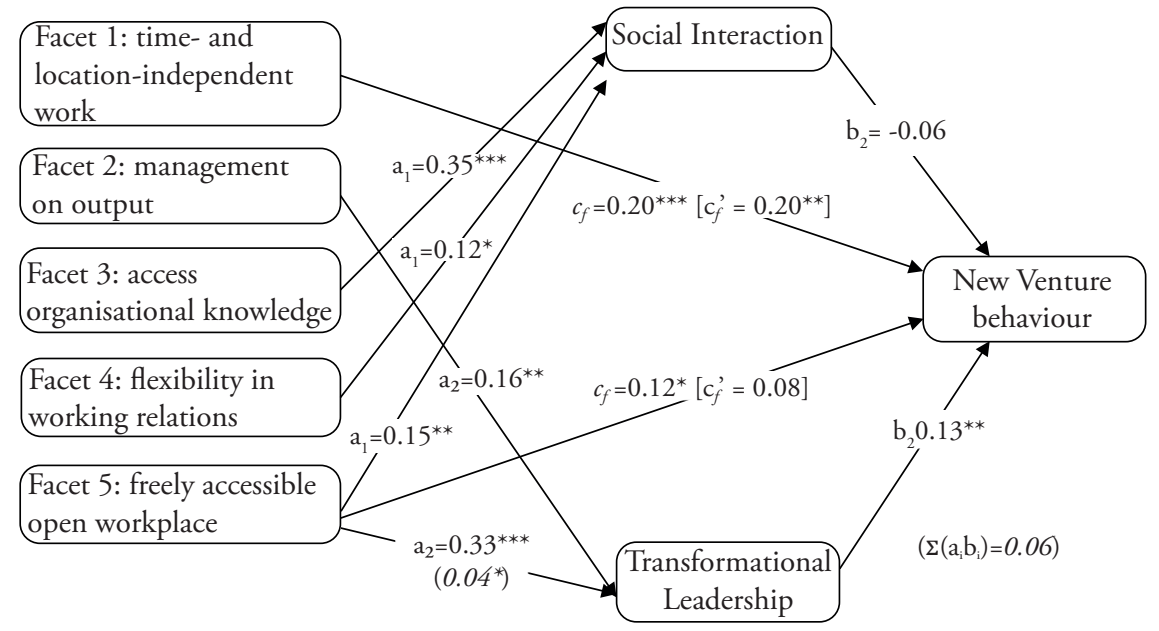

Note: Indirect effects $\left(a_{i} b_{i}\right)$ and total indirect effects $\left(\sum\left(a_{i} b_{i}\right)\right)$ are shown in italics parentheses. Direct effect of NWW facets accounting for mediation is shown in brackets. We show only significant relationships. Total effect per facet ' $f$ ' is $C f=$ $\Sigma\left(\mathrm{a}_{\mathrm{i}, \mathrm{f}}{ }^{*} \mathrm{~b}_{\mathrm{i}}\right)+C f .{ }^{*} \mathrm{p}<0.1,{ }^{* *} \mathrm{p}<.05,{ }^{* * *} \mathrm{p}<.01$. 



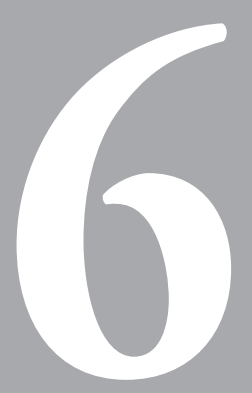

Conclusion 


\subsection{Summary of main results, contributions and implications}

The aim of this thesis was to create more insight into the interplay between individuals' human capital characteristics and characteristics of their work context in explaining intrapreneurial behaviour within organisations.

In Chapter 2, we investigated which job and firm characteristics are attractive for intrapreneurial talent. We used entrepreneurial personality traits and attitudes to identify prospective intrapreneurs, and to distinguish them from other types of workers. We found that intrapreneurs differ from non-entrepreneurial individuals regarding preferences for company mission, type of occupation, workload and performance pay. Our findings show that intrapreneurs prefer jobs in firms that focus on innovation, CSR and sustainability and have a stronger preference for team-based performance pay than others have. Moreover, we found that both intrapreneurs and entrepreneurs are more attracted to management occupations and are more willing to work overtime as compared to non-entrepreneurial individuals. These insights into the differences in job and organizational preferences between intrapreneurs, entrepreneurs and non-entrepreneurial individuals add to the strand of literature that compares intrapreneurs and entrepreneurs (Adachi \& Hisada, 20I7; Douglas \& Fitzsimmons, 20I3; Martiarena; 20I3; Matthews et al., 2009; Monsen, Patzelt \& Saxton, 20IO; Parker, 20II). Moreover, it adds to both the literature on individual level intrapreneurship (e.g. Blanka et al., 20I8) and the literature on targeted recruiting (Breaugh, 2013; Moser et al., 2017).

In Chapter 3, we investigated the extent to which higher-education graduates with higher intrapreneurial skills from II European countries are allocated to innovative tasks according to their intrapreneurial skill levels, and how these intrapreneurial skills are used for innovation in STEM and business occupations. We found that in both STEM and business occupations, high levels of creative skills are important to involvement in innovation. Higher levels of brokering skills are particularly important for graduates employed in STEM occupations. For these graduates, higher levels of brokering skills particularly increase the probability of being involved in innovation in technology, tools, and instruments. However, higher levels of championing skills are particularly important for those in business occupations, for whom these higher championing skill levels increase the probability of being involved in innovation in technology, tools, and instruments. This does not hold for graduates employed in STEM occupations. These differences in the importance of specific intrapreneurial skills for workers' involvement in innovation - arising from either the type of occupation or the type of innovation - add to the literature on the importance of workers' skills for innovation (e.g. Bjornali and Støren, 20I2; Hunter et al., 20I2; Mumford et al., 20I0; Vila et al. 20I2).

In addition, we found that graduates whose intrapreneurial skills are underutilized are less involved in innovation, compared to those whose intrapreneurial skill levels 
match the requirements of their jobs. The results of this chapter therefore suggest that the allocation of intrapreneurial skills not always maximizes the involvement in innovation of graduates with high levels of intrapreneurial skills. Moreover, we found that graduates working in STEM occupations are, on average, more involved in innovation than those employed in business occupations are. By uncovering this skill misallocation with respect to graduates' involvement in innovative tasks, these findings add to the economic literature on the effects of skill mismatch (e.g. Allen and van der Velden, 200I; McGuinness et al., 2017; Sánchez-Sánchez and McGuinness, 20I5).

In Chapter 4, we investigated what personality characteristics are important for intrapreneurial behaviour. Specifically, we investigated the relation between the Big Five personality traits, risk tolerance and intrapreneurial behaviour. In addition, we investigated how employees' perceptions of their organisation's support for intrapreneurship affects these relations. We found that employees with higher levels of Extraversion, Openness and risk tolerance have higher levels of intrapreneurial behaviour. Furthermore, we found that employees who perceive higher levels of support for intrapreneurship in their organisations have higher levels of intrapreneurial behaviour. Moreover, we found that the positive relation between Openness on intrapreneurial behaviour increases when employees are working in organisations in which they perceive higher levels of organisational support for intrapreneurship. These results also show that highly intrapreneurial employees are more similar to entrepreneurs than to other employees in terms of their personality traits.

The findings are valuable for understanding (self-)selection mechanisms into intrapreneurial activities and add to the growing evidence for the positive relation between Extraversion, Openness, risk tolerance and intrapreneurial behaviour (Ahmed et al., 2013; Douglas \& Fitzsimmons, 2013; Farruhk et al., 2016; Sinha \& Strivastava, 20I3; Woo, 20I8). Moreover, these findings contribute to the literature by shedding light on the interplay between employees' personality characteristics and the organisational environment in explaining intrapreneurial behaviour (e.g. Blanka et al., 20I8; Kuratko et al., 1990; 20I4; Mustafa et al., 2018).

In Chapter 5, we investigated the relations between New Ways of Working (NWW) and intrapreneurial behaviour, and the mediating effects of both co-worker social interaction and transformational leadership. We found that NWW positively relate to intrapreneurial behaviour. Moreover, we found that this relation is partially mediated by transformational leadership, but not by social interaction with co-workers. More specifically, we did not find a relation between social interaction with co-workers and employees' level of intrapreneurial behaviour. These findings suggest that positive social exchange relations between managers and employees (in the form of transformational leadership) are more important for stimulating intrapreneurial behaviour than social exchanges between co-workers are. In addition, we found that the positive relation between NWW and intrapreneurship is mainly driven by two NWW facets: (I) 
time- and location-independent work and (2) management on output. This adds to the literature on the work contextual antecedents of employee intrapreneurship (e.g. de Jong et al., 20I5; Moriano et al., 20I4; Mustafa et al., 20I8; Rigtering et al., 20I9; Rigtering \& Weitzel, 2013). Moreover, the study adds to the literature on employee outcomes of NWW (Peters et al., 20I4; de Leede \& Kraijenbrink, 20I4; de Leede \& Heuver, 20I7; Gerards et al., 20I8a; 20I8b).

\subsection{Directions for future research}

In sum, the chapters presented in this thesis show that both human capital and characteristics of the work context are important drivers of intrapreneurship. However, some results are more consistent than others, warranting further investigations. For instance, the relationships we find between educational level and intrapreneurial behaviour are not consistent across the studies presented in this thesis. In Chapter 4 we find that higher educated employees have higher levels of intrapreneurial behaviour, whereas in Chapter 5 we see no relations between educational level and intrapreneurial behaviour. Moreover, in Chapters, 3, 4 and 5 we find that tenure, as a proxy for firm-specific human capital, is generally not related to employees' involvement in innovations, and intrapreneurial behaviour. However, in Chapter 3 , we find that tenure is positively related to employees' involvement in innovations in technology, tools and instruments, but not to employees' involvement in other types of innovation. This implies that the relationship of specific human capital and intrapreneurship depends on the type of innovation. In addition, with respect to the Big Five personality traits, we find both in Chapter 4 and 5 that openness to experience is positively related to intrapreneurial behaviour, whereas extraversion and intrapreneurial behaviour are only positively related in Chapter 4. Furthermore, in Chapters 3 and 5 we find a positive relation between autonomy and employees' involvement in innovations and intrapreneurial behaviour. However, in Chapter 4 we do not find a significant relationship between autonomy and intrapreneurial behaviour. These differences could be due to several factors. For instance, differences in the relationships we find across chapters could be due to differently composed samples that are used in the different studies, or to different ways of measuring work autonomy or personality. Therefore, future studies could further investigate the influence of the work and research context on the relationships between individuals' characteristics and intrapreneurship.

Here, I summarize various potential areas for future research that address the interplay between individuals' characteristics and characteristics of the work context that drives intrapreneurial behaviour. Future studies could further investigate (self-) selection mechanisms of entrepreneurial talent into organisations and intrapreneurial activities. For instance, studies could investigate whether intrapreneurs differ in their 
preferences for job and organisational characteristics such as geographical distance, the learning opportunities in the job or NWW, or whether organisations where managers exhibit high levels of transformational leadership are particularly attractive for intrapreneurial workers. In addition, gender differences in the allocation of workers to intrapreneurial activities are an interesting avenue for future research.

Furthermore, future research is needed on identifying intrapreneurial types of students or workers and how firms can optimise the allocation of their intrapreneurial talent into tasks that require this talent. For instance, future research could investigate the effects of recruitment focusing on education level, intrapreneurial skills and personality traits by comparing the innovative performance of new hires that are selected specifically for their intrapreneurial skills to the innovative performance of those who were hired without considering whether applicants have intrapreneurial skills. In addition, future research could investigate which skills and personality traits lead to successful and unsuccessful intrapreneurial behaviour in different phases of the innovation process, for different types of innovations. Finally, future studies could investigate the consequences of the underutilization of intrapreneurial skills for both employees and firms with respect to wages, promotions, turnover intention, voluntary job quits, job performance, innovation, strategic renewal and internal venturing.

Importantly, to investigate causal effects, future research should aim to use longitudinal data in which indicators of employee intrapreneurship in the work context are observed over time. In addition, (field) experiments in which individuals are randomly allocated to different tasks or work contexts would provide valuable information on the causal effect of contextual characteristics such as work autonomy on intrapreneurial behaviour.

\subsection{Implications for practice}

The results of the studies presented in this thesis have several practical implications particularly for firms that aim to increase their intrapreneurial potential through recruitment and selection, development and internal allocation of talent, through leadership practices and design of the work environment.

With regard to recruitment and selection, the results of Chapter 2 suggest that firms can consider highlighting their innovative mission and employer brand in the recruitment process, emphasizing career opportunities in management positions and team-based performance pay, when they aim to increase the intrapreneurial applicant pool among STEM workers. In addition, the results presented in Chapter 4 of this thesis suggest that when selecting new applicants or internal talent, recruiters can identify potential intrapreneurial workers based on high levels of Extraversion, Openness and risk tolerance. 
The results of Chapter 3 are informative for those involved in the development and allocation of talent in their firms. The results of this chapter suggest that the development of higher levels of creativity, championing and brokering skills increases employees' innovative potential. However, the results of this chapter also suggest that intrapreneurial training should focus on different intrapreneurial skills for employees in business occupations and those in STEM occupations, and should depend on skill demands in employees' jobs and the type of innovation. In addition, the results of this chapter suggest that employees' intrapreneurial skills are not always optimally used by firms for innovation purposes, and firms can make more efficient use of the intrapreneurial skills of their workers.

The results of Chapters 4 and 5 of this thesis mainly have implications for management and design of the working environment. The results of these two chapters show that both organisational and managerial support fosters employees' intrapreneurial behaviour. The results of Chapter 4 suggest that organisational support by means of rewards, time and organisational resources, especially facilitates the intrapreneurial behaviour of those employees with higher levels of Openness. The results of Chapter 5 suggest that implementing New Ways of Working can help firms to foster intrapreneurial behaviour of their employees. Especially giving their employees the autonomy to work independent of time and location and to determine their own work processes is found to positively relate to intrapreneurial behaviour. In addition, the results of this chapter suggest that managers with high levels of transformational leadership are more successful in fostering employees' intrapreneurial behaviour. 


\section{Valorisation addendum}

The research presented in this thesis is not only academically valuable, but is also useful for firms that are interested in stimulating intrapreneurship within their organisations. The research presented in this thesis is particularly informative for practitioners involved in recruitment and selection, development and allocation of talent, management and design of organisations' work environment.

\section{Recruitment and selection}

The results of this thesis are highly relevant for those who are responsible for the recruitment of scarce talent and face that offering higher wages is not a sufficient recruitment strategy to recruit the intrapreneurial talent they aim at. Chapter 2 shows that students in science, technology, engineering and mathematics who possess intrapreneurial talent, are especially attracted to firms that focus on innovation, corporate social responsibility and sustainability. In addition, those with intrapreneurial talent are more attracted to jobs that include team-based performance pay. Furthermore, the results of Chapter 4 suggest that organisations that signal a supportive work environment for innovative activities are more successful in attracting employees with higher intrapreneurial potential. Firms interested in attracting intrapreneurial talent can use these results in the recruitment process. For instance, they could highlight their support and mission for innovation, corporate social responsibility and sustainability in their corporate brand and during the recruitment process, and provide team-based performance pay.

In addition, the results of Chapter 4 show that workers with higher levels of Extraversion, Openness and risk tolerance are more likely to show intrapreneurial behaviour. These results can be used by practitioners involved in the selection of employees. For instance, these traits can be assessed during selection procedures of new hires to identify those applicants with entrepreneurial dispositions.

\section{Development and allocation of talent}

The results of Chapter 3 suggest that it might be beneficial for firms to invest in further developing the intrapreneurial skill-set of their higher-educated employees. They can do this either by hiring new employees that have high levels of intrapreneurial skills, or by increasing the intrapreneurial skill levels of their existing employees. When developing training programmes, the results of Chapter 3 suggest however, that this training should focus on different intrapreneurial skills for employees in business occupations than those in STEM occupations. Moreover, training programmes 
should be further tailored to existing intrapreneurial skill levels of the employees, the skills demands in their jobs, and the type of innovation envisioned by the firm. In addition, the results of Chapter 3 are relevant to those in charge of the design of curricula in higher education. The outcomes of this chapter suggest that the innovative potential of students could be increased by fostering their creativity, championing, and brokering skills. Therefore, curricula that aim to contribute to students' innovation skills, should be designed in such a way that student can develop creative, brokering and championing skills. Curricula design can be informed by for instance Scott et al. (2004), who provide a review of training components and their effects on creativity. In addition, Menzel et al. (2007) provide suggestions on the design of training programmes that aim to increase intrapreneurial skills.

Moreover, the results of Chapter 3 show that intrapreneurial skills are underutilised in firms' innovation processes. This indicates that firms could make more efficient use of their intrapreneurial talent by allocating more employees with higher levels of intrapreneurial skills to innovative tasks. More specifically, the results of Chapter 3 suggest that firms can make more efficient use of employees with higher creative and championing skills in product and service innovation and in process innovation in knowledge and methods.

\section{Management and design of the work environment}

The findings of Chapter 4 suggest that employees show higher levels of intrapreneurial behaviour in organisations that provide rewards, time and organisational resources for intrapreneurship. However, providing these supportive measures does not incentivise all employees to engage in intrapreneurial behaviour, and may especially provide incentives for increased intrapreneurial behaviour for employees with higher levels of Openness, but not for employees with higher levels of Extraversion and risk tolerance.

The results of Chapter 5 suggest that implementing several New Ways of Working facets can help firms to foster intrapreneurial behaviour of their employees. Especially giving employees the autonomy to work independent of time and location and to determine their own work processes are positively related to intrapreneurial behaviour. However, this chapter also shows that not all New Ways of Working facets increase employees' intrapreneurial behaviour. Access to organisational knowledge and flexibility in working relations does not positively relate to employees' intrapreneurial behaviour. Therefore, this suggests that investments in information technology to allow for access to organisational knowledge should be carefully considered when an organisation aims at fostering intrapreneurship. Similarly, providing employees with the opportunity to adjust their working hours depending on their private situation or professional ambition does not seem an effective strategy for fostering intrapreneurship. 
The results of Chapter 5 also show that management style is an important factor when aiming to stimulate intrapreneurial behaviour of the employees in the organisation. These results show that managers with higher levels of transformational leadership promote intrapreneurial behaviour. In particular, the results of Chapter 5 show that creating a freely accessible open workplace only contributes to employees' intrapreneurial behaviour when facilitated by a transformational leadership style. Therefore, organisations that implement New Ways of Working should consider simultaneously promoting a more transformational leadership style among their managers. 



\section{Bibliography}

Adachi, T., \& Hisada, T. (2017). Gender differences in entrepreneurship and intrapreneurship: an empirical analysis. Small Business Economics, 48(3), 447-486.

Agarwal, R., \& Helfat, C. E. (2009). Strategic renewal of organizations. Organization science, 20(2), 28I-293.

Ahmed, S. N., Rehman, A., \& Amjad, M (2013). Job satisfaction and intrapreneurship: The moderating effect of personality trait. Journal of International Studies, 61, 87-95.

Ai, C. \& Norton, E.C. (2003). Interaction terms in logit and probit models. Economics Letters, 80, I23-I29.

Ajzen, I. (I99I). The theory of planned behavior. Organizational behavior and human decision processes, 50(2), I79-2II.

Aldrich, H. E. (1999). Organizations evolving. London: Sage Publishing.

Allen, J. \& De Grip, A. (2OI2). Does skill obsolescence increase the risk of employment loss? Applied Economics, 44(25), 3237-3245.

Allen, J. \& Van der Velden, R. (200I). Educational mismatches versus skill mismatches: effects on wages, job satisfaction and on-the-job search. Oxford Economic papers, 3, 434-452.

Allen, J. \& Van der Velden, R. (2005). The role of Self-Assessment in Measuring Skills. REFLEX Working paper 2. Research Centre for Education and the Labour market, Maastricht University.

Allen, J. \& Van der Velden, R. (201I). The Flexible Professional in the Knowledge Society: New Challenges for Higher Education. Dordrecht: Springer.

Allen, J. P., Levels, M., \& Van der Velden, R. K. W. (2013). Skill mismatch and skill use in developed countries: Evidence from the PIAAC study. (ROA Research Memoranda ROA-RM-2013/I7). Maastricht: Research Centre for Education and the Labour Market (ROA).

Alpkan, L., Bulut, C., Gunday, G., Ulusoy, G. \& Kilic, K. (20I0). Organizational support for intrapreneurship and its interaction with human capital to enhance innovative performance. Management Decision, 48(5), $732-755$.

Amabile, T. (1988). A Model of Creativity and Innovation in Organizations. In B. Staw and L. Cummings (Eds.), Research in Organizational Behavior (pp. 123-167). Greenwich CT: JAI Press.

Amit, R., \& Muller, E. (1995). "Push" and "pull” entrepreneurship. Journal of Small Business \& Entrepreneurship, I2(4), 64-80.

Anderson, N., Potočnik, K. \& Zhou, J. (20I4). Innovation and creativity in organizations: A state-of the-science review, prospective commentary, and guiding framework. Journal of Management, 40(5), I297-I333.

Andries, P., \& Czarnitzki, D. (20I4). Small firm innovation performance and employee involvement. Small Business Economics, 43, 2I-38. 
Antoncic, B., \& Hisrich, R. D. (200I). Intrapreneurship: Construct refinement and cross-cultural validation. Journal of business venturing, I6(5), 495-527.

Antoncic, B., \& Hisrich, R. D. (2003). Clarifying the intrapreneurship concept. Journal of small business and enterprise development, Io(I), 7-24.

Antoncic, B., \& Hisrich, R. D. (2004). Corporate entrepreneurship contingencies and organizational wealth creation. Journal of management development, 23(6), 518-550.

Antonioni, D. (1998). Relationship between the big five personality factors and conflict management styles. International journal of conflict management, $9(4), 336-355$.

Ashton, M.C. (2007). Individual differences and personality. London: Elsevier inc.

Atkinson, R. D. \& Mayo, M. (2010). Refuelling the U.S. innovation economy: Fresh approaches to science, technology, engineering and mathematics (STEM) education. Washington, DC: Information Technology and Innovation Foundation.

Avery, D. R. (2003). Reactions to diversity in recruitment advertising--are differences black and white? Journal of applied psychology, 88(4), 672.

Bal, P.M. \& De Lange, A.H. (2015). From flexibility human resource management to employee engagement and perceived job performance across the lifespan: a multisample study. Journal of Occupational and Organizational Psychology, 88(I), I26-I54.

Bammens, Y. P. (2016). Employees' innovative behavior in social context: A closer examination of the role of organizational care. Journal of Product Innovation Management, 33(3), 244-259.

Baron, R. M., \& Kenny, D. A. (1986). The moderator-mediator variable distinction in social psychological research: Conceptual, strategic, and statistical considerations. Journal of personality and social psychology, ${ }_{5 I}(6), \mathrm{II} 73$.

Barrick, M. R. (2005). Yes, personality matters: Moving on to more important matters. Human performance, I8(4), 359-372.

Bass, B. M. (1999). Two decades of research and development in transformational leadership. European journal of work and organizational psychology, 8(I), 9-32.

Batey, M., Furnham, A., \& Safiullina, X. (20I0). Intelligence, general knowledge and personality as predictors of creativity. Learning and individual differences, 20(5), 532-535.

Baum, J. R., \& Locke, E. A. (2004). The relationship of entrepreneurial traits, skill, and motivation to subsequent venture growth. Journal of applied psychology, 89(4), 587.

Baum, J.R., Locke, E.A. \& Smith K.G. (200I). A Multidimensional Model of Venture Growth. The Academy of Management Journal, 44, 292-303.

Bednall, T. C., E. Rafferty, A., Shipton, H., Sanders, K., \& J. Jackson, C. (2018). Innovative behaviour: how much transformational leadership do you need? British Journal of Management, 29, 796-816.

Bijl, D. (2009). Aan de slag met het nieuwe werken. Zeewolde: Par CC.

Bjornali, E. S., \& Støren, L.A. (20I2). Examining competence factors that encourage innovative behaviour by European higher education graduate professionals. Journal of Small Business and Enterprise Development, I9(3), 402-423.

Blanka, C. (2018). An individual-level perspective on intrapreneurship: A review and ways forward. Review of Managerial Science, https://doi.org/I0.I007/sII846-0I8-0277-0

Blau, P.M. (1964). Exchange and Power in Social Life. New York: Wiley. 
Block, Z., \& MacMillan, I. (1993). Corporate venturing. Cambridge, MA: Harvard Business School Press.

Blok, M. M., Groenesteijn, L., Schelvis, R., \& Vink, P. (20I2). New ways of working: does flexibility in time and location of work change work behavior and affect business outcomes? Work, 4I(Supplement I), 2605-2610.

Blumberg, B. F., \& Pfann, G. A. (2016). Roads Leading to Self-Employment: Comparing Transgenerational Entrepreneurs and Self-Made Start-Ups. Entrepreneurship Theory and Practice, 40(2), 335-357.

Blume, B. D., Rubin, R. S., \& Baldwin, T. T. (2013). Who is attracted to an organization using a forced distribution performance management system? Human Resource Management Journal, 23(4), 360-378.

Boon, J., Van der Klink M. \& Janssen, J. (2013). Fostering intrapreneurial competencies of employees in the education sector. International Journal of Training and Development, I7(3), 2IO-220.

Bosma, N., Stam, E. \& Wennekers, A.R.M. (20IO). Intrepreneurship - An International Study. EIM research reports, Zoetermeer: Nr. H20I005.

Boswell, W. R., \& Olson-Buchanan, J. B. (2007). The use of communication technologies after hours: The role of work attitudes and work-life conflict. Journal of Management, 33(4), 592-610.

Branine, M. (2003). Part-time work and jobsharing in health care: is the NHS a familyfriendly employer? Journal of health organization and management, $17(\mathrm{I}), 53-68$.

Breaugh, J. A. (2013). Employee recruitment. Annual review of psychology, 64, 389-416.

Breaugh, J.A. (2008). Employee recruitment: current knowledge and important areas for future research. Human Resource Management Review, I8, I03-II8.

Brunia, S., De Been, I., \& van der Voordt, T. J. (2016). Accommodating new ways of working: lessons from best practices and worst cases. Journal of corporate real estate, I8(I), 30-47.

Burch, G. S. J., Pavelis, C., Hemsley, D. R., \& Corr, P. J. (2006). Schizotypy and creativity in visual artists. British journal of psychology, 97(2), I77-I90.

Burgelman, R. A. (I99I). Intraorganizational ecology of strategy making and organizational adaptation: Theory and field research. Organization science, 2(3), 239-262.

Burgelman, R.A. (1983). A model of the interaction of strategic behavior, corporate context and the concept of strategy. Academy of Management Review, 8, 6I-7I.

Cable, D. M., \& Judge, T. A. (1994). Pay preferences and job search decisions: A personorganization fit perspective. Personnel psychology, 47(2), 317-348.

Caliendo, M., Fossen, F., \& Kritikos, A. S. (20I4). Personality characteristics and the decisions to become and stay self-employed. Small Business Economics, 42(4), 787-8I4.

Camelo-Ordaz, C., Fernández-Alles, M., Ruiz-Navarro, J., \& Sousa-Ginel, E. (20I2). The intrapreneur and innovation in creative firms. International Small Business Journal, 30(5), 513-535.

Carless, S. A. (2005). Person-job fit versus person-organization fit as predictors of organizational attraction and job acceptance intentions: A longitudinal study. Journal of Occupational and Organizational Psychology, 78(3), 4II-429.

Carless, S. A., Wearing, A. J., \& Mann, L. (2000). A short measure of transformational leadership. Journal of business and psychology, I4(3), 389-405. 
Casper, W. J., Wayne, J. H., \& Manegold, J. G. (2013). Who will we recruit? Targeting deep-and surface-level diversity with human resource policy advertising. Human Resource Management, 52(3), 31I-332.

Castrogiovanni, G. J., Urbano, D., \& Loras, J. (20II). Linking corporate entrepreneurship and human resource management in SMEs. International Journal of Manpower, $32(\mathrm{I})$, 34-47.

Cedefop (2015). Skills, Qualifications and Jobs in the EU: The Making of a Perfect Match? Evidence from Cedefop's European Skills and Jobs Survey. Luxembourg: Publications Office.Choi, J. N. (2004). Person-environment fit and creative behavior: Differential impacts of supplies-values and demands-abilities versions of fit. Human Relations, $57(5), 53 \mathrm{I}-552$.

Cefis, E., \& Marsili, O. (2006). Survivor: The role of innovation in firms' survival. Research Policy, 35(5), 626-64I.

Certo, S. T., Busenbark, J. R., Woo, H. S., \& Semadeni, M. (2016). Sample selection bias and Heckman models in strategic management research. Strategic Management Journal, 37(13), 2639-2657.

Chapman, D. S., Uggerslev, K. L., Carroll, S. A., Piasentin, K. A., \& Jones, D. A. (2005). Applicant attraction to organizations and job choice: a meta-analytic review of the correlates of recruiting outcomes. Journal of applied psychology, 9o(5), 928.

Chen, C. C., Hsu, C. S., \& Tsai, P. S. (2013). The process mechanisms linking recruiter positive moods and organizational attraction. International Journal of Selection and Assessment, 2I(4), 376-387.

Chen, G., Gully, S. M., \& Eden, D. (200I). Validation of a new general self-efficacy scale. Organizational research methods, 4(I), 62-83.

Chlosta, S., Patzelt, H., Klein, S. B., \& Dormann, C. (2012). Parental role models and the decision to become self-employed: The moderating effect of personality. Small Business Economics, 38(I), I2I-138.

Cohen, D. J., \& Prusak, L. (200I). In good company: How social capital makes organizations work. Cambridge, MA: Harvard Business School Press.

Colquitt, J. A., LePine, J. A., Zapata, C. P., \& Wild, R. E. (20II). Trust in typical and high-reliability contexts: Building and reacting to trust among firefighters. Academy of Management Journal, 54(5), 999-IOI5.

Cooper, C. D., \& Kurland, N. B. (2002). Telecommuting, professional isolation, and employee development in public and private organizations. Journal of Organizational Behavior, 23(4), 5II-532.

Covin, J. G., \& Slevin, D. P. (I99I). A conceptual model of entrepreneurship as firm behavior. Entrepreneurship theory and practice, I6(I), 7-26.

Cramer, J. S., Hartog, J., Jonker, N., \& Van Praag, C. M. (2002). Low risk aversion encourages the choice for entrepreneurship: an empirical test of a truism. Journal of economic behavior \& organization, 48(I), 29-36.

Crant, J. M., \& Bateman, T. S. (1990). An experimental test of the impact of drug-testing programs on potential job applicants' attitudes and intentions. Journal of Applied Psychology, 75(2), I27.

Cropanzano, R., \& Mitchell, M. S. (2005). Social exchange theory: An interdisciplinary review. Journal of Management, 3I(6), 874-900. 
Cropley, D. H. (2016). Creativity in engineering. In G. E. Corazza and S. Agnoli (Eds.), Multidisciplinary Contributions to the Science of Creative Thinking, (pp. 155-173). London, UK: Springer.

Damanpour, F. \& Schneider, M. (2008). Characteristics of innovation and innovation adoption in public organizations: Assessing the Role of Managers. Journal of Public Administration Research and Theory, I9, 495-522.

Damanpour, F. (I988). Innovation type, radicalness, and the adoption process. Communication research, $15(5), 545-567$.

Damanpour, F., \& Gopalakrishnan, S. (200I). The dynamics of the adoption of product and process innovations in organizations. Journal of management studies, 38(I), 45-65.

Darcy, C., McCarthy, A., Hill, J., \& Grady, G. (20I2). Work-life balance: One size fits all? An exploratory analysis of the differential effects of career stage. European Management Journal, 30(2), III-I2O.

Davidsson, P. (2004). Researching entrepreneurship. New York: Springer.

Dawson, C., \& Henley, A. (20I2). "Push" versus "pull" entrepreneurship: an ambiguous distinction? International Journal of Entrepreneurial Behavior \& Research, I8(6), 697-719.

Day, G. S. (1994). The capabilities of market-driven organizations. Journal of marketing, 58(4), 37-52.

De Grip, A., Bosma, H., Willems, D., and van Boxtel, M. (2008). Job-worker mismatch and cognitive decline. Oxford Economic Papers, 60, 237-253.

De Jong, J. P., Parker, S. K., Wennekers, S., \& Wu, C. H. (2015). Entrepreneurial behavior in organizations: Does job design matter? Entrepreneurship Theory and Practice, 39(4), 98I-995.

De Leede, J., \& Heuver, P. (2016). New ways of working and leadership: an empirical study in the service industry. In New Ways of Working Practices: Antecedents and Outcomes (pp. 49-71). Emerald Group Publishing Limited.

De Leede, J., \& Kraijenbrink, J. (20I4). The mediating role of trust and social cohesion in the effects of new ways of working: a Dutch case study. In Human resource management, social innovation and technology (pp. 3-20). Emerald Group Publishing Limited.

Deloitte (2015). Five Insights into Intrapreneurship. A Guide to Accelerating Innovation within Corporations. Retrieved from: https://www2.deloitte.com/content/dam/ Deloitte/de/Documents/technology/Intrapreneurship_Whitepaper_English.pdf.

Deprez, J., \& Euwema, M. (2017). You can't always get what you want? Leadership expectations of intrapreneurs. Journal of Managerial Psychology, 326, 430-444.

Deprez, J., Leroy, H., \& Euwema, M. (20I8). Three chronological steps toward encouraging intrapreneurship: Lessons from the Wehkamp case. Business Horizons, 6I(I), I35-I45.

Diaz, I., Chiaburu, D. S., Zimmerman, R. D., \& Boswell, W. R. (20I2). Communication technology: Pros and cons of constant connection to work. Journal of Vocational Behavior, 80(2), 500-508.

Dohmen, T., Falk, A., Huffman, D., Sunde, U., Schupp, J., \& Wagner, G. G. (20II). Individual risk attitudes: Measurement, determinants, and behavioral consequences. Journal of the European Economic Association, 9(3), 522-550. 
Douglas, E. J., \& Fitzsimmons, J. R. (2013). Intrapreneurial intentions versus entrepreneurial intentions: distinct constructs with different antecedents. Small Business Economics, 4I(I), II5-I32.

Dovey, K. \& McCabe, B. (20I4). The politics of innovation: Realising the value of intrapreneurs. International Journal of Learning and Intellectual Capital, II(3), I85-2OI.

Dul, J., Ceylan, C., \& Jaspers, F. (20II). Knowledge workers' creativity and the role of the physical work environment. Human resource management, 5o(6), 715-734.

Dunn, T., \& Holtz-Eakin, D. (2000). Financial capital, human capital, and the transition to self-employment: Evidence from intergenerational links. Journal of labor economics, I8(2), 282-305.

Elsbach, K. D., \& Bechky, B. A. (2007). It's more than a desk: Working smarter through leveraged office design. California management review, 49(2), 80-IoI.

Emerson, R. M. (1976). Social exchange theory. Annual review of sociology, 2(I), 335-362.

Ernst and Young (2010). Igniting innovation. How hot companies fuel growth from within. Retrieved from: https://www.ey.com/Publication/vwLUAssets/EY Igniting_innovation:_How_hot_companies_fuel_growth_from_within/\%24FILE/ ey-igniting-innovation-how-hot-companies-fuel-growth-from-within.pdf.

European Commission (2013). Entrepreneurship 2020 Action Plan. Reigniting the entrepreneurial spirit in Europe. Retrieved from: https:/eur-lex.europa.eu/legalcontent/EN/TXT/PDF/?uri=CELEX:52012DC0795\&from=EN

Evertz, L., \& Süß, S. (20I7). The importance of individual differences for applicant attraction: a literature review and avenues for future research. Management Review Quarterly, 67(3), I4I-I74.

Falk, A., Becker, A., Dohmen, T. J., Huffman, D., \& Sunde, U. (2016). The preference survey module: A validated instrument for measuring risk, time, and social preferences. IZA Discussion Papers No. 9674.

Farr, J. L., Sin, H.-P., \& Tesluk, P. E. (2003). Knowledge management processes and work group innovation. In L. V. Shavinina (Ed.), The international handbook on innovation. New York: Elsevier Science Ltd.

Farrukh, M., Ying, C. W., \& Mansori, S. (20I6). Intrapreneurial behavior: an empirical investigation of personality traits. Management \& Marketing, II(4), 597-609.

Feist, G. J. (1998). A meta-analysis of personality in scientific and artistic creativity. Personality and social psychology review, 2(4), 290-309.

Fleisher, C., van Wetten, S. \& Rigtering, C. (forthcoming). Talent management for intrapreneurship: Taking stock of the current state of the field \& developing avenues for future research.

Fleuren, B. P., van Amelsvoort, L. G., Zijlstra, F. R., de Grip, A., \& Kant, I. (20I8). Handling the reflective-formative measurement conundrum: A practical illustration based on sustainable employability. Journal of clinical epidemiology, I03, 7I-8I.

Fouarge, D., Kriechel, B., \& Dohmen, T. (2OI4). Occupational sorting of school graduates: The role of economic preferences. Journal of Economic Behavior \& Organization, 1o6, $335-35 \mathrm{I}$.

Freeman, C. (1995). The 'National System of Innovation' in historical perspective. Cambridge Journal of economics, Ig(I), 5-24. 
Fried, Y., Levi, A. S., \& Laurence, G. (2007). The job characteristics model and LMX-MMX leadership. LMX leadership: The series, 5, I57-I97.

Fry, A. (1987). The post-it note: An intrapreneurial success. SAM Advanced Management Journal, 52(3), 4.

Fuchs, C., \& Diamantopoulos, A. (2009). Using single-item measures for construct measurement in management research: Conceptual issues and application guidelines. Die Betriebswirtschaft, 69, I95.

Gartner, W. B. (1985). A conceptual framework for describing the phenomenon of new venture creation. Academy of management review, Io(4), 696-706.

Gartner, W. B. (1988). "Who is an entrepreneur?" is the wrong question. American journal of small business, $12(4), \mathrm{II}-32$.

Garud, R., \& Van De Ven, A. H. (1992). An empirical evaluation of the internal corporate venturing process. Strategic Management Journal, I3(SI), 93-I09.

Gawke, J. C., Gorgievski, M. J., \& Bakker, A. B. (20I7). Employee intrapreneurship and work engagement: A latent change score approach. Journal of Vocational Behavior, Ioo, 88-IOо.

Gawke, J. C., Gorgievski, M. J., \& Bakker, A. B. (20I8). Personal costs and benefits of employee intrapreneurship: Disentangling the employee intrapreneurship, well-being, and job performance relationship. Journal of occupational health psychology, 23(4), 508.

Gawke, J. C., Gorgievski, M. J., \& Bakker, A. B. (2019). Measuring intrapreneurship at the individual level: Development and validation of the Employee Intrapreneurship Scale (EIS). European Management Journal, https://doi.org/I0.IOI6/j.emj.2019.03.00I

Gerards, R., de Grip, A., \& Baudewijns, C. (2018a). Do new ways of working increase work engagement? Personnel Review, 47(2), 517-534.

Gerards, R., de Grip, A., \& Weustink, A. (2018b). Do new ways of working increase informal learning? (ROA Research Memoranda; No. ooI). Maastricht: Research Centre for Education and the Labour Market.

Gilad, B., \& Levine, P. (1986). A behavioral model of entrepreneurial supply. Journal of small business management, 24, 45-53.

Globocnik, D., \& Salomo, S. (2015). Do formal management practices impact the emergence of bootlegging behavior? Journal of Product Innovation Management, 32(4), 505-52I.

Goldberg, L.R. J.A. Johnson, H.W. Eber, R. Hogan, M.C. Ashton, C.R. Cloninger, et al. (2006). The international personality item pool and the future of public-domain personality measures. Journal of Research in Personality, 40, 84-96.

Gosling, S. D., Rentfrow, P. J., \& Swann, W. B. (2003). A very brief measure of the Big-Five personality domains. Journal of Research in personality, 37(6), 504-528.

Graen, G. B., \& Uhl-Bien, M. (I995). Relationship-based approach to leadership: Development of leader-member exchange (LMX) theory of leadership over 25 years: Applying a multi-level multi-domain perspective. The Leadership Quarterly, 6(2), 219-247.

Green, F., \& McIntosh, S. (2007). Is there a genuine under-utilization of skills amongst the over-qualified? Applied Economics, 39(4), 427-439.

Guth, W. D., \& Ginsberg, A. (1990). Guest editors' introduction: Corporate entrepreneurship. Strategic management journal, 5-I5. 
Hackman, J. R., \& Oldham, G. R. (1976). Motivation through the design of work: Test of a theory. Organizational behavior and human performance, I6(2), 250-279.

Hainmüller, J., Hangartner, D., \& Yamamoto, T. (2015). Validating vignette and conjoint survey experiments against real-world behavior. Proceedings of the National Academy of Sciences, II2(8), 2395-2400.

Halford, S. (2005). Hybrid workspace: Re-spatialisations of work, organisation and management. New Technology, Work and Employment, 20(I), I9-33.

Hamermesh, D. S. (1990). Shirking or productive schmoozing: Wages and the allocation of time at work. ILR Review, 43(3), I2I-I33.

Hanson, J. (20I7). Exploring Relationships Between K-I2 Music Educators' Demographics, Perceptions of Intrapreneuring, and Motivation at Work. Journal of Research in Music Education, 653, 309-327.

Hargadon, A. B. (2002). Brokering knowledge: Linking learning and innovation. Research in Organizational Behavior, 24, 4I-85.

Hartog, J. (2000). Over-education and earnings: where are we, where should we go? Economics of Education Review, I9, I3I-I47.

Hayes, A. F. (2009). Beyond Baron and Kenny: Statistical mediation analysis in the new millennium. Communication monographs, 76(4), 408-420.

Hayton, J. C. (2005). Promoting corporate entrepreneurship through human resource management practices: a review of empirical research. Human Resource Management Review, I5, 2I-4I.

Hayton, J. C., \& Kelley, D. J. (2006). A competency-based framework for promoting corporate entrepreneurship. Human Resource Management, 45(3), 407-427.

Heckman, J. J. (1976). The common structure of statistical models of truncation, sample selection and limited dependent variables and a simple estimator for such models. Annals of Economic and Social Measurement, 5(4), 475-492.

Heinze, K. L., \& Weber, K. (2016). Toward organizational pluralism: Institutional intrapreneurship in integrative medicine. Organization Science, 27(I), I57-I72.

Hensher, D.A. and Greene, W.H. (2003). The mixed logit model: the state of practice. Transportation, 30(2), 133-176.

Hertel, G., Geister, S., \& Konradt, U. (2005). Managing virtual teams: A review of current empirical research. Human resource management review, IS(I), 69-95.

Hess, S. \& Train, K.E. (2017).Correlation and scale in mixed logit models. Journal of Choice Modelling, 23, I-8.

Holgado-Tello, F. P., Chacón-Moscoso, S., Barbero-García, I., \& Vila-Abad, E. (20Io). Polychoric versus Pearson correlations in exploratory and confirmatory factor analysis of ordinal variables. Quality \& Quantity, 44(I), I53-I66.

Holland, J. L. (1997). Making vocational choices: A theory of vocational personalities and work environments. Florida: Psychological Assessment Resources.

Homans, G. C. (1958). Social behavior as exchange. American Journal of Sociology, 63(6), 597-606.

Hornsby, J. S., Kuratko, D. F., Shepherd, D. A., \& Bott, J. P. (2009). Managers' corporate entrepreneurial actions: Examining perception and position. Journal of Business Venturing, 24(3), 236-247. 
Hornsby, J.S., Kuratko, D.F. \& Zahra, S.A. (2002). Middle managers' perception of the internal environment for corporate entrepreneurship: assessing a measurement scale. Journal of Business Venturing, 17, 253-273.

Howell, J. M., \& Higgins, C. A. (1990). Champions of technological innovation. Administrative science quarterly, 35(2), 317-34I.

Howell, J.M. \& Shea, C.M. (200I). Individual differences, environmental scanning, innovation framing, and champion behavior: key predictors of project performance. The Journal of Product Innovation Management, I8, I5-27.

Hughes, M., Rigtering, J. C., Covin, J. G., Bouncken, R. B., \& Kraus, S. (20I8). Innovative Behaviour, Trust and Perceived Workplace Performance. British Journal of Management, 29, 750-768.

Humburg, M., \& Van der Velden, R. (2015). Skills and the graduate recruitment process: Evidence from two discrete choice experiments. Economics of Education Review, 49, 24-4I.

Hunter, S. T., Cushenbery, L., \& Friedrich, T. (20I2). Hiring an innovative workforce: A necessary yet uniquely challenging endeavour. Human Resource Management Review, $22(4), 303-322$.

International Labour Office (1990). International Standard Classification of Occupations: ISCO-88. Geneva, Switzerland: International Labour Office.

Janssen, O. (2000). Job demands, perceptions of reward fairness and innovative work behaviour. Journal of Occupational and Organizational Psychology, 73, 287-302.

Jarvis, C. B., MacKenzie, S. B., \& Podsakoff, P. M. (2003). A critical review of construct indicators and measurement model misspecification in marketing and consumer research. Journal of consumer research, 30(2), 199-2I8.

Johlke, M. C. (2006). Sales presentation skills and salesperson job performance. Journal of Business \& Industrial Marketing, 2I(5), 3II-3I9.

Judge, T. A., \& Cable, D. M. (1997). Applicant personality, organizational culture, and organization attraction. Personnel psychology, 50(2), 359-394.

Judge, T. A., Higgins, C. A., Thoresen, C. J., \& Barrick, M. R. (1999). The big five personality traits, general mental ability, and career success across the life span. Personnel psychology, 52(3), 62I-652.

Judge, T. A., Locke, E. A., Durham, C. C., \& Kluger, A. N. (1998). Dispositional effects on job and life satisfaction: The role of core evaluations. Journal of applied psychology, 83(I), I7.

Judge, T. A., Thoresen, C. J., Bono, J. E., \& Patton, G. K. (200I). The job satisfaction-job performance relationship: A qualitative and quantitative review. Psychological Bulletin, I27, 376-407.

Jung, D. I., Chow, C., \& Wu, A. (2003). The role of transformational leadership in enhancing organizational innovation: Hypotheses and some preliminary findings. The leadership quarterly, I4(4-5), 525-544.

Kacperczyk, A. J. (2012). Opportunity Structures in Established Firms: Entrepreneurship versus Intrapreneurship in Mutual Funds. Administrative Science Quarterly, 57, $484-52 \mathrm{I}$.

Kanter R.M. (1982). The Middle Manager as Innovator. Harvard Business Review, 60, 95-105. 
Kanter, R. (1985). Supporting innovation and venture development in established companies. Journal of business venturing, $I(\mathrm{I}), 47-60$.

Kim, J., \& De Dear, R. (2013). Workspace satisfaction: The privacy-communication trade-off in open-plan offices. Journal of Environmental Psychology, 36, I8-26.

Kingma, S. (2018). New ways of working (NWW): work space and cultural change in virtualizing organizations. Culture and Organization, https://doi.org/Io.Io80/I475955 I.20I8.1427747.

Knight, F. H. (192I). Risk, uncertainty, and profit. New York: Kelly \& Millman.

Kolvereid, L. (1996). Organizational employment versus self-employment: Reasons for career choice intentions. Entrepreneurship Theory and Practice, 20(3), 23-3I.

Kossek, E. E., \& Lee, M. D. (2008). Implementing a reduced-workload arrangement to retain high talent: A case study. The Psychologist-Manager Journal, II(I), 49-64.

Kristof, A. L. (1996). Person-organization fit: An integrative review of its conceptualizations, measurement, and implications. Personnel psychology, 49(I), I-49.

Kristof-Brown, A. L., Zimmerman, R. D., \& Johnson, E. C. (2005). Consequences of individuals' fit at work: a meta-analysis of person-job, person-organization, persongroup, and person-supervisor fit. Personnel psychology, 58(2), 28I-342.

Krueger Jr, N. F., \& Brazeal, D. V. (1994). Entrepreneurial potential and potential entrepreneurs. Entrepreneurship theory and practice, I8(3), 9I-IO4.

Krueger Jr, N. F., Reilly, M. D., \& Carsrud, A. L. (2000). Competing models of entrepreneurial intentions. Journal of business venturing, I5(5-6), 4II-432.

Krueger, N.F. \& Carsrud, A.L. (1993). Entrepreneurial intentions: Applying the theory of planned behaviour. Entrepreneurship and Regional Development, 5(4), 315-330.

Kruger, J., \& Dunning, D. (1999). Unskilled and unaware of it: how difficulties in recognizing one's own incompetence lead to inflated self-assessments. Journal of Personality and Social Psychology, 77(6), II2I-II34.

Kucel, A., Róbert, P., Buil, M. \& Masferrer, N. (20I6). Entrepreneurial skills and education-job matching of higher education graduates. European Journal of Education, SI (I), 73-89.

Kühn, C., Eymann, T., Urbach, N, \& Schweizer, A. (20I6). From professionals to entrepreneurs: Human resources practices as an enabler for fostering corporate entrepreneurship in professional service firms. German Journal of Human Resource Management-Zeitschrift fur Personalforschung, 30(2), I25-I54.

Kuratko, D. F., Hornsby, J. S., \& Covin, J. G. (20I4). Diagnosing a firm's internal environment for corporate entrepreneurship. Business Horizons, 57(I), 37-47.

Kuratko, D. F., Ireland, R. D., Covin, J. G., \& Hornsby, J. S. (2005). A Model of MiddleLevel Managers' Entrepreneurial Behavior. Entrepreneurship theory and practice, 29(6), 699-7I6.

Kuratko, D. F., Montagno, R.V., \& Hornsby, J. S. (1990). Developing an intrapreneurial assessment instrument for an effective corporate entrepreneurial environment. Strategic Management Journal, II, 49-58.

Kurland, N. B., \& Cooper, C. D. (2002). Manager control and employee isolation in telecommuting environments. The Journal of High Technology Management Research, 13(I), I07-I26. 
Lancsar, E., Fiebig, D. G., \& Hole, A. R. (20I7). Discrete Choice Experiments: A Guide to Model Specification, Estimation and Software. Pharmaco Economics, I-2O.

Lang, F. R., John, D., Lüdtke, O., Schupp, J., \& Wagner, G. G. (20II). Short assessment of the Big Five: Robust across survey methods except telephone interviewing. Behavior research methods, 43(2), 548-567.

Langdon, D., McKittrick, G., Beede, D., Khan, B., \& Doms, M. (20II). STEM: Good jobs now and for the future. Washington, DC: US Department of Commerce. Economics and Statistics Administration.

Larsen, D. A., \& Phillips, J. I. (2002). Effect of recruiter on attraction to the firm: Implications of the elaboration likelihood model. Journal of Business and Psychology, I6(3), 347-364.

Layton, D. F. (2000). Random coefficient models for stated preference surveys. Journal of Environmental Economics and Management, 40(I), 2I-36.

Leiponen, A. (2005). Skills and innovation. International Journal of Industrial Organization, $23,303-323$.

Lepak, D. P., \& Snell, S. A. (1999). The human resource architecture: Toward a theory of human capital allocation and development. Academy of management review, 24(I), $3 \mathrm{I}-48$.

Lewis, M., \& Moultrie, J. (2005). The organizational innovation laboratory. Creativity and innovation management, I4(I), 73-83.

Lievens, F., Decaesteker, C., Coetsier, P., \& Geirnaert, J. (200I). Organizational attractiveness for prospective applicants: A person-organization fit perspective. Applied Psychology, 5o(I), 30-5I.

Long, J. S. \& Freese, J. (2014). Regression Models for Categorical Dependent Variables Using Stata. College Station, Texas: Stata Press.

Lukes, M., \& Stephan, U. (2017). Measuring employee innovation: a review of existing scales and the development of the innovative behavior and innovation support inventories across cultures. International Journal of Entrepreneurial Behavior \& Research, 23(I), I36-I58.

Lumpkin, G. T., \& Dess, G. G. (1996). Clarifying the entrepreneurial orientation construct and linking it to performance. Academy of management Review, 2I(I), I35-I72.

Maidique, M. A. (1980). Entrepreneurs, champions, and technological innovation. Sloan Management Review, 2I, 59-76.

Markman, G. D., Balkin, D. B., \& Baron, R. A. (2002). Inventors and new venture formation: The effects of general self-efficacy and regretful thinking. Entrepreneurship theory and practice, $27(2)$, I49-165.

Markman, G. D., \& Baron, R. A. (2003). Person-entrepreneurship fit: why some people are more successful as entrepreneurs than others. Human resource management review, 13(2), 28I-30I.

Martiarena, A. (2013). What's so entrepreneurial about intrapreneurs? Small Business Economics, 40(I), 27-39.

Martinez-Ros, E. (2000). Explaining the decisions to carry out product and process innovations: the Spanish case. The Journal of High Technology Management Research, Io(2), 223-242.Mavromaras, K., S. Mahuteau, P. Sloane and Z. Wei (2013). The Effect of Overskilling Dynamics on Wages. Education Economics, $2 I$ (3), 28I-303. 
Martins, E. C., \& Terblanche, F. (2003). Building organisational culture that stimulates creativity and innovation. European journal of innovation management, 6(I), 64-74.

Matthews, C., Schenkel, M., Ford, M., \& Human, S. (2009). Comparing nascent entrepreneurs and intrapreneurs and expectations of firm growth. Journal of Small Business Strategy, 20(I), 53.

Mavromaras, K., Sloane, P., \& Wei, Z. (2012). The role of education pathways in the relationship between job mismatch, wages and job satisfaction: a panel estimation approach. Education Economics, 20(3), 303-32I.

Mayer, R. C., Davis, J. H., \& Schoorman, F. D. (1995). An integrative model of organizational trust. Academy of Management Review, 20(3), 709-734.

McCrae, R. R. (1987). Creativity, divergent thinking, and openness to experience. Journal of Personality and Social Psychology, 52, I258 - I265.

McCrae, R. R., \& John, O. P. (I992). An introduction to the five-factor model and its applications. Journal of personality, 60(2), I75-215.

McCrae, R.R. \& Costa, P.T. (1999) A Five Factor theory of personality. In: O.P. John, R.W. Robins \& L.A. Pervin (Eds.), Handbook of personality: Theory and research, pp. I39-I53. New York: Guilford Press.

McGuinness, S., Pouliakas, K., \& Redmond, P. (2017). How Useful Is the Concept of Skills Mismatch? (IZA Discussion Papers Number I0786). Bonn: Institute of Labor Economics (IZA).

McGuirk, H., Lenihan, H. \& Hart, M. (2015). Measuring the impact of innovative human capital on small firms' propensity to innovate. Research Policy, 44, 965-976.

Meeker, B. F. (197I). Decisions and exchange. American Sociological Review, 36, 485-495.

Menzel, H. C. \& Aaltio, I. \& Ulijn, J. M. (2007). On the way to creativity: Engineers as intrapreneurs in organizations. Technovation, 27(I2), 732-743.

Mitchelmore, S., \& Rowley, J. (20IO). Entrepreneurial competencies: a literature review and development agenda. International journal of entrepreneurial Behavior \& Research, I6(2), 92-III.

Mom, T.J.M., Van Den Bosch, F.A.J. \& Volberda, H.W. (2007). Investigating Managers' Exploration and Exploitation Activities: The Influence of Top-Down, Bottom-Up, and Horizontal Knowledge Inflows. Journal of Management Studies, 44(6), 910-931.

Monsen, E., Patzelt, H., \& Saxton, T. (2010). Beyond Simple Utility: Incentive Design and Trade-Offs for Corporate Employee Entrepreneurs. Entrepreneurship Theory and Practice, 34(I), I05-I3O.

Morganson, V. J., Major, D. A., Oborn, K. L., Verive, J. M., \& Heelan, M. P. (20I0). Comparing telework locations and traditional work arrangements: Differences in work-life balance support, job satisfaction, and inclusion. Journal of Managerial Psychology, 25(6), 578-595.

Moriano, J. A., Molero, F., Topa, G., \& Levy Mangin, J. P. (20I4). The influence of transformational leadership and organizational identification on intrapreneurship. International Entrepreneurship and Management Journal, Io(I), IO3-II9.

Moser, K. J., Tumasjan, A., \& Welpe, I. M. (2017). Small but attractive: Dimensions of new venture employer attractiveness and the moderating role of applicants' entrepreneurial behaviors. Journal of Business Venturing, 32(5), 588-610. 
Mumford, M. D. (2000). Managing creative people: Strategies and tactics for innovation. Human resource management review, Io(3), 313-35I.

Mumford, M. D., \& McIntosh, T. (20I7). Creative thinking processes: The past and the future. The Journal of Creative Behavior, SI(4), 317-322.

Mumford, M. D., Antes, A. L., Caughron, J. J., Connelly, S., \& Beeler, C. (20I0). Crossfield differences in creative problem-solving skills: A comparison of health, biological, and social sciences. Creativity Research Journal, 22, I4-26.

Mungai, E., \& Velamuri, S. R. (20II). Parental entrepreneurial role model influence on male offspring: Is it always positive and when does it occur?. Entrepreneurship Theory and Practice, 35(2), 337-357.

Murillo, I. P. (20II). Human capital obsolescence: some evidence for Spain. International Journal of Manpower, 32(4), 426-445.

Murphy, K. M., Shleifer, A., \& Vishny, R. W. (199I). The allocation of talent: Implications for growth. The quarterly journal of economics, I06(2), 503-530.

Mustafa, M., Gavin, F. \& Hughes, M. (2018). Contextual determinants of employee entrepreneurial behavior in support of Corporate Entrepreneurship: A systematic review and a research agenda. Journal of Enterprising Culture, 26(3), 285-326.

Neessen, P. C., Caniels, M. C., Vos, B., \& De Jong, J. P. (2018). The intrapreneurial employee: toward an integrated model of intrapreneurship and research agenda. International Entrepreneurship and Management Journal, I-27.

Neuman, S., \& Weiss, A. (I995). On the effects of schooling vintage on experienceearnings profiles: Theory and evidence. European Economic Review, 39(5), 943-955.

Nijp, H.H., Beckers, D.G., van de Voorde, K., Geurts, S.A. \& Kompier, M.A. (2016). Effects of new ways of working on work hours and work location, health and job-related outcomes. Chronobiology international, 33(6), 604-6I8.

Non, A., Rohde, I., de Grip, A., \& Dohmen, T. (2019). Mission of the company, prosocial attitudes and job preferences: A discrete choice experiment. (ROA Research Memoranda; No. 006). Maastricht: Research Centre for Education and the Labour Market.

Olsen, J. E., Parsons, C. K., Martins, L. L., \& Ivanaj, V. (20I6). Gender diversity programs, perceived potential for advancement, and organizational attractiveness: An empirical examination of women in the United States and France. Group \& Organization Management, 4I(3), 27I-309.

Organisation for Economic Co-operation and Development (2017). Education at a Glance 20I7: OECD Indicators. OECD Publishing, Paris.

Organisation for Economic Co-operation and Development (2018). OECD Review Of National R\&D Tax Incentives And Estimates OfR\&D Tax Subsidy Rates, 2017. Retrieved from: http://www.oecd.org/sti/rd-tax-stats-design-subsidy.pdf.

Parker, S. C. (20II). Intrapreneurship or entrepreneurship? Journal of Business Venturing, 26(I), 19-34.

Perry, A., Wiederhold, S. \& Ackermann-Piek, D. (20I4). How can skill mismatch be measured? New approaches with PIAAC. Methods, data, analyses, 8(2), I37-I74.

Perry-Smith, J. E. (2006). Social yet creative: The role of social relationships in facilitating individual creativity. Academy of Management journal, 49(I), 85-IOI. 
Perry-Smith, J. E., \& Shalley, C. E. (2003). The social side of creativity: A static and dynamic social network perspective. Academy of Management Review, 28(I), 89-106.

Peters, P., \& den Dulk, L. (2003). Cross cultural differences in managers' support for home-based telework: A theoretical elaboration. International Journal of Cross Cultural Management, 3(3), 329-346.

Peters, P., Poutsma, E., Van der Heijden, B. I., Bakker, A. B., \& Bruijn, T. D. (20I4). Enjoying New Ways to Work: An HRM-Process Approach to Study Flow. Human resource management, 53(2), 27I-290.

Pinchot, G. (1985). Intrapreneuring. Why you don't have to leave the corporation to become an entrepreneur. New York: Perennial Library.

Podsakoff, P. M., MacKenzie, S. B., Lee, J. Y., \& Podsakoff, N. P. (2003). Common method biases in behavioral research: A critical review of the literature and recommended remedies. Journal of applied psychology, 88(5), 879.

Potočnik, K., Anderson, N. R., \& Latorre, F. (20I5). Selecting for innovation: methods of assessment and the criterion problem. Recent and New Developments in Recruitment and Selection. London: Taylor and Francis.

Preacher, K. J., \& Hayes, A. F. (2008). Asymptotic and resampling strategies for assessing and comparing indirect effects in multiple mediator models. Behavior research methods, 40(3), 879-89I.

PricewaterhouseCoopers (2019). Secure your future people experience. Five imperatives for action. Retrieved from: https://www.pwc.nl/nl/actueel-publicaties/assets/pdfs/secureyour-future-people-experience-pwc-nl.pdf

Puech, L., \& Durand, T. (2017). Classification of time spent in the intrapreneurial process. Creativity and Innovation Management, 262, I42-I5I.

Quintini, G. (20I1). Right for the Job: Over-Qualified or Under-Skilled? (OECD Social, Employment and Migration Working Papers number 120). Paris: OECD Publishing.

Quintini, G. (20IIb). Over-qualified or under-skilled: A review of existing literature. (OECD Social, Employment, and Migration Working Papers number I2I). Paris: OECD Publishing.

Raja, U., \& Johns, G. (20I0). The joint effects of personality and job scope on in-role performance, citizenship behaviors, and creativity. Human Relations, 63(7), 98I-I005.

Rauch, A., \& Frese, M. (2007). Let's put the person back into entrepreneurship research: A meta-analysis on the relationship between business owners' personality traits, business creation, and success. European Journal of work and organizational psychology, I6(4), 353-385.

Razavi, S. H., \& Ab Aziz, K. (2017). The dynamics between entrepreneurial orientation, transformational leadership, and intrapreneurial intention in Iranian R\&D sector. International Journal of Entrepreneurial Behavior \& Research, 235, 769-792.

Rentz, J. O., Shepherd, C. D., Tashchian, A., Dabholkar, P. A., \& Ladd, R. T. (2002). A measure of selling skill: Scale development and validation. Journal of Personal Selling \& Sales Management, 22(I), I3-2I.

Revelt, D.,\& Train, K.(1998). Mixed logit with repeated choices: Households' choices of appliance efficiency level. The Review of Economics and Statistics, 80(4), 647-657. 
Rigtering, J. C., Weitzel, G. U., \& Muehlfeld, K. K. (20I9). Increasing quantity without compromising quality: How managerial framing affects intrapreneurship. Journal of Business Venturing, 34(2), 224-24I.

Rigtering, J. P. C., \& Weitzel, U. (2013). Work context and employee behaviour as antecedents for intrapreneurship. International Entrepreneurship and Management Journal, 9(3), 337-360.

Rosing, K., Frese, M., \& Bausch, A. (2OII). Explaining the heterogeneity of the leadershipinnovation relationship: Ambidextrous leadership. The leadership quarterly, 22(5), 956-974.

Russell, R. D. (1999). Developing a process model of intrapreneurial systems: A cognitive mapping approach. Entrepreneurship theory and practice, 23(3), 65-84.

Şahin, A., Song, J., Yopa, G. \& Violante, G. (20I4). Mismatch unemployment. American economic review, I04(II), $3529-3564$.

Sánchez-Sánchez, N., \& McGuinness, S. (2015). Decomposing the impacts of overeducation and overskilling on earnings and job satisfaction: an analysis using REFLEX data. Education Economics, 23(4), 419-432.

Santamaría, L., Nieto, M.J. \& Barge-Gil, A. (2009). Beyond formal R\&D: Taking advantage of other sources of innovation in low and medium-technology industries. Research Policy, 38, 507-517.

Sattinger, M. (1993). Assignment Models of the distribution of earnings. Journal of Economic literature, 3I, 85I-80.

Schjoedt, L., \& Shaver, K. G. (2007). Deciding on an entrepreneurial career: A test of the pull and push hypotheses using the panel study of entrepreneurial dynamics data. Entrepreneurship theory and practice, $3 I(5), 733-752$.

Schlaegel, C., \& Koenig, M. (20I4). Determinants of entrepreneurial intent: a metaanalytic test and integration of competing models. Entrepreneurship Theory and Practice, 38(2), 29I-332.

Schon, D. A. (1963). Champions for radical new inventions. Harvard Business Review, $4 I(2), 77-86$.

Schreurs, B., Derous, E., Van Hooft, E. A., Proost, K., \& De Witte, K. (2009a). Predicting applicants' job pursuit behavior from their selection expectations: The mediating role of the theory of planned behavior. Journal of Organizational Behavior, 30(6), 76I-783.

Schreurs, B., Druart, C., Proost, K., \& De Witte, K. (2009b). Symbolic attributes and organizational attractiveness: The moderating effects of applicant personality. International Journal of Selection and Assessment, I7(I), 35-46.

Schumpeter, J.A. (1934). The Theory of Economic Development. London: Transaction Publishers.

Scott, G., Leritz, L. E., \& Mumford, M. D. (2004). The effectiveness of creativity training: A quantitative review. Creativity research journal, I6(4), 36I-388.

Scott, S.G. \& Bruce, R.A. (1994). Determinants of Innovative Behavior: A Path Model of Individual Innovation in the Workplace. The Academy of Management Journal, 37(3), $580-607$.

Segal, G., Borgia, D., \& Schoenfeld, J. (2005). The motivation to become an entrepreneur. International journal of Entrepreneurial Behavior \& research, II (I), 42-57. 
Shane, S. (1993). Cultural influences on national rates of innovation. Journal of business venturing, 8(I), 59-73.

Shane, S. (1994). Cultural values and the championing process. Entrepreneurship Theory \& Practice, I8, 25-4I.

Shane, S., \& Venkataraman, S. (2000). The promise of entrepreneurship as a field of research. Academy of management review, 25(I), 217-226.

Shapero, A. (1975). The displaced, uncomfortable entrepreneur. Psychology Today, 9, 83-88.

Sharma, P., \& Chrisman, J. J. (1999). Toward a Reconciliation of the Definitional Issues in the Field of Corporate Entrepreneurship. Entrepreneurship: Theory and Practice, 23(3), II-27.

Sharma, P., \& Chrisman, J. J. (1999). Toward a Reconciliation of the Definitional Issues in the Field of Corporate Entrepreneurship. Entrepreneurship Theory and Practice, $23(3), \mathrm{II}-28$.

Shimer, R. (2007). Mismatch. The American Economic Review, 97(4), IO74 - IIOI.

Simonen, J. \& McCann, P. (2008). Innovation, R\&D cooperation and labor recruitment: evidence from Finland. Small business economics, 3I, I8I-I94.

Sinha, J. B. (2009). Culture and organizational behaviour. India: Sage Publications.

Sinha N. \& Srivastava, K. B. L. (20I3). Association of Personality, Work Values and Sociocultural Factors with Intrapreneurial Orientation. Journal of Entrepreneurship, 22(I), 97-II3.

Smith, L., Rees, P., \& Murray, N. (2016). Turning entrepreneurs into intrapreneurs: Thomas Cook, a case-study. Tourism Management, 56, I9I-204.

Spector, P. E. (2006). Method variance in organizational research: truth or urban legend? Organizational research methods, $9(2), 22 \mathrm{I}-232$.

Stam, E. (2013). Knowledge and entrepreneurial employees: A country-level analysis. Small Business Economics, $4 \mathrm{I}(4), 887-898$.

Stam, E., Bosma, N., Van Witteloostuijn, A., De Jong, J., Bogaert, S., Edwards, N. \& Jaspers, F. (2012). Ambitious Entrepreneurship. A review of the academic literature and new directions for public policy. $\mathrm{CH}_{3}$ : Intrapreneurship. Advisory Council for Science and Technology Policy (AWT).

Taggar, S. (2002). Individual creativity and group ability to utilize individual creative resources: a multilevel model. Academy of Management Journal, 45, 315-330.

Tanghe, J., Wisse, B., \& Van Der Flier, H. (2010). The role of group member affect in the relationship between trust and cooperation. British Journal of Management, 2I(2), 359-374.

Ten Brummelhuis, L. L., \& Van Der Lippe, T. (20I0). Effective work-life balance support for various household structures. Human Resource Management, 49(2), I73-193.

Ten Brummelhuis, L. L., Bakker, A. B., Hetland, J., \& Keulemans, L. (2012). Do new ways of working foster work engagement? Psicothema, 24(I), II3-I2O.

Ter Hoeven, C. L., \& Van Zoonen, W. (2015). Flexible work designs and employee wellbeing: examining the effects of resources and demands. New Technology, Work and Employment, 30(3), 237-255.

Tett, R. P., \& Burnett, D. D. (2003). A personality trait-based interactionist model of job performance. Journal of Applied Psychology, 88(3), 500-517. 
Trank, C. Q., Rynes, S. L., \& Bretz, R. D. (2002). Attracting applicants in the war for talent: Differences in work preferences among high achievers. Journal of Business and Psychology, I6(3), 33I-345.

Unsworth, K. L., \& Clegg, C. W. 20Io. Why do employees undertake creative action? Journal of Occupational and Organizational Psychology, 83, 77-99.

Urbano, D., \& Turró, A. (2013). Conditioning factors for corporate entrepreneurship: an in (ex) ternal approach. International entrepreneurship and management journal, 9 (3), 379-396.

Valsania, S., Moriano, J. A., \& Molero, F. (2016). Authentic leadership and intrapreneurial behavior: cross-level analysis of the mediator effect of organizational identification and empowerment. International Entrepreneurship and Management Journal, I2(I), I3I-I52.

Van der Velden, R. \& Verhaest D. (2017). Are skill deficits always bad? Toward a learning perspective on skill mismatches. In Polacheck, S.W, Pouliakas, K., Russo, G. \& Tatsiramos, K. (Eds.), Research in Labor Economics: Skill Mismatch in Labor Markets, 45,(pp 305 - 343). Bingley, UK: Emerald Publishing Limited.

Van Loo, J., De Grip, A., \& De Steur, M. (200I). Skills obsolescence: causes and cures. International Journal of Manpower, 22(I/2), I2I-I38.

Van Praag, C. M., \& Versloot, P. H. (2007). What is the value of entrepreneurship? A review of recent research. Small business economics, 29(4), 35I-382.

Vanacker, T. R., Zahra, S. A., \& Holmes, R. M. (2017). Corporate Entrepreneurship, Firm Performance, and Institutions: Evidence from European Firms. In Academy of Management Proceedings (Vol. 2017, No. I, p. 15764). Briarcliff Manor, NY I0510: Academy of Management.

Vargas-Halabí, T., Mora-Esquivel, R., \& Siles, B. (2017). Intrapreneurial competencies: development and validation of a measurement scale. European Journal of Management and Business Economics, 26(I), 86-III.

Vila, L. E., Perez, P. J., \& Morillas, F. G. (2012). Higher education and the development of competencies for innovation in the workplace. Management Decision, 50, I634-I648.

Vroom, V. H. (1966). Organizational choice: A study of pre-and postdecision processes. Organizational behavior and human performance, $I(2), 2 \mathrm{I} 2-225$.

Wachner, T., Plouffe, C. R., \& Grégoire, Y. (2009). SOCO's impact on individual sales performance: The integration of selling skills as a missing link. Industrial Marketing Management, 38(I), 32-44.

Weinberger, C. J. (20I4). The increasing complementarity between cognitive and social skills. Review of Economics and Statistics, 96(4), 849-86I.

Weiss, A. (1995). Human capital vs. signalling explanations of wages. The Journal of Economic Perspectives, 9(4), I33-I54.

West, J., Salter, A., Vanhaverbeke, W. \& Chesbrough, H. (20I4). Open innovation: The next decade. Research Policy, 43(5), 805-8II.

Winters, J. (20I4). Foreign and native-born STEM graduates and innovation intensity in the United States. IZA Discussion Papers Number 8575.

Woo, H. R. (20I8). Personality traits and intrapreneurship: the mediating effect of career adaptability. Career Development International, 23(2), I45-I62. 
Wright, P. C., \& Oldford, A. (1993). Telecommuting and employee effectiveness: Career and managerial issues. International Journal of Career Management, 5(I), https://doi. org/I0.1108/0955621931002475I

Yukl, G. (200I). Leadership in organizations. New Jersey: Prentice-Hall.

Zahra, S. A. (199I). Predictors and financial outcomes of corporate entrepreneurship: An exploratory study. Journal of business venturing, 6(4), 259-285.

Zampetakis, L. A., Beldekos, P., \& Moustakis, V. S. (2009). "Day-to-day” entrepreneurship within organisations: The role of trait Emotional Intelligence and Perceived Organisational Support. European Management Journal, 27(3), I65-175.

Zenovia, C. P. (20II). Entrepreneurship versus intrapreneurship. Journal Review of International Comparative Management, I2(5), 97I-980.

Zhao, H., \& Seibert, S. E. (2006). The Big Five personality dimensions and entrepreneurial status: A meta-analytical review. Journal of applied psychology, $9 I(2), 259$.

Zhao, H., Seibert, S. E., \& Hills, G. E. (2005). The mediating role of self-efficacy in the development of entrepreneurial intentions. Journal of applied psychology, go(6), I265.

Zhao, H., Seibert, S. E., \& Lumpkin, G. T. (2010). The relationship of personality to entrepreneurial intentions and performance: A meta-analytic review. Journal of management, 36(2), 38I-404.

Zwick, T., Frosch, K., Hoisl, K., \& Harhoff, D. (20I7). The power of individual-level drivers of inventive performance. Research policy, 46(I), I2I-I37. 


\section{Curriculum Vitae}

Sanne obtained her bachelor degree in Pedagogy in 2009 at Fontys University of Applied Science and her bachelor degree in Psychology at Maastricht University in 2OI2, cum laude. In addition, she obtained her master degree in Management of Learning in 2013 at Maastricht University. From 2012, Sanne worked as a research assistant at the Faculty of Psychology and Neuroscience at Maastricht University. In November 20I4, she joined the Research Centre for Education and the Labour Market (ROA) at the same university to start her $\mathrm{PhD}$ research on employee entrepreneurship. In 2017, Sanne obtained a university teaching qualification from the School of Business and Economics at Maastricht University. Since May 2019, Sanne works as a postdoctoral researcher at ROA where she is involved in several projects, including the National Cohort Study for Education (NCO) and the Academic Workplace Educational Quality. Sanne's research interests focus on employee entrepreneurship, human resource management, skill acquisition and development, quality of education and inequalities in education. 



\section{ROA Dissertation Series}

1. Lex Borghans (1993), Educational Choice and Labour Market Information, Maastricht, Research Centre for Education and the Labour Market.

2. Frank Cörvers (1999), The Impact of Human Capital on International Competitiveness and Trade Performance of Manufacturing Sectors, Maastricht, Research Centre for Education and the Labour Market.

3. Ben Kriechel (2003), Heterogeneity Among Displaced Workers, Maastricht, Research Centre for Education and the Labour Market.

4. Arnaud Dupuy (2004), Assignment and Substitution in the Labour Market, Maastricht, Research Centre for Education and the Labour Market.

5. Wendy Smits (2005), The Quality of Apprenticeship Training, Conflicting Interests of Firms and Apprentices, Maastricht, Research Centre for Education and the Labour Market.

6. Judith Semeijn (2005), Academic Competences and Labour Market Entry: Studies Among Dutch Graduates, Maastricht, Research Centre for Education and the Labour Market.

7. Jasper van Loo (2005), Training, Labor Market Outcomes and Self-Management, Maastricht, Research Centre for Education and the Labour Market.

8. Christoph Meng (2005), Discipline-Specific or Academic? Acquisition, Role and Value of Higher Education Competencies, Maastricht, Research Centre for Education and the Labour Market.

9. Andreas Ammermüller (2007), Institutional Effects in the Production of Education: Evidence from European Schooling Systems, Maastricht, Research Centre for Education and the Labour Market.

10. Bart Golsteyn (2007), The Ability to Invest in Human Capital, Maastricht, Research Centre for Education and the Labour Market. 
11. Raymond Montizaan (2010), Pension Rights, human capital development and well-being, Maastricht, Research Centre for Education and the Labour Market.

12. Annemarie Nelen (2012), Part-Time Employment and Human Capital Development, Maastricht, Research Centre for Education and the Labour Market.

13. Jan Sauermann (2013), Human Capital, Incentives, and Performance Out-comes, Maastricht, Research Centre for Education and the Labour Market

14. Harald Ulrich Pfeifer (2013), Empirical Investigations of Costs and Benefits of Vocational Education and Training, Maastricht, Research Centre for Education and the Labour Market.

15. Charlotte Büchner (2013), Social Background, Educational Attainment and Labor Market Integration: An Exploration of Underlying Processes and Dynamics, Maastricht, Research Centre for Education and the Labour Market.

16. Martin Humburg (2014), Skills and the Employability of University Graduates, Maastricht, Research Centre for Education and the Labour Market.

17. Jan Feld (2014), Making the Invisible Visible, Essays on Overconfidence, Discrimination and Peer Effects, Maastricht, Research Centre for Education and the Labour Market.

18. Olga Skriabikova (2014), Preferences, Institutions, and Economic Outcomes: an Empirical Investigation, Maastricht, Research Centre for Education and the Labour Market.

19. Gabriele Marconi (2015), Higher Education in the National and Global Economy, Maastricht, Research Centre for Education and the Labour Market.

20. Nicolas Salamanca Acosta (2015), Economic Preferences and Financial RiskTaking, Maastricht, Research Centre for Education and the Labour Market.

21. Ahmed Elsayed Mohamed (2015), Essays on Working Hours, Maastricht, Research Centre for Education and the Labour Market. 
22. Roxanne Amanda Korthals (2015), Tracking Students in Secondary Education, Consequences for Student Performance and Inequality, Maastricht, Research Centre for Education and the Labour Market.

23. Maria Zumbuehl (2015), Economic Preferences and Attitudes: Origins, Behavioral Impact, Stability and Measurement, Maastricht, Research Centre for Education and the Labour Market.

24. Anika Jansen (2016), Firms' incentives to provide apprenticeships - Studies on expected short-and long-term benefits, Maastricht, Research Centre for Education and the Labour Market.

25. Jos Maarten Arnold Frank Sanders (2016), Sustaining the employability of the low skilled worker: Development, mobility and work redesign, Maastricht, Research Centre for Education and the Labour Market.

26. Marion Collewet (2017), Working hours: preferences, well-being and productivity, Maastricht, Research Centre for Education and the Labour Market.

27. Tom Stolp (2018), Sorting in the Labor Market: The Role of Risk Preference and Stress, Maastricht, Research Centre for Education and the Labour Market.

28. Frauke Meyer (2019), Individual motives for (re-) distribution, Maasricht, Research Centre for Education and the Labour Market.

29. Maria Ferreira Sequeda (2019), Human Capital Development at School and Work, Maasricht, Research Centre for Education and the Labour Market.

30. Marie-Christine Martha Fregin (2019), Skill Matching and Outcomes: New Cross-Country Evidence, Maasricht, Research Centre for Education and the Labour Market.

31. Sanne Johanna Leontien van Wetten (2019), Human capital and employee entrepreneurship: The role of skills, personality characteristics and the work context, Maasricht, Research Centre for Education and the Labour Market. 
